\title{
EFFECTIVE SHEAR DESIGN OF FRP REINFORCED CONCRETE
}

\author{
by \\ MITRA NOGHREH KHAJA, BSc
}

\author{
A thesis submitted to \\ the Faculty of Graduate Studies and Research \\ in Partial Fulfillment of the requirements for the degree of \\ Master of Applied Science \\ Department of Civil and Environmental Engineering \\ Carleton University \\ Ottawa, Ontario
}

C2010 Mitra Noghreh Khaja

September of 2010

The Master of Applied Science in Civil Engineering Program is a joint program with the University of Ottawa, administered by the Ottawa-Carleton Institute of Civil and Environmental Engineering 


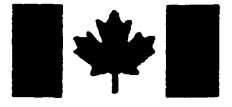

Library and Archives

Canada

Published Heritage Branch

395 Wellington Street Ottawa ON K1A ON4 Canada
Bibliothèque et

Archives Canada

Direction du

Patrimoine de l'édition

395 , rue Wellington

Ottawa ON K1A ON4

Canada
Your file Votre référence

ISBN: 978-0-494-71568-0

Our file Notre référence

ISBN: 978-0-494-71568-0

\section{NOTICE:}

The author has granted a nonexclusive license allowing Library and Archives Canada to reproduce, publish, archive, preserve, conserve, communicate to the public by telecommunication or on the Internet, loan, distribute and sell theses worldwide, for commercial or noncommercial purposes, in microform, paper, electronic and/or any other formats.

The author retains copyright ownership and moral rights in this thesis. Neither the thesis nor substantial extracts from it may be printed or otherwise reproduced without the author's permission.
AVIS:

L'auteur a accordé une licence non exclusive permettant à la Bibliothèque et Archives Canada de reproduire, publier, archiver, sauvegarder, conserver, transmettre au public par télécommunication ou par l'Internet, prêter, distribuer et vendre des thèses partout dans le monde, à des fins commerciales ou autres, sur support microforme, papier, électronique et/ou autres formats.

L'auteur conserve la propriété du droit d'auteur et des droits moraux qui protège cette thèse. $\mathrm{Ni}$ la thèse ni des extraits substantiels de celle-ci ne doivent être imprimés ou autrement reproduits sans son autorisation.
In compliance with the Canadian Privacy Act some supporting forms may have been removed from this thesis.

While these forms may be included in the document page count, their removal does not represent any loss of content from the thesis.
Conformément à la loi canadienne sur la protection de la vie privée, quelques formulaires secondaires ont été enlevés de cette thèse.

Bien que ces formulaires aient inclus dans la pagination, il n'y aura aucun contenu manquant. 


\section{ABSTRACT}

This thesis presents the results of an experimental study designed to investigate various aspects of the shear behavior of concrete beams and slabs reinforced with fiber-reinforced polymer (FRP) laminates. Specifically, the interacting roles that the reinforcement ratio $(\rho)$ and span-to-depth ratio, a/d, have on shear strength of members without stirrups are investigated.

A background review of FRP materials is presented, focusing on the various types of fibers and resins, manufacturing techniques, material properties and practical strengths and weaknesses. Shear behavior of reinforced concrete beams and slabs without stirrups is discussed, with an emphasis on members constructed without stirrups. The roles that different variables have on shear strength are discussed, in particular the strain effect and its role on shear strength. Different prominent shear design methods for FRP-reinforced concrete members are presented, including the general method of shear design used in the CSA A23.3-04 code for design of concrete structures and a modification to the general method designed for FRP reinforced members. The different shear design methods are discussed and evaluated in terms of their generality and rationality.

The experimental study consisted of load testing fifteen shear critical, FRP reinforced concrete members without stirrups to examine the accuracy of shear design methods, in particular to investigate the effect that the $\mathrm{M} / \mathrm{\rho Vd}$ ratio has on the shear strength of members without stirrups. For this purpose the specimens are grouped into four different categories based on the test variables: shear span to depth ratio $(\mathrm{a} / \mathrm{d})$ and reinforcement ratio $\rho$. All 
fifteen members were shear-critical, simply supported, subjected to point loads with rectangular dimensions $400 \mathrm{~mm}$ wide by $280 \mathrm{~mm}$ deep and the length of the specimens varied between $2200 \mathrm{~mm}$ and $4600 \mathrm{~mm}$. All were constructed in the Carleton structures lab. All specimens were loaded monotonically and failed in shear. The ratio of experimental shear stress for each specimen to predicted shear stress of the seven prominent codes $\left(v_{\exp } / v_{\text {pred }}\right)$ was compared.

It was found that the modified CSA equations for shear strength (Hoult's Equation) produce conservative, but accurate, estimates of shear strength with an average $v_{\exp } / \nu_{\text {pred }}$ of 1.14 , a coefficient of variation of $9.9 \%$ and a $1^{\text {st }}$ percentile of 0.88 . This method offers more accurate predictions of the shear strength for FRP-reinforced members than the other methods. In particular, the ACI 440 method (Frosch's Equation) offers extremely conservative and inaccurate predictions.

The experimental results indicated that the failure shear stress of members without shear reinforcement is a function of strain in the longitudinal reinforcement which is a function of $\mathrm{M} / \rho \mathrm{Vd}$. That is, the failure shear stress of a concrete member without shear reinforcement is not a function of reinforcement ratio $\rho$ or $\mathrm{a} / \mathrm{d}$ solely, but rather is a function of $\mathrm{M} / \rho \mathrm{Vd}$. Higher reinforcement strains will result in wider cracks and these wider cracks in turn result in decreased shear strength due to reduced aggregate interlock capacity. 


\section{ACKNOWLEDGEMENTS}

I extend my sincerest gratitude to my supervisor Professor Ted Sherwood. His invaluable guidance helped me to complete the study proficiently. Intellectual and continual, encouragement throughout the whole research period, and endless genial assistance of Professor Sherwood were the core to the achievement of this study. I would first like to express my intimate and deepest appreciation to him.

I would then like to thank the dedicated and resourceful technical staff in the structures laboratory in the Department of Civil Engineering at the Carleton University. Stanely Conely, Pierre Trudel, Jason Arnott and Jacob Hammer all helped make the experiments reported in this thesis run accurately and smoothly. My sincere appreciation is also extended to my friends, Hemant Moudgill and Wan Ashrul, for their dedicated assistance during the testing of my specimens, and to my whole family, my two sisters and brother and my little niece for their support during the period of this study.

I would like to express my deep appreciation to Mr. Mohsen Salehi for all his assistance, support and encouragement during the period of this study.

I would gratefully acknowledge Carleton University and the Natural Sciences and Engineering Research Council (NSERC) for funding this research, Essroc Co. for donating ready-mix concrete and Pultrall Co. for discount in price of FRP rebars.

Finally, I offer my deepest love and sincerest thanks to my lovely parents, Hosein and Goli, for their understanding during the period of this study. This thesis is dedicated to them, 
whose love, encouragement and support helped me to reach this level of education. The success of this study was undoubtedly ensured by the support of them. 


\section{TABLE OF CONTENTS}

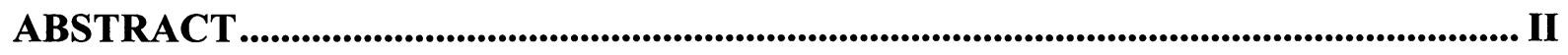

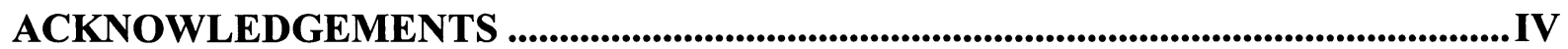

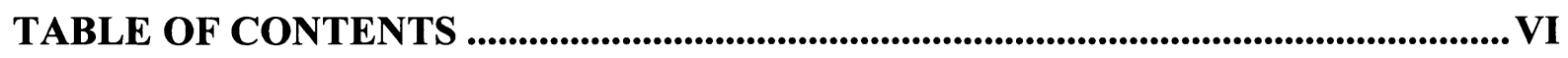

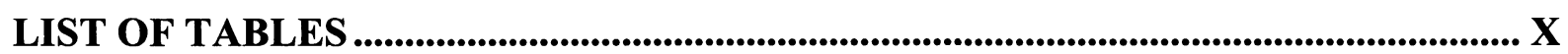

LIST OF FIGURES ................................................................................................

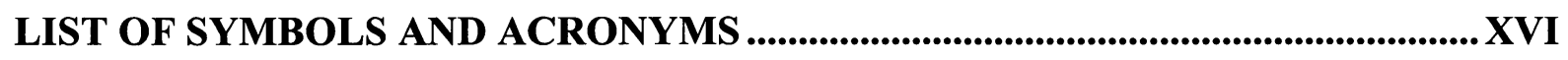

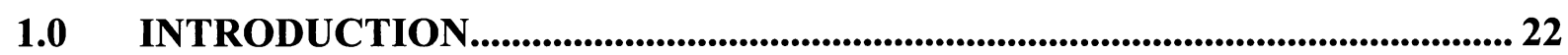

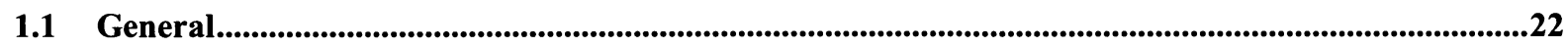

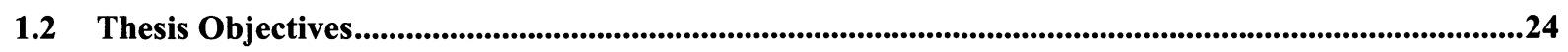

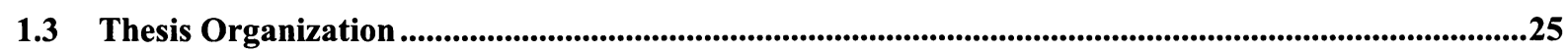

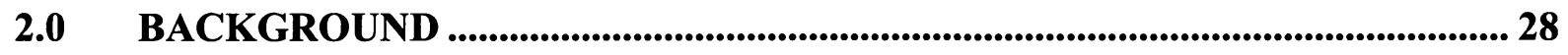

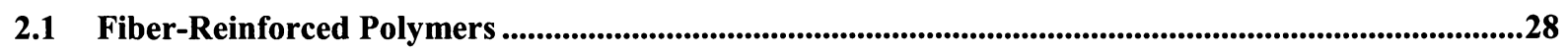

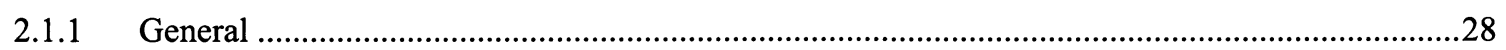

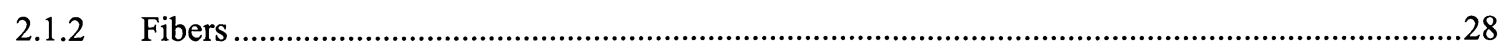

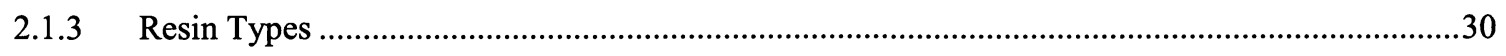

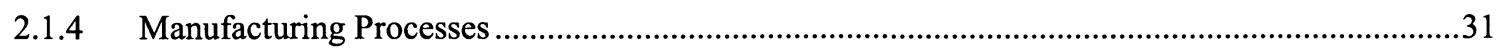

2.1.5 Thermal Properties and Effect of High Temperature on FRPs ..................................................32 
2.2 Shear Behavior of Beams and One-way Slabs without Shear Reinforcement.......................................37

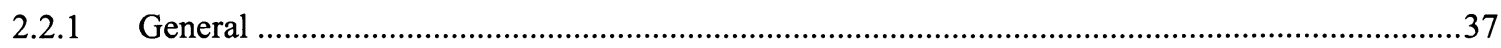

2.2.2 Significance of a Rational Theory in the Shear Design of FRP Reinforced Concrete ..................39

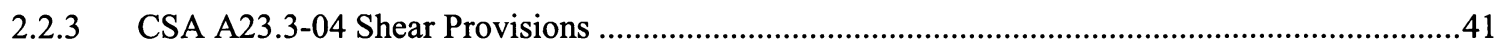

2.2.4 The Strain Effect, Size Effect and Shear Behavior .....................................................................46

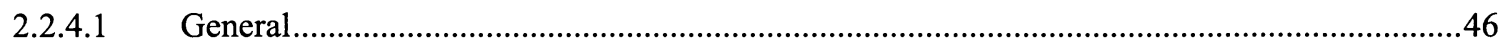

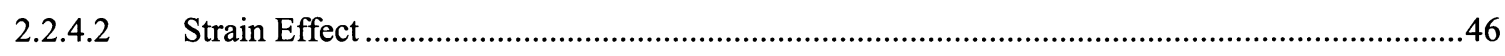

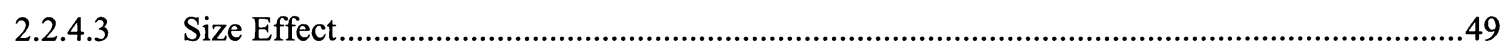

2.2.5 Derivation of $\beta$ Expression for Steel and FRP Reinforced Concrete Beams and One-Way Slabs51

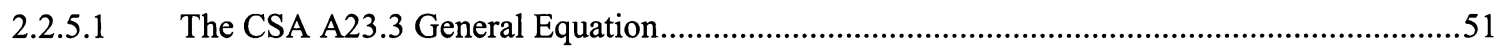

2.2.5.2 Hoult's $\beta$ Expression for Both Steel and FRP Reinforced Concrete.....................................52

2.2.6 The Two Mechanisms of Shear Failure: Beam Action and Arch Action .....................................54

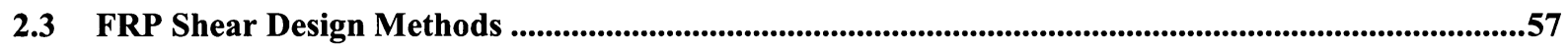

2.3.1 Tureyen and Frosch Equation (2003) ….............................................................................5

2.3.2 Other Shear Design Methods ...............................................................................................61

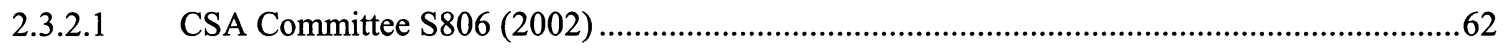

2.3.2.2 ISIS Design Manual No.3 …............................................................................................63

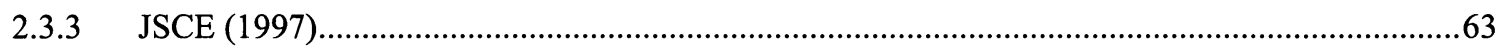

2.3.4 Razaqpur and Isgor (2004) …..........................................................................................64

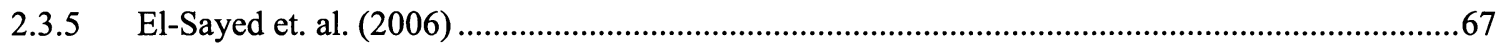

2.4 Comparison of the FRP Shear Design Methods ................................................................................................68

2.5 Concluding Remarks ..........................................................................................................................................68

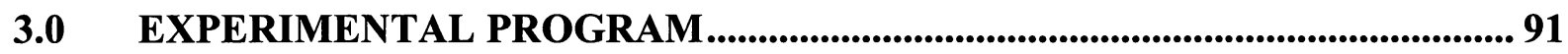

3.1 General. 


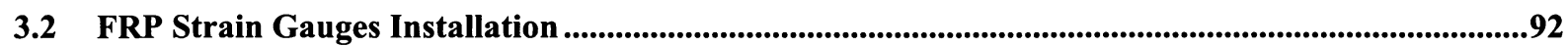

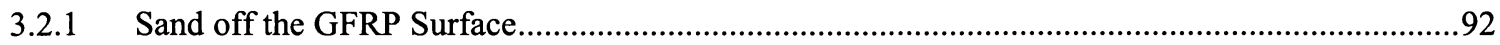

3.2.2 Strain Gauge Installation using M-Bond 200 Adhesive …........................................................93

3.2.3 Soldering, Coating and Covering the Gauge with Wax and Tape ..........................................95

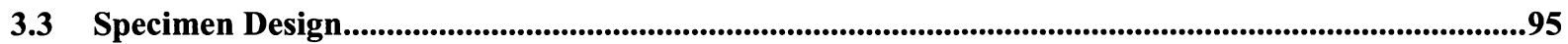

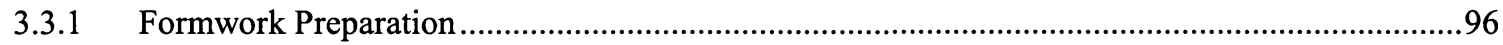

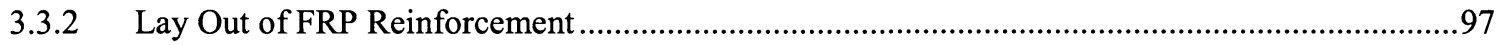

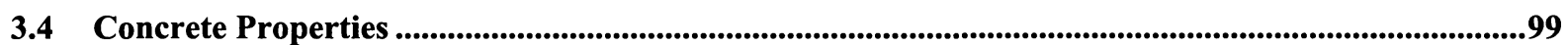

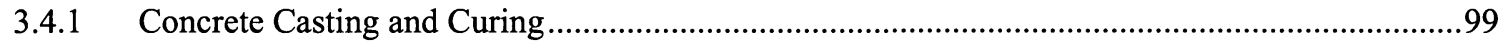

3.4.2 Removing the Formwork and Painting the Specimens ........................................................... 100

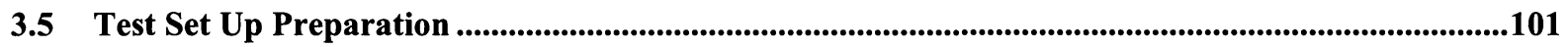

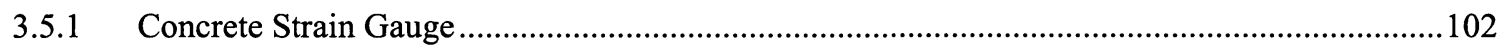

3.5.2 Linear-Variable Displacement Transducers (LVDTs) ............................................................102

3.5.3 Demountable Mechanical Gauges (Demec Gauges) …............................................................. 103

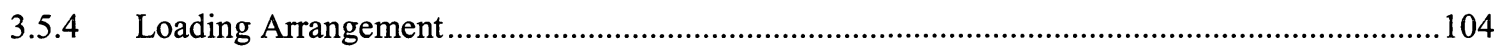

4.0 EXPERIMENTAL RESULTS AND DISCUSSION .............................................. 142

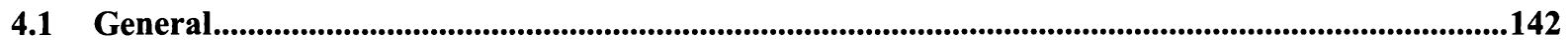

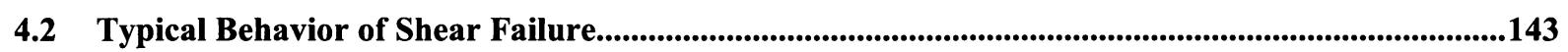

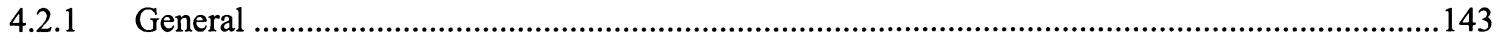

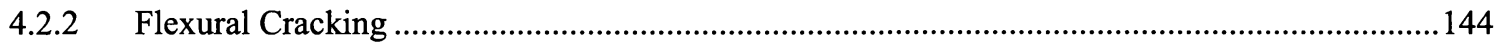

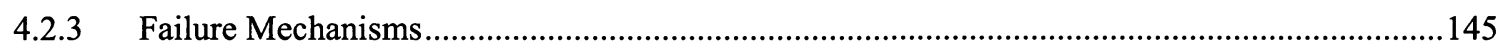

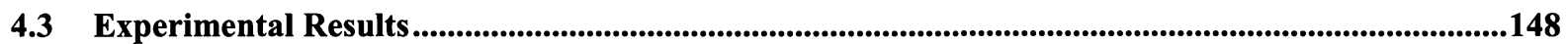

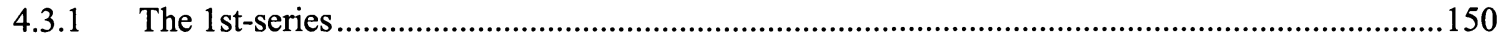

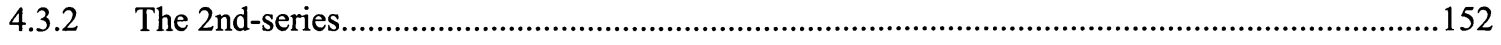


4.4 Code Comparison.................................................................................................................................................158

4.5 Examination of the Role of Crack Widths on Observed Behavior ...........................................................164

5.0 CONCLUDING REMARKS ............................................................................... 203

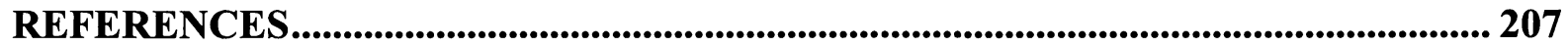

APPENDIX A: SAMPLE CALCULATION OF STRUT-AND-TIE MODEL BY CSA

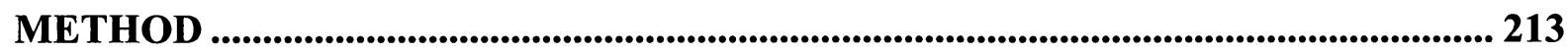

APPENDIX B: SAMPLE CALCULATION OF FRP MID-SPAN STRAIN BY CSA

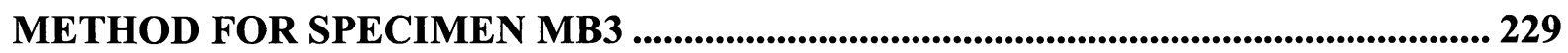




\section{LIST OF TABLES}

Table 2-1: Typical Material Properties of Industrially Available Fibres............................... 71

Table 2-2: Typical Mechanical Properties of FRP Composite Reinforcing Bars................... 71

Table 2-3: Typical Coefficients of Thermal Expansion for FRPs and steel Rebars.............. 71

Table 2-4: Shear Design Methods for FRP-Reinforced Concrete Members .......................... 72

Table 2-5: Summary of Shear Design Methods for 116 FRP Reinforced Concrete Slabs .... 72

Table 3-1: Summary of 15 One-way Slab Specimens ........................................................ 108

Table 3-2: Summary of GFRP Reinforcements Properties.................................................. 108

Table 3-3: Summary of Strain Gauges Arrangement ......................................................... 109

Table 3-4: Concrete Strength Determined From Cylinder Test.......................................... 110

Table 4-1: Experimental Observations ........................................................................... 168

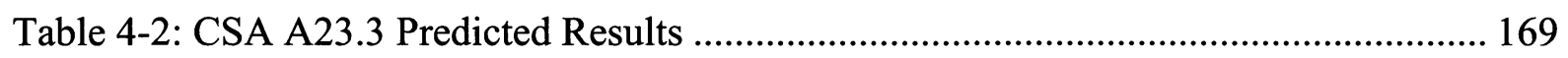

Table 4-3: ACI Method (Frosch (2003)) Predicted Results.................................................. 170

Table 4-4: CSA Committee S806 (2002) Predicted Results.................................................. 171

Table 4-5: El-Sayed et. al. (2006) Predicted Results ........................................................... 172

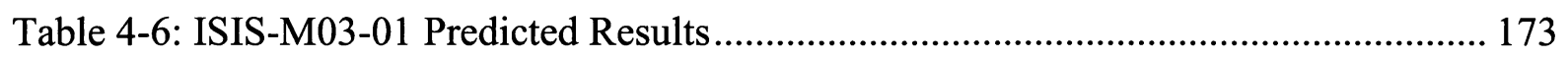

Table 4-7: JSCE (1997) Predicted Results...................................................................... 174

Table 4-8: Razaqpur and Isgor (2006) Predicted Results .................................................. 175

Table 4-9: Comparison of Shear Design Methods for FRP Reinforced Concrete Slabs ...... 176

Table A-1: Numerical Calculations of Strut-And-Tie Model for the $1^{\text {st }}$ Series..................... 216 


\section{LIST OF FIGURES}

Figure 1-1: Corrosion in Steel-Reinforced Concrete Structures

Figure 2-1: Cross-Section of a Composite Material ....................................................... 73

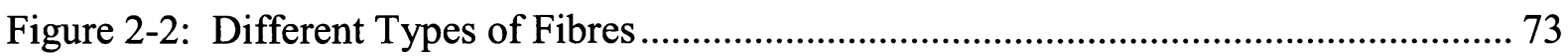

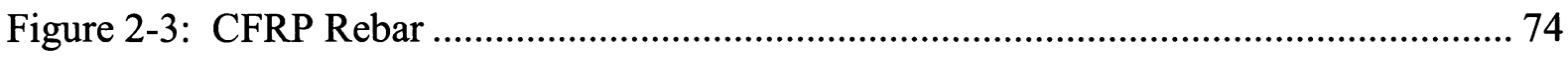

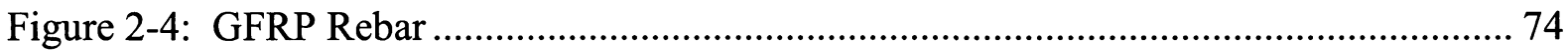

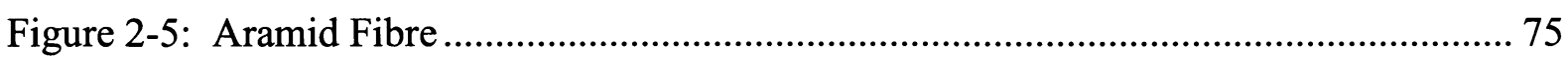

Figure 2-6: Fibres Saturated with Liquid Resin During Manufacturing........................... 75

Figure 2-7: Pultrusion Manufacturing Processes ........................................................ 76

Figure 2-8: GFRP Reinforcement used in Experiments ......................................... 76

Figure 2-9: Stress-Strain Behaviour of Fiber-Reinforced Polymers.............................. 77

Figure 2-10: Typical Geometry of Reinforced Concrete Beams and Slabs...................... 78

Figure 2-11: Summary of 60 Years of Shear Research on Members without Stirrups ........ 79

Figure 2-12: Shear Failure Modes in Reinforced Concrete Beams without Stirrups ........... 80

Figure 2-13: Reinforced Concrete Membrane Elements .............................................. 81

Figure 2-14: Average Stresses and Strains in Cracked Membrane Element, .................... 82

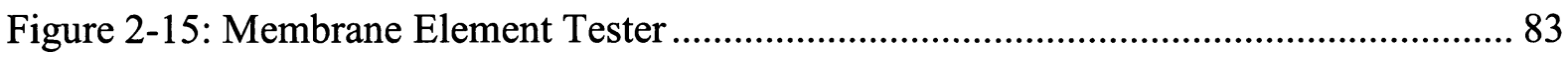

Figure 2-16: 15 Non-Linear Equilibrium Equations, Geometric Conditions ..................... 83

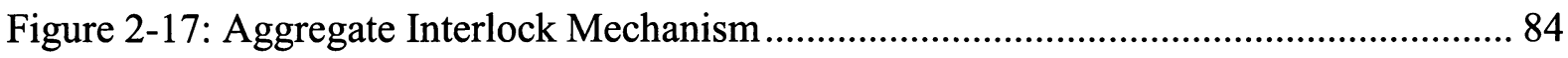

Figure 2-18: Measurement of Shear in Compression Zone (Kani et. al. (1979)) .................. 85

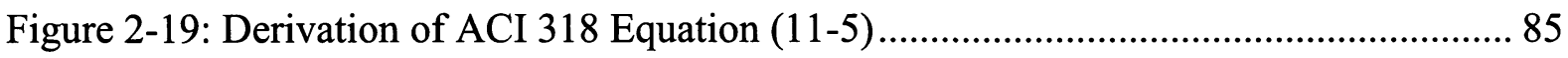

Figure 2-20: Crack Width vs. Longitudinal Strain at Mid-Depth.................................... 86

Figure 2-21: Iterative Analysis Process, CSA A23.3-04 General Method ......................... 87 
Figure 2-22: Normalized Failure Shear Stress vs. $\varepsilon_{\mathrm{x}}$-Experimental Data Points and 88

Figure 2-23: Influence of Shear Span-Depth Ratio on Failure Shear Stress 89

Figure 2-24: Simplified Beam for Model Frosch's Model ........................................... 90

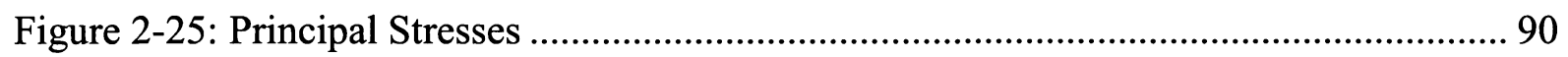

Figure 3-1: Beam Specimen Configuration .............................................................. 111

Figure 3-2: Strain Gauge Instrumentation Locations................................................. 112

Figure 3-3: Strain Gauge Instrumentation Locations for MB15 .................................... 113

Figure 3-4: Instruments to Sand off the FRP Surface ............................................... 114

Figure 3-5: M-Bond 200 Adhesive, Catalyst and Coating ............................................ 114

Figure 3-6: FRP Strain Gauge, Soldering Terminal and Switch and Balance Unit............. 115

Figure 3-7: FRP Strain Gauge Installation........................................................... 115

Figure 3-8: Gauges Coated with Wax and Covered with Tape ....................................... 116

Figure 3-9: Overall View of the Formwork........................................................... 117

Figure 3-10: Final Formwork View after Oiling ....................................................... 117

Figure 3-11: 3/8" Bolt, Plastic Wood and Caulking .................................................... 118

Figure 3-12: Final View of the Formwork................................................................. 119

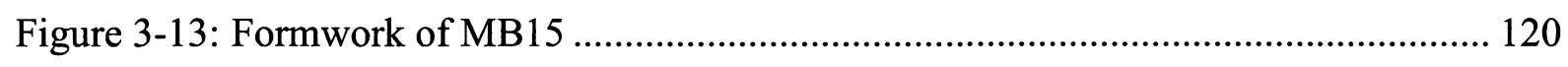

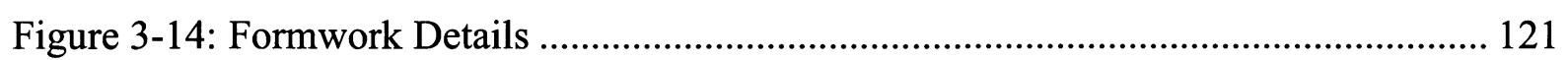

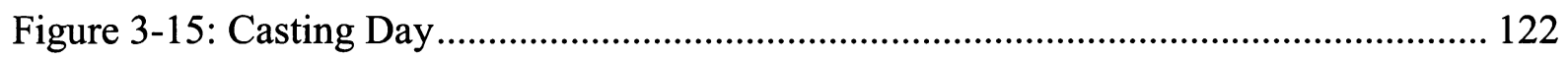

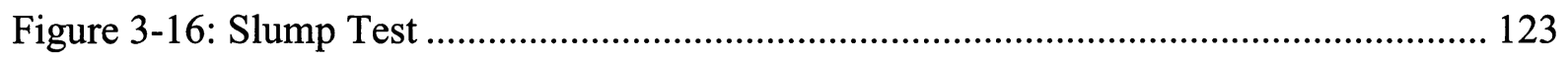

Figure 3-17: Concrete Pouring and Vibrating ....................................................... 124

Figure 3-18: Cylinder Test Samples and Overall View of Specimens .............................. 125

Figure 3-19: Cylinder Capping with Sulphur Powder, Cylinder Test ........................... 126 
Figure 3-20: Removing Specimens from the Formwork

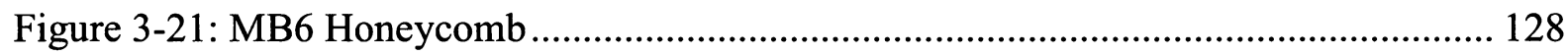

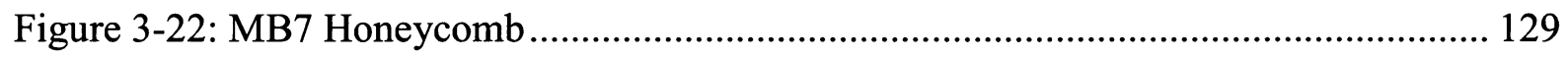

Figure 3-23: Fixing MB6 and MB7 with Verticoat Supreme, Curing and Painting............. 130

Figure 3-24: Overall View of MB6 and MB7 after Fixing................................................. 131

Figure 3-25: Overall View of Painting and Making Grids on Specimens ............................ 132

Figure 3-26: Concrete Strain Gauge Instrumentations and Installation................................ 133

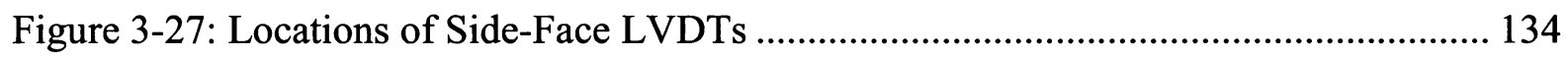

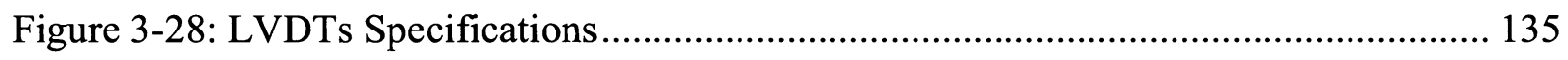

Figure 3-29: Demec Gauge Instrumentation................................................................ 136

Figure 3-30: Overall View of Test Set up, Specimen MB4 ……………............................ 137

Figure 3-31: Overall View of Test Set up, Specimen MB4 (Repeated Side) ....................... 138

Figure 3-32: Overall View of Test Set up, Specimen MB13 …………………………....... 139

Figure 3-33: Overall View of Test Set up, Specimen MB13 (Repeated Side) ..................... 140

Figure 3-34: Overall View of Test Set up, Specimen MB15 …………………………...... 141

Figure 4-1: Typical Failure Mechanism of Beam Action (Specimen MB1) ........................ 177

Figure 4-2: Typical Failure Mechanism of Arch Action (Specimen MB10)....................... 179

Figure 4-3: Development of the Cracks in Beam Action .................................................. 181

Figure 4-4: Applied Load vs Displacement, ${ }^{\text {st }}$ Series ...................................................... 182

Figure 4-5: Applied Load vs Shear Strain, $1^{\text {st }}$ Series .......................................................... 182

Figure 4-6: Applied Load vs Mid-Span FRP Strain, $1^{\text {st }}$ Series.......................................... 183

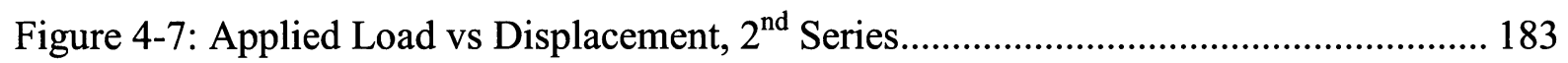

Figure 4-8: Applied Load vs Shear Strain, $2^{\text {nd }}$ Series....................................................... 184 
Figure 4-9: Applied Load vs FRP Strain, $2^{\text {nd }}$ Series

Figure 4-10: Applied Load vs Displacement, $3^{\text {rd }}$ Series

Figure 4-11: Applied Load vs Shear Strain, $3^{\text {rd }}$ Series

Figure 4-12: Applied Load vs Mid-Span FRP Strain, $3^{\text {rd }}$ Series

Figure 4-13: General View of Specimen MB15 with Shear and Moment Diagram

Figure 4-14: Applied Load vs Displacement, $4^{\text {th }}$ Series 188

Figure 4-15: Applied Load vs Displacement, MB2 (Cycle Loading) 188

Figure 4-16: Applied Load vs FRP Strain, MB2 (Cycle Loading).

Figure 4-17: Applied Load vs Shear Strain, MB2 (Cycle Loading)

Figure 4-18: Applied Load vs Shear Strain, $4^{\text {th }}$ Series 190

Figure 4-19: Applied Load vs FRP Strain, $4^{\text {th }}$ Series

Figure 4-20: Effect of Cycle Loading on Crack width, Specimen MB2

Figure 4-21: Comparison of Experimental Results with Hoult Prediction

Figure 4-22: Comparison of Experimental Results with Frosch Prediction

Figure 4-23: Comparison of Experimental Results with Hoult Prediction

Figure 4-24: Comparison of Experimental Results with Frosch Prediction 196

Figure 4-25: Maximum Crack Width vs Experimental Shear Stress, $1^{\text {st }}$ Series

Figure 4-26: Maximum Crack Width vs Experimental Shear Stress, $2^{\text {nd }}$ Series 198

Figure 4-27: Maximum Crack Width vs Experimental Shear Stress, $3^{\text {rd }}$ Series

Figure 4-28: Maximum Crack Width vs Experimental Shear Stress, $4^{\text {th }}$ Series.

Figure 4-29: Comparison of Maximum Crack Widths

Figure 4-30: Maximum Crack Width vs Experimental Shear Stress (Comparison) ........... 200

Figure 4-31: Maximum Crack Width vs Predicted Mid-Span FRP Strain, $1^{\text {st }}$ Series 201 
Figure 4-32: Maximum Crack Width vs Predicted Mid-Span FRP Strain, $2^{\text {nd }}$ Series.......... 201

Figure 4-33: Maximum Crack Width vs Predicted Mid-Span FRP Strain, $3^{\text {rd }}$ Series .......... 202

Figure 4-34: Maximum Crack Width vs Predicted Mid-Span FRP Strain, $4^{\text {th }}$ Series .......... 202

Figure A-1: Sample Strut-And-Tie Model of a Beam ………........................................... 228 


\section{LIST OF SYMBOLS AND ACRONYMS}

a.

Shear Span

$a_{g}$

Maximum coarse aggregate size

ACI. American Concrete Institute

AFRP Aramid Fiber Reinforced Polymer

$A_{r}$ .Longitudinal reinforcement area

$A_{s}$ Longitudinal reinforcement area ASCE American Society of Civil Engineers

$\mathrm{b}_{\mathrm{w}}$ Width of rectangular concrete section

\section{c.} Neutral axis depth of the cracked section

$\mathrm{cm}$ ..Centimeter cot. Cotangent

C. Concrete compression force

CFR Carbon Fiber Reinforced Polymer

$\mathrm{COV}$ Coefficient of Variation CSA Canadian Standard Association d. Effective depth of section

$\mathrm{d}_{\mathrm{v}}$ Flexural lever arm

$\mathrm{dx}$ Differential

$\mathrm{D}_{1}, \mathrm{D}_{2}$ Reading from LVDT

E. Modulus of elasticity of longitudinal reinforcement

$\mathrm{E}_{\mathrm{c}}$ Modulus of elasticity of Concrete

$\mathrm{E}_{\mathrm{f}}$ Modulus of elasticity of FRP reinforcement

$\mathrm{E}_{\mathbf{r}}$ .Modulus of elasticity of reinforcement 

Concrete compressive stress in strut

$\mathrm{f}_{\mathrm{mcd}}$ Design compressive strength of concrete

$f_{t}$. Concrete Tensile Stress

$f_{x}$ In-plane stress in $\mathrm{x}$ direction

$f_{\mathrm{y}}$ In-plane stress in y direction

$f_{\mathrm{y}}$ Yielding strength of steel

$\mathrm{f}_{\mathrm{r}}$ Modulus of rupture of concrete

FRP. .Fiber Reinforced Polymer

g. Gram

GFRP Glass Fiber Reinforced Polymer GPa. Giga Pascal h. .Height of section

I. Moment of Inertia

$I_{g}$ Gross moment of inertia ISIS Intelligent Sensing for Innovative Structure $\mathrm{j}_{\mathrm{d}}$ Flexural Lever Arm JSCE. Japan Society of Civil Engineers $\mathbf{k}_{\mathrm{a}}$ Factor representing the effect of arch action $\mathrm{kg}$. Kilogram $\mathbf{k}_{\mathrm{m}}$ Factor representing the effect of $\mathrm{a} / \mathrm{d}$ $\mathrm{kN}$ kilonewton $\mathrm{k}_{\mathrm{r}}$. Factor representing the effect of reinforcement rigidity $\mathrm{k}_{\mathrm{s}}$. Factor representing the size effect 
LVDT Linear Variable Displacement Transducer

$\mathrm{L}_{1}$ Effective horizontal length of LVDT

$\mathrm{L}_{2}$. Effective vertical length of LVDT

$\mathrm{m}$ Meter $\mathrm{mm}$. Millimeter

M. Moment

MB Name of specimen (Mitra's Beam)

$\mathrm{M}_{\mathrm{cr}}$ ..Cracking Moment

MCFT Modified Compression Field Theory

$\mathrm{M}_{\mathrm{f}}$ Factored moment applied to the section $\mathrm{MPa}$. Mega Pascal MRI. Magnetic resonance imaging

n. Modular ratio

$\mathrm{P}$ .Load, Failure load

$\mathrm{P}_{\mathrm{cr}}$ cracking load

$P_{\exp }$ ..Experimental failure load

$\mathrm{PH}$ Measure of the acidity or basicity of a solution psi Pounds per square inch

Q. First Moment area about the centroidal axis of the area

RC. Reinforced Concrete

RTM Resin Transfer Molding S. Crack spacing Sec. Unit of time (Second)

Xviii 

crack spacing parameter

$\mathrm{S}_{\mathrm{xe}}$ Equivalent crack spacing parameter

$\mathrm{T}$ Tensile force in reinforcement $T_{g}$ Glass transition temperature

UV Ultraviolet

$\mathrm{V}$ Shear force

$\mathrm{V}_{\mathrm{c}}$ Concrete shear strength

$\mathrm{V}_{\mathrm{c}, \exp }$ Experimental shear strength of concrete $\mathrm{V}_{\mathrm{cz}}$ Vertical shear force in uncracked compression zone $\mathrm{V}_{\mathrm{d}}$ shear force due to the dowel action in reinforcement

$\mathrm{V}_{\exp }$ .Experimental shear strength $\mathrm{V}_{\mathrm{f}}$ Factored shear applied to the section $\mathrm{V}_{\text {pred }}$ Predicted shear strength

w Crack width

$\mathrm{W}_{\max }$ Maximum crack width

$\mathrm{W}_{\text {max,diagonal }}$ Maximum diagonal crack width

y. Distance from the neutral axis of the section to the extreme tension fiber of the section

$\beta \ldots \ldots \ldots \ldots \ldots$........ Parameter describing the aggregate interlock capacity of cracked concrete $\beta_{\mathrm{d}}$ Factor in JSCE shear design equation $\beta_{n}$ Factor in JSCE shear design equation

$\beta_{\mathrm{p}}$ Factor in JSCE shear design equation $\beta_{1} \ldots \ldots . \ldots . .$. Ratio of depth of the rectangular compression block to depth to the neutral axis $\gamma$ Shear strain 

Average shear strain in xy plane Maximum shear strain Mid-span deflection Difference in tension force Maximum mid-span deflection

$\varepsilon$ .Longitudinal reinforcement strain Tensile strain in longitudinal reinforcement $\varepsilon_{\mathrm{s}, \max }$ .Longitudinal reinforcement strain at mid-span at peak load $\varepsilon_{\mathrm{t}}$ Strain in the tensile steel reinforcement Average strain in $\mathrm{x}$ direction (MCFT) $\varepsilon_{\mathrm{x}}$ longitudinal strain at mid-depth of beam Average strain in y direction Principal tensile strain in the strut Angle of inclination of the cracks at mid-depth of the section $\theta_{\mathrm{s}}$ Smallest angle between the strut and the adjoining ties $\lambda$ Factor to account for low-density concrete

$\mu$ Micro

$\mathrm{v}$ Shear stress

v.......................shear stress applied across the crack due to interlocking of aggregate particles along the crack

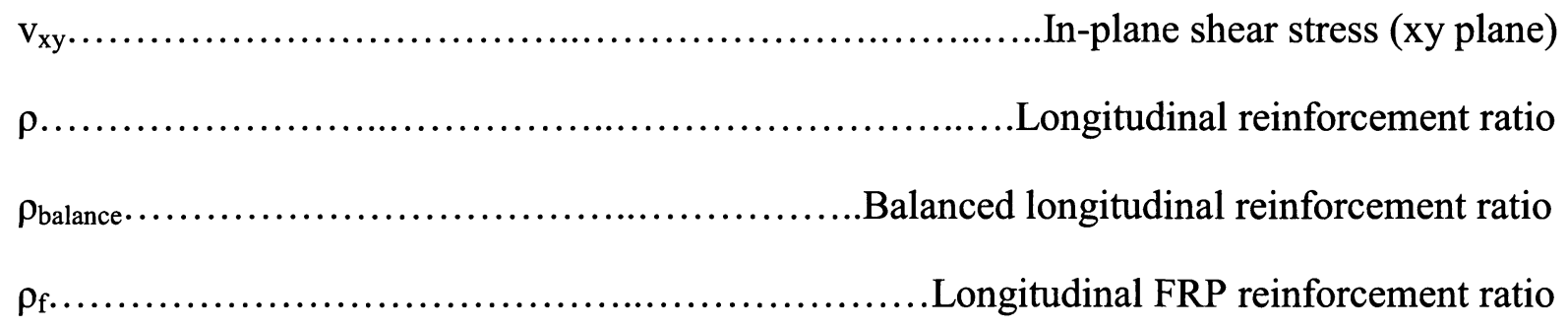



Maximum axial flexural compression stress

$\tau$ Shear stress

$\varphi_{\mathrm{c}}$ Concrete material resistance factor ${ }^{\circ} \mathrm{C}$. Degree Centigrade

$\Omega$. Unit of electrical resistance (Ohm) 


\subsection{INTRODUCTION}

\subsection{General}

Deterioration of reinforced concrete structures due to corrosion of steel reinforcement is a very common problem throughout the world, especially in Canada and the northern regions of the U.S. due to the use of deicing salt. This problem is common in marine and offshore structures, bridge decks and parking garage beams and slabs (Figure 1-1)

The presence in concrete pore water of a large amount of calcium hydroxide and small amounts of alkali elements, such as sodium and potassium, makes concrete a highly alkaline material with $\mathrm{pH}$ of 12 to 13 . This high alkalinity causes a passive film to form on the surface of the steel reinforcement. As long as this film is undisturbed, it prevents the steel from corroding. However, if exposed to deicing salts or salt water, chloride ions will slowly penetrate into the concrete until reaching the steel, at which point the protective film can be destroyed and the steel corrode, given adequate quantities of oxygen and moisture. This steel corrosion can result in decreased flexural and shear capacity of the member and decrease the effective and beneficial age of the structure. The corrosion can also cause spalling of the concrete, presenting a safety hazard to people underneath the structure.

Several solutions have been investigated for this significant issue such as the use of galvanized steel rebar, epoxy coated rebar or stainless steel. A solution for the corrosion issue which has been heavily explored in recent years is the use of non-corrosive Fiber Reinforced Polymer (FRP) reinforcement. FRP reinforcements are non-corrosive, fatigue resistant, easy to handle and install, and have a high strength and stiffness to weight ratio. These properties 
permit the effective use of FRP in concrete structures either internally as reinforcing bars in new construction or externally as plates or sheets for strengthening existing structures.

Since FRP is a new material, researchers have been heavily exploring the real behavior of FRP-reinforced concrete members in flexure and shear. A significant challenge, however, is accurately predicting the shear strength of concrete members reinforced with FRP reinforcement. Shear failures in concrete structures occur suddenly without significant advanced warning. Because of the brittle nature of shear failure, designers have to design sections to have an adequate shear resistance. In the past, researchers working in this field tried to generate empirical curve-fits to beam test results. However, as shear is a complex phenomenon influenced by many variables, understanding the meaning of particular experiments and the range of applicability of the results is extremely difficult unless the researchers are guided by an adequate theory which can identify the important parameters. One such theory is the Modified Compression Field Theory (MCFT) (Vecchio and Collins (1986)) which forms the basis of the shear design provisions of the Canadian CSA A23.3 design code (CSA Committee A23.3 (2004)).

Many researchers have suggested applying modification factors to existing equations for steel reinforced concrete members to obtain new methods for FRP reinforced concrete members. However, before proposing a method, the key parameters that affect the shear resistance of FRP-reinforced concrete members must be identified. For reinforced concrete sections without shear reinforcement, among the prime parameters which influence failure shear stress are: concrete compressive strength $f_{c}$, modulus of elasticity of longitudinal 
reinforcement $E$, effective depth $d$, and the ratio of $\frac{M}{\rho V d}$ as a measure of strain in the longitudinal reinforcement.

In actual design, the amount of the longitudinal reinforcement and the value of moment are related together. That is, by increasing the load on a member or by increasing the span-todepth (a/d) ratio, the member must sustain a larger value of moment, and as a result the amount of the reinforcement should be increased to sustain this moment. Therefore, the parameter $\frac{M}{\rho \mathrm{Vd}}$ tends to be fairly constant. Unlike the practical case, in experimental tests the (a / d) value (which represents the term $\frac{\mathrm{M}}{\mathrm{Vd}}$ in the case of a point-loaded beam) and $\rho$ are treated as independent variables. Furthermore, to ensure that shear failure occurs before flexural failure, the amount of the longitudinal reinforcement, $\rho$, is often unrealistically large. Hence, empirical design equations derived from test results often overestimate the importance of $\rho$, and underestimate or ignore the importance of the a/d. As such, existing shear design methods for FRP reinforced concrete have not shown themselves to be very accurate at predicting a full range of experimental results. Bearing in mind that it is critically important that shear design methods be accurate and safe, this has slowed the full acceptance of FRP materials as legitimate options in corrosive environments.

\subsection{Thesis Objectives}

The inadequate state of current shear design methods for FRP reinforced concrete requires experimental studies to investigate the possibility of using more rational, 
theoretically-based shear design methods. In this regard, this study consists of a large experimental program wherein fifteen large, shear-critical FRP-reinforced one-way slabs were tested to failure. The goals of the program are as follows:

To investigate whether formulating shear design methods for FRP-reinforced concrete beams and slabs in terms of the longitudinal strain in the web, rather than $\rho$, offers enhanced accuracy.

To investigate the role that the ratio $\frac{\mathrm{M}}{\rho \mathrm{Vd}}$ has on the shear strength of FRP-reinforced concrete beams and slabs. In particular, the purpose is to investigate whether FRPreinforced beams with a constant $\frac{\mathrm{M}}{\rho \mathrm{Vd}}$ ratio have a constant failure shear stress.

$>$ To show that, unlike empirically-derived methods, shear design methods based on an adequate theory are capable of accurately and rationally predicting strength of beams where no experimental data exists.

$>$ To provide additional experimental data in regards to FRP-reinforced beams and slabs at large $\mathrm{a} / \mathrm{d}$ ratio.

\subsection{Thesis Organization}

This thesis is organized into four chapters and two appendices. Chapter 2 presents an introduction of FRP properties and applications, and a brief review of the literature on the shear design methods of FRP-reinforced concrete members. Chapter 3 presents the 
experimental program of this thesis on the fifteen one-way slabs reinforced with FRP reinforcement without stirrups, focusing on the shear behaviour of beams or one-way slabs reinforced with FRP. The results of Chapter 3 are discussed in Chapter 4 and are compared with the seven prominent shear design methods of FRP-reinforced members. Concluding remarks and recommendations are presented in Chapter 5. Details of how to use the CSA code strut-and-tie models are presented in Appendix A. Appendix B contains sample calculations of mid-span FRP strains using linear-elastic approximations. 

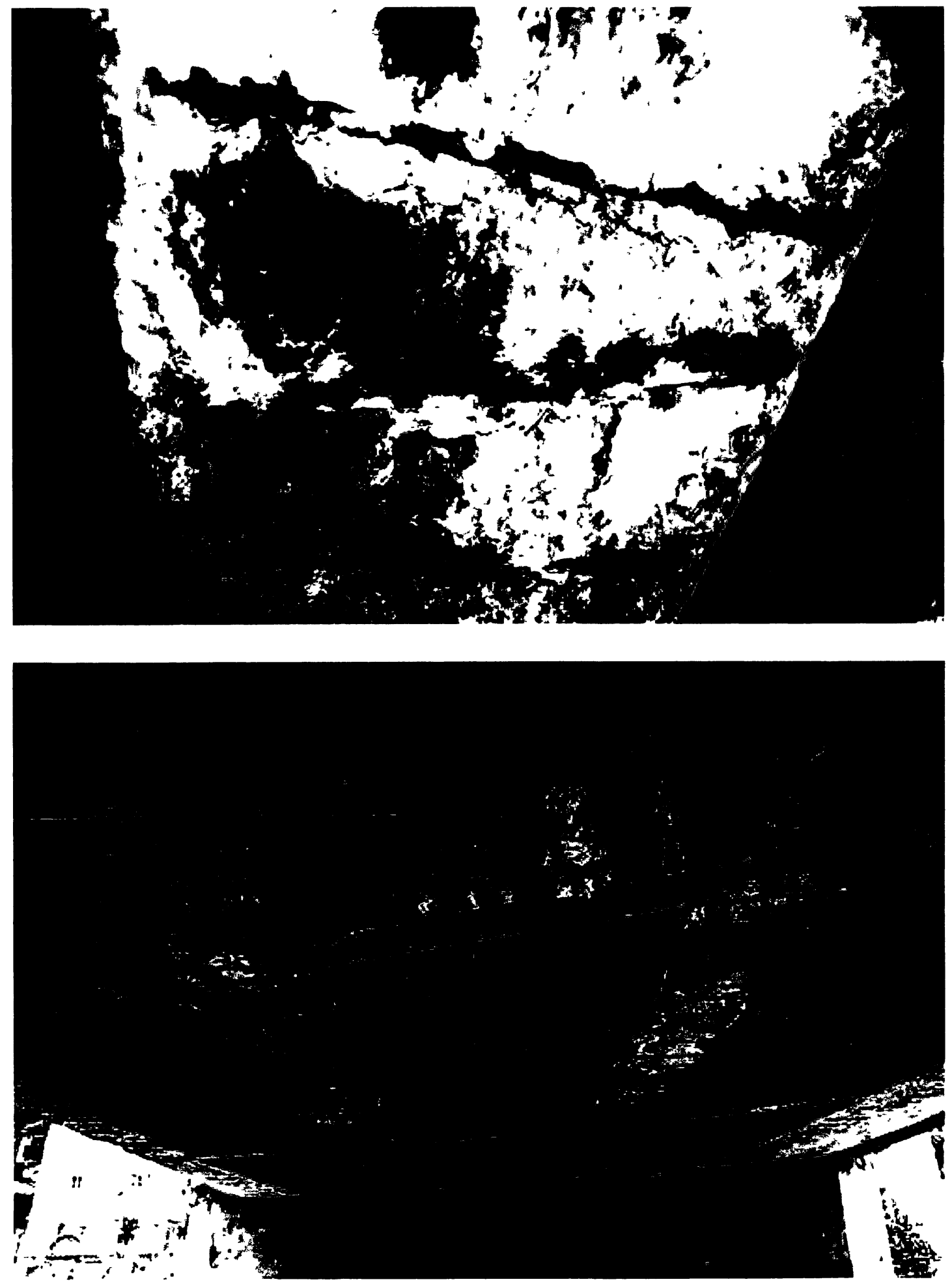

Figure 1-1: Corrosion in Steel-Reinforced Concrete Structures 


\subsection{BACKGROUND}

\subsection{Fiber-Reinforced Polymers}

\subsubsection{General}

Fiber reinforced polymer (FRP) composite materials have been used successfully for decades in aerospace, shipbuilding and more recently in civil engineering structures. They consist of high strength fibers embedded in a resin matrix. In order to successfully use FRP as reinforcement for construction applications, the fiber-volume fraction should be more than 55 per cent. The mechanical properties of FRP bars depend on the fiber type, orientation, shape and volumetric ratio in the matrix. Also the manufacturing processes have an influence on the quality of FRP bars. All of these parameters can significantly change the final properties of FRP reinforcement. Figure 2-1 shows a cross-section of a composite material.

\subsubsection{Fibers}

Fibers carry axial loads and give FRP composites mechanical strength and stiffness. Fibers must have high strength, toughness and durability in order to be used in composite materials (Figure 2-2). The efficiency of the fibers depends on their length, cross-sectional 
shape, size and chemical composition. The three most common types of fiber used in construction are carbon, glass and aramid.

Carbon fibers have been used commercially since 1959 and consist of thin fibers about 0.005-0.010 $\mathrm{mm}$ in diameter. Carbon fibers are extremely corrosion resistant. They have also extremely good resistance to fatigue, creep, heat and stress rupture. This fiber exhibits the best mechanical properties among these three fiber types, but is typically the most expensive one (Figure 2-3).

Glass fibers are made from extremely fine fibers of silica, $\mathrm{SiO}_{2}$ (Figure 2-4). The two most common types for structural applications are S-glass and E-glass. E-glass, more common than S-glass, is electrical grade glass which was originally developed for standoff insulators for electrical wiring. In general, glass fibers show less fatigue resistance than either carbon or aramid fibers. They are also susceptible to stress rupture and in both high PH and high humidity conditions. However, they are not susceptible to creep and in mild acids and basic conditions, they are corrosion resistant. The physical properties of glass fibers are extremely dependant on the resin type. Although glass fibers exhibit the lowest tensile strength and modulus of elasticity compared to the two other types of fibers, carbon and aramid, they are significantly less expensive than them.

Aramid fibers were first introduced in commercial applications in the early 1960s, and are characterized by excellent resistance to heat (Figure 2-5). They show excellent resistance to fatigue and compared to glass fibers, they exhibit less susceptibility to stress rupture. They have low density, high strength and good impact resistance. They, however, exhibit low performance in high humidity, strong acids-bases and UV radiation conditions. 
The typical material properties of these three common types of fibers compared to steel fibers are listed in Table 2-1. Table 2-2 shows the typical mechanical properties of FRP composite reinforcing bars, compared to those of steel reinforcing bars.

\subsubsection{Resin Types}

The physical and thermal properties of the resin matrix can significantly affect the mechanical properties and chemical resistance of the composite. Resin is used in FRP polymers to transfer tensile stresses between fibers through shear. The resin matrix is weaker than fibers, but protects fibers from abrasion and environmental effects. The resin matrix also can act as a lateral support for fibers against buckling when subjected to compressive loads (Figure 2-6).

There are three common types of resin used for structural applications: epoxy, polyester and vinyl-ester. All of these three types of resin are thermosetting, meaning that the curing process is irreversible. That is, during curing, their molecules join together by chemical cross-links, resulting in a rigid three-dimensional structure. This nature does not let them reshape by applying heat or pressure. Hence, they do not soften on heating and cannot be remelted.

Among these three types of resin matrix, epoxy resin exhibits the best properties due to its high strength, fatigue resistance, environmental resistance, low shrinkage, excellent adhesion between fibers and higher viscosity which is beneficial for ease of application.

For civil engineering applications, the most common resin types are polyester resins. Ethylene glycols are used as a reactant in the manufacture of polyester resins. They are 
resistant to most acids and solvents but are susceptible to corrosion in basic environments. These resins tend to be fairly rigid when cured and also more brittle than epoxy resins. Polyester resin has also less resistance to fatigue. It is overall less expensive than epoxy, and this explains its wide use in civil applications.

Vinyl-ester resins are made from a chemical reaction between an epoxy resin and an unsaturated mono-carboxylic acid. They have better physical properties than polyesters. However, compared to epoxy resins they are weaker and susceptible to fatigue. Vinyl-ester is less expensive than epoxy but more expensive than polyesters. This resin matrix has also low viscosity compared to polyester and epoxy resins.

\subsubsection{Manufacturing Processes}

As mentioned earlier, the manufacturing processes have an influence on the properties of FRP bars. Consideration of the manufacturing process is necessary in order to get the required shape and size, to ensure that the reinforcement phase is completely encapsulated by the resin phase, to eliminate voids and entrapped air, to ensure the proper fiber direction and fiber-resin proportion and to produce a homogeneous distribution of reinforcement phase. The most common manufacturing methods for FRP composites are: Hand Lay-up, Spray-up, Compression \& Resin Transfer Molding (RTM), Pultrusion and Filament Winding.

The two main methods of the hand lay-up process are wet lay-up and dry lay-up. In the wet lay-up process, dry fibers are first applied to the mold and then saturated with liquid resin. In the dry lay-up process, fibers and resin are applied and impregnated simultaneously. 
Among the processes, pultrusion is the most common technique to make continuous lengths of FRP bars. In this process, continuous fibers are drawn from creels into a resin tank to saturate with resin. The performing die, curing and pulling processes come afterwards (Figure 2-7). To improve bond between concrete and bars, it is then braided or sand-coated. The glass FRP rebars used in this study had a sand-coated surface to enhance bond and improve force transfer between bars and concrete (Figure 2-8).

\subsubsection{Thermal Properties and Effect of High Temperature on FRPs}

One issue which can affect the performance of FRP reinforcement is in regard to the thermal properties of FRP. Unlike steel, thermal properties of FRPs are different in the longitudinal and transverse directions and are dependent on the fiber type, the fiber-volume ratio and the matrix type. Typical coefficients of thermal expansion for FRP reinforcements and steel are summarized in Table 2-3. As can be seen, among the three common types of FRP, aramid has a negative thermal coefficient in longitudinal direction, -2 to $-6 \times 10^{-6} /{ }^{\circ} \mathrm{C}$, which means that AFRPs tend to contract with increasing the temperature and expanding with decreasing the temperature. Carbon fiber reinforcement however, has roughly a zero thermal coefficient in longitudinal direction.

The behaviour of FRP reinforced concrete members at high temperature is still not fully understood and needs to be investigated (Saafi et. al. (2002)). Sen et. al. (1993) carried out studies on the effects of two high and low temperatures $\left( \pm 550^{\circ} \mathrm{C}\right)$ on the tensile strength of glass fibres. He found that, at a temperature of both $+550{ }^{\circ} \mathrm{C}$ and $-550{ }^{\circ} \mathrm{C}$, glass fibre has half the value of its tensile strength at the room temperature. However, for carbon fibres, Rostasy 
et. al (1992) found that the tensile strength of carbon fibres seemed to be unaffected by temperatures of up to about $1000{ }^{\circ} \mathrm{C}$.

In the case of fire, the lack of oxygen inside the concrete prevents FRP reinforcement from burning. However, when subjected to increasing temperature, resin tends to soften at the glass transition temperature, $T_{g}$, which is considerably less than the temperature at which the fibres start to degrade. As a result, at elevated temperatures resin can no longer effectively transfer stresses from the concrete to the fibre so the bond between them will fail. This failure can cause cracking and increased crack widths and deformations. As such, the thermal properties of resins need to be improved for FRPs.

For unprotected steel, however, after exposure to temperature of about $600{ }^{\circ} \mathrm{C}$, it can visibly deform, twist and buckle in 15 minutes and above $600{ }^{\circ} \mathrm{C}$, the crystalline and metallurgical structure of steel undergoes a transformation. For steel reinforced concrete structures however, steel reinforcement retain much of the yield strength up to $425{ }^{\circ} \mathrm{C}$. However, it can take up to almost three hours for the heat to penetrate through the concrete cover and reach the steel (Bilow et. al. (2008)).

The value of the glass transition temperature depends on the type of the resin. This temperature has a greater effect on thermoplastic resins than thermosetting resins. While there are a limited number of studies on the effects of temperature on FRP reinforced concrete, it is reported that the flexural and bond strength of FRP reinforced concrete can be affected at this temperature (Katz et. al. (1998)). He noted a reduction of between $80 \%$ and $90 \%$ in the bond strength of his four types of FRP rebars when the temperature increased 
from $20{ }^{\circ} \mathrm{C}$, to $250{ }^{\circ} \mathrm{C}$. However for steel reinforcement, he observed only a reduction of $38 \%$ in the same temperature range. Saafi et. al. (2002) observed that FRP reinforced concrete beams exhibit degradation in shear and flexural strengths with increases in temperature which is significantly dependant on the concrete cover. However, for a given concrete cover, steel exhibits far better fire endurance than FRP. He investigated four beams with concrete cross-section of $(200 \mathrm{~mm} \times 300 \mathrm{~mm})$ and clear cover of $64 \mathrm{~mm}$. Each beam had one layer of GFRP, CFRP, AFRP and steel reinforcement respectively. It was found that the GFRP, CFRP and AFRP reinforced concrete beams had a reduction of $75 \%$ in their flexural capacity 23, 52 and 31 minutes after starting the fire, respectively. However, for the steel reinforced concrete beam, he observed only a $41 \%$ reduction in flexural capacity after 106 minutes. $\mathrm{He}$ suggested that increased cover is required to provide adequate fire resistance for FRP reinforcements.

\subsubsection{Structural Applications of FRP}

One of the significant issues for managers of public infrastructures is that reinforced concrete structures are susceptible to deterioration due to steel reinforcement corrosion. Parking garages and bridge decks, for example, are susceptible to corrosion because of the use of deicing salts on these structures. Several solutions have been explored such as the use of galvanized steel rebar, epoxy coated steel or stainless steel. In Ontario, for example, epoxy-coated steel is widely used in bridges. One potential solution is the use of noncorrosive FRP reinforcement. 
In general, the properties of FRPs which make them useful in structural applications are:

- High strength and stiffness to weight ratio

- High resistance to corrosion and chemicals

- High residence to abrasion

- Toughness

- Fatigue life

- Lightweight; as a comparison, they weigh 20 to 25 per cent less than aluminum.

The high strength of FRP materials is achieved due to the low probability of flaws in individual fibers. One of the drawbacks of FRPs, however, is their brittle-elastic behavior because FRPs do not show any yield plateau unlike steel (Figure 2-9). FRPs exhibit a linear stress-strain relationship up to failure without yield plateau. They also have higher ultimate strengths than steel, but with lower strain at failure.

The disadvantage of the brittle linear-elastic nature of FRP can be partially overcome in the flexural design of beams by designing sections to be over-reinforced. This avoids brittle rupturing of FRP reinforcement and allows more energy to be absorbed as the concrete in the compression zone will crush. Furthermore, higher reinforcement ratios will result in stiffer members that will exhibit less deflection.

Another major drawback of FRPs is that they have relatively low moduluii of elasticity and lower stiffness compared to steel reinforcement. FRPs also have relatively low compressive strength compared to their tensile strength. As a result, it is not recommended to use FRP bars in compression. 
Overall, these properties have permitted the application of FRPs in civil engineering structures either internally as reinforcement or externally for strengthening reinforced concrete structures such as bridges, parking garages and marine structures. In general, the structural application of FRPs can be summarized as below:

- Reinforcing bars and tendons

- Wraps and laminates

- Composite bridge decks

- Linings for tunnel applications (corrosive applications)

- Beams and slab for MRI supports at hospitals (applications requiring electromagnetic neutrality)

- Electrical underground concrete chambers (corrosive and electromagnetic applications)

- Concrete structures exposed to marine salts such as seawalls and structures near waterfronts.

A particular application in which FRP materials have been beneficially used is in strengthening concrete members such as beams, slabs and columns. These FRPs are in the form of rigid or flexible sheets that are externally bonded with epoxy. The traditional method of strengthening has involved bonding steel plates with epoxy or bolts. These plates are heavy, however, and are susceptible to corrosion. They can be particularly difficult to apply over long spans. FRPs offer a light-weight, cost-effective alternative and are not susceptible to corrosion. 
There are also issues which need to be addressed regarding the use of FRPs for structural purposes:

- FRPs must be protected against UV radiation

- FRP products must be stored and handled carefully

- Contact between FRPs and steel must be avoided to prevent galvanic corrosion of the steel

- FRP bars should be tied to formwork with plastic ties

- Due to their light weight, FRP bars should tie to formwork to avoid shifting during casting.

Finally, FRP reinforcing bars are available commercially in different sizes. However, Faza et. al. (1992) showed that due to the shear lag in fibers, fibers near the outer surface are stressed more than the fibers located near the center of the FRP bars. Based on this study, the bar diameter can have effect on the tensile strength of FRP rebars. That is, smaller diameter FRP bars can exhibit higher tensile strength.

\subsection{Shear Behavior of Beams and One-way Slabs without Shear Reinforcement}

\subsubsection{General}

A critical aspect of structural design is ensuring that brittle materials have adequate shear strength. A well-designed beam should be critical in flexure rather than shear. That is, reinforced concrete beams show considerable warning before flexural failure occurs as the 
steel will yield, resulting in wide cracks and large deformations. However for shear failures, there are no such warnings for members without stirrups. Reinforced concrete beams and slabs without stirrups show brittle behavior as shear failure in these members can occur suddenly without any sufficient warning. As such, engineers must design concrete members relying solely on building code provisions to provide designers with adequate safety against shear failure. These provisions must hence be accurate, rational and safe.

It is worthwhile to briefly discuss the typical geometry of reinforced concrete beams and slabs used in experimental studies on the shear strength of concrete (Figure 2-10). This will clarify the discussion in the rest of this chapter. There is a long and rich history of testing steel-reinforced concrete beams without stirrups such as that shown in Figure 2-10 (see Figure 2-11). Shown in the figure is a "3-point bending test" in which a simply-supported beam is subjected to a central point-load, resulting in constant shear forces on either side and a varying moment. Also commonly used is a "4-point bending test", whereby two point loads are applied to the top of the beam, resulting in a constant moment region between the two point loads.

For an uncracked rectangular concrete beam the shear stress at a given section can be calculated by:

$$
v=\frac{V Q}{I b_{w}}
$$

Where in this equation:

$\mathrm{V}=$ shear force on the cross section

$b_{w}=$ width of the section where shear stress is calculated 
$\mathrm{Q}=$ the first moment area about the centroidal axis of the area

$I=$ moment of inertia of the cross section

Two major types of cracks can happen as load is applied. First, vertical flexural cracks occur and start at the bottom of the beam where the flexural stresses are large. These flexural cracks extend up the beam and rotate, reflecting the reorientation of principal stresses due to shear stresses. Inclined diagonal cracks can happen close to the end of the beam due to the shear and flexure stresses acting together. Typical cracking patterns and failure modes are shown in Figure 2-12.

After cracking, internal shear stresses redistribute due to the presence of these cracks and the distribution can no longer be described using Equation 2-1. The post-cracking shear stress distribution is well understood, yet still represents a source of debate. Its accurate prediction is critical in the accurate prediction of shear strength of concrete members. For example, debate is ongoing as to whether shear stresses can be carried below the neutral axes in a cracked beam. This issue will be discussed shortly.

\subsubsection{Significance of a Rational Theory in the Shear Design of FRP Reinforced Concrete}

Numerous researchers have studied the shear behavior of FRP reinforced concrete, and numerous design equations have been proposed. All of these equations were derived by empirical curve-fits to beam test results. Many of these equations consist of modification factors applied to existing equations for steel reinforced concrete members. In reality, the shear phenomenon is influenced by many variables and these variables may or may not be 
accounted for in these equations. To understand the influence of just one variable, an adequate number of experimental tests are needed in which just that specific variable is varied over a wide range. In contrast, an adequate theory of the shear behavior of the concrete could identify the effect of these variables on the shear strength of concrete members. The shear design provisions of the CSA A23.3-04 design code (CSA Committee A23.3 (2004)), for example, are derived from a rational theory and are not based on empirical curves fit to beam test results. This theory is known as the Modified Compression Field Theory (MCFT) (Vecchio and Collins (1986)).

Most researchers believe that FRP reinforced concrete exhibits different behavior in shear compared to steel-reinforced concrete members due to the lower modulus of elasticity of FRP reinforcement. As a result, the perceived difference between steel reinforcement and FRP reinforcement is reflected in their equations. The fact is, shear failure in concrete members without shear reinforcement occurs in the concrete, not in the reinforcement. Therefore, a general shear design method which is derived from a rational theory of the behavior of reinforced concrete in shear should be able to account for the use of FRP reinforcements with their low modulus of elasticity. As the CSA shear design provisions are based on a rational theory and not based on the empirical curves fit to the lab results, it is expected that this code can accurately account for the use of FRP reinforcement (Sherwood et. al. (2008)). 


\subsubsection{CSA A23.3-04 Shear Provisions}

The 2004 CSA A23.3 general shear design method was derived from the Simplified Modified Compression Field Theory, SMCFT, (Bentz et. al. (2006)) which itself is based on the Modified Compression Field Theory.

The MCFT was developed to predict the load deformation response of reinforced concrete membrane elements such as those described in Figure 2-13. Average stress and average strain conditions were described using Mohr's circles of stress and strain. The challenge, however, was how to relate in-plane stresses $f_{x}, f_{y}$ and $v_{x y}$ to average strains $\varepsilon_{x}, \varepsilon_{y}$ and $\gamma_{x y}$ (Figure 2-14). This was accomplished through testing concrete membrane elements in a unique membrane element tester (Figure 2-15). This permitted the generation of unique stress-strain relationships that relate the principal stresses to the principal strains. This theory gives us 15 non-linear equilibrium equations, geometric conditions and stress-strain relationships that can be used to predict the whole load-deformation relationship for RC members loaded in shear (Figure 2-16).

A full analysis using the MCFT to predict the shear strength of a membrane element involves solving these 15 equations. This is clearly beyond the scope of typical design applications without the aid of computer software. As such, the SMCFT was recently developed to derive simplified equations appropriate for "back-of-the-envelope" calculations. The SMCFT was further refined to develop the shear design provisions in the CSA A23.3 standard.

One of the main simplifying assumptions in deriving the CSA shear design equations is that the shear strength of members without stirrups is controlled by a mechanism known as aggregate interlock (Fenwick and Paulay (1968)). Aggregate interlock can be described with 
the help of Figure 2-17. Consider the cracked RC beam without stirrups shown, and the freebody diagram of the end portion. The vertical shear force is transferred from the point load to the support through three primary mechanisms: vertical shear in the uncracked compression zone $\left(\mathrm{V}_{\mathrm{cz}}\right)$, shear due to dowel action in the reinforcement $\left(\mathrm{V}_{\mathrm{d}}\right)$ and shear stress applied across the crack due to interlocking of aggregate particles along the crack $\left(v_{\mathrm{a}}\right)$. Several studies (Fenwick and Paulay (1964), Taylor (1970), Kani et. al. (1979), Sherwood et. al. (2007)) have shown that up to $80 \%$ of the vertical shear force is transferred by shear stress across the crack. These tests consisted of careful instrumentation of cracked beams and subassemblies which permitted the quantification of each component. Referring to Figure 218 , it can be seen that at three adjacent cracks, Kani et. al. (1979) measured that $19 \%, 32 \%$ and $17 \%$ of the shear force was carried within the compression zone. They also noted that the dowel component was quite small, perhaps $10 \%$, leaving about $71 \%, 58 \%$ and $73 \%$ to be carried by aggregate interlock. These proportions were confirmed by Sherwood et. al. (2007) who indicated that about $75 \%$ of the shear was carried by aggregate interlock.

The ability of the dowel action to resist shear stresses depends on the transverse rigidity and strength of the longitudinal reinforcement. FRP bars are generally understood to contribute very little to dowel action due to their very low transverse rigidity.

In additional to the above, residual tension in cracked concrete is predicted to be present at cracks which have a width less than $0.15 \mathrm{~mm}$ (ACI-ASCE Committee 445, (1998)). The residual tension tends to be quite small and is typically neglected. In FRP reinforced concrete, cracks tend to be quite wide due to the low stiffness of the reinforcement. Hence this mechanism is even less significant. 
In early attempts at developing shear design equations, researchers neglected the role of aggregate interlock on the shear behavior of concrete members and believed that in members without shear reinforcement once cracking occurs, all the vertical shear force will be carried only in the uncracked concrete compression zone (Zwoyer and Siess et. al. (1954), Moretto et. al. (1955), Moody et. al. (1954), Hanson et. al. (1958), Bresler et. al. (1958), Walther et. al. (1962)). The understanding of the importance of aggregate interlock is a fairly recent phenomenon. As research progressed, it was realized that aggregate interlock has significant effect on shear behavior (Moe at. al. (1962), Fenwick et. al. (1964), MacGregor et. al. (1964), Fenwick et. al. (1968), Taylor et. al. (1970), Kani et. al. (1979)).

The SMCFT suggests the following equations to determine the shear resistance of a reinforced concrete section without stirrups:

$$
V_{c}=\beta \sqrt{f_{c}^{\prime}} b_{w} d_{v}
$$

where

$$
\begin{aligned}
& \beta=\frac{0.40}{\left(1+1500 \varepsilon_{\mathrm{x}}\right)} \cdot \frac{1300}{\left(1000+\mathrm{s}_{\mathrm{xe}}\right)}=(\text { strain effect term }) \cdot(\text { size effect term }) \\
& \varepsilon_{\mathrm{x}}=\frac{\mathrm{M}_{\mathrm{f}} / \mathrm{d}_{\mathrm{v}}+\mathrm{V}_{\mathrm{f}}}{2 \mathrm{E}_{\mathrm{s}} \mathrm{A}_{\mathrm{s}}} \\
& \mathrm{s}_{\mathrm{xe}}=\frac{35 \mathrm{~s}_{\mathrm{x}}}{15+\mathrm{a}_{\mathrm{g}}} \geq 0.85 \mathrm{~s}_{\mathrm{x}}(\mathrm{mm}) \\
& \theta=\left(29+7000 \varepsilon_{\mathrm{x}}\right)\left(0.88+\mathrm{s}_{\mathrm{xe}} / 2500\right) \leq 75^{\circ}
\end{aligned}
$$

where

$\mathrm{V}_{\mathrm{c}}=$ concrete shear strength $(\mathrm{kN})$ 
$\mathrm{a}_{\mathrm{g}}=$ maximum coarse aggregate size $(\mathrm{mm})$

$\varepsilon_{\mathrm{x}}=$ longitudinal strain at mid-depth of beam

$\mathrm{S}_{\mathrm{xe}}=$ equivalent crack spacing parameter $(\mathrm{mm})$

$\mathrm{S}_{\mathrm{x}}=$ crack spacing parameter $(\mathrm{mm})$

$\theta=$ angle of inclination of the cracks at mid-depth of the section (degree)

$\mathrm{d}_{\mathrm{v}}=$ flexural lever arm $(\mathrm{mm})$

$\mathrm{f}_{\mathrm{c}}=$ concrete compression strength $(\mathrm{MPa})$

$b_{w}=$ width of the beam $(\mathrm{mm})$

$A_{s}=$ longitudinal reinforcement area $\left(\mathrm{mm}^{2}\right)$

$E_{S}=$ modulus of elasticity of longitudinal reinforcement (MPa)

$\mathrm{M}_{\mathrm{f}}=$ moment applied to the section (N.mm)

$\mathrm{V}_{\mathrm{f}}=$ Shear applied to the section $(\mathrm{N})$

The term $\beta$ is a parameter that describes the aggregate interlock capacity of the concrete. It is a function of:

- $\varepsilon_{\mathrm{x}}$, the longitudinal strain at the mid-depth of the web

- The crack spacing at the mid-depth of the web

- $a_{g}$, the maximum coarse aggregate size

The crack spacing parameter $\mathrm{s}_{\mathrm{x}}$ is a measure of the longitudinal spacing of cracks at the beam mid-depth and is equal to the flexural lever arm, $d_{v}=0.9 \mathrm{~d}$ or $0.72 \mathrm{~h}$, whichever is greater, for 
members with neither stirrups nor longitudinal crack control steel distributed over the beam height.

The equivalent crack spacing parameter $s_{x e}$ is used to account for the effect of different maximum aggregate sizes on shear strength. In this equation if the American aggregate diameters (3/8", 3/4" etc) are used instead of Canadian aggregate diameters $(10 \mathrm{~mm}, 20 \mathrm{~mm}$ etc), the 15 will be replaced with 16 .

In general shear strength increases as the aggregate size increases. Sherwood et. al. (2007) realized that beyond an aggregate size of $25 \mathrm{~mm}$ this increase seems to be unreliable. Based on his test results, it was recommended that a lower limit of $0.85 \mathrm{~s}_{\mathrm{x}}$ be placed on the equivalent crack spacing $\mathrm{s}_{\mathrm{xe}}$. This limit has been implemented in the CSA code.

In regular strength concrete, cracks occur along the interface between the hydrated cement paste and aggregate, and as a result the crack has a rough surface which can transfer shear by aggregate interlock. For high strength concrete, however, as cracks tend to go through the aggregate rather than around the aggregate, the crack surface tends to be smoother. This is because the cement paste can be stronger than the aggregate. As a result, the effect of the aggregate size is neglected for high strength concrete. That is, the term $\mathrm{a}_{\mathrm{g}}$ is set equal to zero if $\mathrm{f}_{\mathrm{c}}$ is greater than $70 \mathrm{MPa}$. To prevent any discontinuity, $\mathrm{a}_{\mathrm{g}}$ is linearly reduced to zero when $\mathrm{f}_{\mathrm{c}}$ increases from 60 to $70 \mathrm{MPa}$. To reflect the limited experimental data available, the term $\sqrt{f^{\prime}}$ is limited to $8 \mathrm{MPa}$ in equation $2-2$. 


\subsubsection{The Strain Effect, Size Effect and Shear Behavior}

\subsubsection{General}

As mentioned, the CSA A23.3-04 shear design equations were derived based on the rational assumption that shear strength is governed by aggregate interlock. In a classic series of tests by Walraven (1981) it was found that the aggregate interlock capacity of cracks in normal strength concrete is directly related to the concrete strength $\left(\mathrm{f}_{\mathrm{c}}\right)$ and aggregate size $\left(\mathrm{a}_{\mathrm{g}}\right)$, and inversely related to crack width $(\mathrm{w})$. That is, higher shear stresses can be transferred across cracks by aggregate interlock by increasing the concrete strength and aggregate sizes. Likewise, actions that increase crack widths will reduce shear strength.

The width of a crack, $\mathrm{w}$, in concrete can be calculated as $\mathrm{w}=\varepsilon \times \mathrm{s}$, where $\varepsilon$ and $\mathrm{s}$ are respectively the average strain and crack spacing, both perpendicular to the crack. In this case, very small tensile strains in the uncracked concrete between cracks are not significant and can be neglected. It can thus be seen that any action that increases either $\varepsilon$ or $\mathrm{s}$ will increase crack widths, decrease aggregate interlock capacities of the crack, and hence decrease shear strength. The effects of these two parameters on shear strength are respectively called the strain effect and size effect, and will be discussed below.

\subsubsection{Strain Effect}

The effect of the longitudinal strain in a beam on the shear strength of that beam is termed the strain effect. It is accounted for through the use of the $\varepsilon_{\mathrm{x}}$ term in Equation 2-3. Beams and slabs with larger longitudinal strains will exhibit reduced shear strengths as cracks in the 
concrete will be wider. Factors that lead to higher longitudinal strains include, but are not limited to, the following: increasing the ratio of moment to shear (a/d ratio), decreasing the area of longitudinal steel, $A_{s}$, decreasing the modulus of elasticity, $E_{s}$, of the longitudinal steel and applying axial tension. Likewise, applying axial compression and prestressing can decrease longitudinal strains, reduce crack width and hence increase shear strength.

The longitudinal strain at the beam mid-depth, $\varepsilon_{\mathrm{x}}$, is conservatively taken to be one-half of the strain in the longitudinal steel. It can be more accurately calculated by the average of the top and bottom strains at the section, but for design purposes this level of accuracy is not generally necessary.

The widely known equation to calculate concrete shear strength in the ACI 318 code (ACI Committee 318 (2008)) is shown below. It was derived (ACI Committee 326 (1962)) from extensive research following a series of shear failures of concrete beams in US Air Force warehouses.

$$
\begin{aligned}
& \frac{\mathrm{Vc}}{\mathrm{b}_{\mathrm{w}} \mathrm{d}}=\frac{1}{7} \sqrt{\mathrm{f}_{\mathrm{c}}}+17 \frac{\rho V \mathrm{~d}}{\mathrm{M}} \leq 0.29 \sqrt{\mathrm{f}_{\mathrm{c}}} \\
& \frac{\mathrm{Vc}}{\mathrm{b}_{\mathrm{w}} \mathrm{d}}=1.9 \sqrt{\mathrm{f}_{\mathrm{c}}}+2500 \frac{\rho V d}{\mathrm{M}} \leq 3.5 \sqrt{\mathrm{f}_{\mathrm{c}}}
\end{aligned}
$$

A major innovation in equation 2-7 was the use of the parameter $\frac{M}{\rho V d}$. In the research, it was found that the failure shear stress decreased as the stress in the longitudinal steel increased. As the longitudinal steel stress is directly proportional to $\frac{M}{\rho V d}$, it was shown that the failure shear stress could be accurately related to this parameter (Figure 2-19). 
In Figure 2-19, equation (11-5) of ACI 318 is derived by fitting an equation to 194 data points. Low values of the term $1000 \frac{\rho V d}{\mathrm{M}} \sqrt{\mathrm{f}_{\mathrm{c}}}$ are beams with either high $\mathrm{a} / \mathrm{d}$ ratios, low reinforcement ratios $\left(\rho=\frac{A_{s}}{b_{w} d}\right)$, or a combination of both. Likewise high values are associated with beams with low a/d ratios or high values of $\rho$. Practical values of $1000 \frac{\rho \mathrm{Vd}}{\mathrm{M}} \sqrt{\mathrm{f}_{\mathrm{c}}}$ typically seen in design practice tend to be to the left of the figure. Thus, it can be seen that generally as the stress in the longitudinal steel decreases, shear strength increases. Of course, steel stresses can be converted to steel strains by dividing by the Young's Modulus of Elasticity for the steel, and it can thus be seen that ACI Committee 326 were the first to discover the strain effect.

In actual design practice, the longitudinal steel area, $A_{s}$, and hence the reinforcement ratio, $\rho$, at a section is chosen to resist the applied moment, $M$. If during the design process the applied moment at the section increases, $\rho$ will be increased as well to resist the higher moment. In such a case, the $\frac{\mathrm{M}}{\rho \mathrm{Vd}}$ ratio remains unchanged, and it can be expected that the failure shear stress will be unchanged. Noting this, ACI Committee 326 suggested simply using $\mathrm{V}_{\mathrm{c}}=2 \sqrt{\mathrm{f}_{\mathrm{c}}} \mathrm{b}_{\mathrm{w}} \mathrm{d}$ (in psi units) as a safe lower bound to the experimental data shown in Figure 2-19. In MPa units this equation is $\mathrm{V}_{\mathrm{c}}=0.167 \sqrt{\mathrm{f}_{\mathrm{c}}} \mathrm{b}_{\mathrm{w}} \mathrm{d}$, and is Equation (11-3) in the ACI 318 code.

Unlike the practical case, in experimental studies on the shear strength of beams and slabs, researchers tend to provide extra longitudinal steel to prevent flexural failure from occurring 
before shear failures. These $\rho$ values can be unrealistically high. Furthermore, $\rho$ is often varied with a constant $\frac{\mathrm{M}}{\mathrm{Vd}}$, which is somewhat unrealistic in practice. As such, empirical relations derived from these experiments may account for $\rho$, but not the coexisting moment. As such, they may not accurately account for the effect of $\rho$.

It can be summarized that the longitudinal reinforcement ratio, $\rho$, does not govern shear strength solely, but rather it is the strain in this reinforcement which is related to $\frac{M}{\rho V d}$ that governs shear strength. This means that, simply, shear strength of a given section can be expected to stay constant if the amount of the longitudinal reinforcement doubles when the moment doubles.

\subsubsection{Size Effect}

It has been experimentally ((Sherwood et. al. (2007), Shioya et. al. (1989), Kani et. al. (1979)) and theoretically (Bazant and $\mathrm{Yu}(2005)$ ) verified that the failure shear stress of concrete beams without stirrups decreases as the beam depth increases. This is known as the size effect. It is accounted for in the CSA standards, but not the ACI 318 standard. This is a serious limitation of the ACI 318, so serious that Sherwood et. al. (2007) and Bazant and Yu et. al. (2005) have shown it to represent a risk to public safety.

The clearest explanation for the size effect relates to crack spacing and crack widths. Shioya et. al. (1989) and Sherwood (2008) have shown that, in members without stirrups, the longitudinal spacing between cracks at beam mid-height tends to be $0.5 \mathrm{~d}$ regardless of beam depth. Thus, doubling the effective depth tends to double the crack spacing. At identical 
values of longitudinal strain, the cracks in the deeper member will thus be about twice as wide. These wider cracks precipitate shear failure at a lower shear stress due to reduced aggregate interlock capacity.

The size effect is not significant in members with shear reinforcement (Sherwood et. al. (2007)). Also, distributing longitudinal crack control reinforcement along the height of the member will control crack widths and decrease the spacing between cracks. In this case, the failure shear stress is related to the vertical distance between steel layers, rather than the overall depth of the member. This can be accounted for by the CSA standards, but not the ACI 318 standard.

It is important to note that while there is a clear effect of depth on failure shear stress, the beam width has no effect (Sherwood et. al. (2004), Kani et. al. (1979)). That is, doubling the depth, $d$, of a beam without stirrups will not double the shear strength, $V_{c}$, because the failure shear stress, $\frac{V_{c}}{b_{w} d}$ decreases due to the size effect. However, doubling the width, $b_{w}$, of a beam, will, in fact, double the shear strength. This is an important finding, as experimental results from narrow beams can be applied to the analysis of wide one-way slabs. 


\subsubsection{Derivation of $\beta$ Expression for Steel and FRP Reinforced Concrete Beams and One-Way Slabs}

\subsubsection{The CSA A23.3 General Equation}

Figure 2-20 shows the diagonal crack width versus the longitudinal strain at the middepth of the section $\varepsilon_{\mathrm{x}}$, for $\mathrm{s}_{\mathrm{xe}}=300 \mathrm{~mm}$ based on a full analysis by the MCFT using the 15 equations in Figure 2-16. As the figure shows, by increasing the strain at the longitudinal reinforcement level, the diagonal crack width will increase as well. The implementation of the CSA A23.3-04 assumes that the behavior of the members at their mid-height is representative of the behavior of member over the full depth. Therefore, to represent the shear behavior of the members, only the strain and crack spacing at mid-height are required. Assuming that plane sections remain plane and that the strain in flexural compression is small, the average longitudinal strain at the mid-depth of the section will be half the strain in the tension steel, that is, $\varepsilon_{\mathrm{x}}=\varepsilon_{\mathrm{t}} / 2$. A linear $1^{\text {st }}$ order equation was derived to approximate the MCFT curve to estimate the diagonal crack width at shear failure. This $1^{\text {st }}$ order approximation was used to transform the average longitudinal strain at mid-depth, $\varepsilon_{\mathrm{x}}$, to a diagonal crack width and produce a relationship between $\varepsilon_{\mathrm{x}}$ and crack width, w, as shown in the figure. The $\beta$ expression in equation 2.3 was then derived from this linear equation for steel-reinforced members.

It can be seen in the figure that for large values of longitudinal strain, the $1^{\text {st }}$ order approximation overestimates the crack width. As such, the value of $\beta$ will be underestimated and a conservative prediction of shear strength, $V_{c}$, will result. However, for grade 400 steel 
reinforcement, yielding of flexural steel is associated with a strain in the steel of $\frac{400}{200,000}=2 \times 10^{-3}$. This is, in turn, associated with a longitudinal strain at mid-depth of $1 \times 10^{-3}$. As such, for normal grade steel, the $1^{\text {st }}$ order approximation offers a reasonably accurate prediction of the shear strength.

In order to calculate the shear strength of experimental beams using the general method, equations 2-2 through 2-5 must be solved using a quadratic equation or an iterative approach. The iterative process is shown in a flowchart in Figure 2-21. For simply-supported pointloaded beams, typical of those used in experimental programs, the critical section can be taken at a distance $\mathrm{d}$ from the maximum moment at the applied point load. This iterative process will continue until convergence is achieved. It is worth noting that no iteration is needed when designing a beam using the general method since $\varepsilon_{\mathrm{x}}$ can be obtained directly from the design loads.

\subsubsection{Hoult's $\beta$ Expression for Both Steel and FRP Reinforced Concrete}

The $1^{\text {st }}$ order approximation can be safely used to predict shear strength of members with high axial strains as the crack width is over estimated. Concrete beams and slabs reinforced with high-strength steel $\left(f_{y}>400 \mathrm{MPa}\right)$ will tend to have higher strains as $\varepsilon_{\mathrm{x}}$ values associated with yield will exceed $1 \times 10^{-3}$. These members can be designed with very small reinforcement ratio, resulting in higher $\frac{\mathrm{M}}{\rho \mathrm{Vd}}$ values, and decreased shear strengths. 
Likewise, members reinforced with FRP bars will have higher strains due to a lower elastic modulus, $\mathrm{E}$.

Hoult et. al. (2008) generated a $2^{\text {nd }}$ order approximation to the full MCFT analysis as shown in Figure 2-20 to more accurately estimate the crack width at higher strains. The resulting equation for $\beta$ is as shown in equation 2-9. Equation 2-9 can be used as a direct substitute for equation 2-3.

$$
\beta=\frac{0.30}{0.5+\left(1000 \varepsilon_{\mathrm{x}}+0.15\right)^{0.7}} \cdot \frac{1300}{\left(1000+\mathrm{s}_{\mathrm{xe}}\right)}
$$

As can be seen from Figure 2-20, for strains within the pre-yield range of normal strength steel both equations estimate similar values of crack width. However, this equation provides markedly more accurate estimations of shear strength for both steel and FRP reinforced sections (Sherwood et. al. (2008)).

Sherwood et. al. (2008) used a database of 116 FRP-reinforced and 30 steel-reinforced members without stirrups to compare the CSA and modified CSA expression for $\beta$. Figure 2-22 shows the experimental failure shear stress $\left(V_{\text {exp }} / b_{w} d\right)$ normalized by the size effect term $\left(\frac{1300}{1000+s_{x e}}\right)$ and $\left(f_{c}^{\prime}{ }^{0.5} b_{w} d\right)$ versus the longitudinal strain at mid-depth. As a result, the only variation is strain effect. For the CSA A23.3-04 $\beta$ expression, it can be seen that the CSA expression becomes more conservative for the larger values of longitudinal strain. However more accurate predictions of the shear strength over the whole range of $\varepsilon_{\mathrm{x}}$ for the both steel and FRP reinforced sections can be obtained using the Hoult et. al. modification. It is evident from these two figures that there is no fundamental difference in 
the shear behavior between steel and FRP reinforced concrete. Hence, a rational theory of the behavior of reinforced concrete in shear should be able to account for the use of FRP reinforcement in the concrete members.

\subsubsection{The Two Mechanisms of Shear Failure: Beam Action and Arch}

\section{Action}

The shear force, $V$, in the beam is the derivative of the moment $\left(M=T d_{v}\right)$ and V made up of two actions:

1) A change in the internal lever arm, $d_{v}$, over constant flexural forces $\left(T \frac{d\left(d_{v}\right)}{d_{x}}\right)$

2) A change in the flexural forces over a constant lever arm $\left(\mathrm{d}_{\mathrm{v}} \frac{\mathrm{dT}}{\mathrm{dx}}\right)$

Methods of design to account for the first action, called arch action or strut-and-tie action, were introduced in the 1984 edition of the CSA code. Arch action occurs if the shear force cannot be transmitted due to unbonded longitudinal reinforcement or if the applied load is very close to the support (Figure 2-12a). It is generally associated with diagonal compression in struts in the beam web. That is, shear can be sustained by inclined compression struts even after aggregate interlock breaks down on the cracks, so in this case failure happens by crushing of the compression zone over the crack.

The arch action mechanism depends on the inclination of the line of the strut which is related to the shear span to depth ratio, a/d. At the time that arch action governs the shear failure, over the length of the shear span, a, the horizontal component of the compression force, $\mathrm{C}$, in 
the inclined strut and the tension force in the reinforcement are constant. As such, reinforcement must be well anchored at the support to prevent a local bond failure.

The second action is called beam action and is the component of shear for beams where plane sections are remaining plane. When aggregate interlock breaks down on a crack, beam action can no longer be maintained. In beams where the support is close to the load, arch action can be engaged following breakdown in beam action, and higher shear loads resisted.

In sections of a beam located further than about $\mathrm{d}$ from a point load or support, the variation in internal lever arm is very small and can be neglected. Hence, shear is carried by beam action. Within d from a load or support, the internal lever arm varies considerably. Hence, shear is carried by arch action. As such, the shear strength of beams with a/d ratios less than about 2.5 tends to be governed by strut-and-tie action, whereas in beams with a/d $>2.5$, it tends to be governed by beam action. Overall, for any given a/d ratio, the shear strength is taken as the larger of the beam action strength or the strut-and-tie strength.

The effect of a/d on beam shear strength is summarized in Figure 2-23. In this figure the failure shear stresses of a number of reinforced concrete beams tested by Kani (1979) are shown in relation to their span-to-depth (a/d) ratio. Also shown are strength predictions using sectional models (Eq. 2-2 to 2-5) and strut-and-tie models from the ACI and CSA codes. The strut-and-tie predictions were generated using the model shown in the figure, and the algorithm summarized in Appendix A.

The major difference between the two strut-and-tie models is the assumed failure stress of the diagonal strut. The ACI model assumes that the diagonal strut will crush at a compressive stress of $0.51 \mathrm{f}_{\mathrm{c}}$. The CSA provisions, on the other hand, are based on the MCFT and predict 
a compressive failure stress that varies with the principal tensile strain, $\varepsilon_{1}$, in the strut, as shown below:

$$
\mathrm{f}_{\mathrm{cu}}=\frac{\mathrm{f}_{\mathrm{c}}^{\prime}}{\left(0.8+170 \varepsilon_{1}\right)} \leq 0.85 \mathrm{f}_{\mathrm{c}}^{\prime}
$$

where

$\varepsilon_{1}=\varepsilon_{\mathrm{s}}+\left(\varepsilon_{\mathrm{s}}+0.002\right) \cot ^{2} \theta_{\mathrm{s}} \quad$ (principle tensile strain)

$\varepsilon_{\mathrm{s}}=$ tensile strain in the longitudinal reinforcement

$\theta_{\mathrm{s}}=$ the smallest angle between the strut and the adjoining ties

$\mathrm{f}_{\mathrm{cu}}=$ compressive stress in strut

$\mathrm{f}_{\mathrm{c}}=$ concrete cylinder strength

In these equations, $\varepsilon_{\mathrm{s}}$ is the strain in the longitudinal reinforcement crossing the strut. It can be calculated based on equilibrium of the node above the support. That is, the force in the tension tie (the tensile reinforcement) is $\frac{V \cot \theta_{s}}{E_{s} A_{s}}$. In the CSA method, as the shear span, a, increases, $\theta_{\mathrm{S}}$ decreases and $\varepsilon_{1}$ increases, in turn reducing the compressive strength of the strut, $\mathrm{f}_{\mathrm{cu}}$. In turn, the ACI code predicts that $\mathrm{f}_{\mathrm{cu}}$ is constant, but places a lower limit of $25^{\circ}$ on the angle $\theta_{s}$. 
Note also that the bearing plate size has an effect on the strut-and-tie strength, but little to no effect on the sectional strength. With a larger plate size a wider strut can be formed, and hence a larger load resisted before the concrete crushes.

In practice, if a member shows the behavior of a strut-and-tie mechanism at the shear failure rather than a sectional shear mechanism, at about $2 / 3$ of the failure load daylight may become visible through the shear cracks in the beam, and this occurs when beam-action switches to strut-and-tie action. Cracks that are this wide are clearly unable to transfer shear through aggregate interlock. If the distance from the load to the support is not too great, the strut-andtie mechanism can carry higher loads after breaking down the beam action. Overall the strutand-tie mechanism really depends on the $\mathrm{a} / \mathrm{d}$ ratio and the size of the bearing plate $\mathrm{l}_{\mathrm{b}}$.

\subsection{FRP Shear Design Methods}

This section presents a review of shear design methods for FRP-reinforced members. Six major shear design methods will be presented and discussed.

\subsubsection{Tureyen and Frosch Equation (2003)}

Tureyen and Frosch (2003) presented a new model to determine the shear contribution of slender concrete beams reinforced with either FRP or steel reinforcement and proposed a new equation. They compared this proposed equation with the traditional Equation (11-3) of ACI $318\left(\mathrm{Vc}=2 \sqrt{\mathrm{f}^{\prime} \mathrm{c}} \mathrm{b}_{\mathrm{w}} \mathrm{d}(\mathrm{psi})\right)$. They supported the applicability of the model by comparing experimental test results of 370 specimens. 
In this model, they considered a beam subjected to constant shear (Figure 2-24). A major assumption was made that the entire shear force, V, was carried in the uncracked compression zone. In other words, the major role that aggregate interlock plays on shear strength was ignored. The shear stress, $\tau$, and axial compression, $\sigma$, in the uncracked concrete above the neutral axis are determined as shown in Figure 2-25. Hence, the following equation was derived for the tensile stress in the compression zone, considering that the principle tensile stress reaches the tensile strength of the concrete $f_{t}$ at the time of failure:

$$
\frac{\sigma}{2}-\sqrt{\tau^{2}+\left(\frac{\sigma}{2}\right)^{2}}=-\mathrm{f}_{\mathrm{t}}
$$

From this equation the shear stress $\tau$ at the time of failure then derived as:

$$
\tau=\sqrt{\mathrm{ft}_{\mathrm{t}}^{2}+\mathrm{f}_{\mathrm{t}} \sigma}
$$

To find the shear stress in the compression zone, $\tau$, and the compressive stress, $\sigma$, in order to find the shear capacity of a section, they investigated a free body diagram located at a crack. They found the maximum shear stress $\tau_{\max }$ equals $\frac{3}{2} \frac{\mathrm{V}}{\mathrm{b}_{\mathrm{w}} \mathrm{c}}$ and the flexural stress at the middepth equals $\sigma_{\max } / 2$. Then $\mathrm{V}_{\mathrm{c}}$ was derived solving equation (2-10) with the above $\tau_{\max }$ and $\sigma$ values as $V c=2 / 3 b_{w} c \sqrt{f_{t}^{2}+f_{t}+\frac{\sigma_{\max }}{2}}$. However, in this equation, the appropriate value of the flexural stress, $\sigma_{\mathrm{m}}$, should be taken at a section where failure occurs in the compression zone due to the variation of the flexural stress value along the length of the beam according to the authors. This failure location cannot be loaded exactly, however, a conservative 
estimate predicted by taking the lower value of $\sigma_{\mathrm{m}}$ which occurs at a point just above the cracking moment $\mathrm{M}_{\mathrm{cr}}$ in a cracked section.

Further, the Vc equation was compared with 370 test results of 26 different investigations to examine the applicability of the Vc equation. Among these 370 specimens, 326 of them were longitudinally reinforced with steel reinforcement and 44 of them reinforced with FRP reinforcement. To simplify the Vc equation, they took a concrete tensile strength, $\mathrm{f}_{\mathrm{t}}$, of 6 $\sqrt{f^{\prime}} \mathrm{c}$ (psi) and found the following equation:

$$
\mathrm{Vc}=\left(\sqrt{16+\frac{4 \sigma_{\mathrm{m}}}{3 \sqrt{\mathrm{f}^{\prime} \mathrm{c}}}}\right) \sqrt{\mathrm{f}^{\prime} \mathrm{c}} \mathrm{b}_{\mathrm{w}} \mathrm{c}
$$

They called the first parameter in the parentheses $\mathrm{K}$ and computed this value from the data of 370 specimens based on the $\rho_{\text {eff }}$ greater than $0.8 \%$ where:

$$
\rho_{\mathrm{eff}}=\rho\left(\frac{\mathrm{Er}}{\mathrm{Es}}\right)
$$

They found that the value of $\mathrm{K}$ tends to stay constant at 5.5 roughly. However, for values of $\rho_{\text {eff }}$ smaller than $0.8 \%$ they found that the $\mathrm{K}$ value increases to approximately 7.5 due to the higher flexural stresses, $\sigma_{\mathrm{m}}$, which occur at the cracking moment in the members with the low value of reinforcement ratio. Further, the $\mathrm{K}$ value directly was computed from the experimental results by $K_{\exp }=\frac{V c, \exp }{b_{w} c \sqrt{f^{\prime} c}}$. They found that the $K$ factor follows the same trend in both experimental results and calculated values. As a result, a value of 5 was selected 
to provide the conservative estimation of shear strength and then they expressed the following equation to calculate the shear strength of both FRP and steel-reinforced members:

$$
\mathrm{V}_{\mathrm{c}}=5 \sqrt{\mathrm{f}^{\prime} \mathrm{c}} \mathrm{b}_{\mathrm{w}} \mathrm{c} \quad(\mathrm{psi})
$$

where

$\mathrm{f}_{\mathrm{c}}=$ compressive strength of concrete $(\mathrm{psi})$

$\mathrm{b}_{\mathrm{w}}=$ beam width (in)

$\mathrm{c}=\mathrm{kd}=$ neutral axis depth of the cracked transformed section (in)

$\mathrm{k}=\sqrt{2 \rho n+(\rho n)^{2}}-\rho n$

$\mathrm{d}=$ effective depth of the section (in)

$\mathrm{n}=\mathrm{E}_{\mathrm{r}} / \mathrm{E}_{\mathrm{c}}=$ modulus ratio

$\mathrm{A}_{\mathrm{r}}=$ area of longitudinal tension reinforcement (in $\left.{ }^{2}\right)$

$E_{c}, E_{r}=$ modulus of elasticity of concrete and reinforcement, steel or FRP, respectively (psi)

If the metric system is used, 5 will change to $5 / 12$ in this equation. It can be seen that, because of the low modulus of elasticity of FRP reinforcements, the simplification in the K factor to take the value of 5 increases the conservatism of the shear strength calculated by this equation for members reinforced with FRP reinforcement. This equation, however, does not account for the size effect nor does it account for the effect of $M / V$ in the strain effect. Lastly, it is based on a flawed physical model whereby aggregate interlock is neglected. 
Despite these serious drawbacks, it has found much acceptance due to its perceived simplicity.

\subsubsection{Other Shear Design Methods}

There are a number of researchers who have developed shear design methods for FRP reinforced concrete by applying empirically derived modification factors to equations for steel-reinforced concrete beams. Some of them are based on the 1994 CSA A23.3 design code, for steel-reinforced concrete which is summarized below.

The 1994 CSA A23.3 simplified $V_{c}$ expression was derived from Equation (11-3) of the ACI-318 code as follows:

$$
\mathrm{V}_{\mathrm{c}}=0.2 \lambda \phi_{\mathrm{c}} \sqrt{\mathrm{f}^{\prime} \mathrm{c}} \mathrm{b}_{\mathrm{w}} \mathrm{d}
$$

For beams with $d$ greater than $300 \mathrm{~mm}$ and no shear reinforcement $V_{c}$ is equal to:

$$
V_{c}=\left(\frac{260}{1000+d}\right) \lambda \phi_{c} \sqrt{f_{c}^{\prime} b_{w}} d \geq 0.1 \lambda \phi_{c} \sqrt{f_{c}^{\prime} b_{w}} d
$$

where

$\lambda=$ factor to account for low-density concrete

$\phi_{\mathrm{c}}=$ concrete material resistance factor 


\subsubsection{CSA Committee S806 (2002)}

The Canadian code for design and construction of concrete building components with fiber-reinforced polymers, CSA Committee $S 806$ (2002), derived the $V_{c}$ equation by, in part, applying a modification factor to Equation 2-16 and 2-17 as below:

$$
V_{c}=0.035 \varphi_{c}\left(f_{c}^{\prime} \rho_{f} E_{f} \frac{V_{f}}{M_{f}} d\right)^{1 / 3} b_{w} d
$$

where

$$
0.1 \varphi_{c} \sqrt{f_{c}^{\prime}} \leq V_{c} / b_{w} d \leq 0.2 \varphi_{c} \sqrt{f_{c}^{\prime}} \quad \text { and } \quad \frac{V_{f}}{M_{f}} d \leq 1.0
$$

For the sections with $\mathrm{d}>300 \mathrm{~mm}$, the following expression is presented:

$$
V_{c}=\left(\frac{130}{1000+d}\right) \phi_{c} \sqrt{f_{c}^{\prime}} b_{w} d \geq 0.08 \phi_{c} \sqrt{f_{c}^{\prime}} b_{w} d
$$

In equation 2-18, $\rho_{\mathrm{f}}$ and $\mathrm{E}_{\mathrm{f}}$ are the longitudinal FRP reinforcement ratio and modulus of elasticity of FRP reinforcement respectively.

For members having an effective depth less than $300 \mathrm{~mm}$, the CSA-S806 $\mathrm{V}_{\mathrm{c}}$ expression empirically accounts for the all parameters of the strain effect term which are $M / V, E$ and $\rho$, however, it did not consider the effect of the size effect on these members. For members with $\mathrm{d}$ more than $300 \mathrm{~mm}$ this code just accounts for the size effect term. 


\subsubsection{ISIS Design Manual No.3}

The Intelligent Sensing for Innovative Structures handbook (ISIS Design Manual No.3 (2001)) offers the following expression for $V_{c}$ which is also derived by applying the modification factors to the 1994 CSA A23.3 simplified shear design method:

$$
\begin{aligned}
& V_{c}=0.2 \varphi_{c} \sqrt{f_{c}^{\prime}} b_{w} d \sqrt{E_{f} / E_{s}} \quad d \leq 300 m m \\
& V_{c}=\left(\frac{260}{1000+d}\right) \varphi_{c} \sqrt{f_{c}^{\prime} b_{w} d} \sqrt{\frac{E_{f}}{E_{s}}} \geq 0.1 \varphi_{c} \sqrt{f_{c}^{\prime}} b_{w} d \sqrt{\frac{E_{f}}{E_{s}}} \quad d>300 m m
\end{aligned}
$$

In these equations, $E_{f}$ and $E_{s}$ are the modulus of elasticity of FRP and steel reinforcements respectively. For the strain effect, this code accounts for just the effect of $\mathrm{E}$ for all members, but not $\rho$ or $\mathrm{M} / \mathrm{V}$, and considers the size effect term just for the members with having $d>300$ $\mathrm{mm}$.

\subsubsection{JSCE (1997)}

The Japan Society of Civil Engineers (JSCE 1997) suggested the following equations:

$$
v_{c}=\beta_{d} \beta_{p} \beta_{n} f_{v c d} b_{w} d / \gamma_{b}
$$

where

$$
\begin{aligned}
& \beta_{p}=\sqrt[3]{100 \rho_{f} E_{f} / E_{s}} \leq 1.5 \\
& \beta_{d}=(1000 / d)^{1 / 4} \leq 1.5
\end{aligned}
$$


$\mathrm{f}_{\mathrm{vcd}}=0.2\left(\mathrm{f}_{\mathrm{mcd}}\right)^{1 / 3} \leq 0.72$

In this equation, $\beta_{\mathrm{n}}$ is equal to 1 for no axial load; the member safety factor $\left(\gamma_{\mathrm{b}}\right)$ is also equal

to 1 for analysis of experimental results. $f_{m c d}$ is the design compressive strength of the concrete, $E_{f}$ and $E_{s}$ are the modulus of elasticity of FRP and steel reinforcement respectively in this equation. Although the JSCE expression considers the effect of size effect in its expression but does not account for $\mathrm{M} / \mathrm{V}$ influence on the strain effect term.

\subsubsection{Razaqpur and Isgor (2004)}

Razaqpur and Isgor (2004) tested seven rectangular beams simply supported over a $2000 \mathrm{~mm}$ span under four-point loading to determine the concrete contribution to shear resistance of members reinforced with FRP reinforcement. They used CFRP as the longitudinal reinforcement in their specimens which were constructed without stirrups. All 7 specimens had the same dimensions with effective depths of $225 \mathrm{~mm}, 200 \mathrm{~mm}$ widths and concrete strength of $40.5 \mathrm{MPa}$. The test variables were the shear span to depth ratio, $1.82<$ $\mathrm{a} / \mathrm{d}<4.5$, and the flexural reinforcement ratio, $1.1<\rho / \rho_{\text {balance }}<3.88$. All seven beams were designed as over-reinforced and the flexural failure load of each beam was at least double the expected shear failure load to ensure that shear failure occurred before the flexural reinforcement rupture. They used the CSA S806-02 design code to design their sections.

They compared their results and 20 results from the literature with the CSA-S806-02, ACI 440 and Japan Society of Civil Engineers (JSCE) codes to assess the accuracy of these codes in predicting the shear strength. They found that, compared to the extreme conservative shear 
predictions of the ACI 440 report, both CSA-S806-02 and JSCE methods predict reasonably well the shear strength of the concrete beams reinforced with FRP reinforcements without stirrups. The mean value and the standard deviation of 3.06 and 1.42 respectively for ACI method based on these 27 results pointed that the ACI method is extremely conservative. CSA-S806-02 had a mean value and standard deviation of 1.21 and 0.17 respectively with coefficient of variation of $14 \%$. The corresponding mean value and standard deviation for JSCE method are 1.27 and 0.27 respectively with a coefficient of variation of $21.2 \%$.

Overall, they found that the CSA-S806-02 predictions of shear strength of concrete reinforced beams with FRP reinforcement without shear reinforcement are in better agreement with experimental data than ACI and JSCE predictions.

Further, Razaqpur and Isgor (2008) developed a proposed shear equation based on their 2004 results and accounted for the effect of the arch action and beam size effect. This proposed method is intended as an improved version of the current CSA-S806-02 method which accounts for most of the major parameters that affect the shear resistance of concrete members without stirrups. However, it does not include the effect of size effect for beams with $\mathrm{d}<300 \mathrm{~mm}$ and the maximum aggregate size effect because in the authors' opinion, there is not sufficient data available for the effect of aggregate size on the shear resistance of concrete members reinforced with FRP. These proposed, entirely empirical, equations are as below:

$$
\mathrm{V}_{\mathrm{c}}=0.035 \mathrm{k}_{\mathrm{m}} \mathrm{k}_{\mathrm{s}} \mathrm{k}_{\mathrm{a}}\left(1+\mathrm{k}_{\mathrm{r}}\right) \sqrt{\mathrm{f}_{\mathrm{c}}^{\prime}} \mathrm{b}_{\mathrm{w}} \mathrm{d} \leq 0.2 \mathrm{k}_{\mathrm{s}} \sqrt{\mathrm{f}_{\mathrm{c}}^{\prime}} \mathrm{b}_{\mathrm{w}} \mathrm{d}
$$

where 


$$
\begin{array}{ll}
\mathrm{k}_{\mathrm{s}}=750 /(450+\mathrm{d}) \text { for } \mathrm{d}>300 \mathrm{~mm} & \mathrm{k}_{\mathrm{a}}=2.5 /\left(\mathrm{M}_{\mathrm{f}} / \mathrm{V}_{\mathrm{f}} \mathrm{d}\right) \text { for }\left(\mathrm{M}_{\mathrm{f}} / \mathrm{V}_{\mathrm{f}} \mathrm{d}\right)<2.5 \\
\mathrm{k}_{\mathrm{s}}=1.0 \text { for } \mathrm{d}<300 \mathrm{~mm} & \mathrm{k}_{\mathrm{a}}=1.0 \text { for }\left(\mathrm{M}_{\mathrm{f}} / \mathrm{V}_{\mathrm{f}} \mathrm{d}\right) \geq 2.5 \\
\mathrm{k}_{\mathrm{m}}=\left(\mathrm{v}_{\mathrm{f}} \mathrm{d} / \mathrm{M}_{\mathrm{f}}\right)^{2 / 3} & \mathrm{k}_{\mathrm{r}}=\left(\mathrm{E}_{\mathrm{f}} \rho_{\mathrm{f}}\right)^{1 / 3}
\end{array}
$$

In this equation, $k_{m}$ represents the effect of $a / d, k_{r}$ represents the effect of reinforcement rigidity $\left(E_{f} \rho_{f}\right), K_{s}$ represents the size effect and $k_{a}$ represents the effect of arch action. $E_{f}$ and $\rho_{\mathrm{f}}$ are the modulus of elasticity and reinforcement ratio of FRP reinforcement respectively.

They further used a comparison of these proposed equations using a larger database of 56 beams and one-way slabs and their seven beam test results with CSA-S806-02, ACI 440 and JSCE equations. Among this database, only a single beam (with $\mathrm{a} / \mathrm{d}=1.82$ ) was used to assess the effect of arch action and only one beam was used to assess the size effect (an unpublished, incorrectly cited FRP-reinforced beam with $d=970 \mathrm{~mm}$ ). All members were simply supported with the reinforcement ratio ranging from $0.52-2.6$ times the balanced reinforcement ratio, the concrete strength ranging from $24-81 \mathrm{MPa}$ and a/d varying from 1.82 to 12.5 .

They found that the proposed method has the lowest standard deviation of 0.27 compared to the CSA-S806-02, ACI 440, JSCE and ACI 440 Frosch equations which had standard deviations of $0.39,1.95,0.39$ and 0.51 respectively. Overall they found that the prediction of shear strength from the proposed method is in better agreement with the available experimental data compared to those codes for FRP-reinforced concrete beams and one-way slabs. 


\subsubsection{El-Sayed et. al. (2006)}

El-Sayed et. al. (2006) developed a modified version of Equation 11-3 from the ACI 318 code as shown below:

$$
V_{c}=\left(\frac{\rho_{f} E_{f}}{90 \beta_{1} f_{c}^{\prime}}\right)^{1 / 3}\left(\frac{\sqrt{f_{c}^{\prime}}}{6} b_{w} d\right) \leq \frac{\sqrt{f_{c}^{\prime}}}{6} b_{w} d
$$

The term $\beta_{1}$ is the ratio of depth of the rectangular compression block to depth to the neutral axis. It can be seen that this equation neither accounts for the size effect nor the effect of $\mathrm{M} / \mathrm{V}$ on the strain effect term.

It is important to mention that if the 1994 CSA-A23.3 $\mathrm{V}_{c}$ equations are used (Equation 2-16 and 2-17) to predict the shear capacity of experimental results with $\Phi_{\mathcal{C}}$ equal to 1 , the results must be multiplied by $0.167 / 0.2$ (Sherwood et. al. (2006)). This is because the 1994 CSA A23.94 $\mathrm{V}_{\mathrm{c}}$ equation for $\mathrm{d}<300$ (Equation 2-16), is actually the ACI-318 simplified $\mathrm{V}_{\mathrm{c}}$

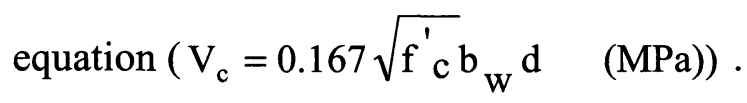

The ACI-318 equations for $\mathrm{V}_{\mathrm{c}}$ multiply by a strength reduction factor of $\Phi=0.75$ to obtain a factored shear resistance for design purposes. In the 1994 CSA-A23.3 code, the equivalent strength reduction factor is $\Phi_{\mathcal{C}}=0.6$. When deriving equation 2-16, the CSA committee modified the 0.167 coefficient in the ACI-318 expression to $0.167 \times\left(\frac{0.75}{0.6}\right) \approx 0.2$, the coefficient in equation 2-16. As such, when using equations 2-16 and 2-17 to predict 
experimental shear strengths, they must be multiplied by $0.167 / 0.2$. This must also be applied when the CSA-S806, ISIS and Razaqpur equations are used, as they were derived from the 1994 CSA-A23.3 expressions.

\subsection{Comparison of the FRP Shear Design Methods}

Table 2-4 and 2-5 summarize the FRP-reinforced concrete shear design methods discussed in this chapter. As mentioned earlier, all of those equations are derived from empirical curve-fits to experimental data from beam tests or obtained from applying modifications factors to existing design methods for steel reinforcement. It can be seen from Table 2-5 that all methods account for various combinations of the size and strain effect. Among them, only Razaqpur's equation accounts for all three parameters of the strain effect, though it does not account for the size effect in members when $\mathrm{d}<300 \mathrm{~mm}$. Only the 2004 CSA equations account for all strain and size effect parameters.

The average ratio of experimental to predicted shear strengths of the data points in Figure 2-22 are summarized in Table 2-5. It can be seen that the Hoult et. al. modification to the 2004 CSA equations offers the most accurate and safe predictions of shear strength for FRP-reinforced concrete members without stirrups.

\subsection{Concluding Remarks}

As mentioned earlier in this chapter, among the parameters which influence the shear strength of reinforced concrete members is the ratio $\mathrm{M} / \rho \mathrm{Vd}$. In practical designs, the 
reinforcement ratio $\rho$ and the value of moment are related, in that an increase in moment is usually associated with an increase in reinforcement ratio. As such, the parameter $\mathrm{M} / \rho \mathrm{Vd}$ tends to be fairly constant, and the shear strength is in fact not increased with the increase in $\rho$. Unlike the practical case, in experimental tests $\rho$ and $\mathrm{M} / \mathrm{Vd}$ are treated as independent variables. Furthermore, in experimental tests the reinforcement ratio is high to ensure that shear failure occurs before flexural failure. Hence, since empirical design equations derived from these results are often formulated in terms of $\rho$ not in terms of the coexisting moment, they cannot properly predict the shear behavior of concrete members. Analysis of the literature has shown the fact that none of the empirical equations fully account for the effect of this parameter in their shear design methods.

On the other hand, due to the fact that shear failures in concrete members without shear reinforcement occur in the concrete and not in the reinforcement, a general shear design method derived from a rational theory of the behavior of reinforced concrete in shear should be able to account for the use of FRP reinforcement in concrete structures as well as steel reinforcement.

Review of the experimental database summarized in Figure 2-22 indicates that there are no series of tests in which $\rho$ and a/d are varied in such a way that the $M / \rho V d$ ratio is kept constant. Further analysis shows that there is a lack of experimental data for beams with high $\mathrm{a} / \mathrm{d}$ ratios.

The experiments described in the following chapters have been designed to address these issues and are focused on the effect of $\rho$ and $M / \rho V d$ ratio on the shear strength of FRP reinforced members, and will demonstrate that design methods formulated in terms of the 
$\mathrm{M} / \mathrm{V}$ ratio and $\rho$ are better able to predict shear strengths of practical FRP-reinforced concrete members. This study also will show that the CSA shear provisions which are derived from the MCFT and are not based on empirical curves fits to beam tests, should accurately account for the use of FRP reinforcements, and further the $2^{\text {nd }}$ order approximation to the MCFT (the Hoult et. al. equation) can more accurately model the effects of FRP reinforcement. The concepts of this study will also reflect the fact that it is not the percentage of longitudinal reinforcement which governs the shear failure of a member but rather the strain in the longitudinal reinforcement which is a function of $\frac{\mathrm{M}}{\rho \mathrm{Vd}}$. That is, the shear stress of members without shear reinforcement, $V_{c}$, tends to decrease as the stress in the longitudinal reinforcement increase and this stress equals about $\frac{M}{\rho V d}$ times $V_{c}$. Overall, the goal of this study is to improve the accuracy of shear design methods of FRP reinforced concrete beams and one-way slabs, so as to enhance their cost-competitiveness. 
Table 2-1: Typical Material Properties of Industrially Available Fibres

\begin{tabular}{|l|c|c|c|c|}
\hline Fibre & Diameter & $\begin{array}{c}\text { Relative } \\
\text { Density } \\
\left(\mathrm{g} / \mathrm{cm}^{\mathbf{3}}\right)\end{array}$ & $\begin{array}{c}\text { Modulus of } \\
\text { Elasticity } \\
(\mathrm{GPa})\end{array}$ & $\begin{array}{c}\text { Tensile } \\
\text { Strength } \\
(\mathrm{GPa})\end{array}$ \\
\cline { 1 - 4 } Glass & $(9-15)$ & 2.58 & $(70-86)$ & $(2-4.3)$ \\
\cline { 1 - 4 } Aramid (Kelvar) & 10 & 1.45 & $(65-133)$ & 3.6 \\
\cline { 1 - 4 } Carbon (High Strength) & 9 & 1.90 & 230 & $(2.6-3.8)$ \\
\hline
\end{tabular}

Table 2-2: Typical Mechanical Properties of FRP Composite Reinforcing Bars

\begin{tabular}{|l|c|c|c|c|}
\hline FRP Composite & Fiber Content & Density & $\begin{array}{c}\text { Longitudinal } \\
\text { Tensile Modulus } \\
\text { (GPa) }\end{array}$ & $\begin{array}{c}\text { Tensile Strength } \\
\text { (MPa) }\end{array}$ \\
\hline GFRP & $50-80$ & $1600-2000$ & $20-55$ & $400-1800$ \\
\cline { 1 - 1 } CFRP & $65-75$ & $1600-1900$ & $120-250$ & $1200-2250$ \\
\cline { 1 - 1 } AFRP & $60-70$ & $1050-1250$ & $40-125$ & $1000-1800$ \\
\cline { 1 - 1 } Steel & & 7860 & 200 & $\begin{array}{c}400-\text { yeild } \\
600-\text { Rupture }\end{array}$ \\
\hline
\end{tabular}

Table 2-3: Typical Coefficients of Thermal Expansion for FRPs and steel Rebars

\begin{tabular}{|l|c|c|c|c|}
\cline { 2 - 5 } \multicolumn{1}{c|}{} & \multicolumn{4}{c|}{ Coefficient of Thermal Expansion $\left(* 10^{-6} /{ }^{\circ} \mathrm{C}\right)$} \\
\hline Direction & Steel & GFRP & CFRP & AFRP \\
\hline Longitudinal & 11.7 & 6 to 10 & -1 to 0 & -6 to -2 \\
\cline { 1 - 5 } Transverse & 11.7 & 21 to 23 & 22 to 23 & 60 to 80 \\
\hline
\end{tabular}


Table 2-4: Shear Design Methods for FRP-Reinforced Concrete Members

\begin{tabular}{|c|c|}
\hline $\begin{array}{l}\text { CSA Committee } \\
\text { S806 (2002) }\end{array}$ & $\begin{array}{l}\mathrm{V}_{\mathrm{c}}=0.035 \phi_{\mathrm{c}}\left(\mathrm{f}_{\mathrm{c}}^{\prime} \rho_{\mathrm{f}} \mathrm{E}_{\mathrm{f}} \frac{\mathrm{V}_{\mathrm{f}}}{\mathrm{M}_{\mathrm{f}}} \mathrm{d}\right)^{1 / 3} \mathrm{~b}_{\mathrm{w}} \mathrm{d} \text { where } 0.1 \phi_{\mathrm{c}} \sqrt{\mathrm{f}_{\mathrm{c}}^{\prime}} \leq \mathrm{V}_{\mathrm{c}} / \mathrm{b}_{\mathrm{w}} \mathrm{d} \leq 0.2 \phi_{\mathrm{c}} \sqrt{\mathrm{f}_{\mathrm{c}}^{\prime}} \text { and } \frac{\mathrm{V}_{\mathrm{f}}}{\mathrm{M}_{\mathrm{f}}} \mathrm{d} \leq 1.0 \\
\text { For members where } \mathrm{d}>300 \mathrm{~mm}, \mathrm{~V}_{\mathrm{c}}=\left(\frac{130}{1000+\mathrm{d}}\right) \phi_{\mathrm{c}} \sqrt{\mathrm{f}_{\mathrm{c}}^{\prime}} \mathrm{b}_{\mathrm{w}} \mathrm{d} \geq 0.08 \phi_{\mathrm{c}} \sqrt{\mathrm{f}_{\mathrm{c}}^{\prime}} \mathrm{b}_{\mathrm{w}} \mathrm{d}\end{array}$ \\
\hline ISIS-M03-01 & $\begin{array}{l}\mathrm{V}_{\mathrm{c}}=0.2 \phi_{\mathrm{c}} \sqrt{\mathrm{f}_{\mathrm{c}}^{\prime}} \mathrm{b}_{\mathrm{w}} \mathrm{d} \sqrt{\mathrm{E}_{\mathrm{f}} / \mathrm{E}_{\mathrm{s}}} \\
\text { For members where } \mathrm{d}>300 \mathrm{~mm}, \mathrm{~V}_{\mathrm{c}}=\left(\frac{260}{1000+\mathrm{d}}\right) \phi_{\mathrm{c}} \sqrt{\mathrm{f}_{\mathrm{c}}^{\prime}} \mathrm{b}_{\mathrm{w}} \mathrm{d} \sqrt{\frac{\mathrm{E}_{\mathrm{f}}}{E_{s}}} \geq 0.1 \phi_{\mathrm{c}} \sqrt{\mathrm{f}_{\mathrm{c}}^{\prime}} \mathrm{b}_{\mathrm{w}} \mathrm{d} \sqrt{\frac{\mathrm{E}_{\mathrm{f}}}{\mathrm{E}_{\mathrm{s}}}}\end{array}$ \\
\hline $\begin{array}{l}\text { Razaqpur and } \\
\text { Isgor (2006) }\end{array}$ & $\begin{array}{ll}\mathrm{V}_{\mathrm{c}}=0.035 \mathrm{k}_{\mathrm{m}} \mathrm{k}_{\mathrm{s}} \mathrm{k}_{\mathrm{a}}\left(1+\mathrm{k}_{\mathrm{r}}\right) \sqrt{\mathrm{f}_{\mathrm{c}}^{\prime}} \mathrm{b}_{\mathrm{w}} \mathrm{d} \leq 0.2 \mathrm{k}_{\mathrm{s}} \sqrt{\mathrm{f}_{\mathrm{c}}^{\prime}} \mathrm{b}_{\mathrm{w}} \mathrm{d} \\
\mathrm{k}_{\mathrm{s}}=750 /(450+\mathrm{d}) \text { for } \mathrm{d}>300 \mathrm{~mm} & \mathrm{k}_{\mathrm{a}}=2.5 /\left(\mathrm{M}_{\mathrm{f}} / \mathrm{V}_{\mathrm{f}} \mathrm{d}\right) \text { for }\left(\mathrm{M}_{\mathrm{f}} / \mathrm{V}_{\mathrm{f}} \mathrm{d}\right)<2.5 \\
\mathrm{k}_{\mathrm{s}}=1.0 \text { for } \mathrm{d}<300 \mathrm{~mm} & \mathrm{k}_{\mathrm{a}}=1.0 \text { for }\left(\mathrm{M}_{\mathrm{f}} / \mathrm{V}_{\mathrm{f}} \mathrm{d}\right) \geq 2.5 \\
\mathrm{k}_{\mathrm{m}}=\left(\mathrm{V}_{\mathrm{f}} \mathrm{d} / \mathrm{M}_{\mathrm{f}}\right)^{2 / 3} & \mathrm{k}_{\mathrm{r}}=\left(\mathrm{E}_{\mathrm{f}} \rho_{\mathrm{f}}\right)^{1 / 3}\end{array}$ \\
\hline $\begin{array}{l}\text { El-Sayed et. al. } \\
(2006)\end{array}$ & $V_{c}=\left(\frac{\rho_{f} E_{f}}{90 \beta_{1} f_{c}^{\prime}}\right)^{1 / 3}\left(\frac{\sqrt{f_{c}^{\prime}}}{6} b_{w} d\right) \leq \frac{\sqrt{f_{c}^{\prime}}}{6} b_{w} d$ \\
\hline JSCE (1997) & $\begin{array}{lll}\mathrm{V}_{\mathrm{c}}=\beta_{\mathrm{d}} \beta_{\mathrm{p}} \beta_{\mathrm{n}} \mathrm{f}_{\mathrm{vdd}} \mathrm{b}_{\mathrm{w}} \mathrm{d} / \gamma_{\mathrm{b}} & \beta_{\mathrm{p}}=\sqrt[3]{100 \rho_{\mathrm{f}} \mathrm{E}_{\mathrm{f}} / \mathrm{E}_{\mathrm{s}}} \leq 1.5 \quad \beta_{\mathrm{n}}=1 \text { for no axial loads } \\
\mathrm{f}_{\mathrm{vcd}}=0.2\left(\mathrm{f}_{\mathrm{mcd}}\right)^{1 / 3} \leq 0.72 & \beta_{\mathrm{d}}=(1000 / \mathrm{d})^{1 / 4} \leq 1.5 & \gamma_{\mathrm{b}}=1 \text { for analysis of experimental results }\end{array}$ \\
\hline $\begin{array}{l}\text { ACI } 440(2006) \\
\text { (Tureyen and } \\
\text { Frosch }(2003))\end{array}$ & $\mathrm{V}_{\mathrm{c}}=\frac{5}{12} \mathrm{k} \sqrt{\mathrm{f}_{\mathrm{c}}^{\prime}} \mathrm{b}_{\mathrm{w}} \mathrm{d}$, where $\mathrm{k}=\sqrt{2 \rho n+(\rho n)^{2}}-\rho n$ and $\mathrm{n}=\mathrm{E}_{\mathrm{f}} / \mathrm{E}_{\mathrm{c}}$ \\
\hline
\end{tabular}

Table 2-5: Summary of Shear Design Methods for 116 FRP Reinforced Concrete Slabs

Adopted From (Sherwood et. al. (2008))

\begin{tabular}{|c|c|c|c|c|c|c|c|c|}
\hline \multirow{3}{*}{ Design Method } & \multicolumn{5}{|c|}{ Description } & \multicolumn{3}{|c|}{ Predictive Capabilities } \\
\hline & \multirow{2}{*}{ Intended Use } & \multirow{2}{*}{$\begin{array}{r}\text { Size } \\
\text { Effect }\end{array}$} & \multicolumn{3}{|c|}{ Strain Effect } & \multirow{2}{*}{$\begin{array}{l}\text { Average } \\
\mathbf{V}_{\text {exp }} N_{\text {pred }}\end{array}$} & \multirow{2}{*}{$\begin{array}{l}\text { Coefficient } \\
\text { of Variation }\end{array}$} & \multirow{2}{*}{$\begin{array}{c}\text { 1st } \\
\text { Percentile }\end{array}$} \\
\hline & & & $\mathrm{M} / \mathrm{V}$ & $\rho$ & $\overline{E_{r}}$ & & & \\
\hline $\begin{array}{l}\text { Modified CSA A23.3 } \\
\text { CSA A23.3 }\end{array}$ & $\begin{array}{l}\text { Steel and FRP } \\
\text { Steel }\end{array}$ & $\begin{array}{l}x \\
x\end{array}$ & $\begin{array}{l}x \\
x\end{array}$ & $\begin{array}{l}x \\
x\end{array}$ & $\begin{array}{l}\mathbf{x} \\
\mathbf{x}\end{array}$ & $\begin{array}{l}1.17 \\
1.44\end{array}$ & $\begin{array}{l}14.1 \% \\
15.3 \%\end{array}$ & $\begin{array}{l}0.79 \\
0.92\end{array}$ \\
\hline Razaqpur & $\begin{array}{l}\text { FRP, } d \leq 300 \mathrm{~mm} \\
\text { FRP, } d>300 \mathrm{~mm}\end{array}$ & $\mathbf{x}$ & $\begin{array}{l}\mathbf{x} \\
\mathbf{x}\end{array}$ & $\begin{array}{l}x \\
x\end{array}$ & $\begin{array}{l}\mathbf{x} \\
\mathbf{x}\end{array}$ & 1.22 & $19.1 \%$ & 0.68 \\
\hline El-Sayed & FRP & & & $\bar{x}$ & $\bar{X}$ & 1.30 & $16.4 \%$ & 0.80 \\
\hline JSCE & FRP & $\bar{x}$ & & $\bar{x}$ & $\bar{x}$ & 1.30 & $18.2 \%$ & 0.75 \\
\hline ISIS & $\begin{array}{l}\text { FRP, } d \leq 300 \mathrm{~mm} \\
\text { FRP, } d>300 \mathrm{~mm}\end{array}$ & $\mathbf{x}$ & & & $\begin{array}{l}\mathbf{x} \\
\mathbf{x}\end{array}$ & 1.51 & $29.8 \%$ & 0.46 \\
\hline CSA S806 & $\begin{array}{l}\text { FRP, } d \leq 300 \mathrm{~mm} \\
\text { FRP, } d>300 \mathrm{~mm}\end{array}$ & $\mathbf{x}$ & $\mathbf{x}$ & $y$ & & 1.55 & $29.1 \%$ & 0.50 \\
\hline$\overline{A C l} 440$ (Frosch (2003)) & Steel and FRP & & & $\bar{x}$ & $\bar{x}$ & 1.73 & $17.7 \%$ & 1.01 \\
\hline
\end{tabular}




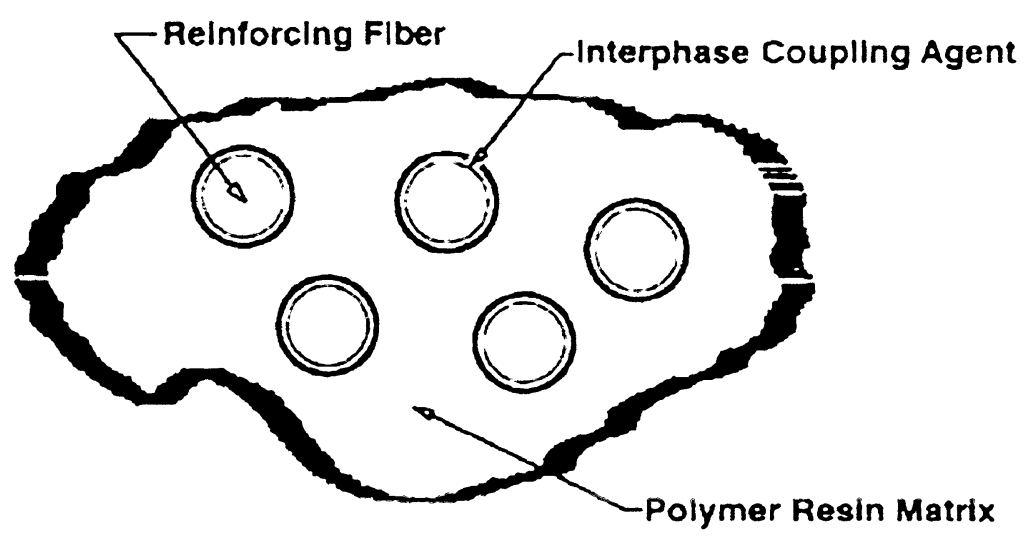

Figure 2-1: Cross-Section of a Composite Material (ACI Committee 440 (1996))

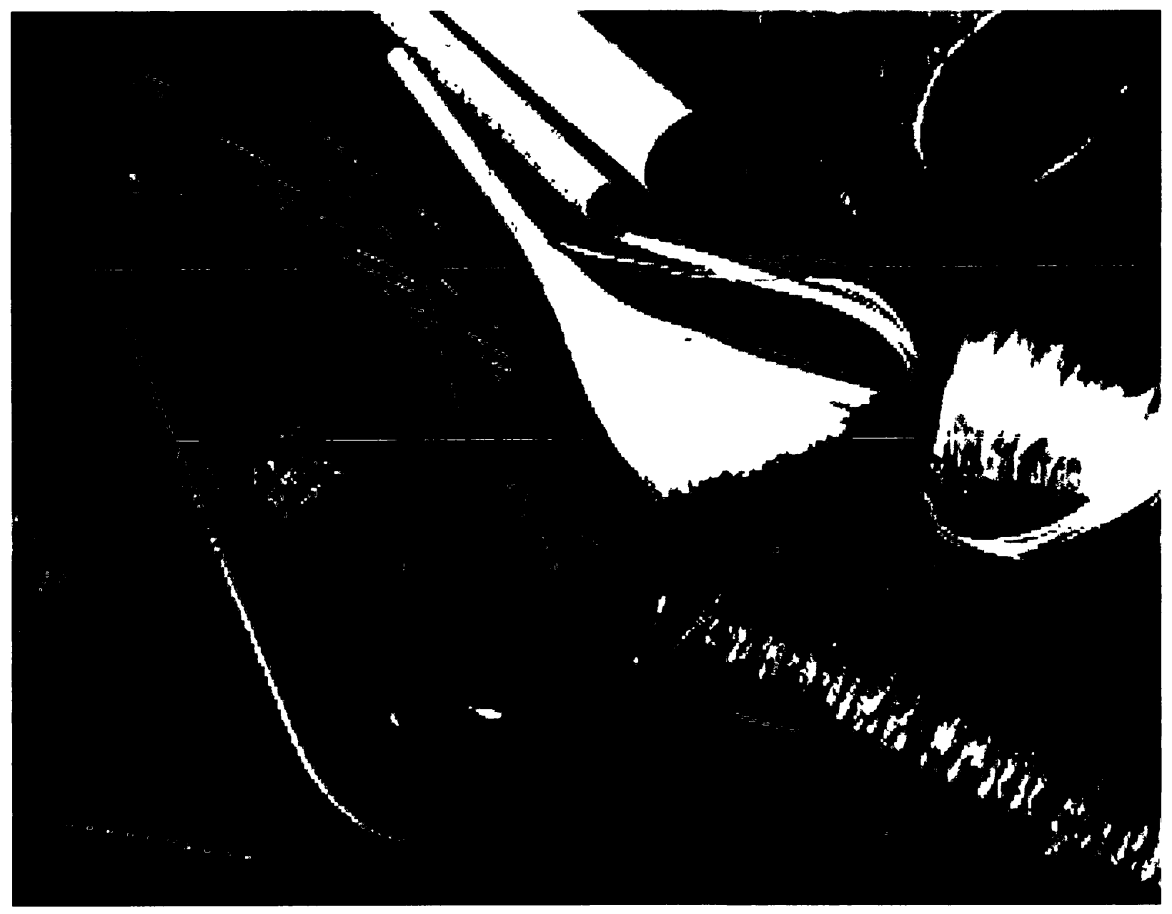

Figure 2-2: Different Types of Fibres

(ACI Committee 440 (1996)) 


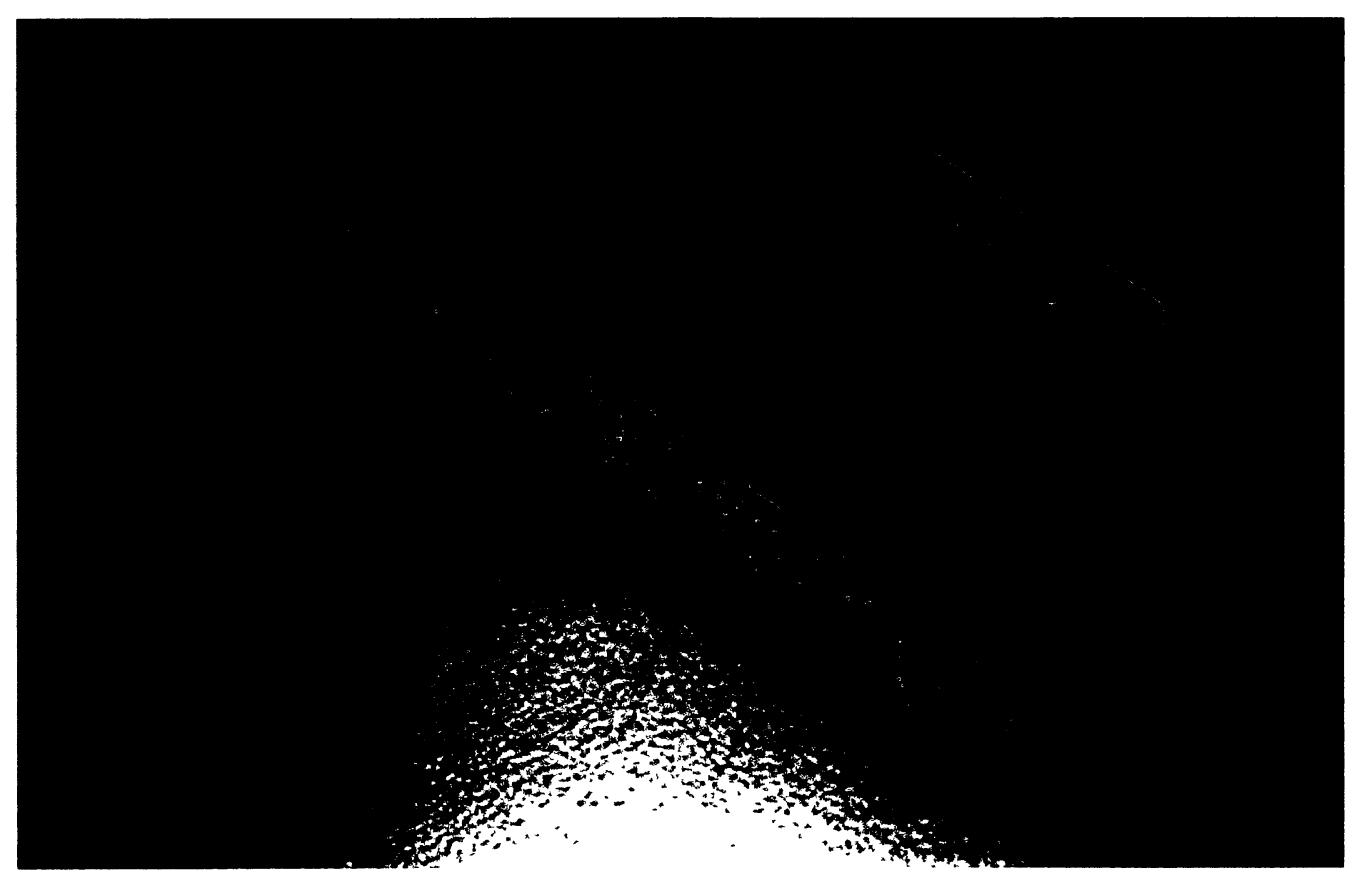

Figure 2-3: CFRP Rebar

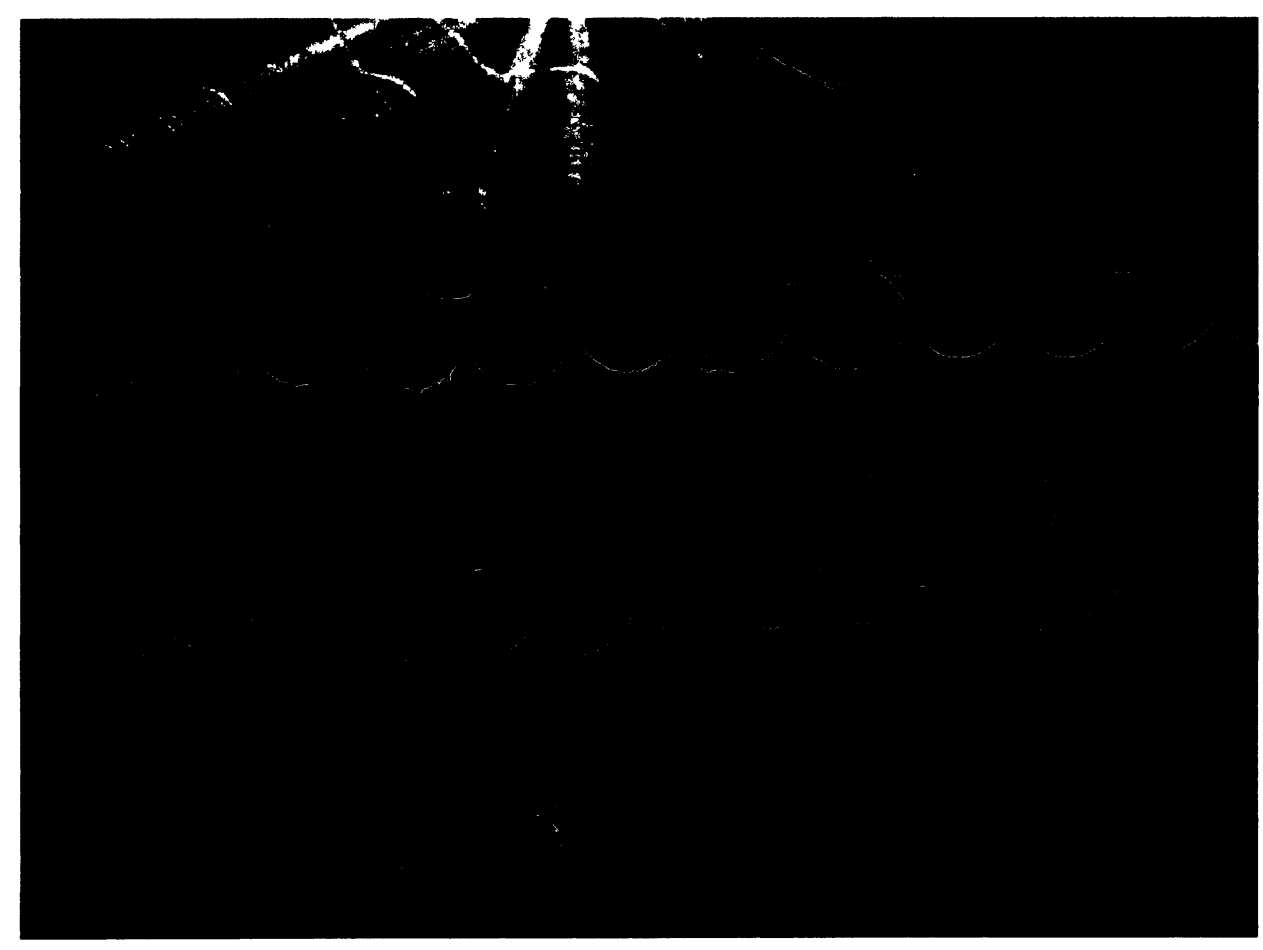

Figure 2-4: GFRP Rebar 


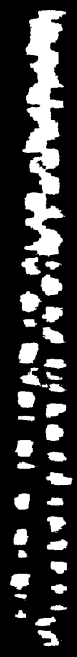

Figure 2-5: Aramid Fibre

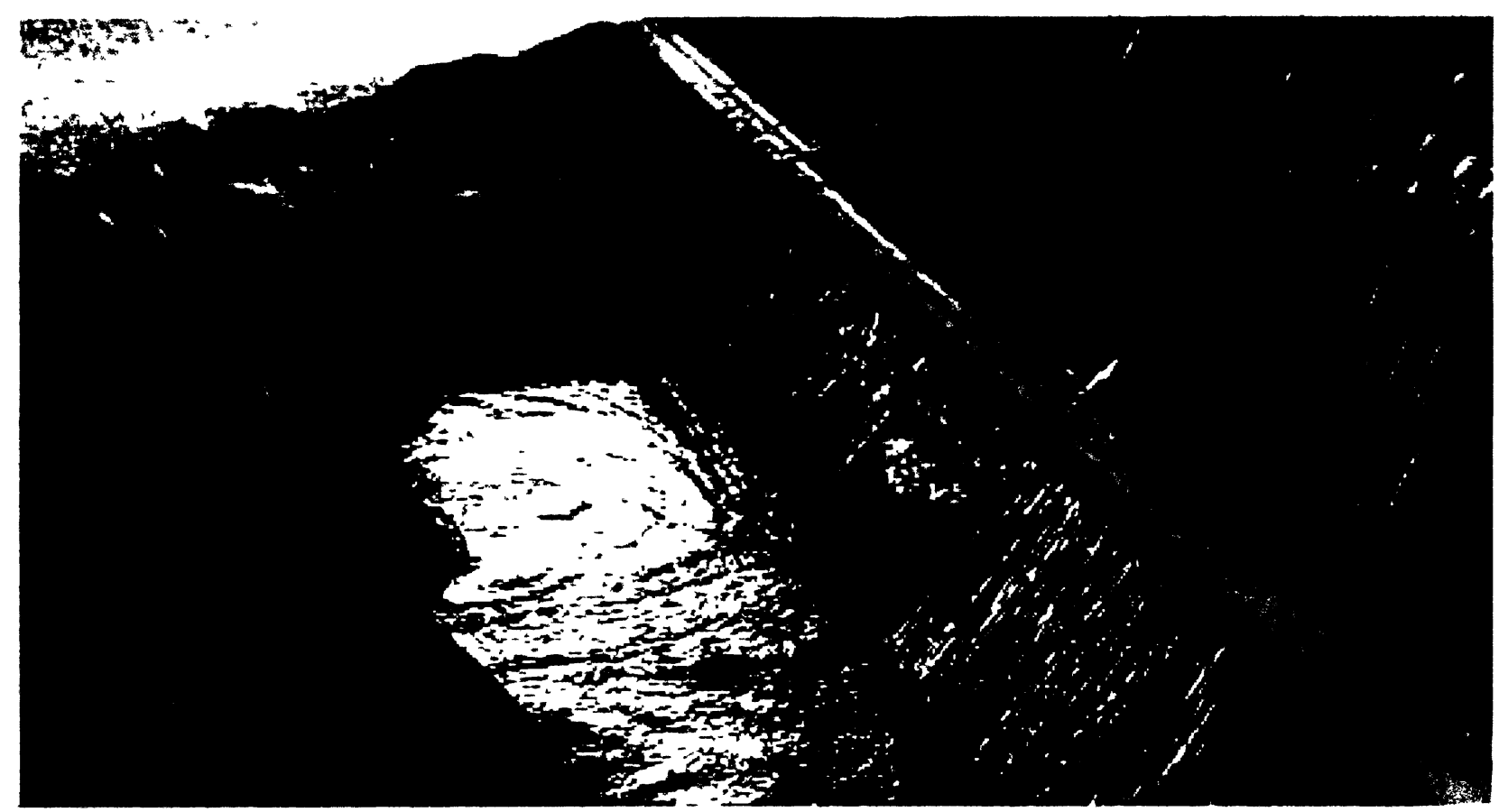

Figure 2-6: Fibres Saturated with Liquid Resin During Manufacturing 


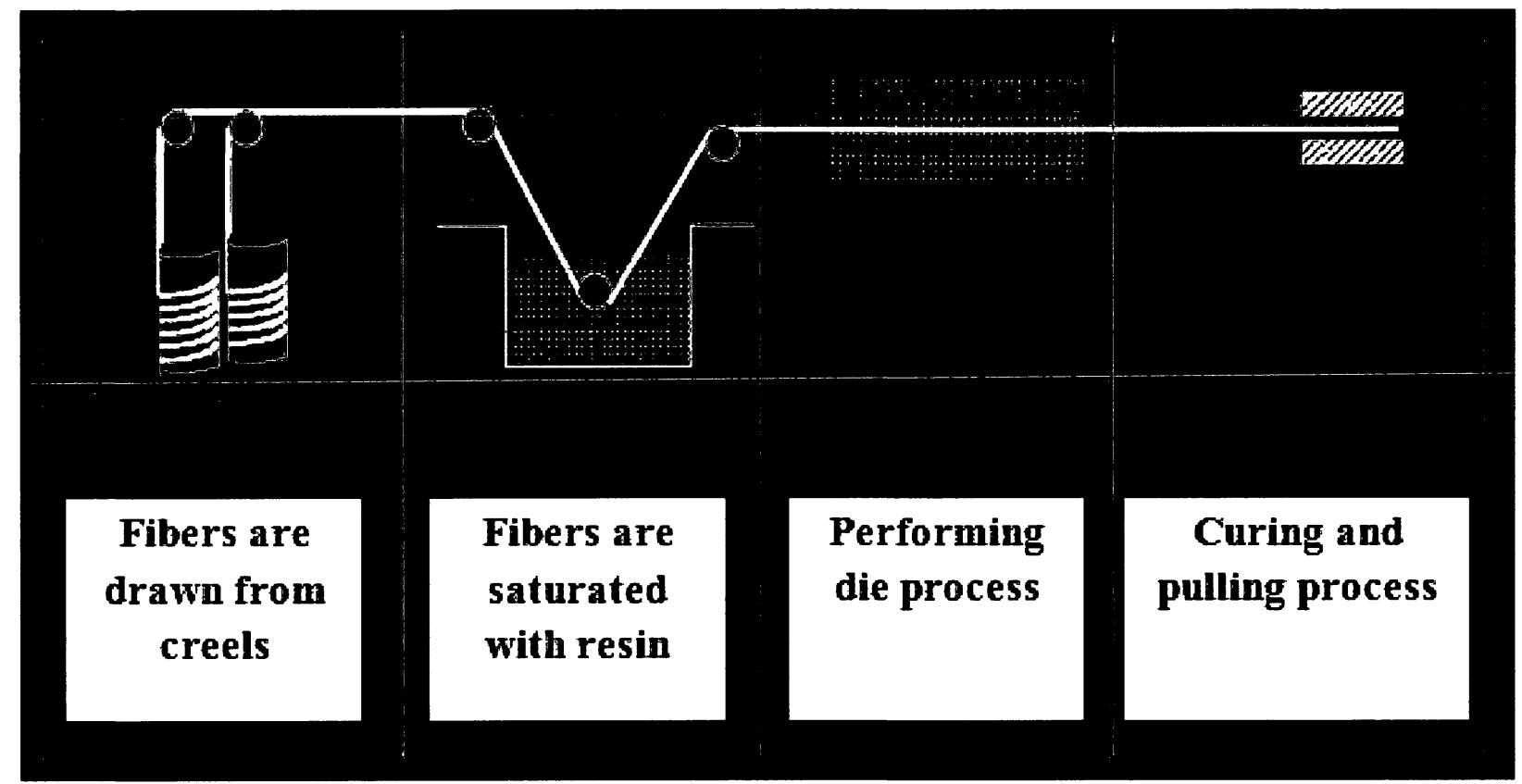

Figure 2-7: Pultrusion Manufacturing Processes

Figure 2-8: GFRP Reinforcement used in Experiments 


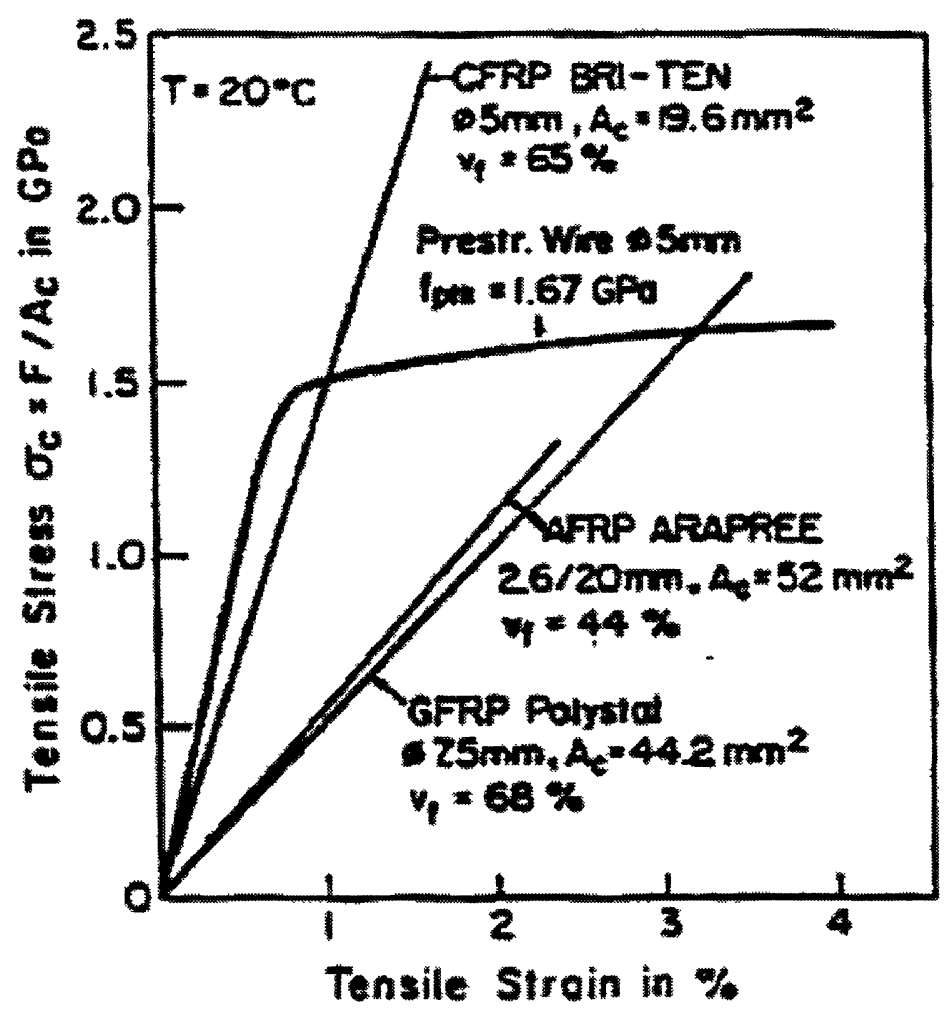

Figure 2-9: Stress-Strain Behaviour of Fiber-Reinforced Polymers (ACI Committee 440 (1996)) 

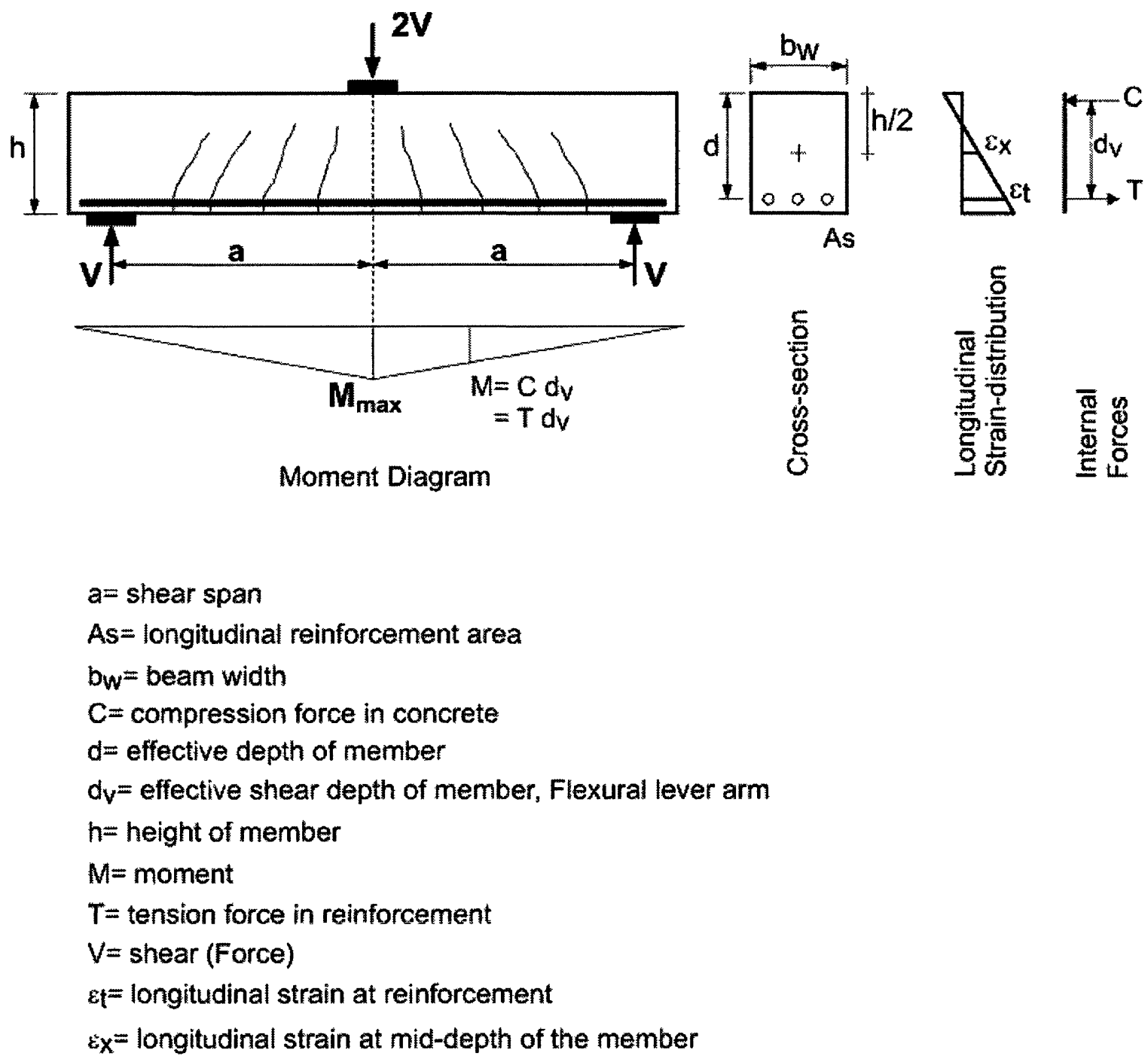

Figure 2-10: Typical Geometry of Reinforced Concrete Beams and Slabs used in Experimental Studies 


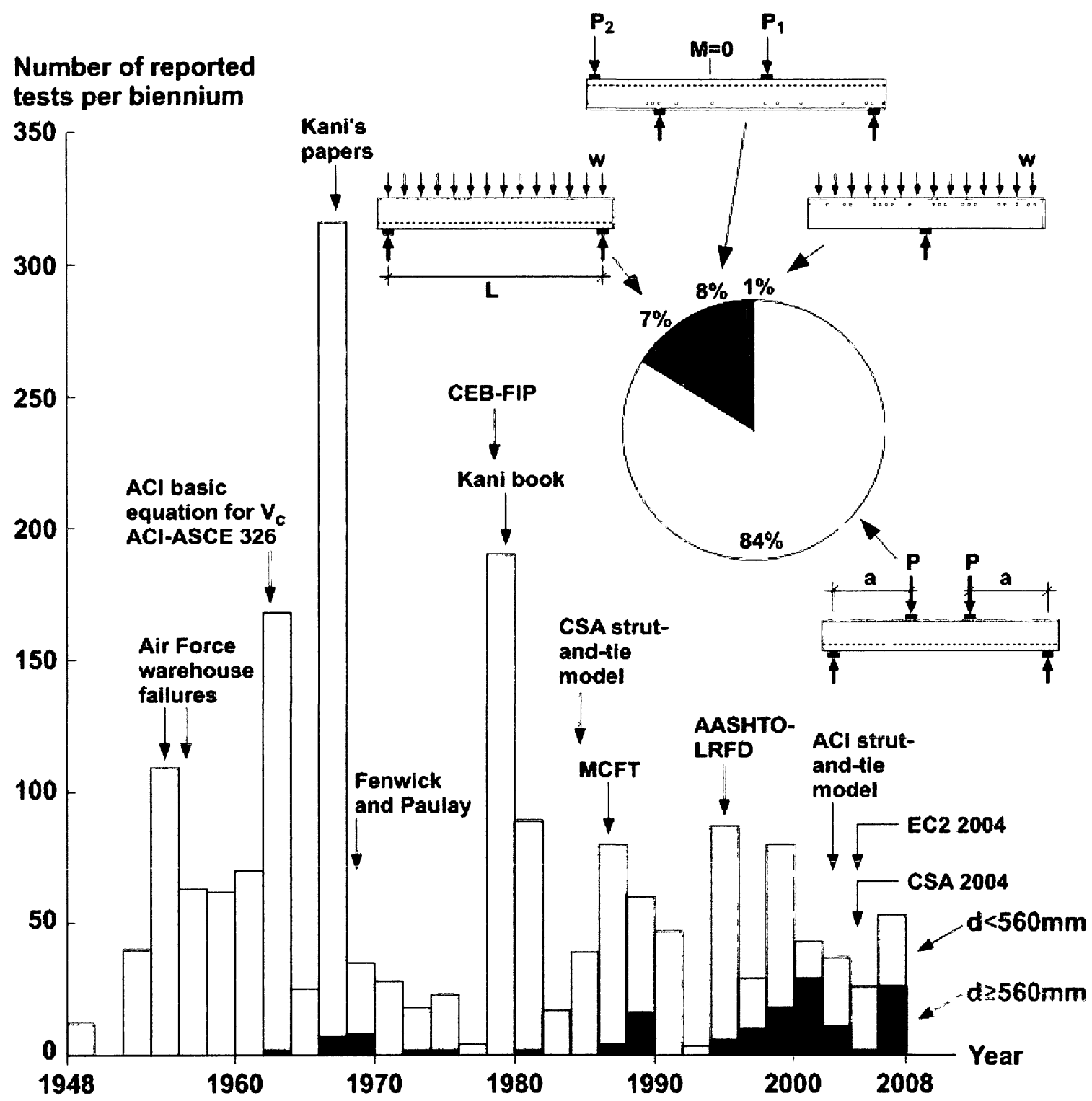

Figure 2-11: Summary of 60 Years of Shear Research on Members without Stirrups (Collins et. al. (2007)) 


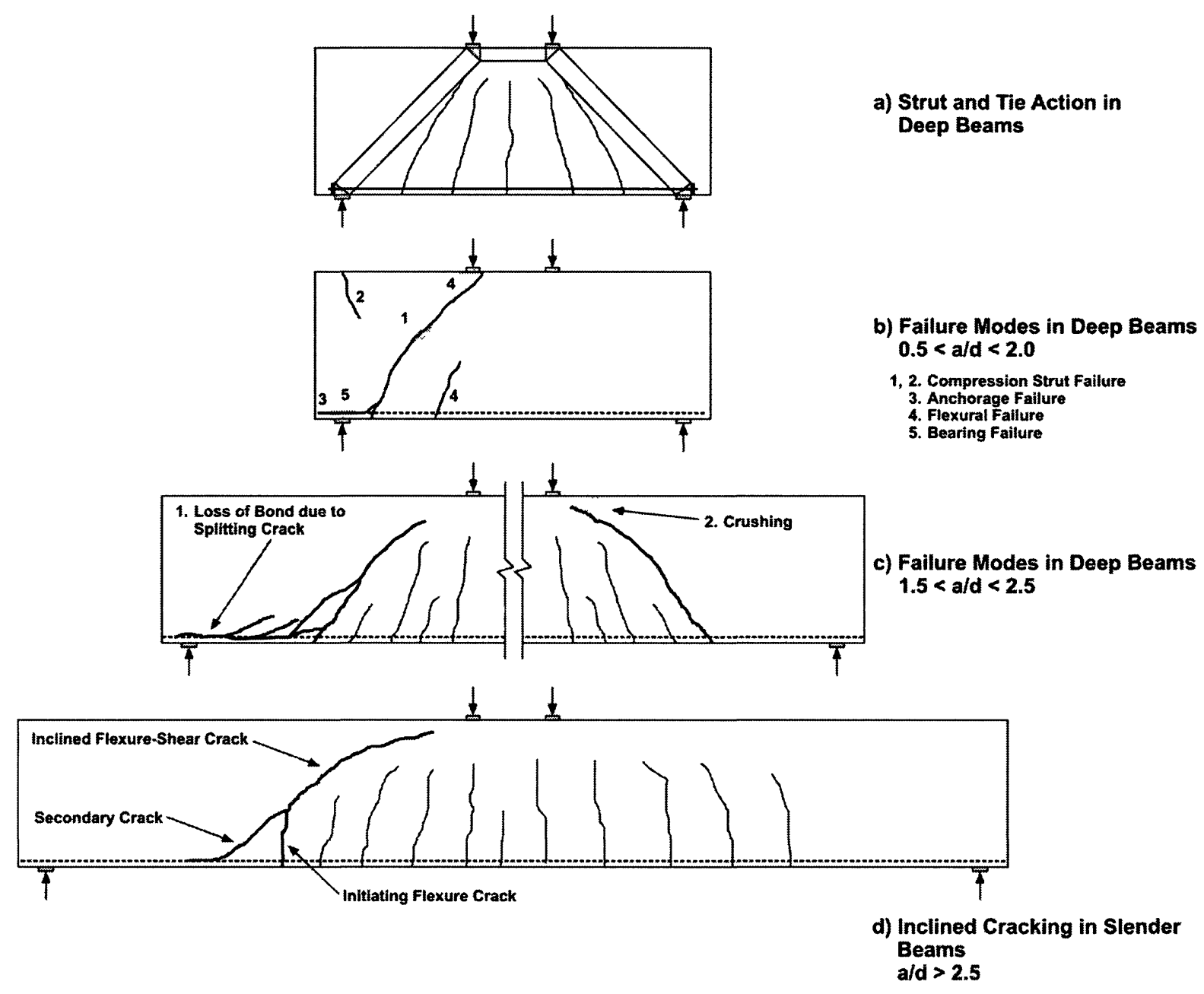

Figure 2-12: Shear Failure Modes in Reinforced Concrete Beams without Stirrups (Sherwood (2008)) 


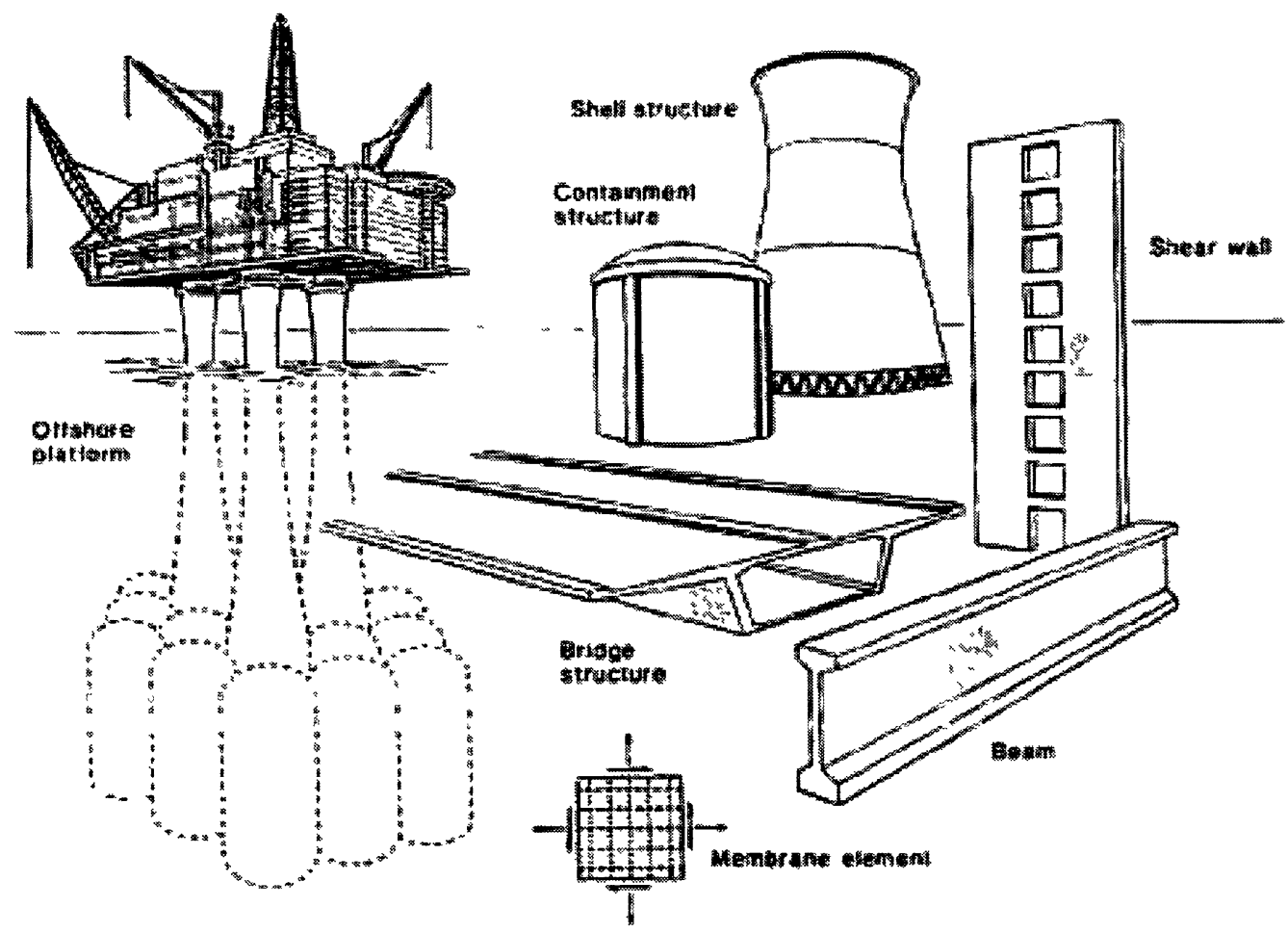

Figure 2-13: Reinforced Concrete Membrane Elements

(Vecchio and Collins (1986)) 


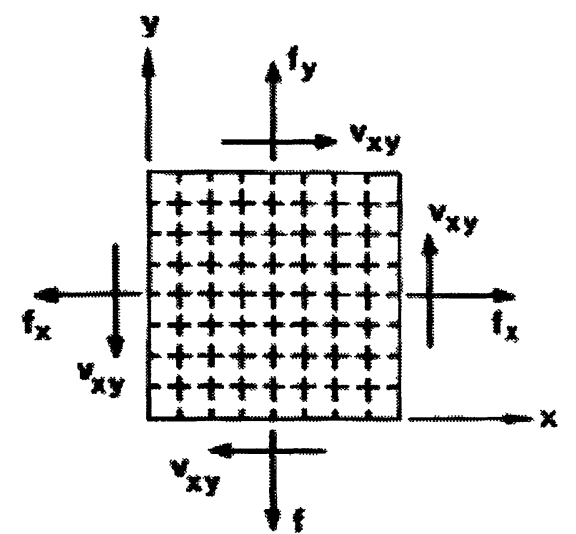

Loading

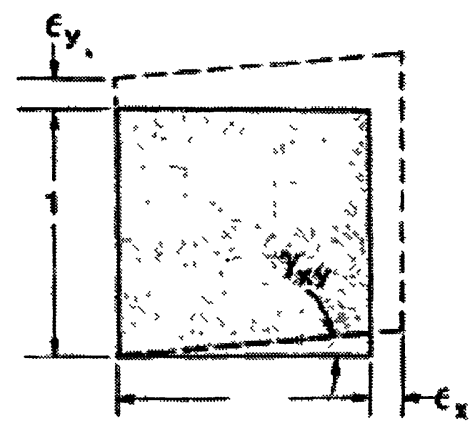

Deformation
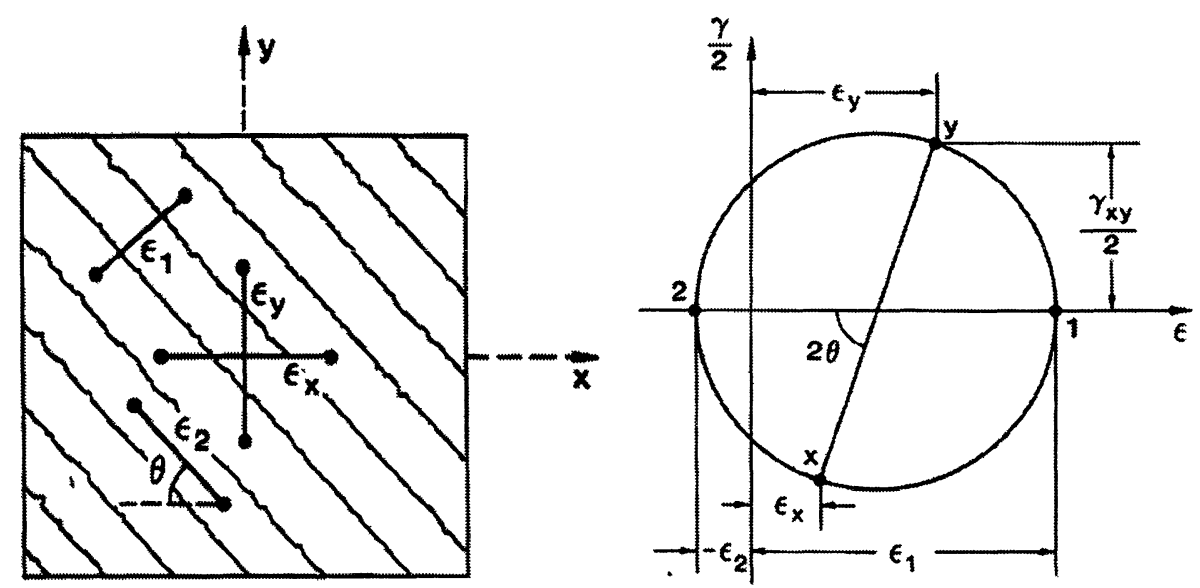

Figure 2-14: Average Stresses and Strains in Cracked Membrane Element, Mohr's Circle (Vecchio and Collins (1986)) 


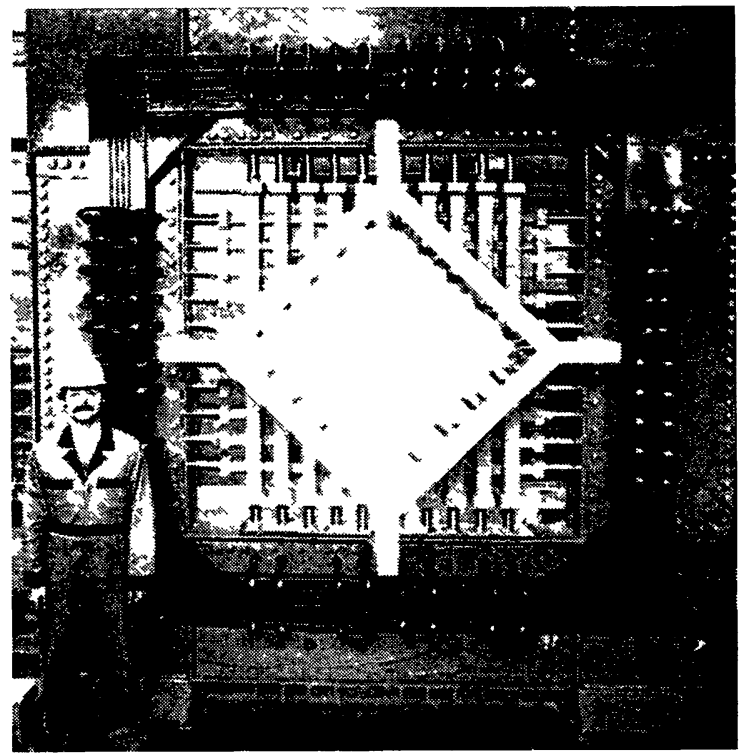

Figure 2-15: Membrane Element Tester

(Vecchio and Collins (1986))

\begin{tabular}{|c|c|c|}
\hline 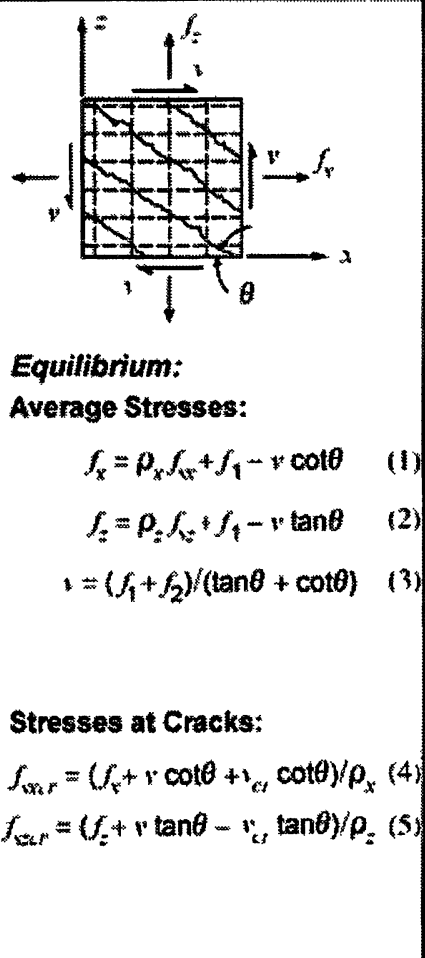 & $\begin{array}{l}\text { Geometric Conditions: } \\
\text { Average Strains: } \\
\tan ^{2} \theta=\frac{\epsilon_{x}+\epsilon_{2}}{\epsilon_{z}+\epsilon_{2}} \\
\epsilon_{q}=\epsilon_{v}+\epsilon_{z}+\epsilon_{2} \\
\gamma_{x=}=2\left(\epsilon_{x}+\epsilon_{2}\right) \cot \theta \\
\text { Crack Widths: } \\
w=s_{\theta} \epsilon_{1} \\
s_{\theta}=1 /\left(\frac{\sin \theta}{s_{1}}+\frac{\cos \theta}{s_{z}}\right)(10)\end{array}$ & 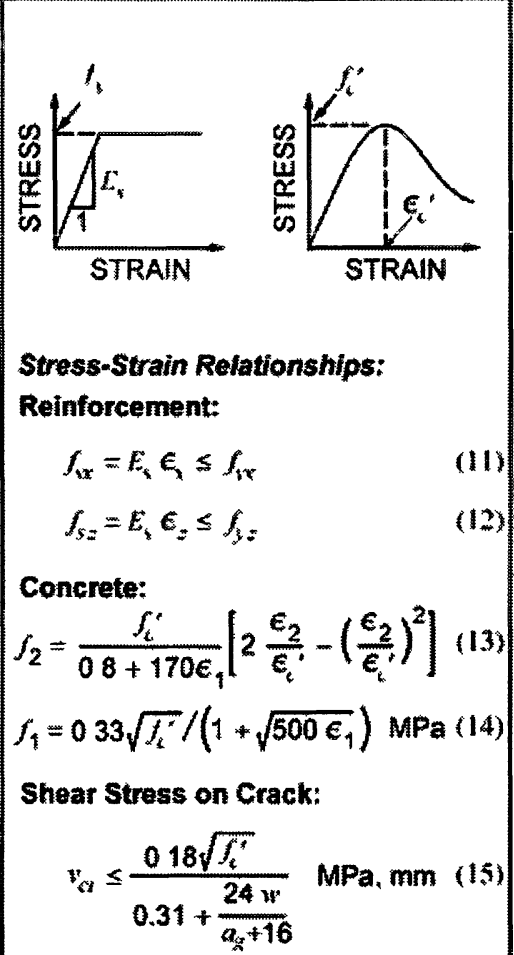 \\
\hline
\end{tabular}

Figure 2-16: 15 Non-Linear Equilibrium Equations, Geometric Conditions and StressStrain Relationships of the MCFT (Vecchio and Collins (1986)) 

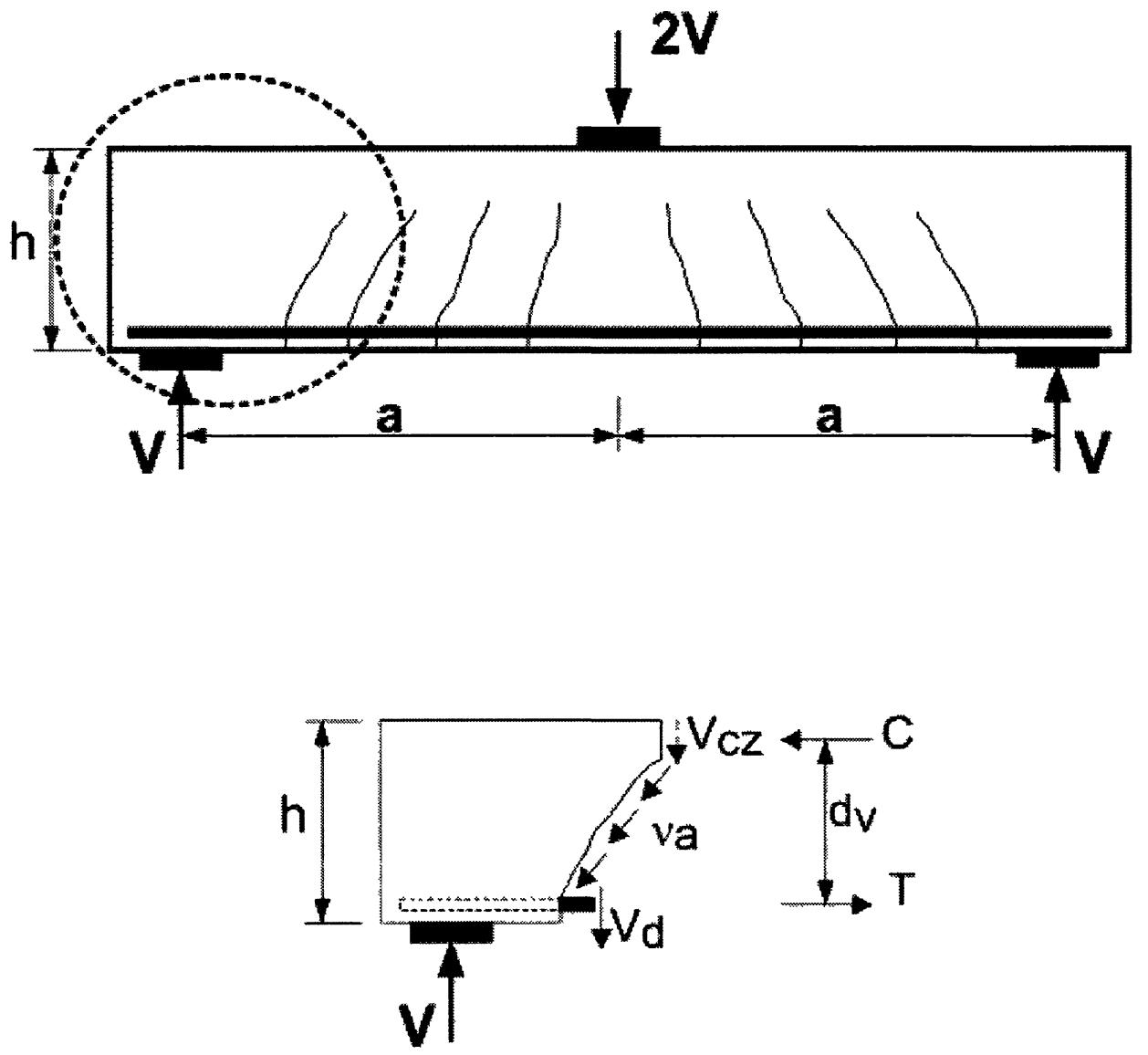

$\mathrm{C}=$ compression force in concrete

$T=$ tension force in steel

va= aggregate interlock shear stress

$V_{C Z}=$ shear force in compression zone

$V_{d}=$ shear force due to dowel action in reinforcing steel

$V=$ shear force

Figure 2-17: Aggregate Interlock Mechanism 


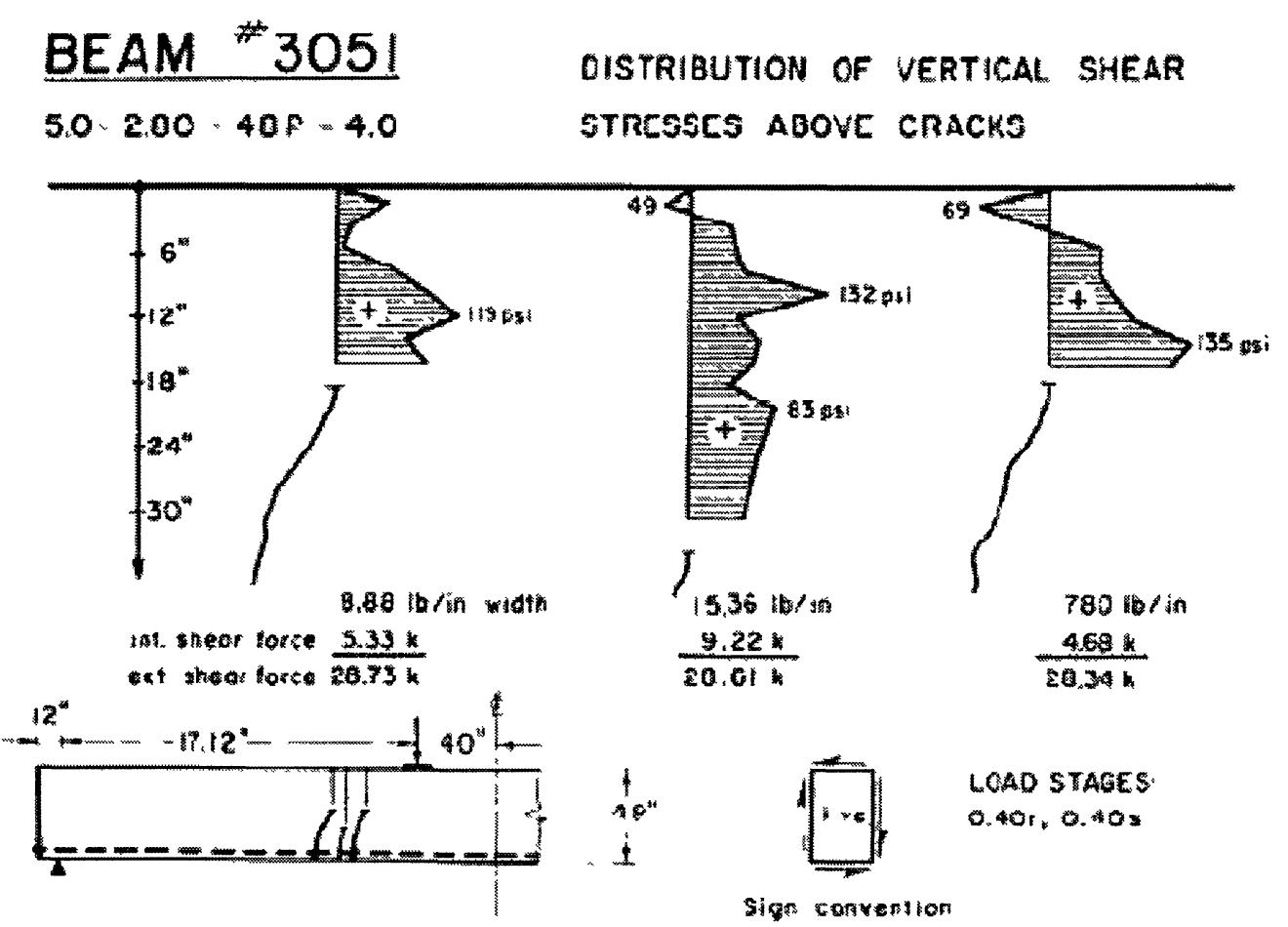

Figure 2-18: Measurement of Shear in Compression Zone (Kani et. al. (1979))

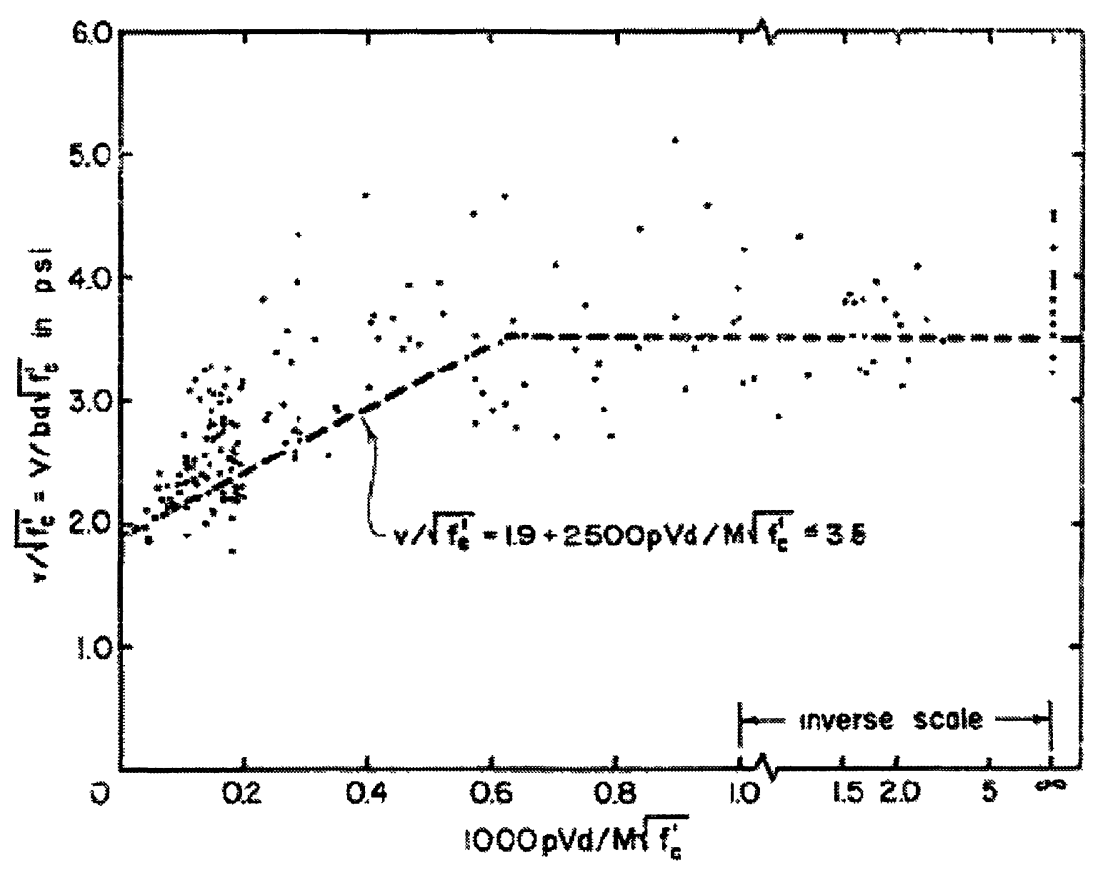

Figure 2-19: Derivation of ACI 318 Equation (11-5)

(Reproduced from ACI Committee 326 (1962)) 


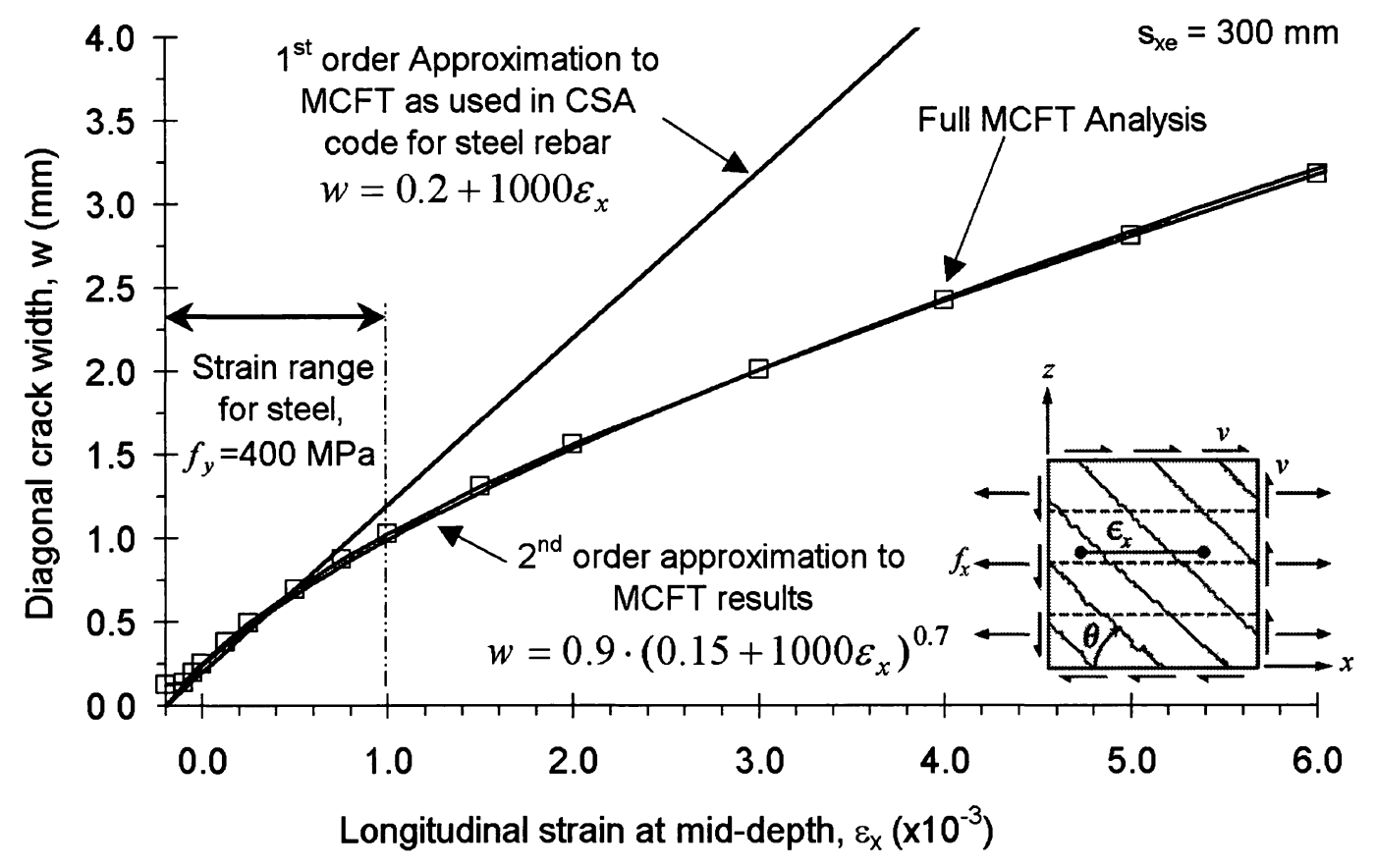

Figure 2-20: Crack Width vs. Longitudinal Strain at Mid-Depth

(Hoult et. al. (2008)) 


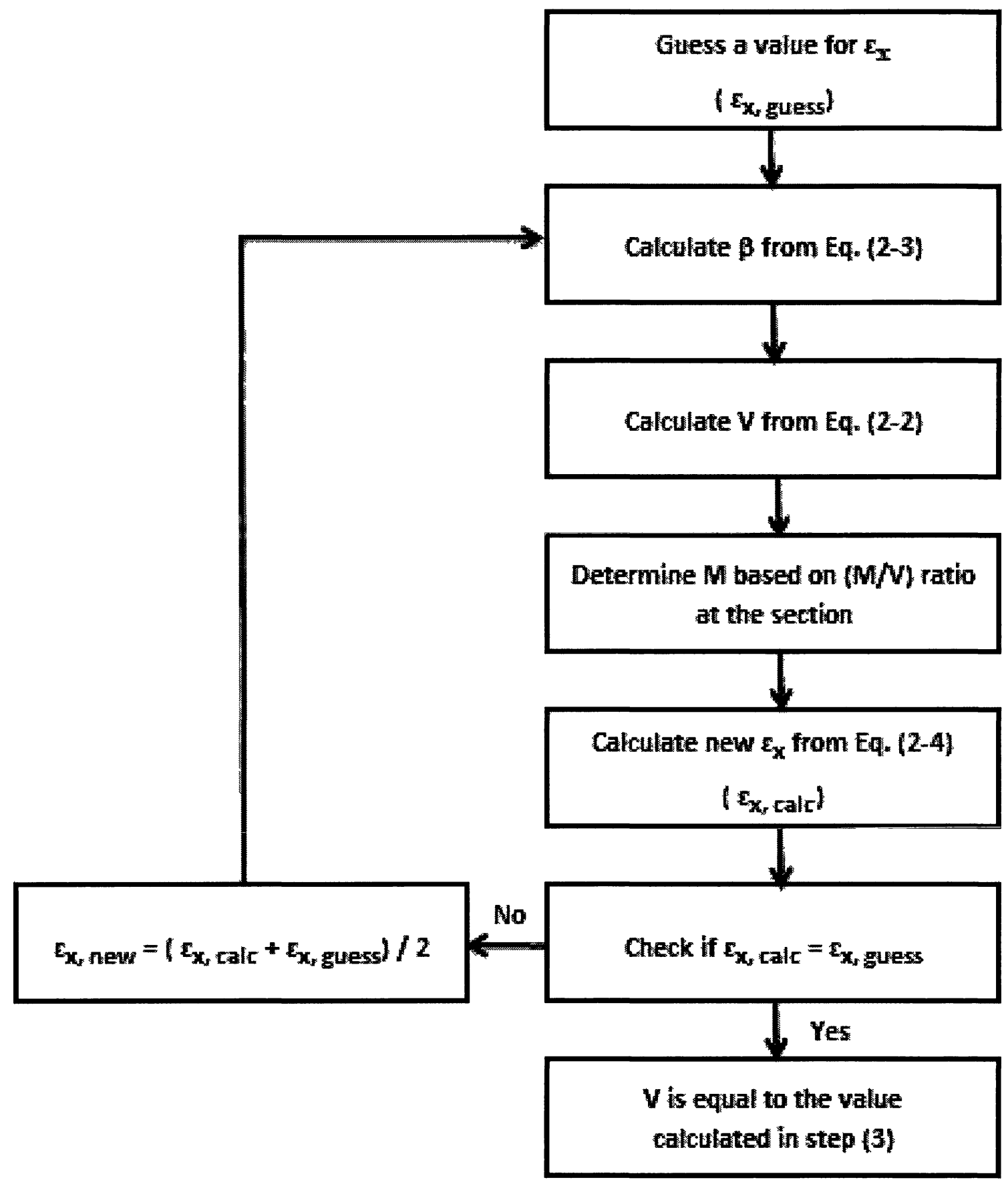

Figure 2-21: Iterative Analysis Process, CSA A23.3-04 General Method 


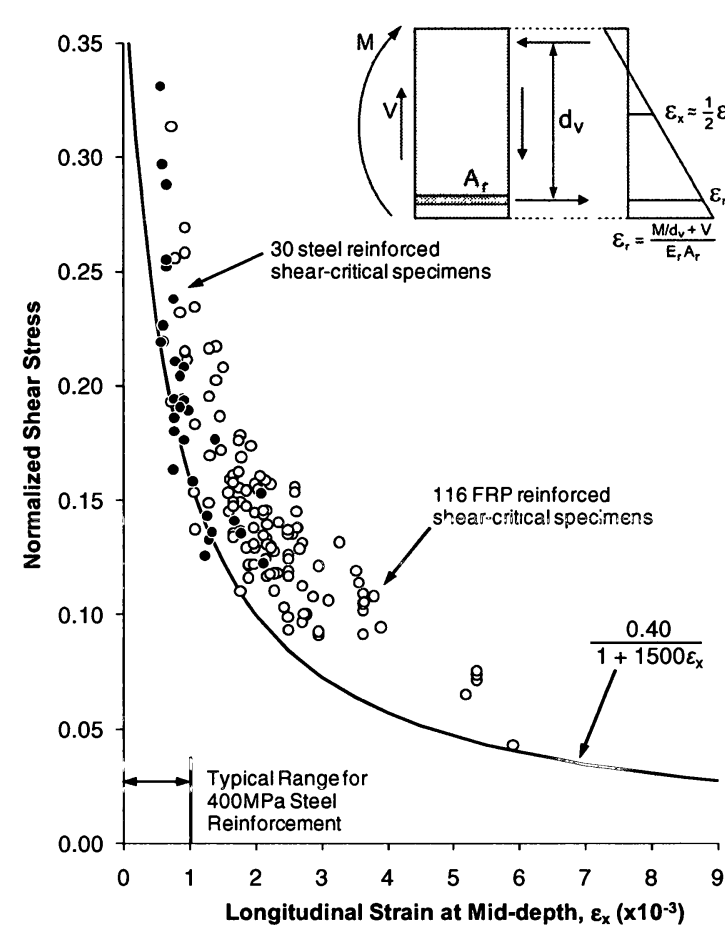

(a) CSA A23.3-04 Expression

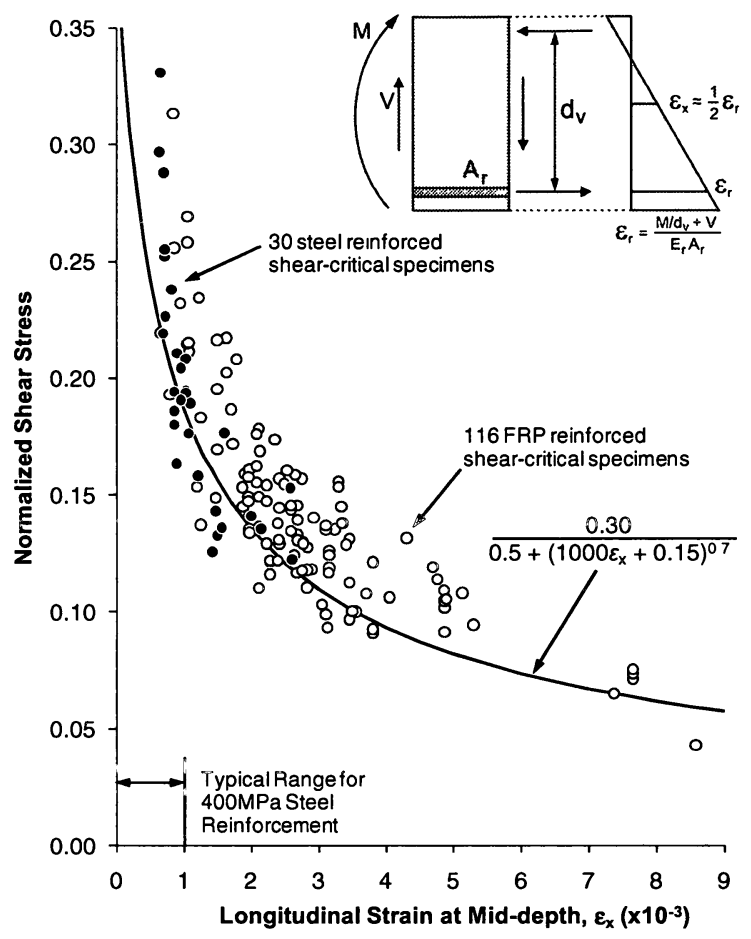

(b) Modified CSA A23.3 Expression

Figure 2-22: Normalized Failure Shear Stress vs. $\varepsilon_{\mathbf{x}}-$ Experimental Data Points and Predicted Variation (Sherwood et. al. (2008)) 


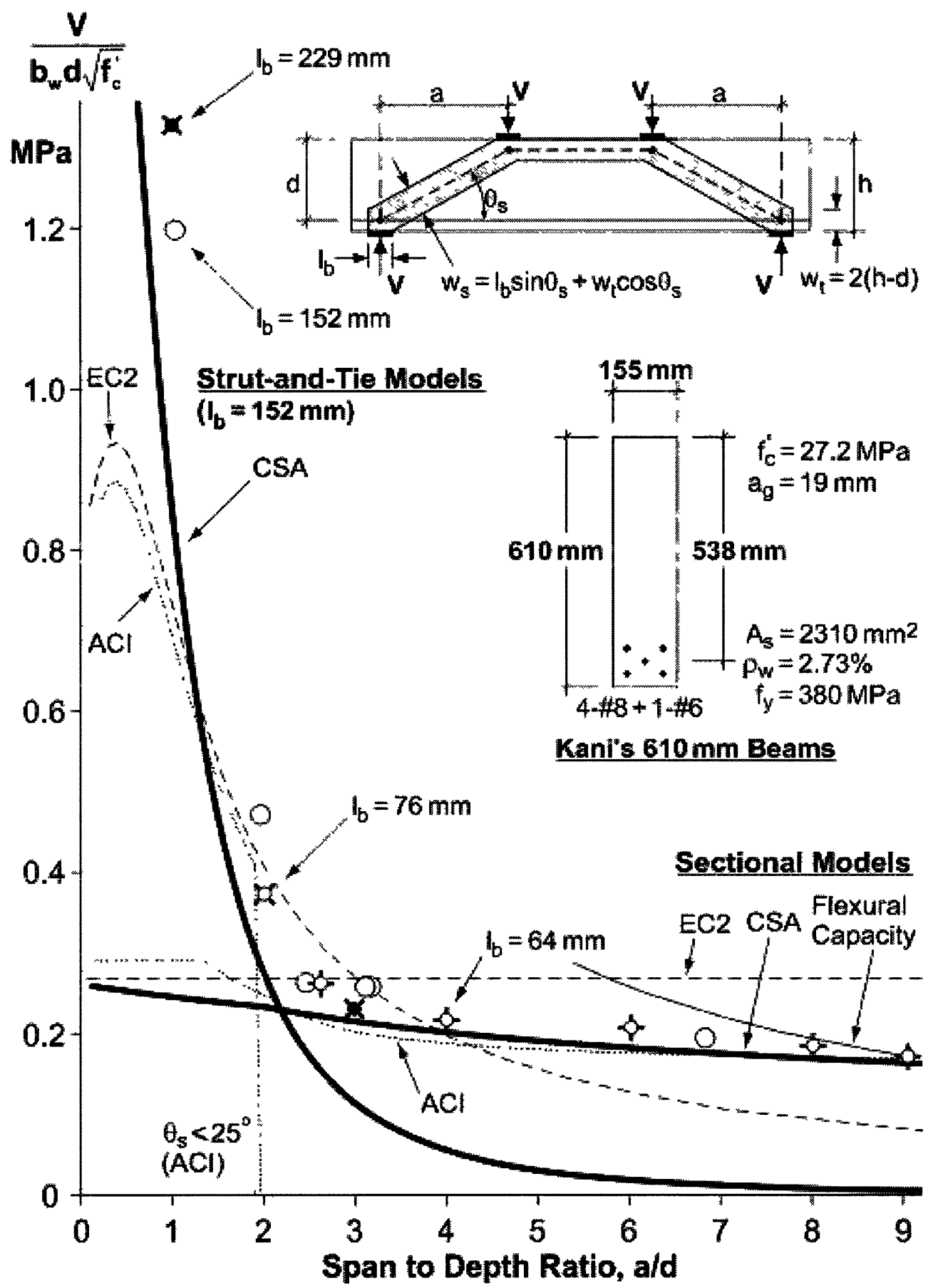

Figure 2-23: Influence of Shear Span-Depth Ratio on Failure Shear Stress (Collins et. al. (2007)) 


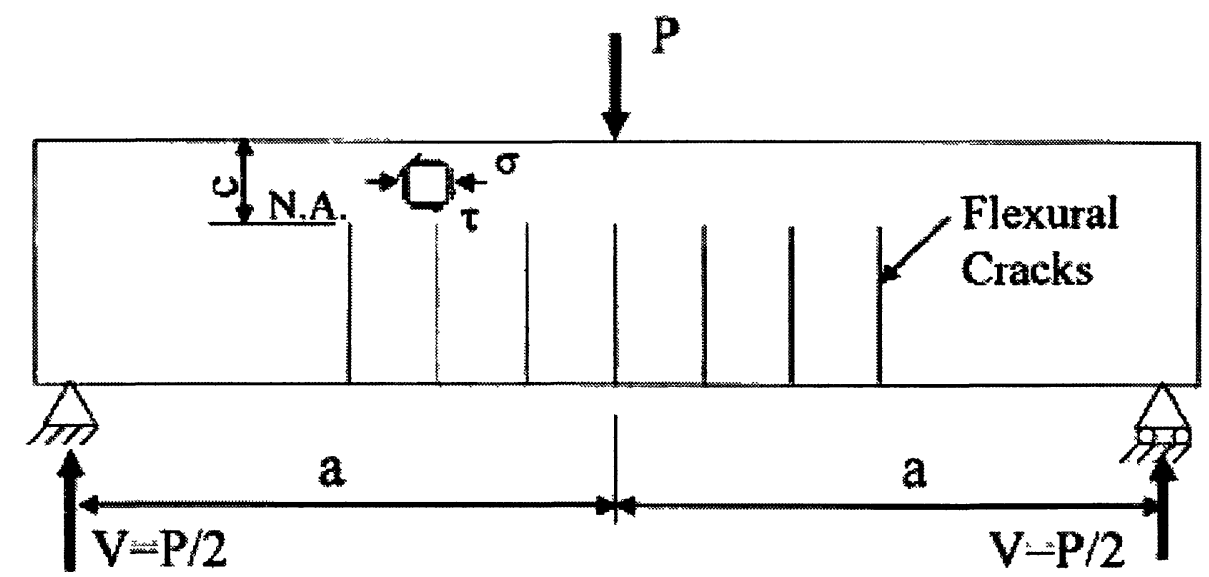

Figure 2-24: Simplified Beam for Model Frosch's Model

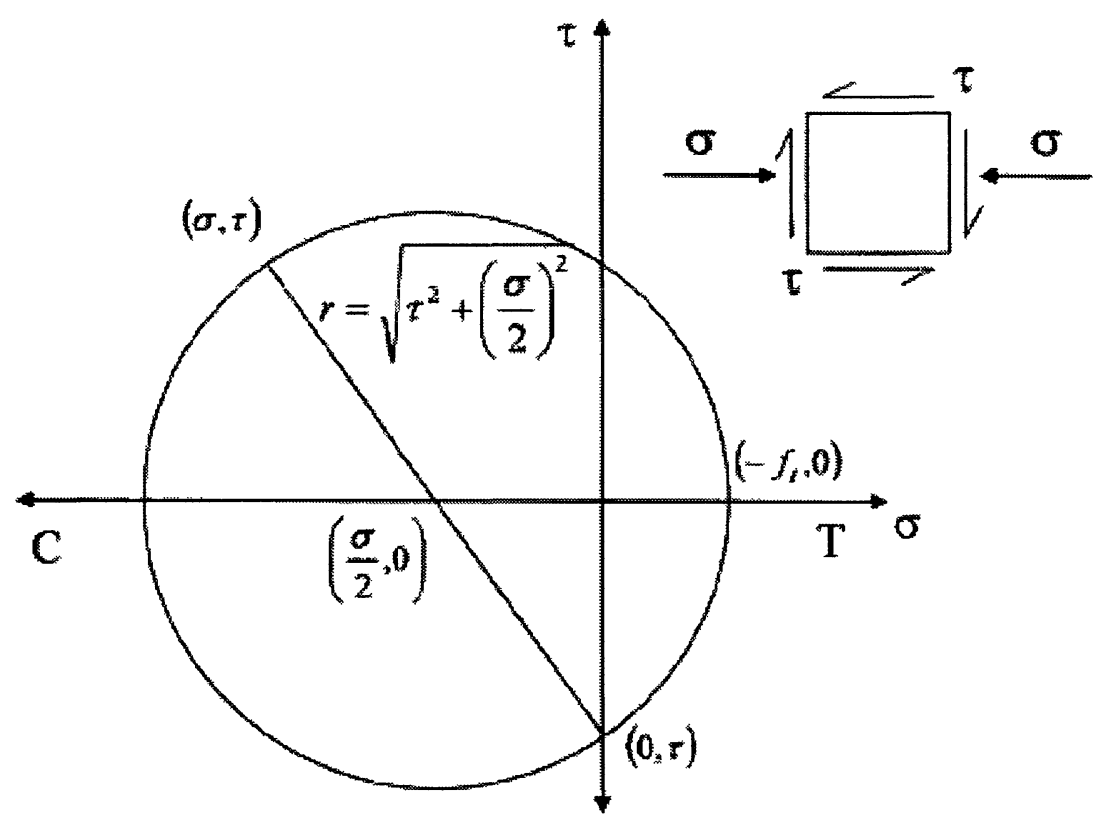

Figure 2-25: Principal Stresses 


\subsection{EXPERIMENTAL PROGRAM}

\subsection{General}

This section presents the experimental program portion of this research, in which fifteen one-way slab strips longitudinally reinforced with glass FRP reinforcement without shear reinforcement were tested in Carleton University's structural engineering laboratory. All fifteen slab strips were shear-critical, simply supported, subjected to point loads, with rectangular dimensions $400 \mathrm{~mm}$ wide by $280 \mathrm{~mm}$ deep and the length of the specimens varied between $2200 \mathrm{~mm}$ and $4600 \mathrm{~mm}$ (Figure 3-1). All specimens were designed to fail in shear. Since one-way slabs have the same structural behavior as beams, the slab strips will be referred to as beams for simplicity.

In fourteen of the specimens, FRP reinforcement was laid out on one layer in the bottom of the specimens, and one of the specimens was reinforced with two layers of bars on the top and bottom of the specimen. These will be described in more detail in this chapter.

A summary of these fifteen specimens is presented in Table 3-1 and Figure 3-1. In this table, specimens are arranged in four groups based on the test variables: shear span to depth ratio (a/d), and reinforcement ratio $\rho$.

The $1^{\text {st }}$ series of beams (MB-8, MB-9 and MB-10) was designed to study the effect of $\rho$ on the shear strength of FRP-reinforced beams where failure is expected to occur by strut-andtie action. The $2^{\text {nd }}$ series was designed to study the effect of increasing a/d at a constant $\rho$, 
where $\rho$ is relatively high. The $3^{\text {rd }}$ and $4^{\text {th }}$ sets of beams were designed to study the interacting effects of $\mathrm{a} / \mathrm{d}$ and $\rho$ on shear strength. Both series had 5 beams where $\rho$ was increased from $0.57 \%$ to $2.28 \%$. However, a constant a/d of 3 was used in series 3 , whereas a/d was increased from 2 to 8 in series 4 , such that $\frac{M}{\rho V d}$ ratio is constant.

Shear design methods that neglect the effect of a/d while accounting for $\rho$ will predict similar increases in shear strength for both series 3 and 4 . However, methods that property account for both a/d and $\rho$ predict that series 4 beams will fail at an approximately constant shear stress.

\subsection{FRP Strain Gauges Installation}

In order to determine and record the FRP reinforcement strain during the loading, at the mid-span of all beams a number of strain gauges were installed on the side of FRP bars. In some of the specimens, to record the strain at the center of the shear span, a, one more strain gauge was installed at the center point of the shear span, a. The locations of the strain gauges are outlined in Figures 3-2 and 3-3.

\subsubsection{Sand off the GFRP Surface}

The first step in installing the strain gauges on the surface of the FRP bars was to make a smooth surface to attach the strain gauge properly. Since the GFRP reinforcement used was coated with sand to improve bond between the reinforcement and concrete, at the location of installing the gauges, the sand coat of FRP had to be removed. 
A small piece of steel plate with sharp teeth was used to carefully remove all the sand from the surface of the FRP reinforcement without damaging the rebar (Figure 3-4). After that, to avoid damaging the surface of the FRP and to make a very smooth surface, a dynafile air abrasive belt machine was used. While using this tool, the sander was rolled on the curved surface of the FRP to avoid making a flat surface and disturbing the real shape of the FRP rebars. To prevent significant reduction in bond strength between the FRP and concrete at the location of the gauges, only a minimum area of sand was removed.

\subsubsection{Strain Gauge Installation using M-Bond 200 Adhesive}

To attach the strain gauge to the surface of the FRP, the Vishay Micro-Measurements Certified M-Bond 200 adhesive was used because of its fast room-temperature cure and ease of application. M-bond 200 is compatible with all Vishay Micro-Measurements strain gages and most common structural materials. The M-Bond 200 Catalyst was also used to control the reactivity rate of this adhesive. Figure 3-5 shows the M-Bond 200 products which used in this experimental work.

To obtain the proper results, the installation procedure as outlined in the Installation Bulletin of M-Bond 200 Adhesive was used, and is described below.

In the first step, the gauge area was cleaned with two solvents, M- PREP Neutralizer and MPREP Conditioner. Then, the installation area was abraded by wiping using a gauze sponge and then drying by wiping slowly through with a new gauze sponge for final cleaning. Based on the instruction bulletin recommendation, for removing all residuals, the final gauze was 
not wiped back and forth. To mark the exact location of attaching the gauge, a pencil was used then the surface was cleaned after marking the point using the solvent.

Tweezers were used to remove the gauge from the transparent envelope and place on the alignment mark on the surface of the FRP. Also a soldering terminal was placed on the FRP approximately $2 \mathrm{~mm}$ from the gage backing. The solder terminal was used so that the strain gauge wires can be easily and safety connected to the lead wires on the gauge. A 50mm piece of tape was used afterwards and placed over the gage and the terminal area. After insuring that the tape attached to the gage and terminal properly, a finger was placed firmly on one side of the tape (the side of the gauge, not the terminal) and carefully the tape was lifted at an angle of $45^{\circ}$ such that the terminal and gauge were free from the FRP surface. Next, a small amount of M-Bond 200 catalyst was applied in a thin and uniform coat on the surface of the gauge and terminal by sliding the brush-cap over the entire gauge surface and terminal. Then the catalyst dried for about one minute.

After the catalyst dried, glue was applied. One or two drops of the M-Bond 200 Adhesive were applied on the FRP surface. Then the tape with the solder pad and gauge was rotated back onto the surface of the FRP over the adhesive. A piece of gauze then was used to apply a firm pressure with a finger while wiping over the gauge. Continuous pressure was applied for one minute. Finally, after 2 minutes, the tape was pulled back over the surface, peeling and removed slowly so that the gauge and terminal strip remained to the surface of the FRP. 


\subsubsection{Soldering, Coating and Covering the Gauge with Wax and Tape}

After gauge installation the wires were attached to the gauges. A $1000 \mathrm{~mm}$ length of wire was used. Both ends of the wires then were cut and stripped with wire cutters. Nominal gauge resistance of $\Omega=120$ ohms was checked using a switch and balance unit, and $5 \%$ and $10 \%$ showed deviation of gauge resistance from nominal resistance. The wires were then soldered to the terminal, and the strain gauge lead wires were also soldered to the terminal. The conductivity of the all gauges were checked by using the switch and balance unit before any further processing.

After soldering, the gauges were allowed to cool then the wires were tied to the bars using one or two zip-ties to avoid any movement during the casting. The next step was covering the installation area by adequate protective coatings. For this purpose, the M-Coat B rubber coating was used to cover the whole area of installation properly to protect the gauges against humidity.

To insure protection against humid exposure during the casting the concrete, the whole surface of the installation area was covered by wax, applied in four or five thin layers. The wax was then covered using water proofing tape. Figures 3-6, 3-7 and 3-8 show these processes with all instrumentations.

\subsection{Specimen Design}

All beam specimens were cast in the Carleton structures lab in formwork constructed in the lab. The overall depth and width of all fifteen specimens were $280 \mathrm{~mm}$ and $400 \mathrm{~mm}$ respectively. Ten overall lengths of the specimens were $2200 \mathrm{~mm}$. Two of the specimens 
were built to have an overall length of $2600 \mathrm{~mm}$. One of the specimens was built with the overall length of $3600 \mathrm{~mm}$. The last two long specimens had an overall length of $4600 \mathrm{~mm}$. All specimens were named MB1 to MB15 (Mitra's Beam1-15) according to the test date.

\subsubsection{Formwork Preparation}

Formwork was constructed using $1220 \mathrm{~mm}$ by $2440 \mathrm{~mm}$ (4' by 8') sheets of $19 \mathrm{~mm}$ (3/8') plywood and 2' by 4' lumber for framing. All plywood in contact with the concrete was formply. This type of plywood has a finished surface on one side to provide a smooth finish to the concrete (Figures 3-9 to 3-11).

All formwork was built, placed on, and secured to $1220 \mathrm{~mm} \times 2440 \mathrm{~mm}$ base sheets of plywood. Each unit of formwork was fabricated to cast two specimens. Each unit consisted of end faces, side faces and a middle divider. The faces and dividers were framed using $2 \times 4$ lumber and sheathed with formply. A sheet of formply was also screwed to the plywood base to provide a smooth finish to the bottoms of the beams. The bottom edges of the formply on the side and end faces and the dividers were placed in grooves along the formwork base to provide uniform support along their lengths. Side and end faces were secured to the base using 3/8" bolts.

All knots and screw holes on the formply were filled by plastic wood and all corners, edges, joints and minor holes were covered by silicone caulking using a caulking gun to prevent any water leakage during casting. The caulk was carefully smoothed out with a wet finger. Prior to placing the reinforcement, all formwork was cleaned with compressed air to remove all dust and debris and were coated in form oil and allowed to dry. 


\subsubsection{Lay Out of FRP Reinforcement}

The quantity of reinforcement was selected to provide a reinforcement ratio of 0.57\%- 4.05\%. All GFRP reinforcement was supplied by Pultrall. The FRP reinforcement properties are shown in Table 3-2.

All reinforcing bars were supported on plastic rebar chairs at a clear cover of $20 \mathrm{~mm}$ from the bottom of the specimens. The rebars were supported at both ends on chairs and at about one meter along their length to avoid bending during the casting of the concrete. Chairs were placed in a zigzag manner along the widths of the specimen to avoid forming a plane of weakness across the beam width (Figure 3-12).

All bars were placed so that the face of the gauges was on the side of the bars. Half of the bars had the gauges face toward the left side of the specimen and the rest had the gauges face toward the right. For specimen MB15, since this specimen had two bars on top, four plywood supports were attached on top of the formwork then the two top bars were held to these timbers using U- threaded rod, couplers and washers. To avoid any floating of these two bars during casting the concrete, they were firmly tied to the two bottom bars in the formwork by two pairs of wire ties (Figure 3-13).

Lengths of $10 \mathrm{M}$ ribbed steel rebars were used as spacing rebars to prevent any side-to-side movement of the FRP bars to keep them in their desired arrangement in the specimens. These spacing bars were placed at both ends of the bars in the specimens with $2200 \mathrm{~mm}$ length, along the width of the specimens. For the other specimens with $2600 \mathrm{~mm}, 3600 \mathrm{~mm}$ and $4600 \mathrm{~mm}$ length, a spacing bar was also used at the middle of the specimen. All reinforcement was tied firmly to the spacing bars using rebar tie (Figure 3-14). 
Since FRP reinforcement is light compared to steel reinforcement, to prevent any movement or floating during the casting and vibrating of the concrete, the reinforcement grids were firmly tied to the bottom of the formwork. To accomplish this, holes were drilled on the bottom of the formwork then the reinforcement grids were tied to the bottom of the forms by threading metal ties through them. These holes were subsequently covered by caulking.

To permit lifting of the specimens $10 \mathrm{M}$ ribbed steel bars were shaped and used as hooks at each end of the formwork. For the longer specimens two pairs of hooks were used at each end. Hooks were fixed to the reinforcement. As a final step of preparing the formwork before casting, a strip of plywood was attached to the top of each formwork unit along the width of the formwork to tie the side faces and divider together. For the longer specimens two strips were used.

In each formwork, gauges were named by dividing reinforcing bars to the left and right side. For example for the specimen with six bars in it, the arrangement of the reinforcement is: 1Left, 2-Left and 3-Left and for the right side: 1-Right, 2-Right and 3-Right. A summary of all specimens' strain gauges with bar spacing is presented in Table 3-3. All right side and left side wires were wrapped and tied together and brought out of the formwork from the right and left side separately. Then all wires were covered in plastic bags and stacked beside the formwork to prevent damage during the casting (Figure 3-14). All formwork was vacuumed and then placed on plastic sheets to be ready for casting. 


\subsection{Concrete Properties}

All specimens were cast using ready-mix concrete donated by ESSROC in Ottawa. The concrete did not have air entrainment and had a maximum aggregate size of $10 \mathrm{~mm}$ and a target 28-day strength of $30 \mathrm{MPa}$. The concrete had a 3-day cylinder strength of $32 \mathrm{MPa}$ and at the end of testing, which was roughly 5 months after the casting day, it reached $52 \mathrm{MPa}$. Concrete had a slump of $100 \mathrm{~mm}$ (4"). The concrete strength was determined from testing $100 \times 200 \mathrm{~mm}$ cylinders as listed in Table 3-4.

\subsubsection{Concrete Casting and Curing}

Casting of all specimens was performed in a single morning and took 2 hours (Figures 3-15 to 3-18). A slump test was performed immediately after the truck arrived. The result was a two-inch slump. Since the desired slump was four inches, super-plasticizer was added to the mix and the concrete was mixed again in the truck to obtain the four inch slump. In a second slump test, the four inch slump was obtained and pouring of the concrete was then started immediately. Concrete was carried right on top of the formwork by crane and bucket then slowly poured in the formwork. Immediately after pouring, concrete was vibrated with an electrical vibrator to release the entrapped air and let concrete settle firmly in to place in the formwork to make a solid mix. Vibrating each part of the formwork was stopped once there were no more small bubbles of air releasing from the surface of the concrete. The surfaces of all specimens were floated using timber and trowelled smooth. At the same time, a total of eighteen concrete test cylinders were cast in three lifts using $100 \mathrm{~mm}$ by $200 \mathrm{~mm}$ plastic molds and each lift was tamped with a steel rod. 
In the afternoon of the casting day, all specimens and concrete cylinders were wetted and covered with wet burlap and 2 layers of plastic sheets. They were left to cure for one week at the temperature of the lab of about $22^{\circ} \mathrm{C}$. All specimens and cylinders were kept continuously moist during the curing period. After one week the burlap and plastic sheeting were removed.

The first cylinder test was done 3 days after casting. Two cylinders were tested at that day. Both cylinders were capped with melted sulphur powder on both ends. Cylinders were then stood up in the hydraulic loading machine. An arm of the machine pushed down on the top of the cylinder until the cylinder crushed. The loading rate used was $1 \mathrm{kN} / \mathrm{Sec}$. The amount of the load was recorded by a computer attached to the loading machine (Figure 3-19).

\subsubsection{Removing the Formwork and Painting the Specimens}

Nine days after casting, the end faces were stripped from the specimens and the steel wires tying the reinforcement to the bottoms of the forms were cut. All specimens were then lifted slowly by crane using the hook inside the specimen and removed from the formwork. All parts of each formwork unit were then reassembled, cleaned and put aside for the further research. Figure 3-20 shows this process.

After removing all specimens from the formwork it was noted that two specimens, the last two cast and vibrated on the casting day, had minor honeycombing of the concrete cover below the reinforcement (MB6 and MB7) (Figures 3-21, 3-22, 3-23 and 3-24). In order to fix these two specimens, a special repair cement product called Verticoat Supreme was used. Verticoat Supreme is a one-component, microsilica and latex modified non-sag repair mortar. 
The repair cement first was mixed with appropriate amounts of water and then mixed for 3 to 5 minutes to be as fluid as possible to fill the holes properly. Then the mix was poured into the holes and allowed to go down deeply inside the holes before the next pour and then the mix was trowelled into place and allowed to stiffen. The surface was then made even with a trowel without adding any additional water according to the instruction. Wet cure was done for three days.

Three weeks after casting, specimens started to be painted with white latex paint in order to more easily observe crack propagation on the surface while loading. Since the cracks are so narrow, in order to prevent crack bridging, the paint was diluted with water to decrease the thickness of the paint on the surface of the concrete. After the paint dried, gridlines were drawn on both sides of the beams. The gridlines permit the position of the cracks to be later identified using photos. Gridlines were drawn at $140 \mathrm{~mm}$ spacing vertically and horizontally. Therefore a $140 \mathrm{~mm}$ square matrix was drawn on each side of the specimen. The top and bottom surface of the reinforcing bars along the length of each specimen and the location of two simple supports were also marked on the sides of the specimens (Figure 3-25).

\subsection{Test Set Up Preparation}

This section presents the test set up preparation for the specimens. The instrumentations which were used for the test setup will be discussed. Loading arrangement will be presented at the end of this section and the figures of four specimens test setup will be shown. 


\subsubsection{Concrete Strain Gauge}

In order to record the concrete compression strain during the loading, a $60 \mathrm{~mm}$ strain gauge was installed on one side of each specimen. The concrete gauge was attached at the mid-span of the specimens, $10 \mathrm{~mm}$ from the top surface. This distance was used to avoid damage to the gauge during the loading since the specimens were loaded at the mid span of the specimen.

To attach the strain gauge on the surface of the concrete the paint was first removed using the dynafile air abrasive belt machine. Compressed air was then used to remove all dust and debris to have a clean surface to install the gauge. Since the concrete always has some small bug holes on the surface, to make a smooth surface to install the gauge, the holes were filled by an epoxy resin. After letting the epoxy dry, the dynafile was again used to remove a very thin layer of the dried epoxy resin. The procedure of installing the $60 \mathrm{~mm}$ concrete gauge was the same as the strain gauges on the FRP reinforcement which is described in Part 3.2.2. The conductivity of all gauges was then checked with the switch-and-balance unit. Figure 3-26 shows this process.

\subsubsection{Linear-Variable Displacement Transducers (LVDTs)}

In order to measure shear strains in the specimens, Linear-Variable Displacement Transducers (LVDTs) were installed on the side faces of the beams. The diameters and locations of the side-face LVDTs are shown in Figure 3-27.

For specimens with $\mathrm{a} / \mathrm{d}=2,3$ and 4 , a set of four LVDTs were installed at each quarter-span. For specimens with $\mathrm{a} / \mathrm{d}=6$ and 8 , additional sets of two diagonal LVDTs were installed at a/4 
from the support and a/4 from the load. These LVDTs were installed on both spans, but on one side only.

Since the length of the LVDTs was longer than the height of the specimens, to let them move properly during the test, two steel brackets were made and installed on the beam then LVDTs were mounted on the bracket. To attach the brackets, beams were drilled in the proper location. Compressed air was then used to clean all holes before screwing the brackets to let the brackets sit properly on the beam. However, for each specimen, considering the location of the FRP gauges, drilling was performed to avoid damaging the FRP gauges. Hence, the length of the LVDT for each specimen could be different as outlined in Figure 3-27. Conductivity of all FRP strain gauges then was checked to insure that there was no damage on the gauges after drilling the beams.

In order to measure vertical displacements of the specimens during loading, three or five pairs of LVDTs were placed below the specimens. For specimens with $a / d=2,3$ and 4 , three pairs of LVDTs were placed below the specimen: at mid-span and the locations of the supports. For specimens with $\mathrm{a} / \mathrm{d}=6$ and 8 , five pairs of LVDTs were placed below the specimens: at mid-span, quarter-span and the locations of the supports. An overall view of the LVDTs' arrangement with the specific details is shown in Figure 3-28.

\subsubsection{Demountable Mechanical Gauges (Demec Gauges)}

Demountable mechanical gauges (demec gauges) were used to measure the concrete strains at the location of reinforcing bars in order to compare with the strains at the rebars (Figure 3-29). Demec consists of a dial gauge attached to an Invar main bar with two conical 
locating points; one fixed conical point mounted at one end of the bar and the moving conical point pivoting on a knife edge at the opposite end. The pivoting movement of this moving conical point is measured by the dial gauge.

Epoxy glue was used to mount the demec points (pre-drilled stainless steel discs) on the specimens at every $50 \mathrm{~mm}$ at the center location of the rebars. Demec points were then allowed to dry for a couple of hours. In every load stage, a reading (movement of the pivoting point which was measured by the strain gauge) had to be taken. That is, the conical points of the gauge were inserted into the holes in the discs and the reading on the dial gauge was recorded. So that, strain changes in the specimens were converted into a change in the reading on the dial gauge.

An invar reference bar was used to control measurements and a setting out bar was used to enable accurate positioning of locating the discs while attaching in the surface of the specimens.

\subsubsection{Loading Arrangement}

All specimens except for specimen MB15 were loaded to failure in three-point bending. Specimen MB15 was designed to have double curvature with four-point bending. All specimens were supported and loaded on $75 \mathrm{~mm}$ by $400 \mathrm{~mm}$ steel plates on steel rollers. The rollers in turn were supported on steel beams directly on the strong floor of the laboratory. All components of the roller supports were separated completely before loading and after cleaning and removing all rust from the metal, they were assembled back together. Between the bearing plates and the specimens, thin plaster layers using hydro-stone mixed 
with water (about $5 \mathrm{~mm}$ thick) were used to provide a smooth surface to load or react against. In order to have a double curvature for specimen MB15, two \#6 bars were used on the top of the beam with the reinforcement ratio of $\rho=0.57 \%$, similar to the bottom bars, and a spreader beam was used to spread the machine load to two points load at the top of the beam. For this purpose, a steel roller was used at each location of the point load. The jack was located at the geometry center of the beam on top of spreader beam. By this way, spreader beam could spread the load from the jack to those steel rollers as a point load. Each specimen was tested with the goal of failing both sides: an original test and a repeat test. Therefore, six pairs of steel bandages were also fabricated in order to clamp the broken side of each specimen to obtain the result from the repeat side.

Loading was applied monotonically by a $500 \mathrm{kN}$ capacity testing machine. A hydraulic load jack was attached to the center and top of the steel frame set up. The two supports of the steel frame set up were attached to the floor of the laboratory by thick threaded rods. All rods were cleaned. The efficiency and performance of the jack was checked accurately. Loading was applied through a metal rectangular piston and the load from the piston was applied to the specimens through a stiff spreader beam supported on a $75 \mathrm{~mm}$ by $400 \mathrm{~mm}$ steel plate, and prior to loading this plate also was embedded in a thin layer of plaster to eliminate stress concentrations between the piston and the top of the specimens. The jack load cell way then attached to a computer to capture the load data by a data acquisition system. The load rate of the jack for most specimens was $0.02 \mathrm{~mm} / \mathrm{sec}$ for the first part and $0.05 \mathrm{~mm} / \mathrm{sec}$ for the repeated part, representing the speed of the movement of the piston head on top of the specimens at the location of the load. Every time the program cycled through once, the machine moved the piston head and then recorded the readings on all the gauges. 
Each specimen was named based on the loading date, for example, MB1 refers to the first specimen that was tested. Prior to loading, all LVDTs and strain gauges were connected to the computer using extension cables. All cables and channels then were named and labeled. LVDTs then were set to zero displacement, and the first reading of the demec points was done at the load of zero. The reading, and each subsequent reading, was performed two times for accuracy. During the test, loading was periodically halted for a load stage. The first load stage for the first failure side of the specimens was obtained upon observing the first cracks. At each load stage the load was reduced approximately by $10 \%$ of the present load for safety. During these load stages all cracks were marked and photographed. The crack widths were measured using a handle-held graduated magnifying scope and labeled on the beam, and dial gauge readings (demec gauges) were obtained two times for accuracy. Sufficient photos were taken at each load stage to observe the crack patterns at each side of the specimens. The loading process was recorded by a video camera. All loading strain gauges and LVDTs' data were captured by the computer. These processes were performed until failure happened.

After failure of one side of the beam, the beam was completely unloaded. All LVDTs then were checked and the rollers parts of the supports were cleaned from the dust and concrete pieces to allow them move properly during the repeated side loading. The broken side was then clamped by pairs of steel bandages. Before loading, demec dial gauge reading from the unbroken side of the beam were obtained. Then on the same day of the first side failure or on a different day, specimens were reloaded. The first load stage for each repeated specimen was obtained at about the same failure load of the first test. Crack widths and dial gauge readings were obtained at this load stage. Specimens were loaded either until the failure of the repeated side happened or another load stage was obtained before failure happened. 
Figures 3-30, 3-31, 3-32, 3-33 and 3-35 show an overall view of the test set up for the three specimens for the first failure part and the repeated failure side of these specimens. 
Table 3-1: Summary of 15 One-way Slab Specimens

\begin{tabular}{|l|c|c|c|c|c|c|c|c|c|c|}
\hline $\begin{array}{c}\text { Specimen } \\
\text { Name }\end{array}$ & $\begin{array}{c}\mathbf{L} \\
(\mathbf{m})\end{array}$ & $\begin{array}{c}\mathbf{b}_{\mathbf{w}} \\
(\mathbf{m m})\end{array}$ & $\begin{array}{c}\mathbf{h} \\
(\mathbf{m m})\end{array}$ & $\begin{array}{c}\mathbf{d} \\
(\mathbf{m m})\end{array}$ & $\begin{array}{c}\text { No. of } \\
\text { Rebar }\end{array}$ & $\begin{array}{c}\mathbf{A}_{\mathbf{F R P}} \\
\left(\mathbf{m m}^{2}\right)\end{array}$ & $\begin{array}{c}\rho=\mathbf{A}_{\mathbf{F R P}} / \mathbf{b}_{\mathbf{w}} \mathbf{d} \\
(\mathbf{\%})\end{array}$ & $\begin{array}{c}\mathbf{a} \\
(\mathbf{m m})\end{array}$ & $\mathbf{a} / \mathbf{d}$ & $(\mathbf{a} / \mathbf{d}) / \rho$ \\
\hline MB-8 & 3.0 & 400 & 280 & 250 & $2 \# 6$ & 570 & 0.57 & 500 & 2 & 351 \\
MB-9 & 2.2 & 400 & 280 & 250 & $4 \# 6$ & 1140 & 1.14 & 500 & 2 & 175 \\
MB-10 & 2.2 & 400 & 280 & 250 & $8 \# 6$ & 2280 & 2.28 & 500 & 2 & 88 \\
\hline
\end{tabular}

\begin{tabular}{|l|cccccccccc|}
\hline MB-7 & 2.2 & 400 & 280 & 250 & $8 \# 8$ & 4054 & 4.05 & 750 & 3 & 74 \\
MB-14 & 4.6 & 400 & 280 & 250 & $8 \# 8$ & 4054 & 4.05 & 2000 & 8 & 197 \\
\hline
\end{tabular}

\begin{tabular}{|c|c|c|c|c|c|c|c|c|c|c|}
\hline MB-3 & 2.2 & 400 & 280 & 250 & $2 \# 6$ & 570 & 0.57 & 750 & 3 & 526 \\
\hline MB-1 & 2.2 & 400 & 280 & 250 & $3 \# 6$ & 855 & 0.86 & 750 & 3 & 351 \\
\hline MB-4 & 2.2 & 400 & 280 & 250 & 4 \# 6 & 1140 & 1.14 & 750 & 3 & 263 \\
\hline MB-5 & 2.2 & 400 & 280 & 250 & $6 \# 6$ & 1710 & 1.71 & 750 & 3 & 175 \\
\hline MB-6 & 2.2 & 400 & 280 & 250 & $8 \# 6$ & 2280 & 2.28 & 750 & 3 & 132 \\
\hline MB-15 & 2.2 & 400 & 280 & 250 & $2 \# 6$ & 570 & 0.57 & 500 & 2 & 351 \\
\hline MB-2 & 2.2 & 400 & 280 & 250 & $3 \# 6$ & 855 & 0.86 & 750 & 3 & 351 \\
\hline MB-11 & 2.6 & 400 & 280 & 250 & 4 \# 6 & 1140 & 1.14 & 1000 & 4 & 351 \\
\hline MB-12 & 3.6 & 400 & 280 & 250 & $6 \# 6$ & 1710 & 1.71 & 1500 & 6 & 351 \\
\hline MB-13 & 4.6 & 400 & 280 & 250 & $8 \# 6$ & 2280 & 2.28 & 2000 & 8 & 351 \\
\hline
\end{tabular}

Table 3-2: Summary of GFRP Reinforcements Properties

\begin{tabular}{|l|c|c|c|}
\hline \multicolumn{2}{|c|}{ PULTRULL - V.ROD } & \#6 GFRP & \#8 GFRP \\
\hline Nominal Cross- sectional Area & (mm) $^{\mathbf{2}}$ & 285 & 507 \\
Nominal Diameter & $\mathbf{m m}$ & 19.05 & 25.4 \\
Nominal Tensile Strength & $\mathrm{MPa}$ & 728 & 675 \\
Nominal Tensile Modulus & $\mathrm{GPa}$ & 47.5 & 51.9 \\
Tensile Strain & $\%$ & 1.53 & 1.30 \\
Poission's Ratio & $\mathbf{( - )}$ & 0.25 & 0.28 \\
Nominal Compressive Strength & $\mathrm{MPa}$ & 519 & 339 \\
Nominal Flexural Strength & $\mathrm{MPa}$ & 882 & 776 \\
Flexural Strain & $\%$ & 1.96 & 1.72 \\
Nominal Shear Strength & $\mathrm{MPa}$ & 200 & 203 \\
Nominal Bond Strength & $\mathrm{MPa}$ & 16.7 & 14.8 \\
Moisture Absorption & \% & 0.21 & 0.17 \\
\hline
\end{tabular}


Table 3-3: Summary of Strain Gauges Arrangement

\begin{tabular}{|l|c|c|c|}
\hline $\begin{array}{l}\text { Specimen } \\
\text { Name }\end{array}$ & $\begin{array}{c}\text { No. of } \\
\text { Rebar }\end{array}$ & Gauge Arrangement & Gauge Name \\
\hline MB-8 & $2 \# 6$ & 2 gauges @ mid span & 1-Left/ 1-Right \\
MB-9 & $4 \# 6$ & 2 gauges @ mid span & 1-Left/ 1-Right \\
MB-10 & $8 \# 6$ & 2 gauges @ mid span & 2-Left/ 2-Right \\
\hline
\end{tabular}

\begin{tabular}{|l|ccc|}
\hline MB-7 & $8 \# 8$ & $\begin{array}{l}\text { 8 gauges @ mid span } \\
\text { 4 gauges @ mid shear-span }\end{array}$ & $\begin{array}{c}\text { 1, 2, 3, 4-Left/ 1, 2, 3, 4-Right } \\
\text { 3-Left/ 3-Right }\end{array}$ \\
MB-14 & $8 \# 8$ & $\begin{array}{l}\text { 8 gauges @ mid span } \\
\text { 4 gauges @ mid shear span }\end{array}$ & $\begin{array}{c}\text { 1, 2, 3, 4-Left/ 1, 2, 3, 4-Right } \\
\text { 3-Left/ 3-Right }\end{array}$ \\
\hline
\end{tabular}

\begin{tabular}{|l|ccc|}
\hline MB-3 & 2\# 6 & 2 gauges @ mid span & 1-Left/ 1-Right \\
MB-1 & 3\#6 & 3 gauges @ mid span & 1-Left/ 1, 2-Right \\
MB-4 & 4\#6 & 4 gauges @ mid span & 1, 2-Left/ 1, 2-Right \\
MB-5 & $6 \# 6$ & 6 gauges @ mid span & 1, 2, 3-Left/ 1, 2, 3-Right \\
& & $\begin{array}{l}\text { 8 gauges @ mid span } \\
\text { 4 gauges @ mid shear-span }\end{array}$ & $\begin{array}{c}\text { 1, 2, 3, 4-Left/ 1, 2, 3, 4-Right } \\
\text { 3-Left/ 3-Right }\end{array}$ \\
\hline
\end{tabular}

\begin{tabular}{|l|ccc|}
\hline MB-15 & $2 \# 6$ & 4 gauges @ mid span & $\begin{array}{c}\text { 1-Left-Top/ 1-Right-Top } \\
\text { 1-Left-Bott/ 1-Right-Bott }\end{array}$ \\
MB-2 & $3 \# 6$ & $\begin{array}{l}\text { 3 gauges @ mid span } \\
\text { 4 gauges @ mid shear-span }\end{array}$ & $\begin{array}{c}\text { 1, 2-Left/ 1-Right } \\
\text { 1-Left/ 1-Right }\end{array}$ \\
MB-11 & $4 \# 6$ & 4 gauges @ mid span & 1, 2-Left/ 1, 2-Right \\
MB-12 & $6 \# 6$ & 6 gauges @ mid span & 1, 2, 3-Left/ 1, 2, 3-Right \\
& & 8 gauges @ mid span & 1, 2, 3, 4-Left/ 1, 2, 3, 4-Right \\
MB-13 & $8 \# 6$ & 4 gauges @ mid shear-span & 3-Left/ 3-Right \\
\hline
\end{tabular}


Table 3-4: Concrete Strength Determined From Cylinder Test

\begin{tabular}{|c|c|c|}
\hline \multicolumn{3}{|c|}{ Cylinder Test Result } \\
\hline Date & $\begin{array}{c}\text { Concrete } \\
\text { Age (day) }\end{array}$ & $\mathbf{f}^{\prime}$ (MPa) \\
\hline 1-Feb-2010 & 5 & 32.0 \\
4-May-2010 & 97 & 49.6 \\
11-May-2010 & 104 & 51.4 \\
20-May-2010 & 113 & 44.0 \\
27-May-2010 & 120 & 51.6 \\
7-Jun-2010 & 131 & 50.0 \\
22-Jun-2010 & 146 & 47.7 \\
28-Jun-2010 & 152 & 48.0 \\
23-Jul-2010 & 177 & 47.0 \\
\hline
\end{tabular}



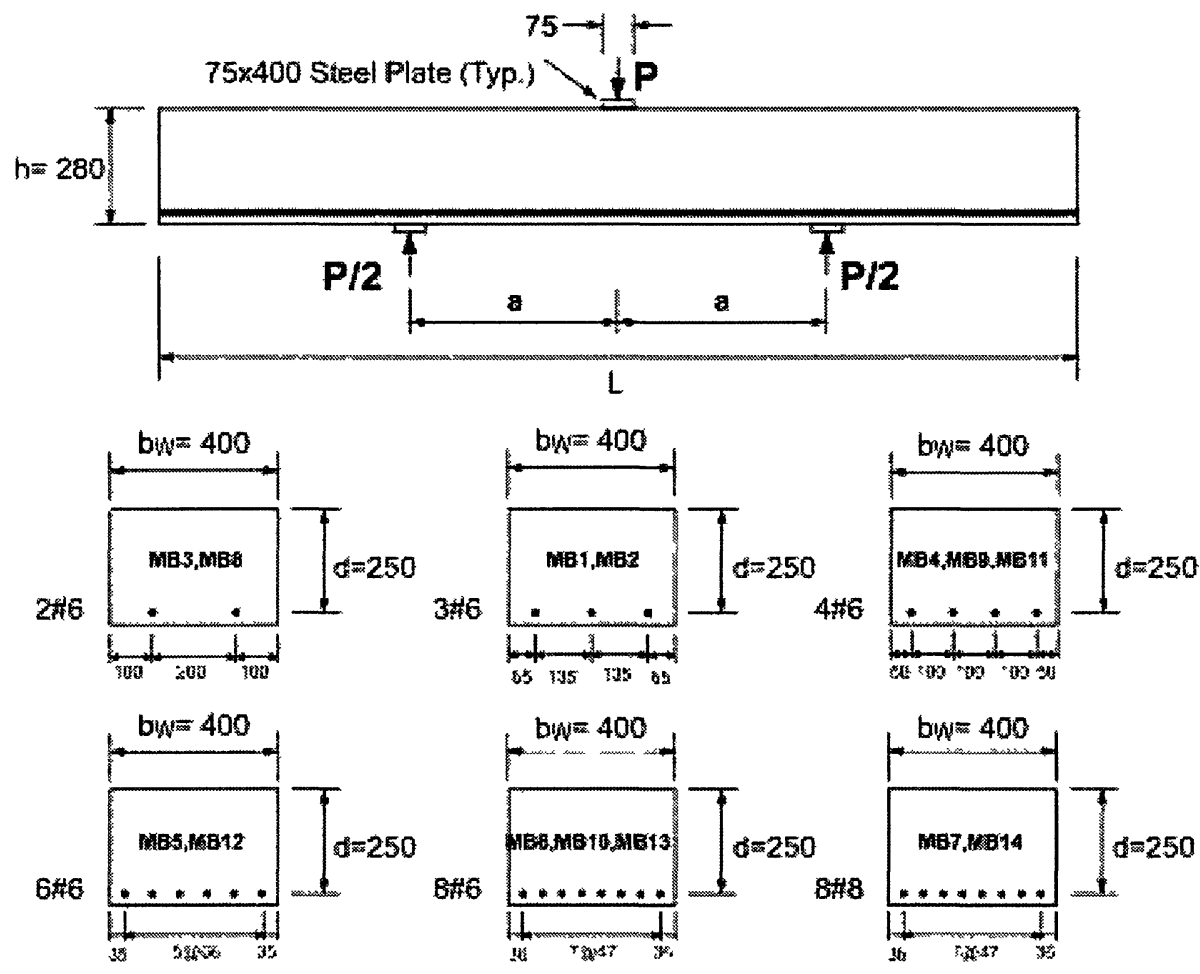

Beam Specimen Configuration, MB1=MB14

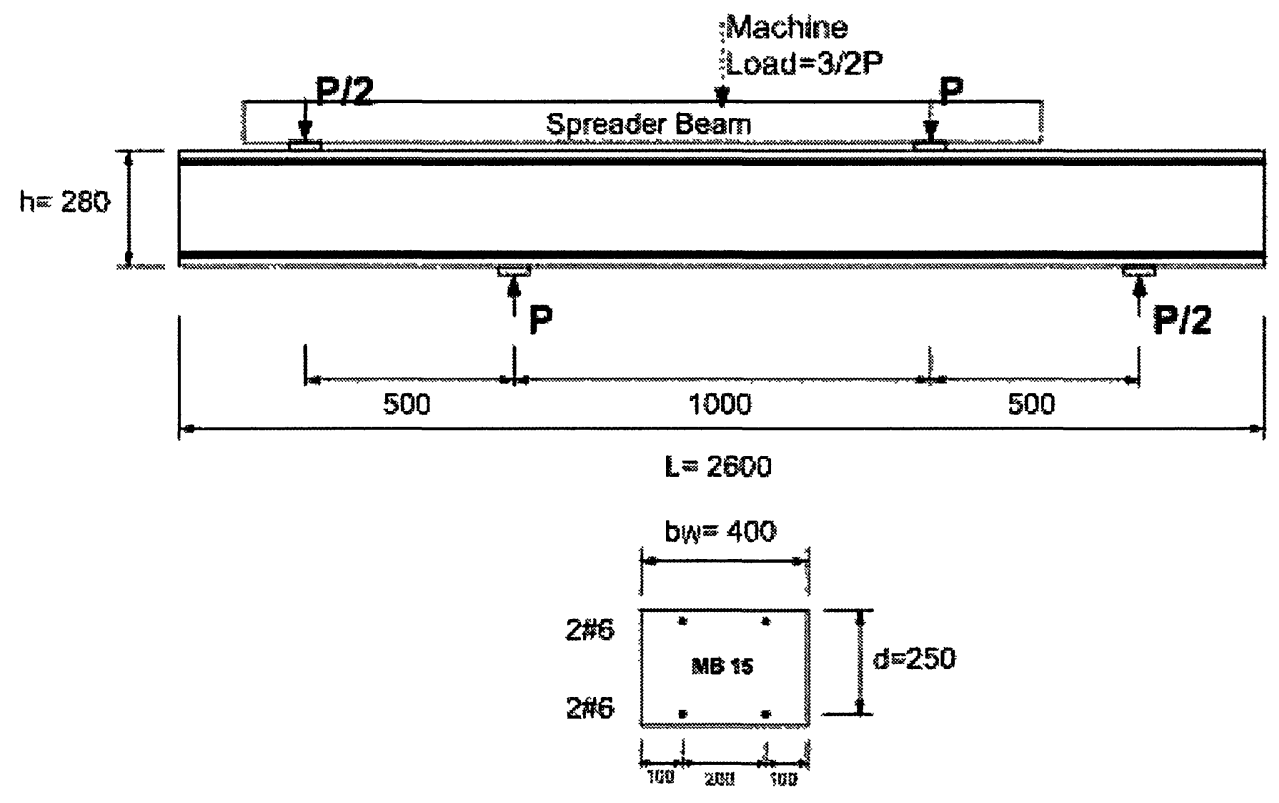

Beam Specimen Configuration, MB 15

All Dimensions in $\mathrm{mm}$

Figure 3-1: Beam Specimen Configuration 

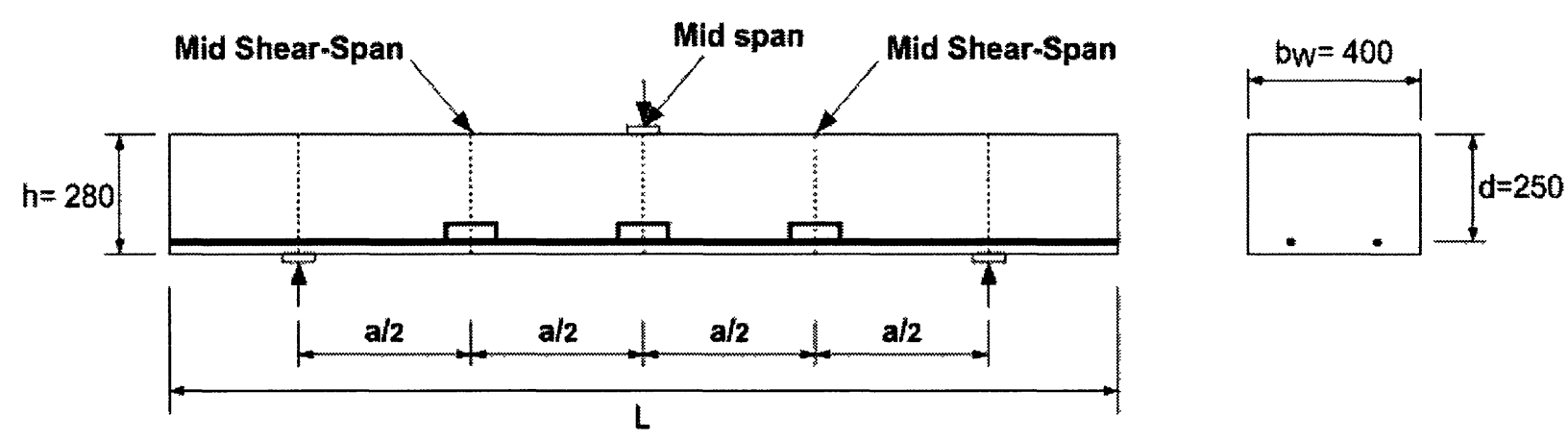

Side view

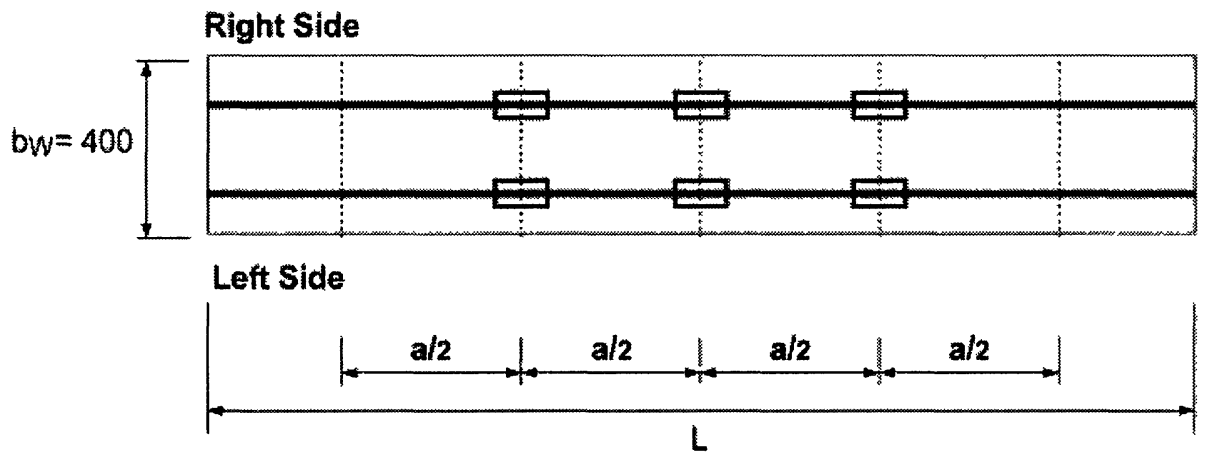

Top view

All Dimensions in mm

Figure 3-2: Strain Gauge Instrumentation Locations 


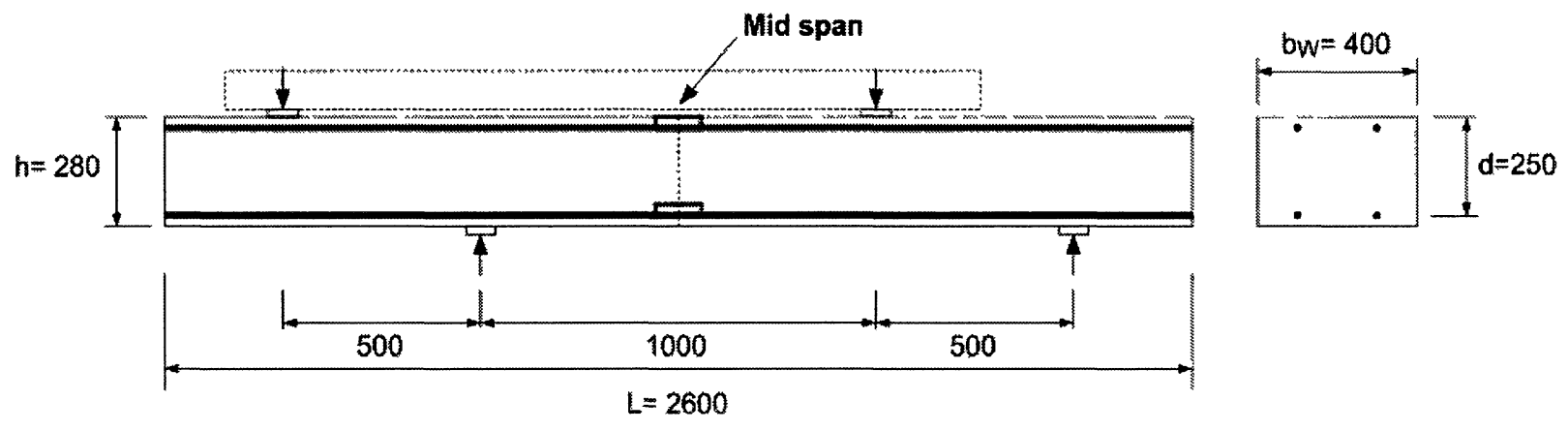

Side view

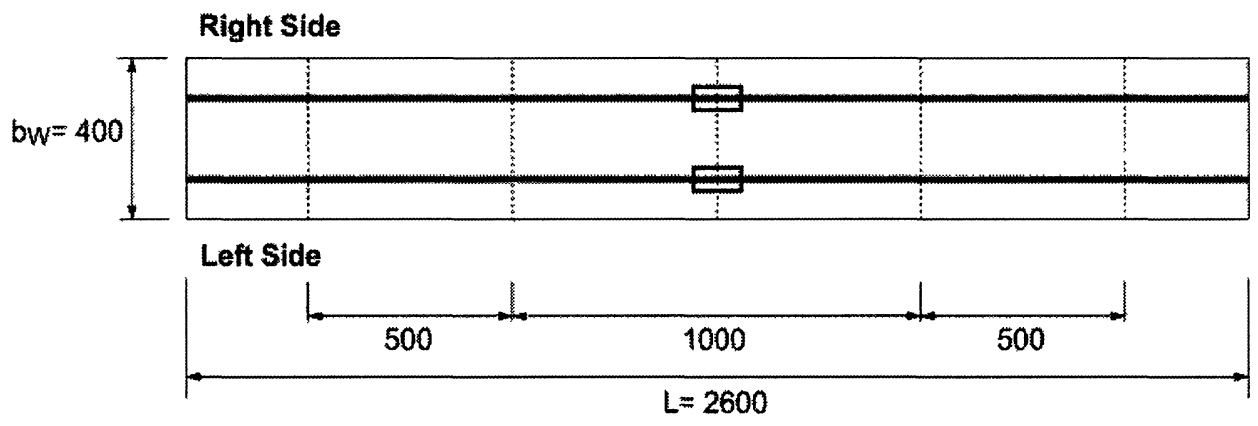

Top view

MB 15

Figure 3-3: Strain Gauge Instrumentation Locations for MB15 


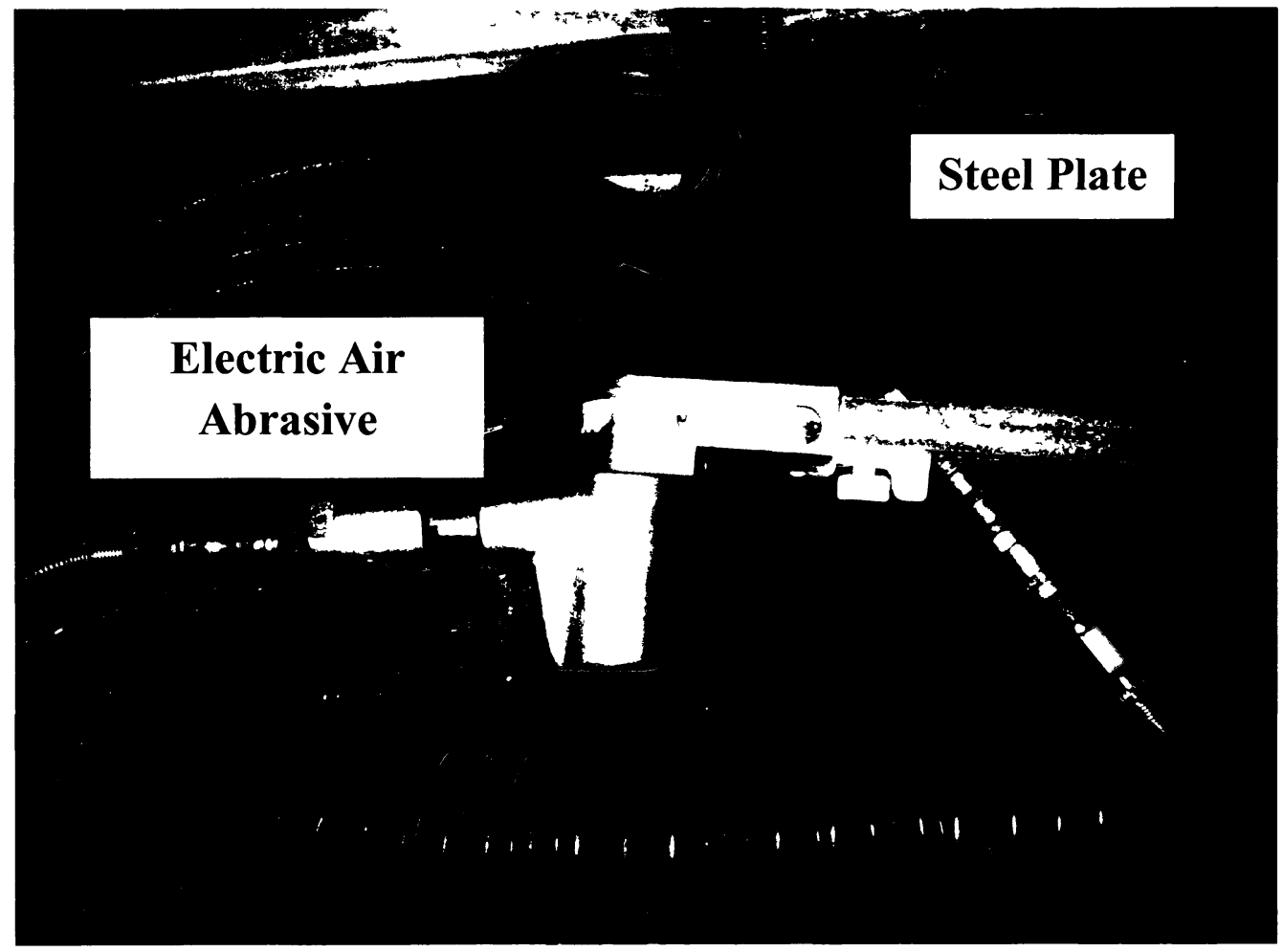

Figure 3-4: Instruments to Sand off the FRP Surface

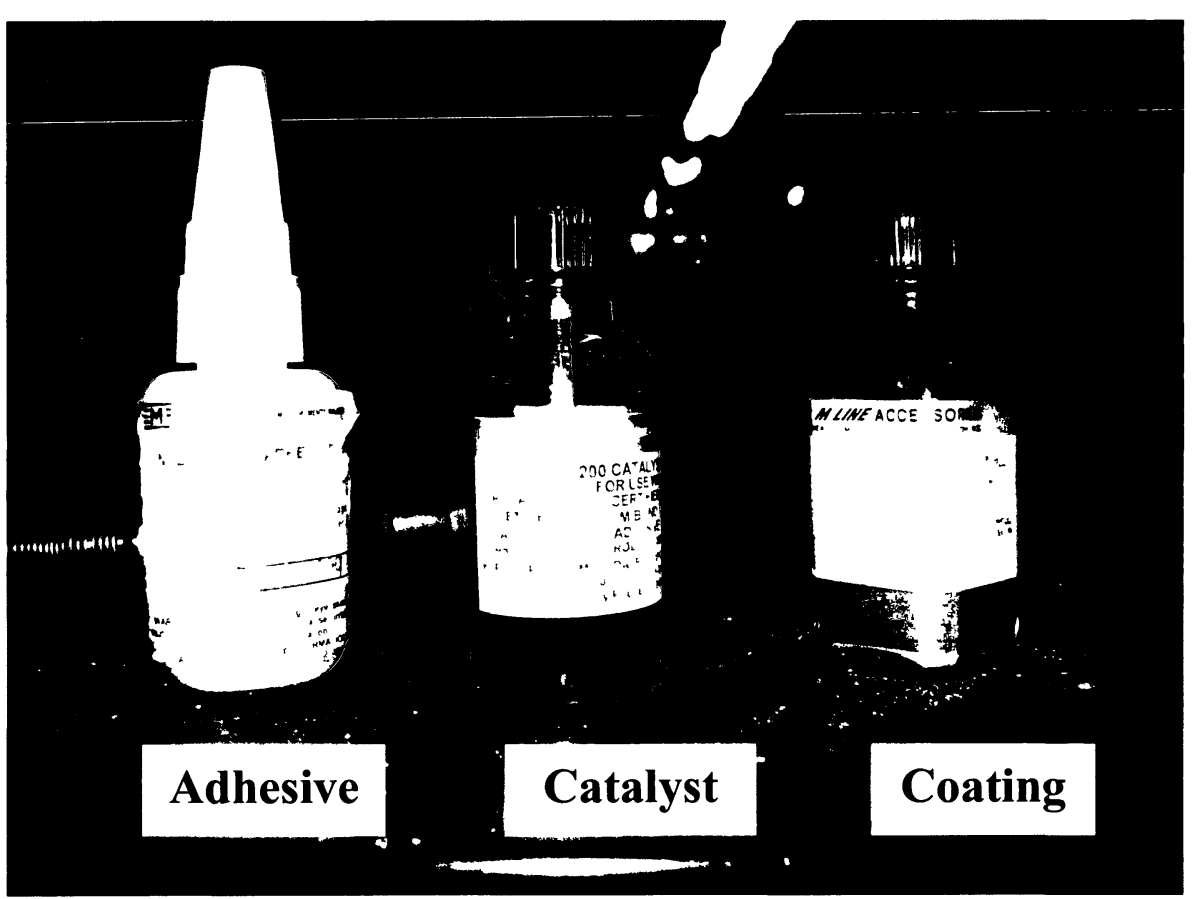

Figure 3-5: M-Bond 200 Adhesive, Catalyst and Coating 

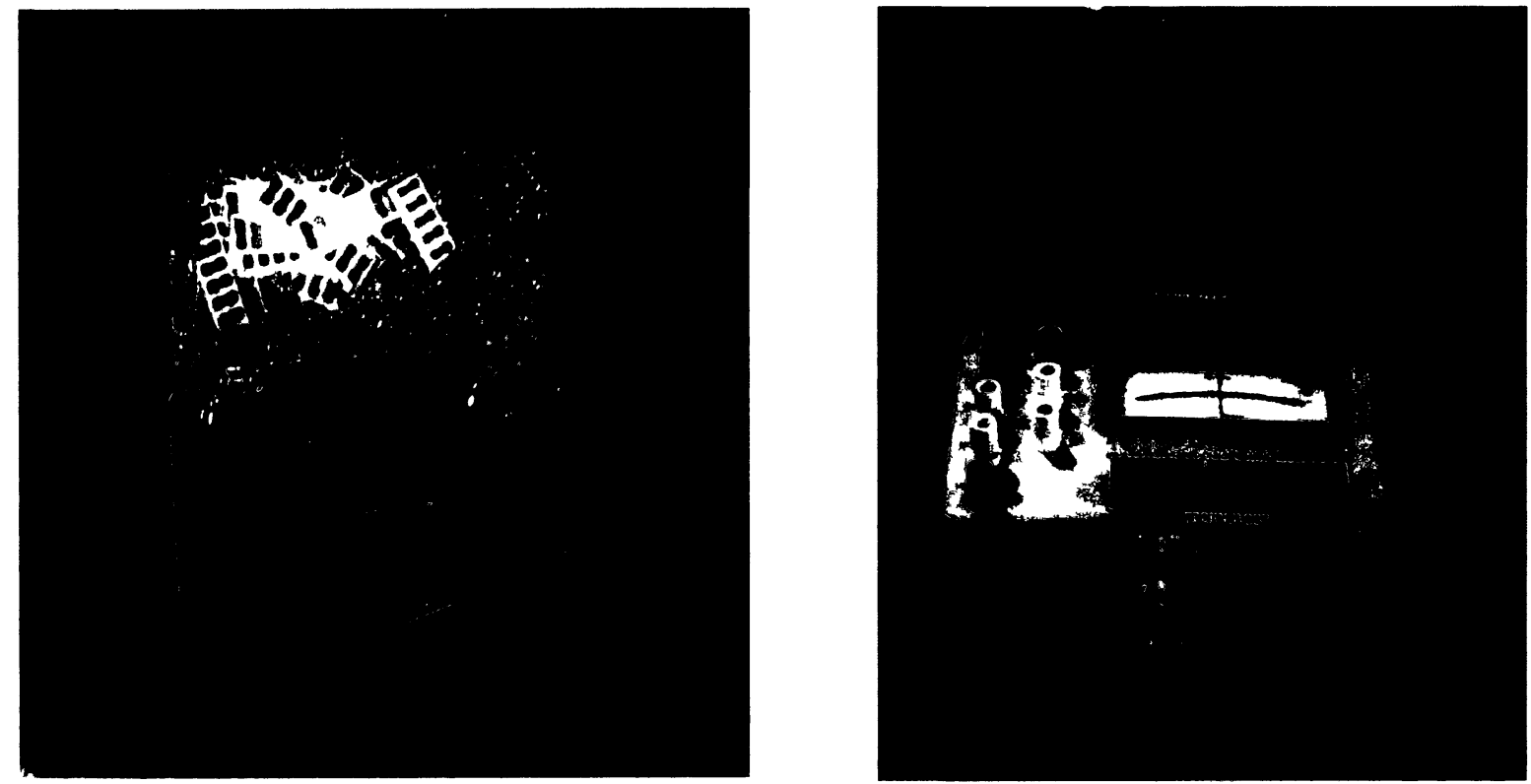

Figure 3-6: FRP Strain Gauge, Soldering Terminal and Switch and Balance Unit

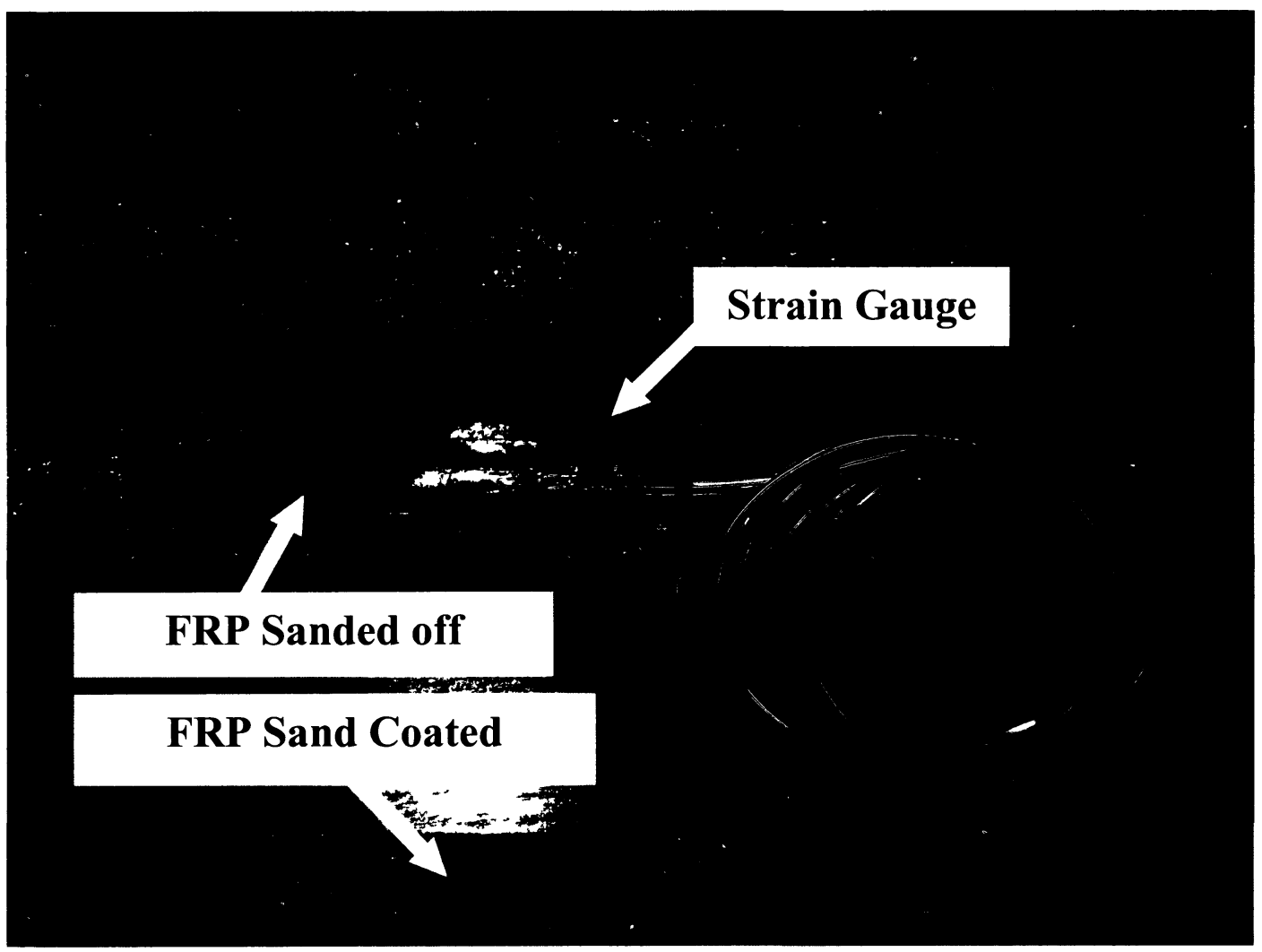

Figure 3-7: FRP Strain Gauge Installation 


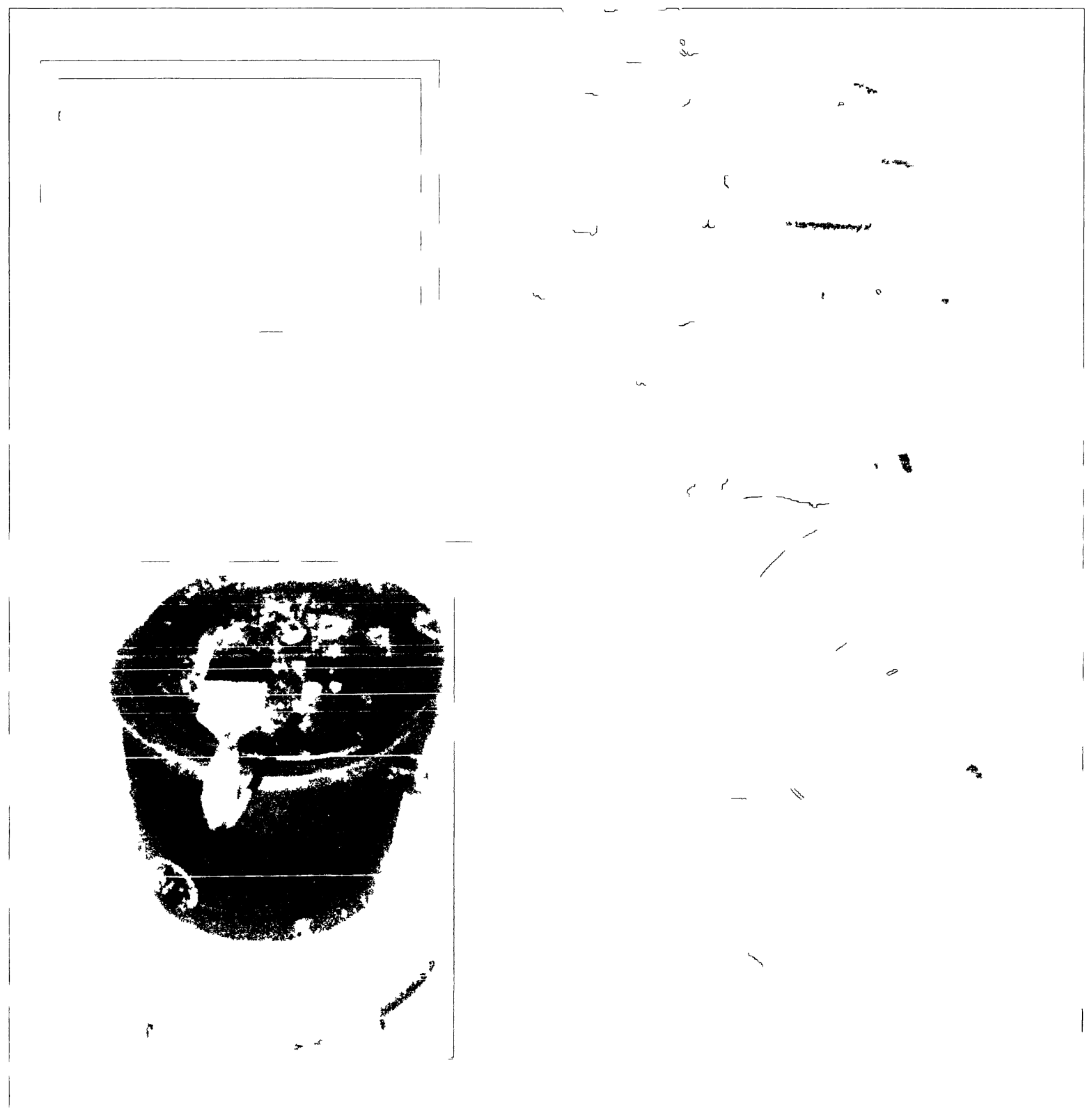

Figune 3-\$: Ganges Coated with Wax amd Covered with Tape 


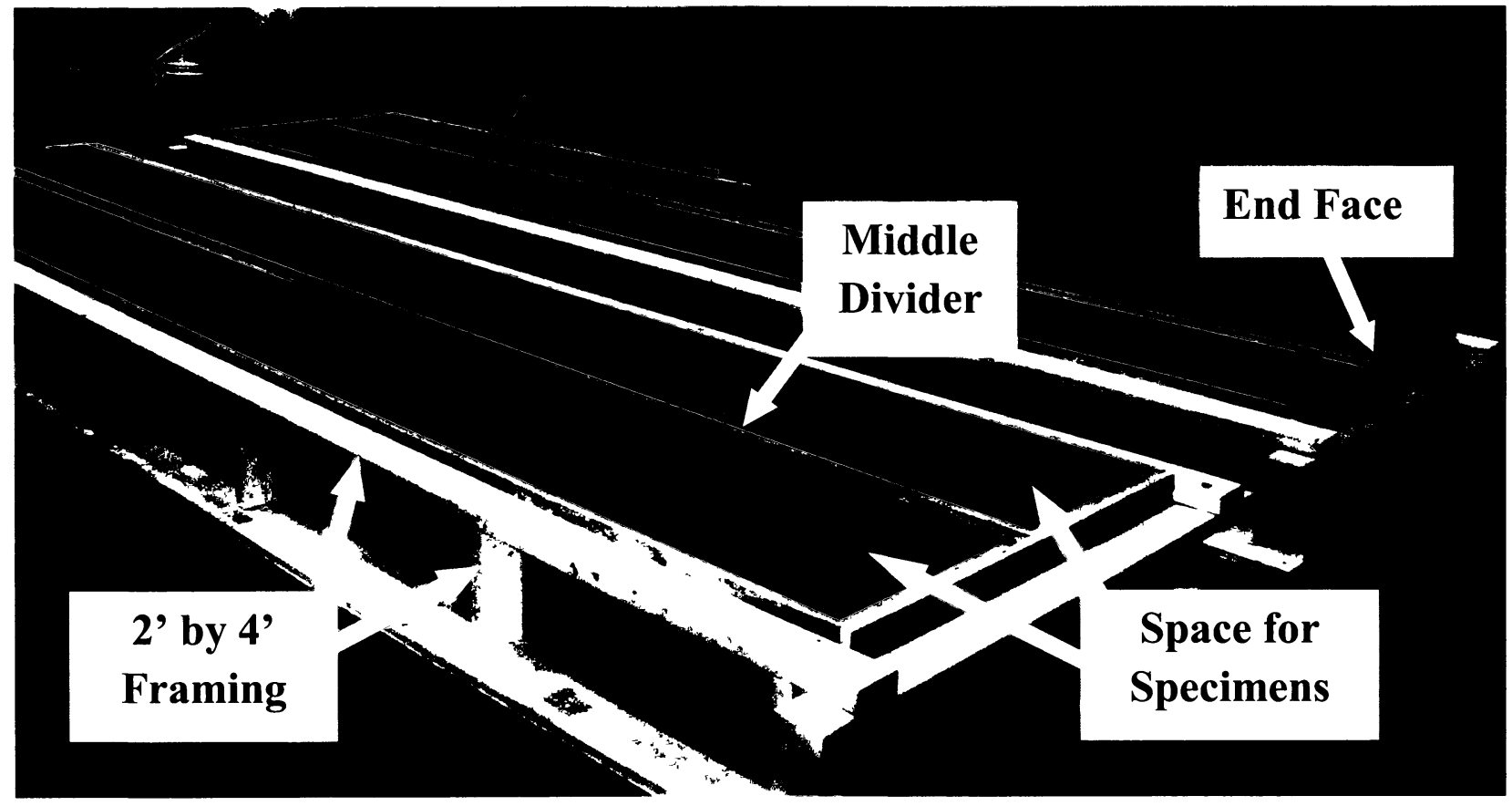

Figure 3-9: Overall View of the Formwork

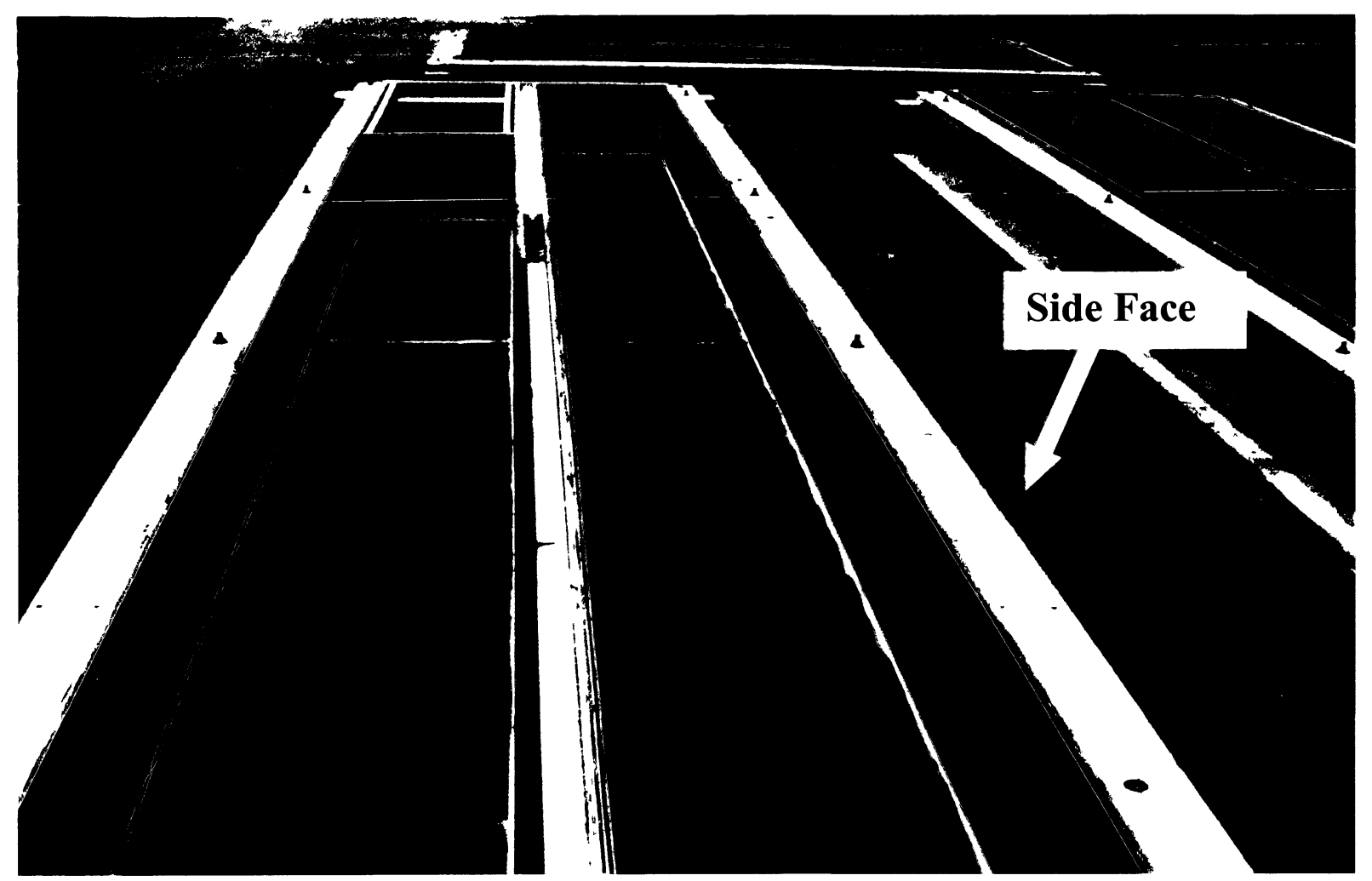

Figure 3-10: Final Formwork View after Oiling 

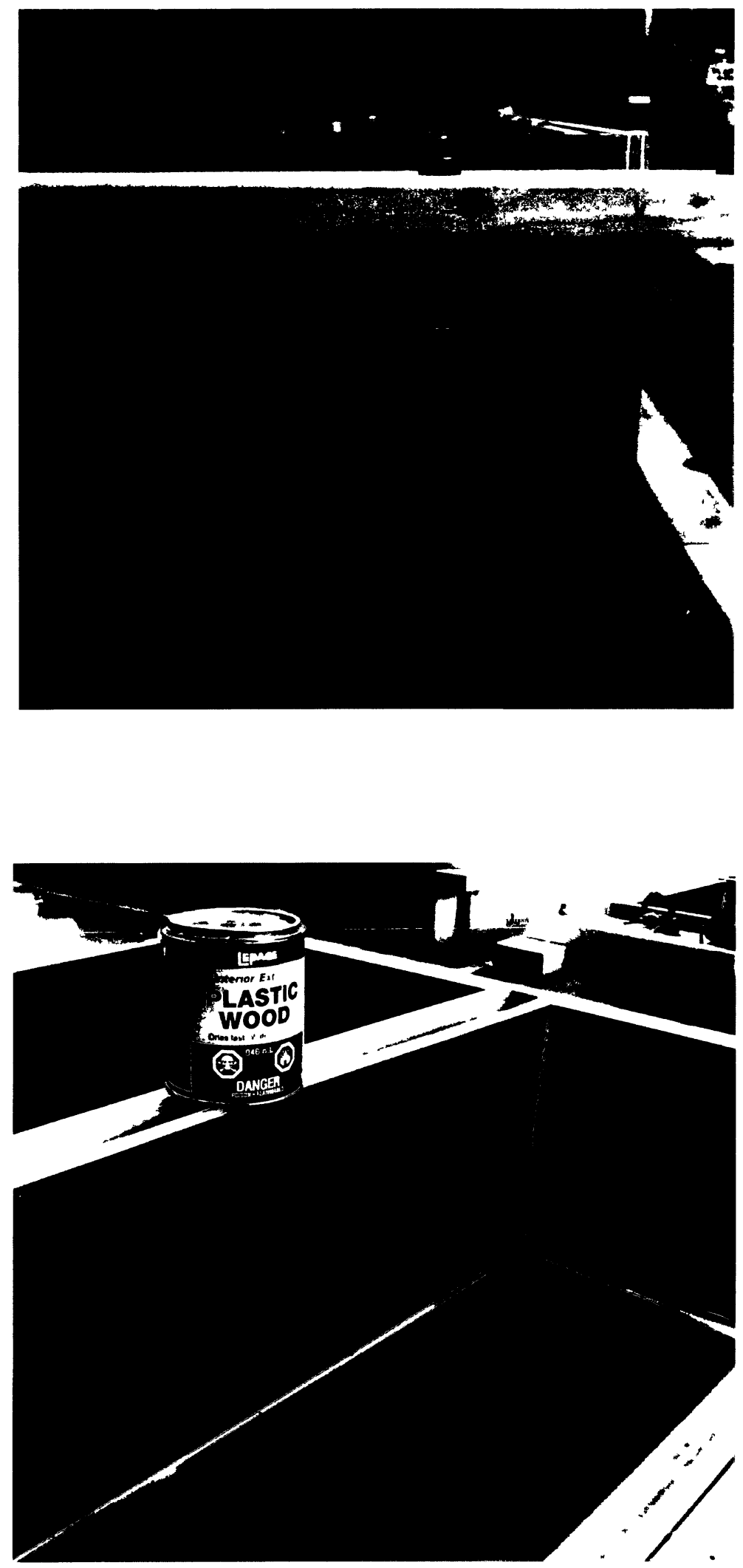

Figure 3-11: 3/8" Bolt, Plastic Wood and Caulking 


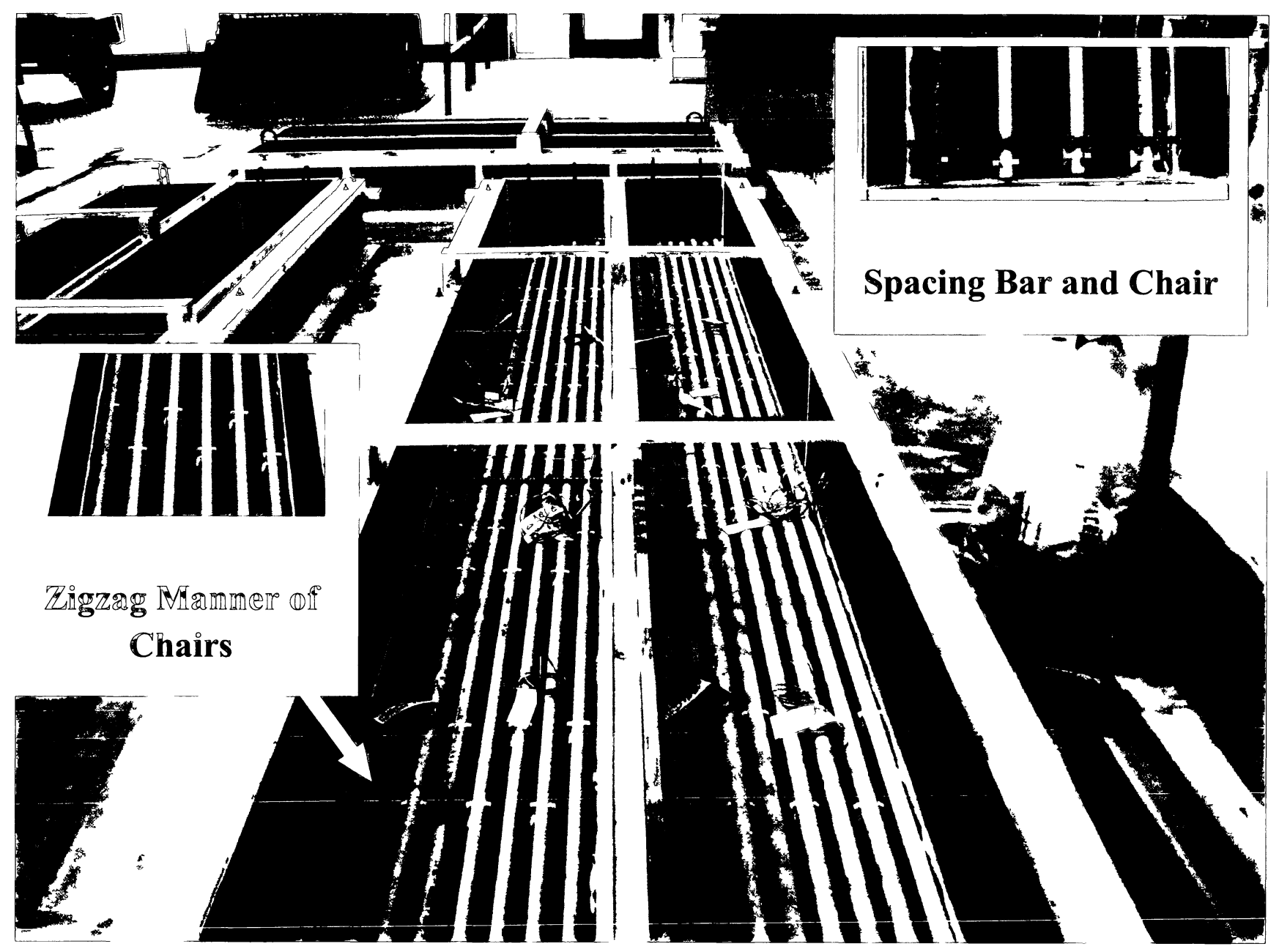

Figure 3-12: Final View of the Formwork 

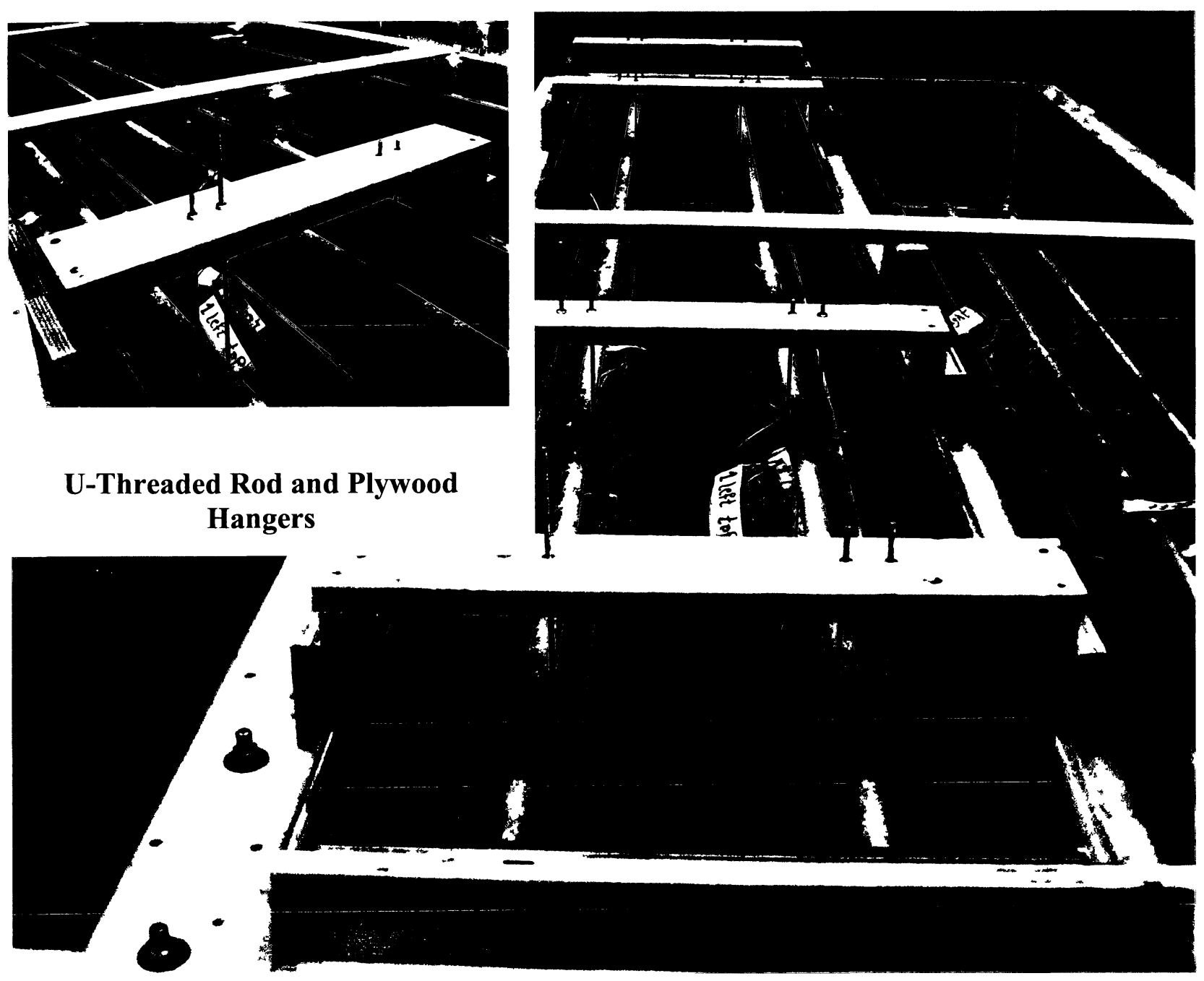

Figure 3-13: Formwork of MB15 


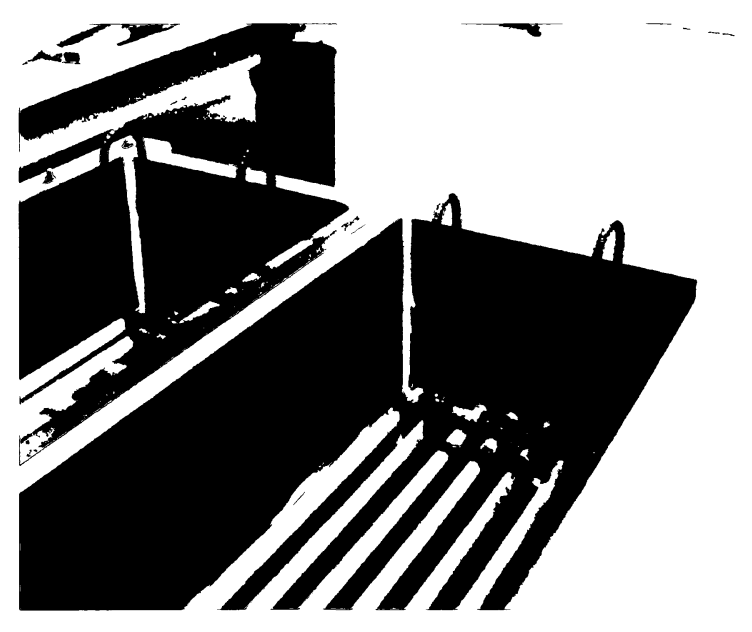

Hook

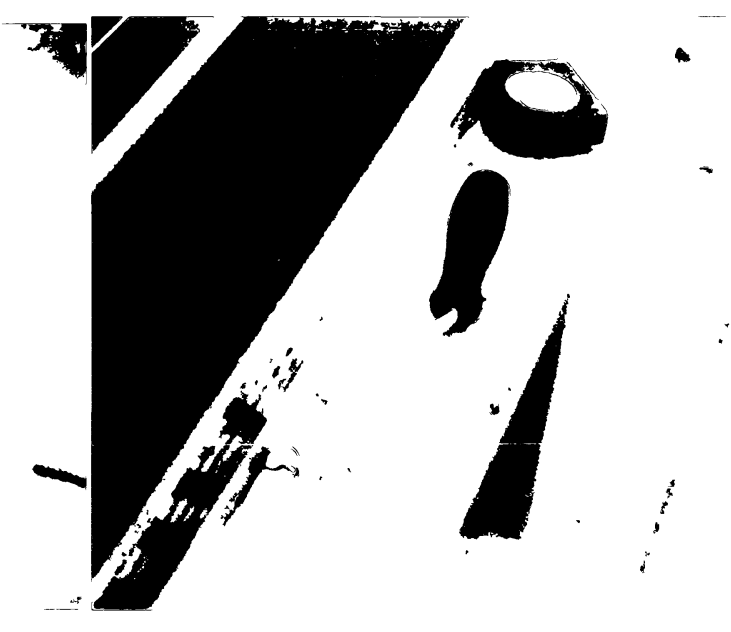

Rebar Tie wire
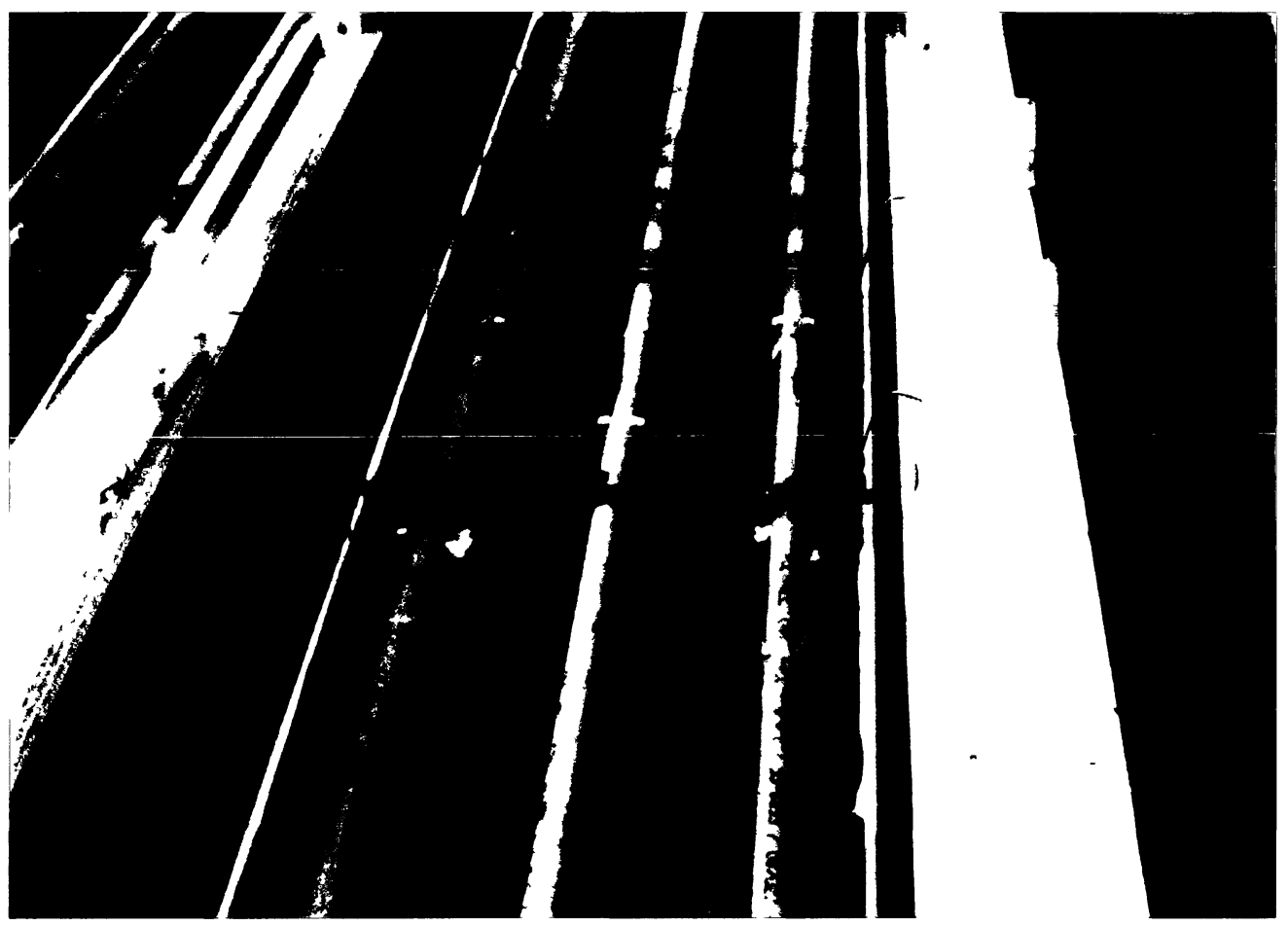

Strain Gauges Covered in Plastic Bags and 10 M Spacing Bars

Figure 3-14: Formwork Details 


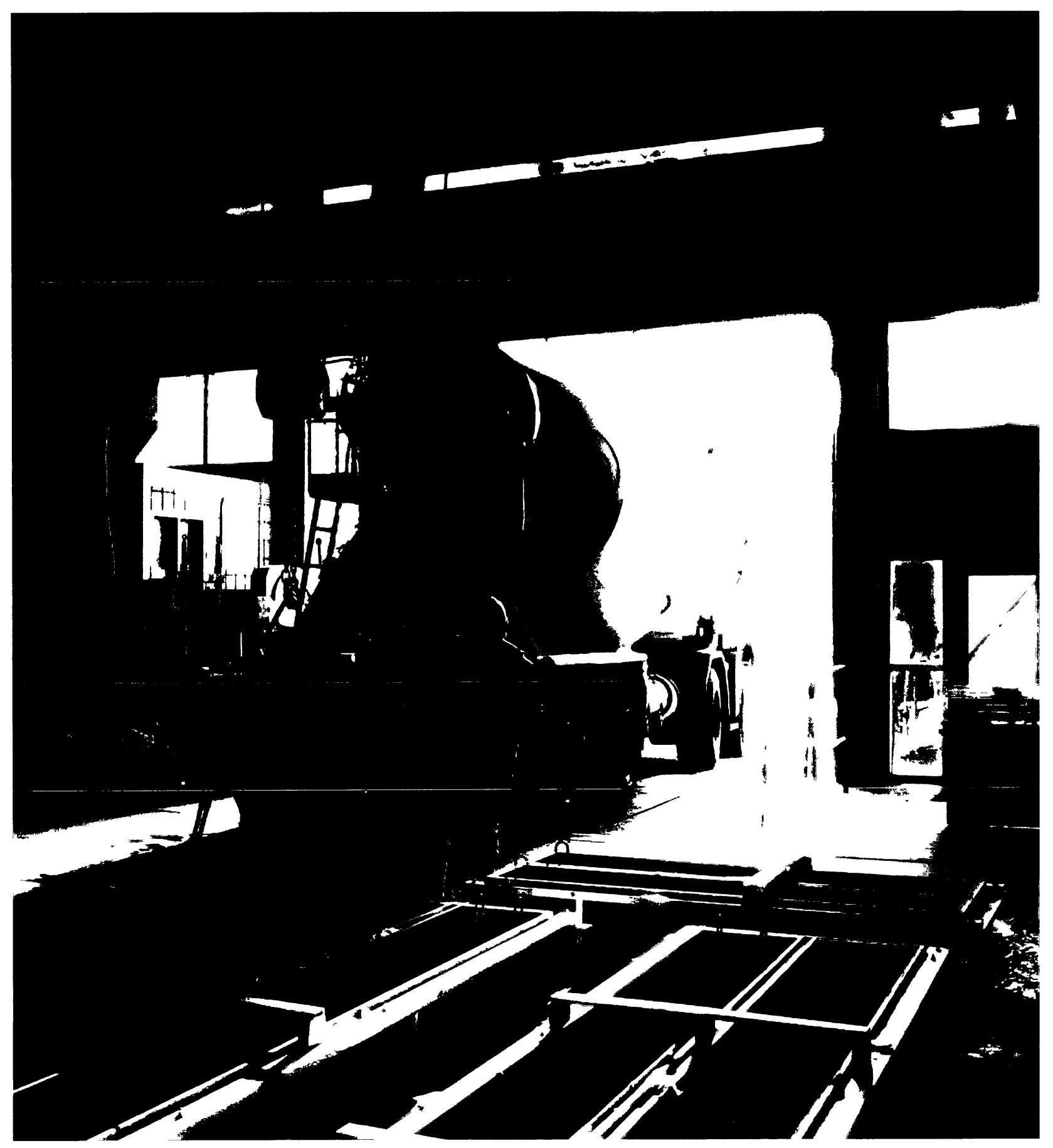

Figure 3-15: Casting Day 


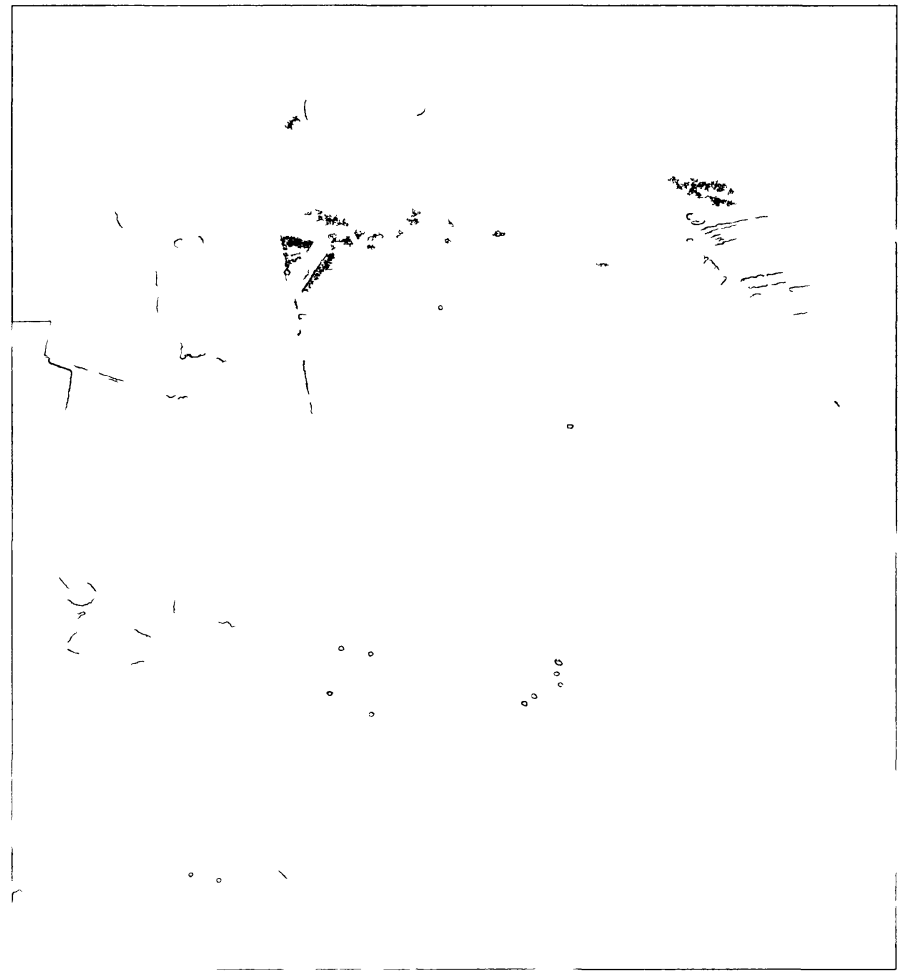

Firrest SHump Test, 29 Dreop im Heighnt

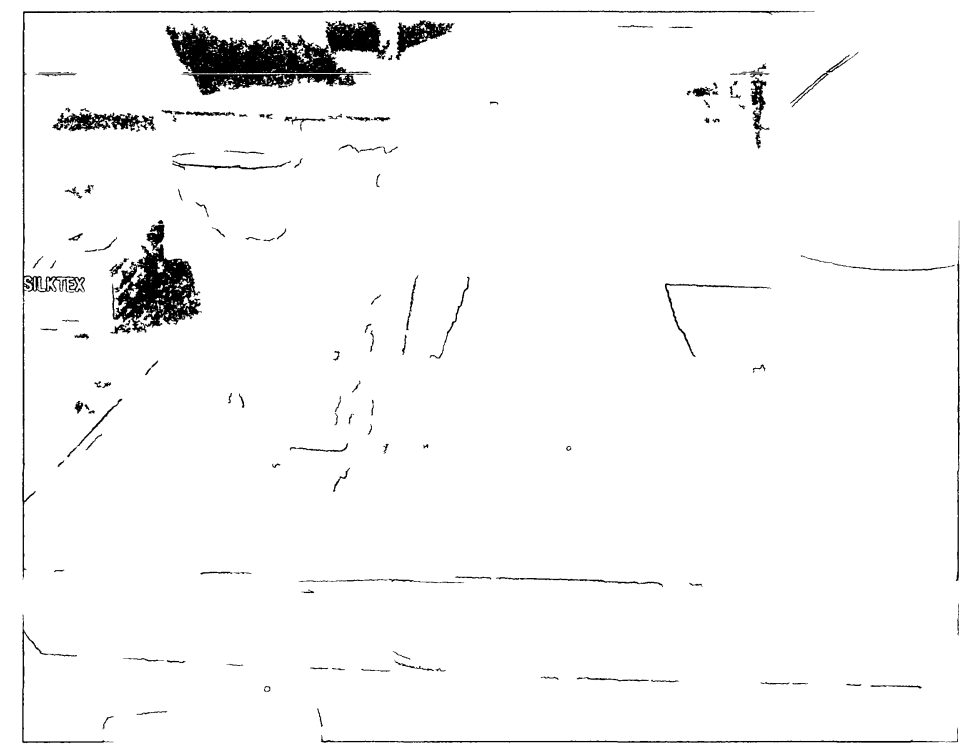

Secomd Slnmp Test, $4^{99}$ Drop im Height

Figunre 3-16: Slnnmp Test 

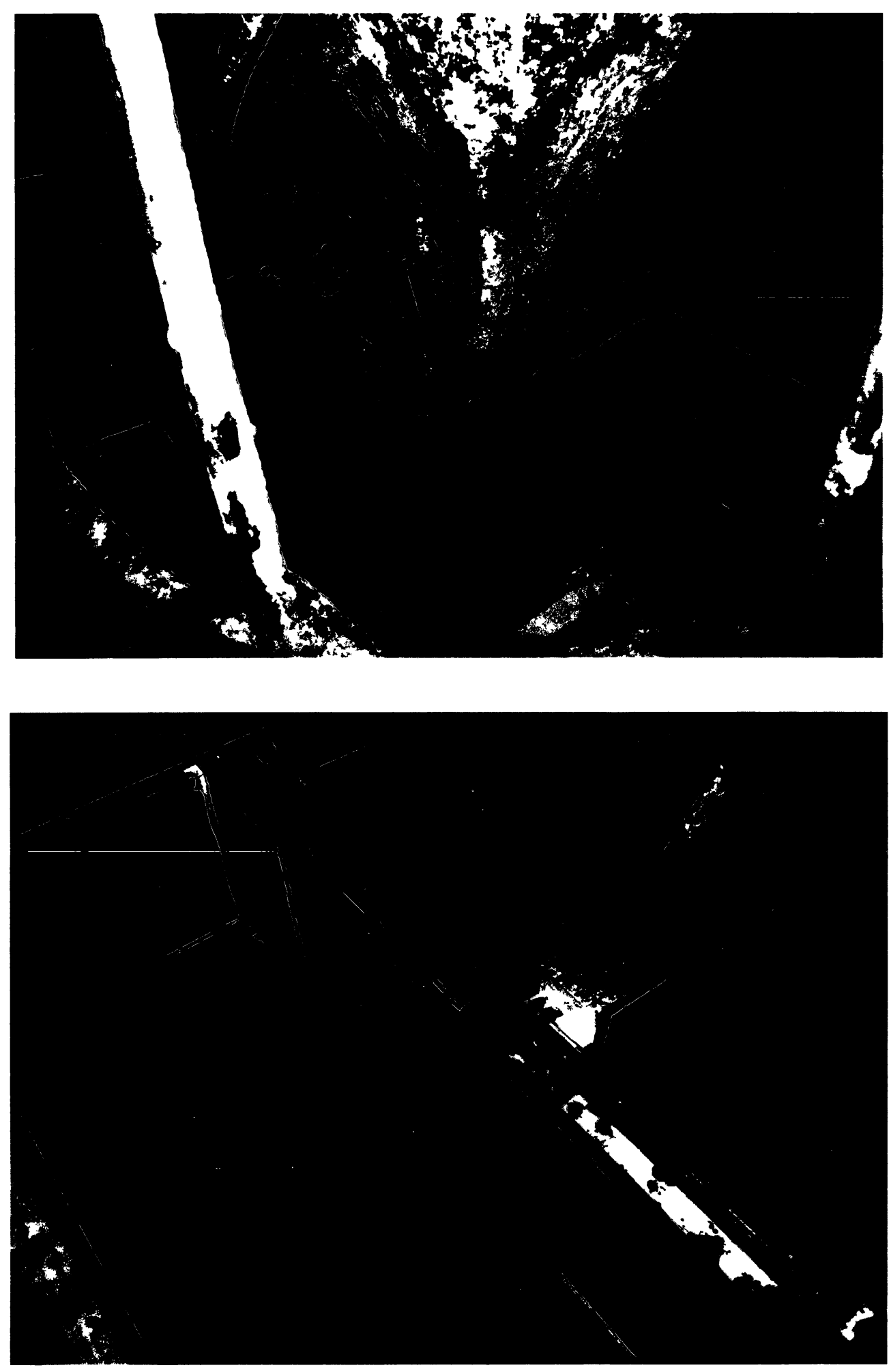

Figure 3-17: Concrete Pouring and Vibrating 

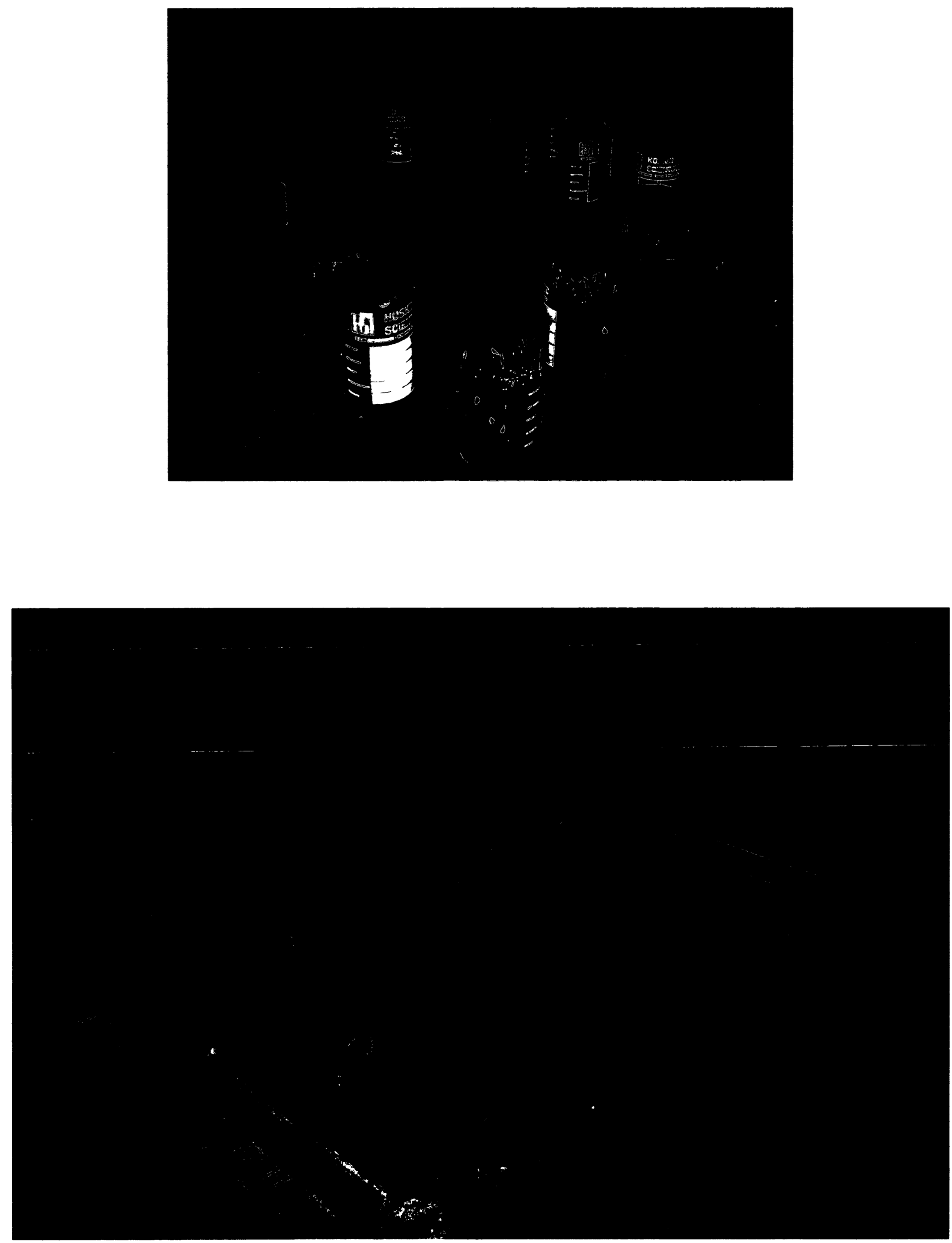

Figure 3-18: Cylinder Test Samples and Overall View of Specimens 

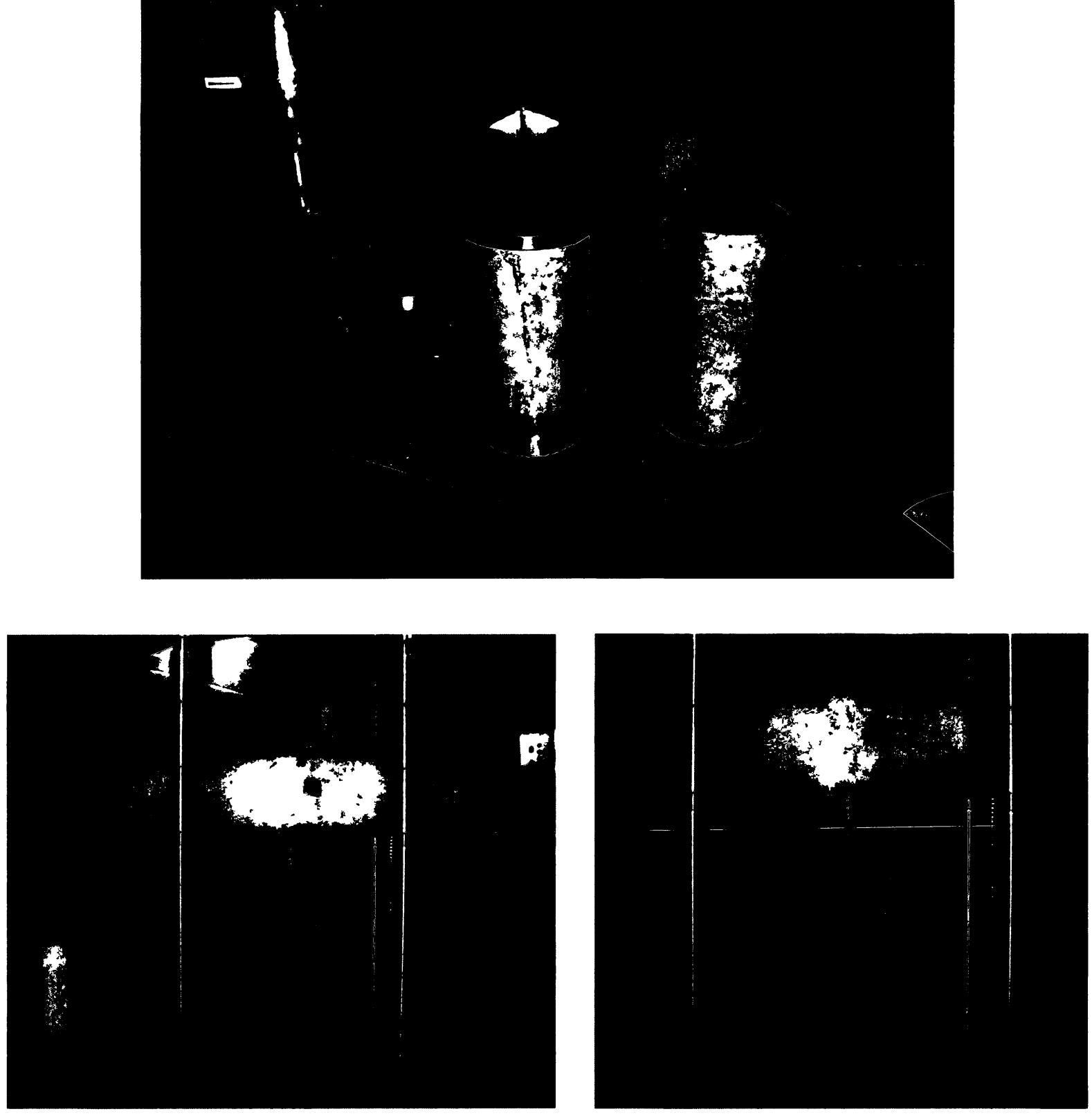

Figure 3-19: Cylinder Capping with Sulphur Powder, Cylinder Test 

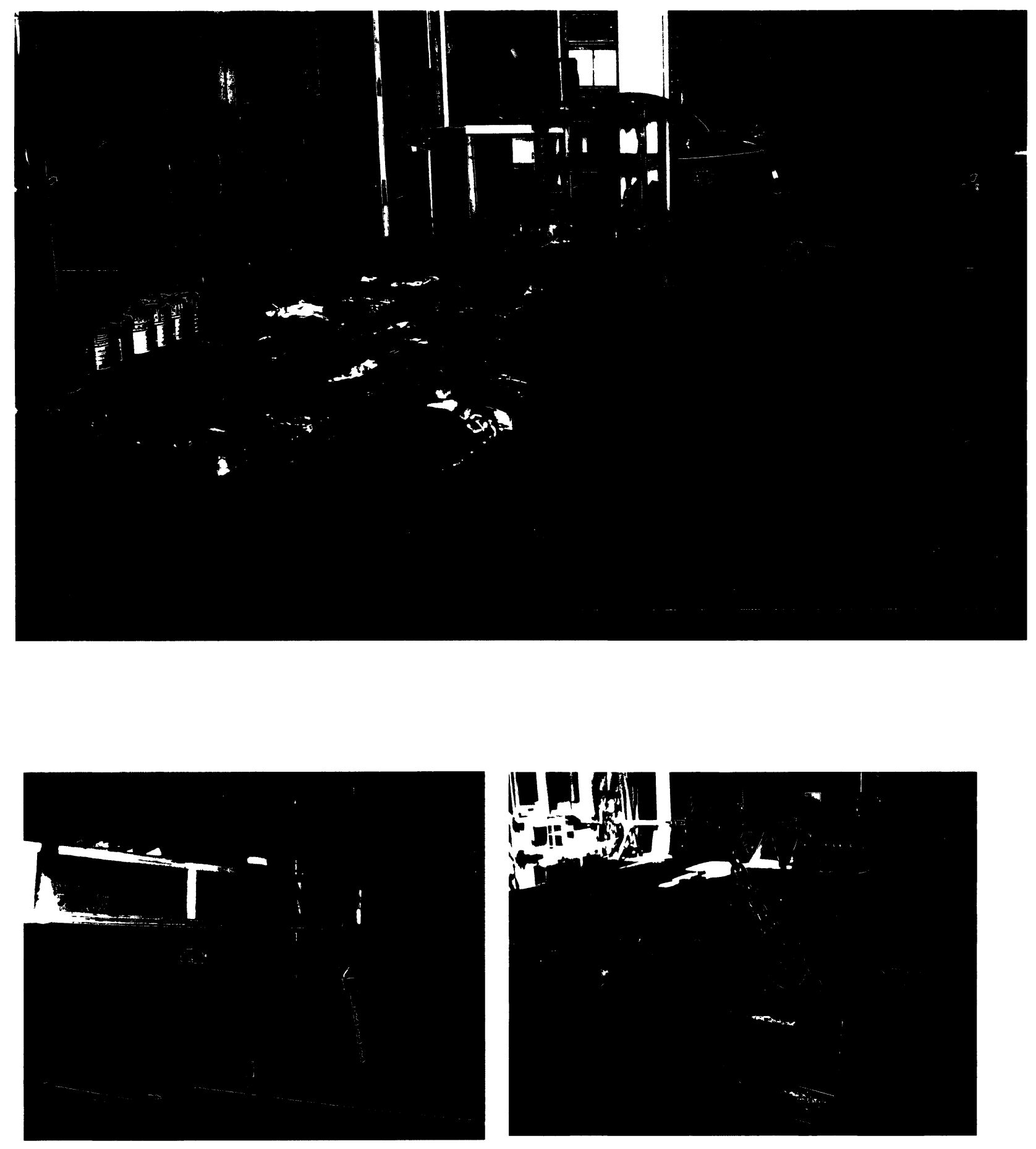

Figure 3-20: Removing Specimens from the Formwork 

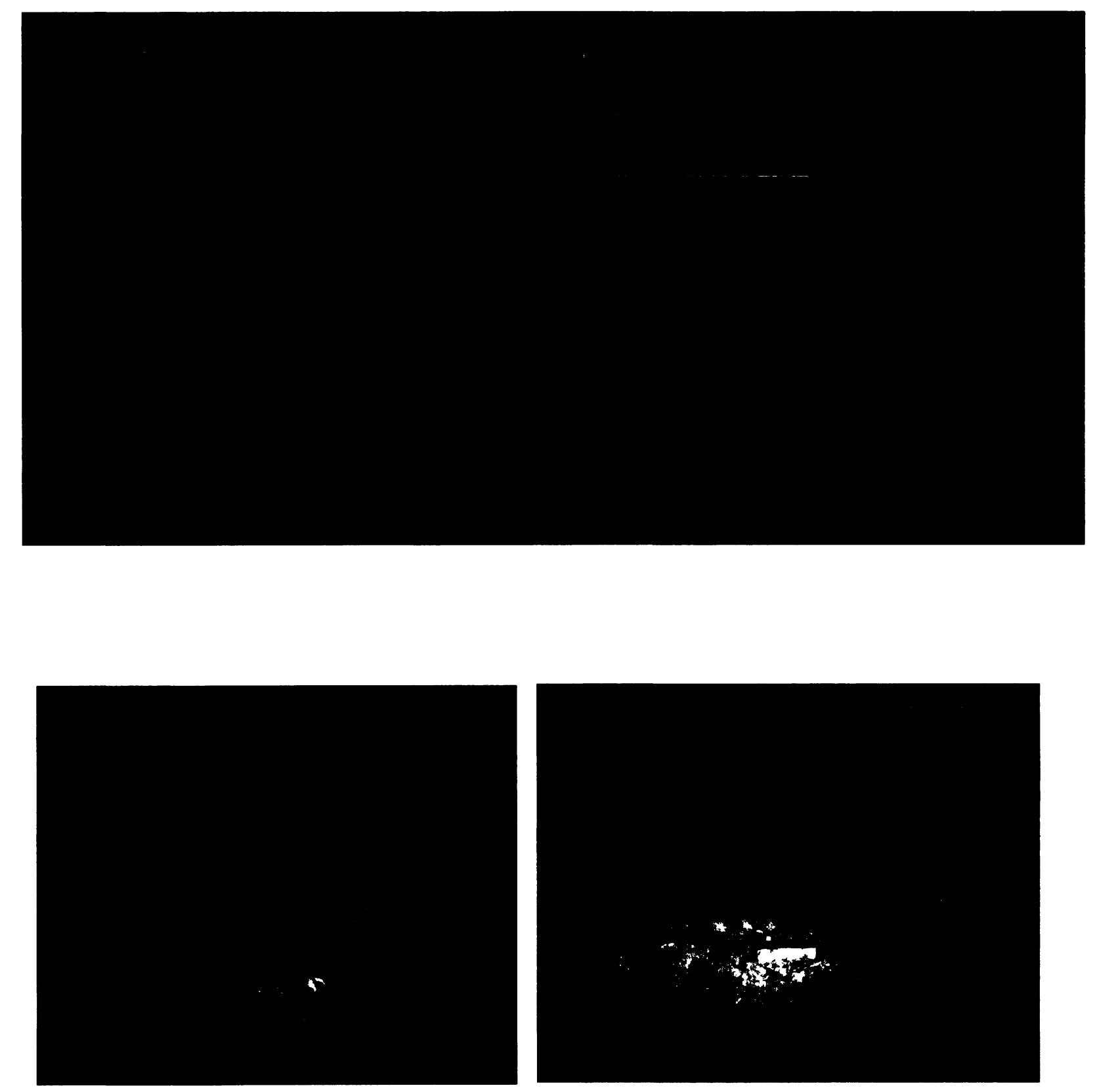

Figure 3-21: MB6 Honeycomb 
$+$
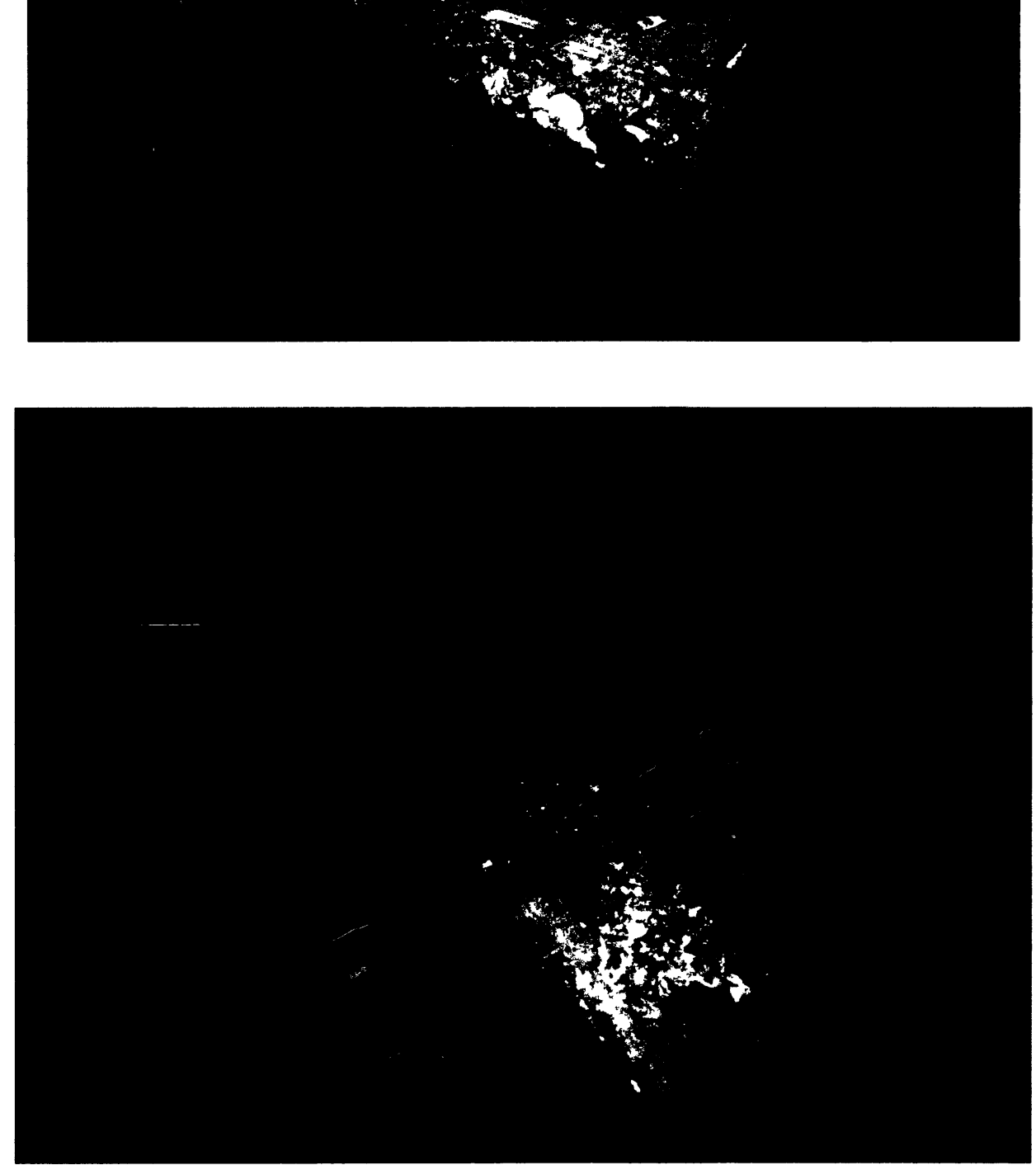

Figure 3-22: MB7 Honeycomb 

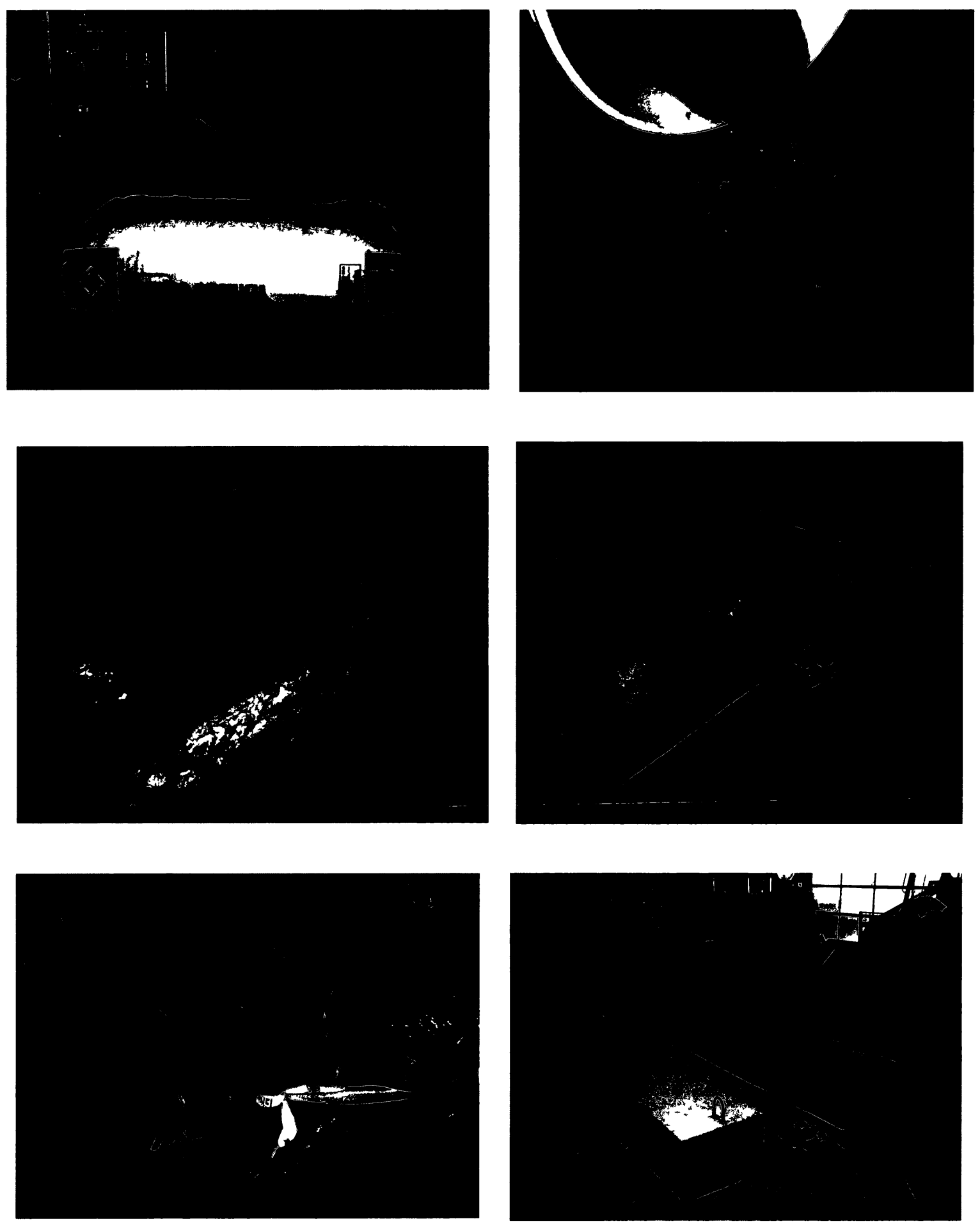

Figure 3-23: Fixing MB6 and MB7 with Verticoat Supreme, Curing and Painting 

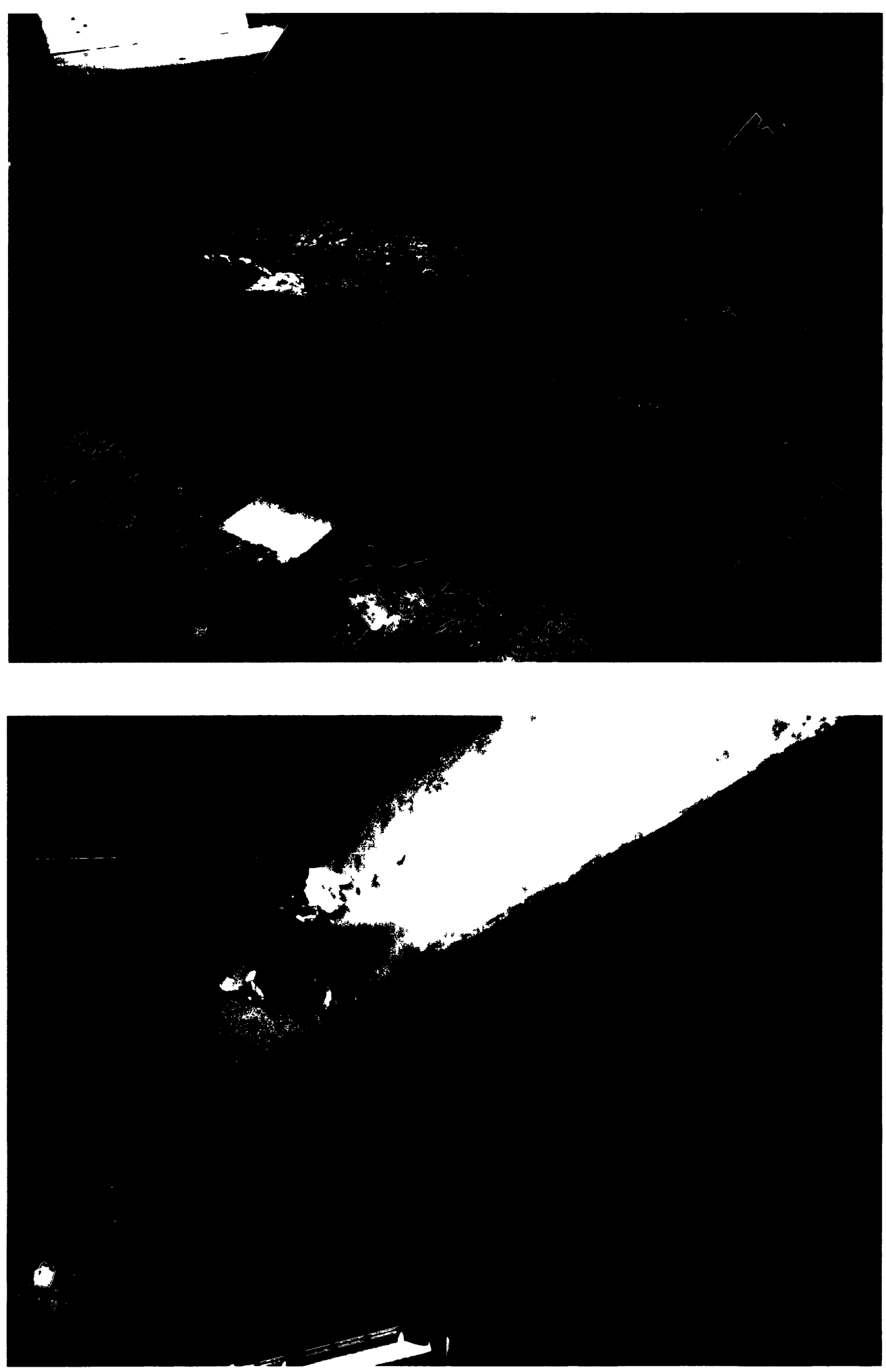

Figure 3-24: Overall View of MB6 and MB7 after Fixing 


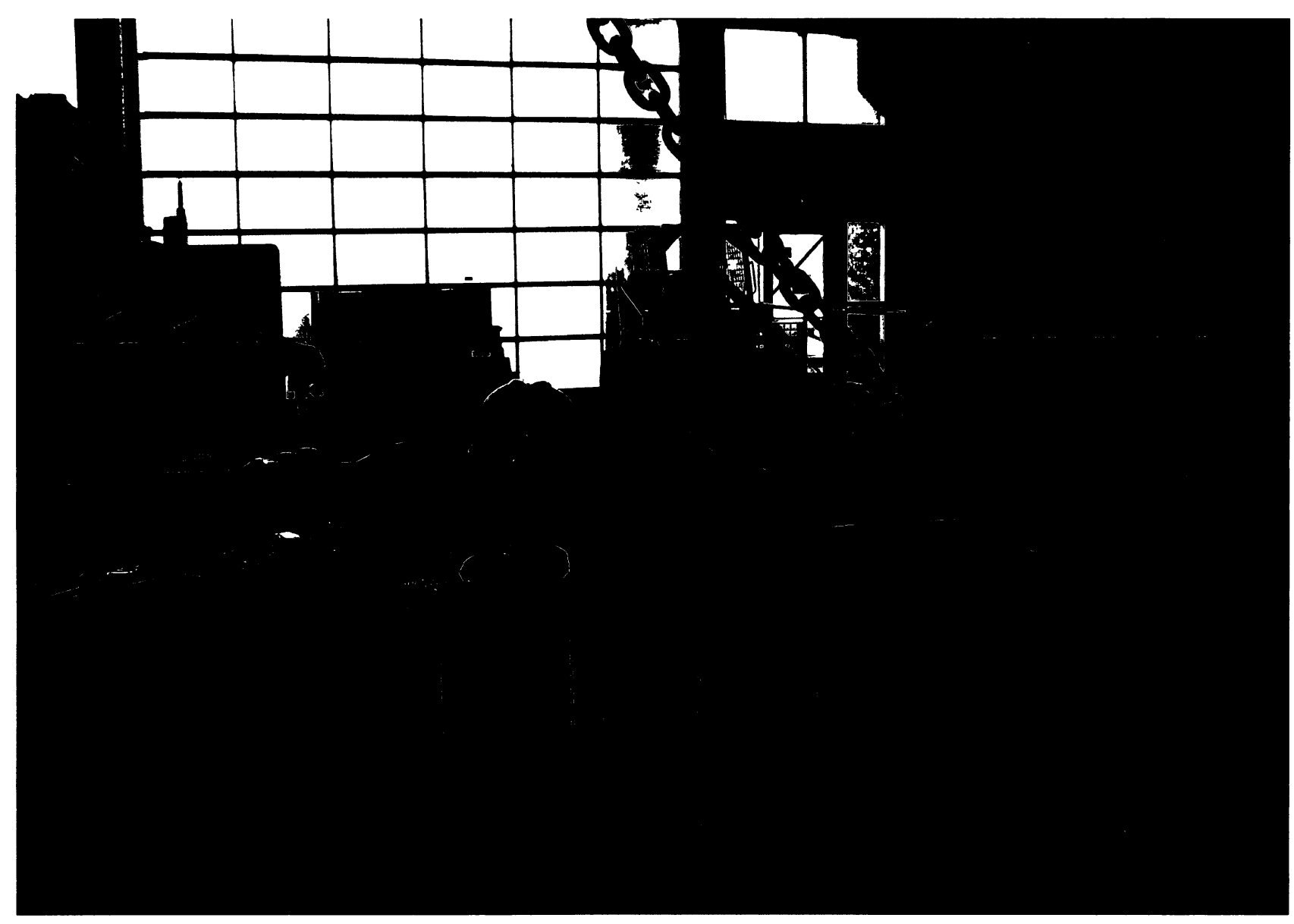

Figure 3-25: Overall View of Painting and Making Grids on Specimens 

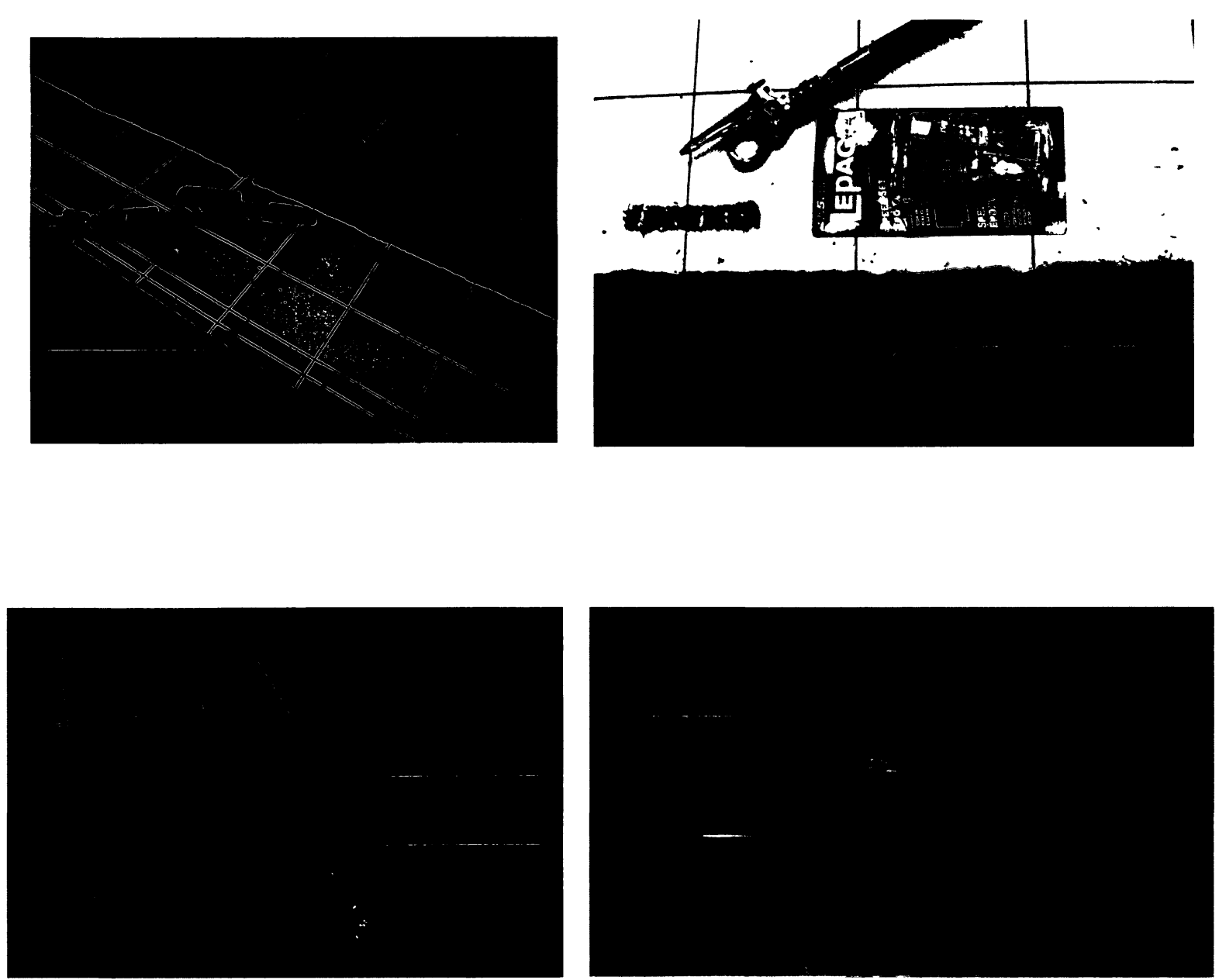

Figure 3-26: Concrete Strain Gauge Instrumentations and Installation 


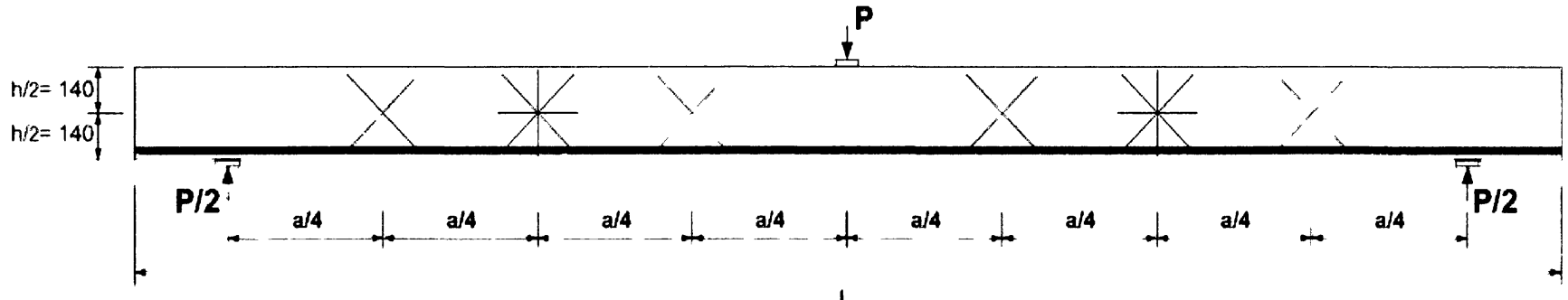

Specimens MB12 to MB14 (a/d= 68 )

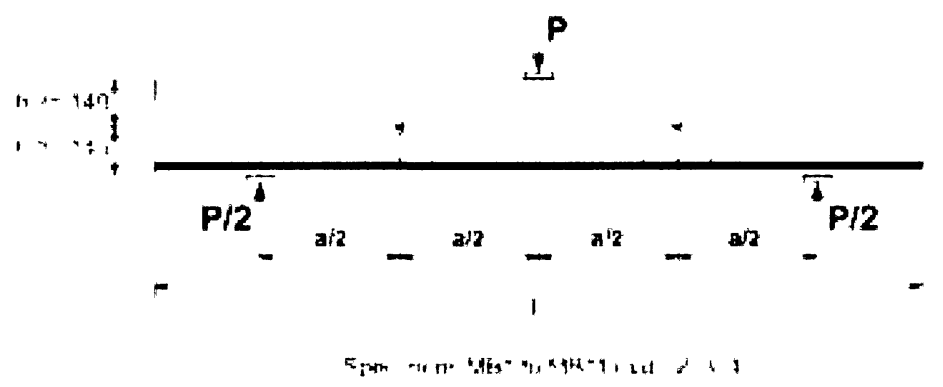

Spocimen Name

$L \cdots$

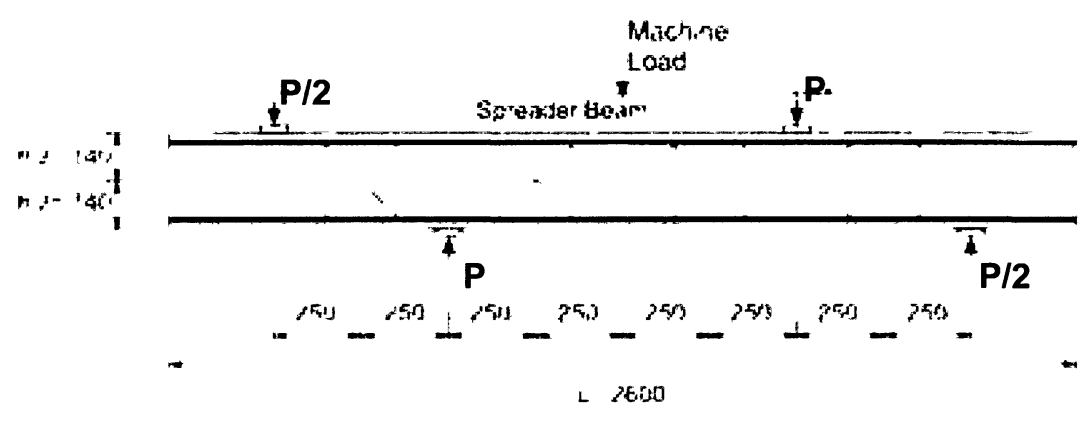

Mes MB2 MBS MBbs Mbs, MBQ, MB10, MB13 $305 \mathrm{~mm}$ ME3, MBS, NB?, MB11. Mbr2 MB13 MB14

Lim

$45^{4}$

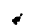

$1+4$

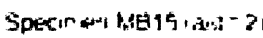

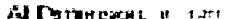

Figure 3-27: Locations of Side-Face LVDTs 


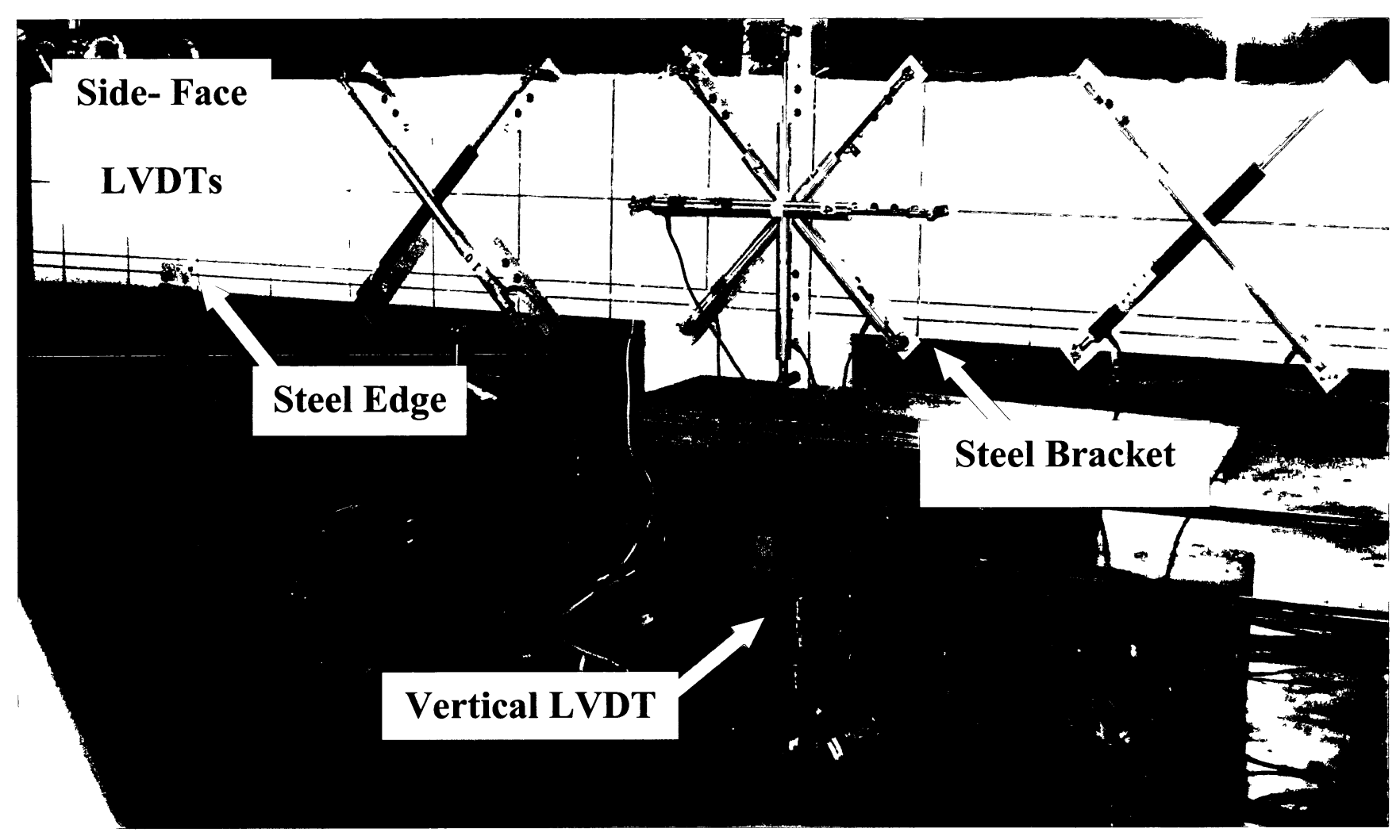

Figure 3-28: LVDTs Specifications 

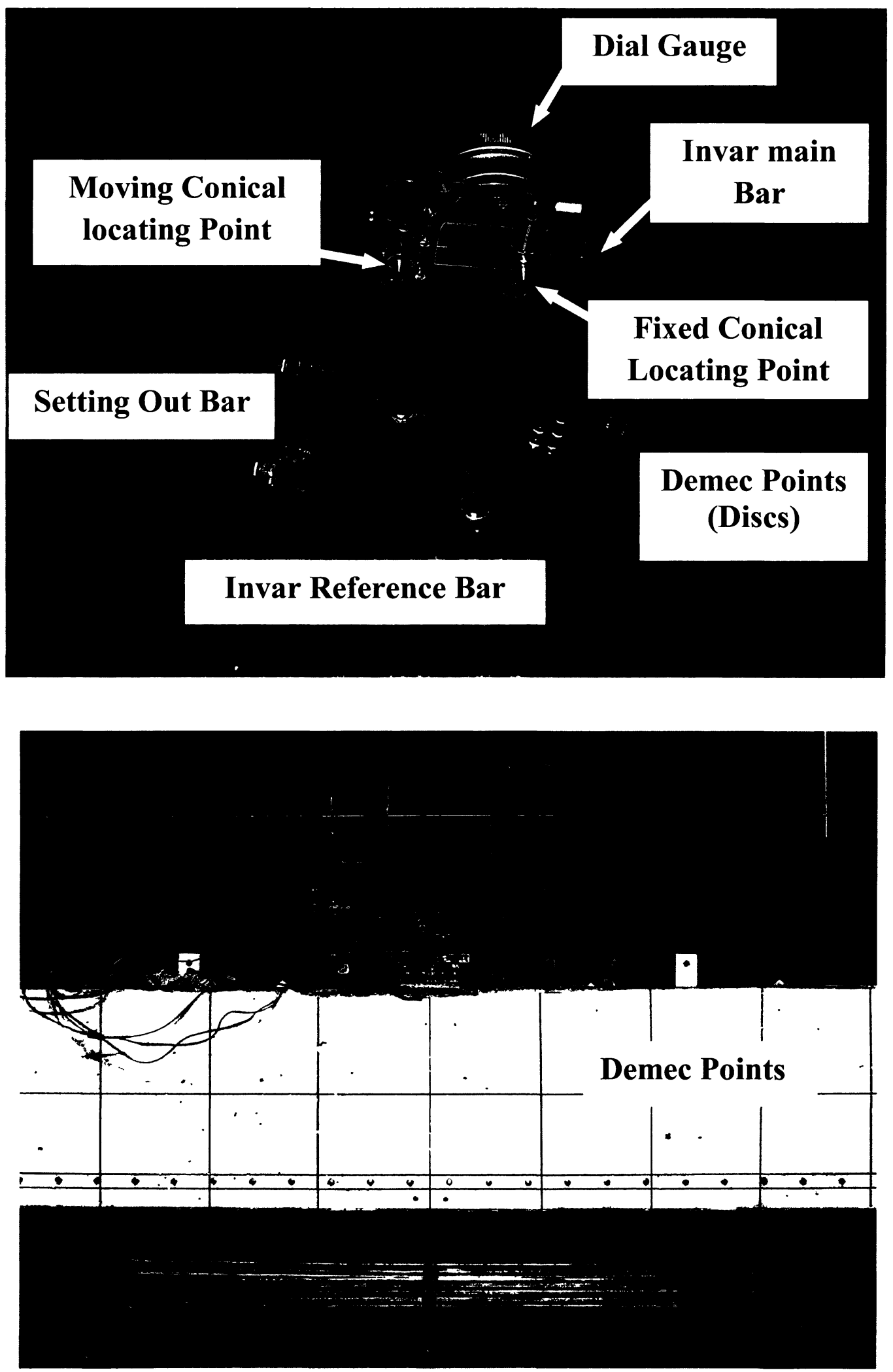

Figure 3-29: Demec Gauge Instrumentation 


\section{i}
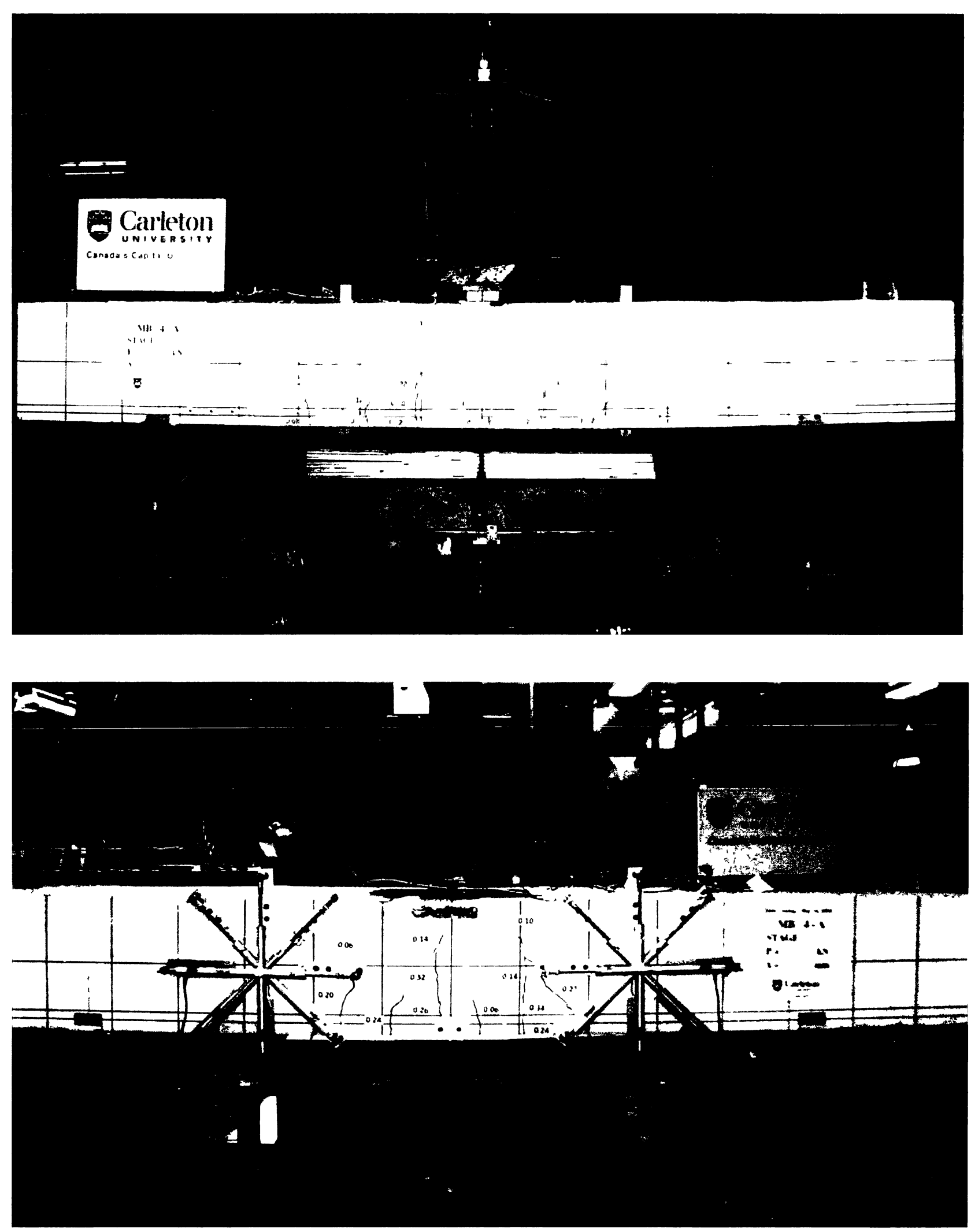

Figure 3-30: Overall View of Test Set up, Specimen MB4 

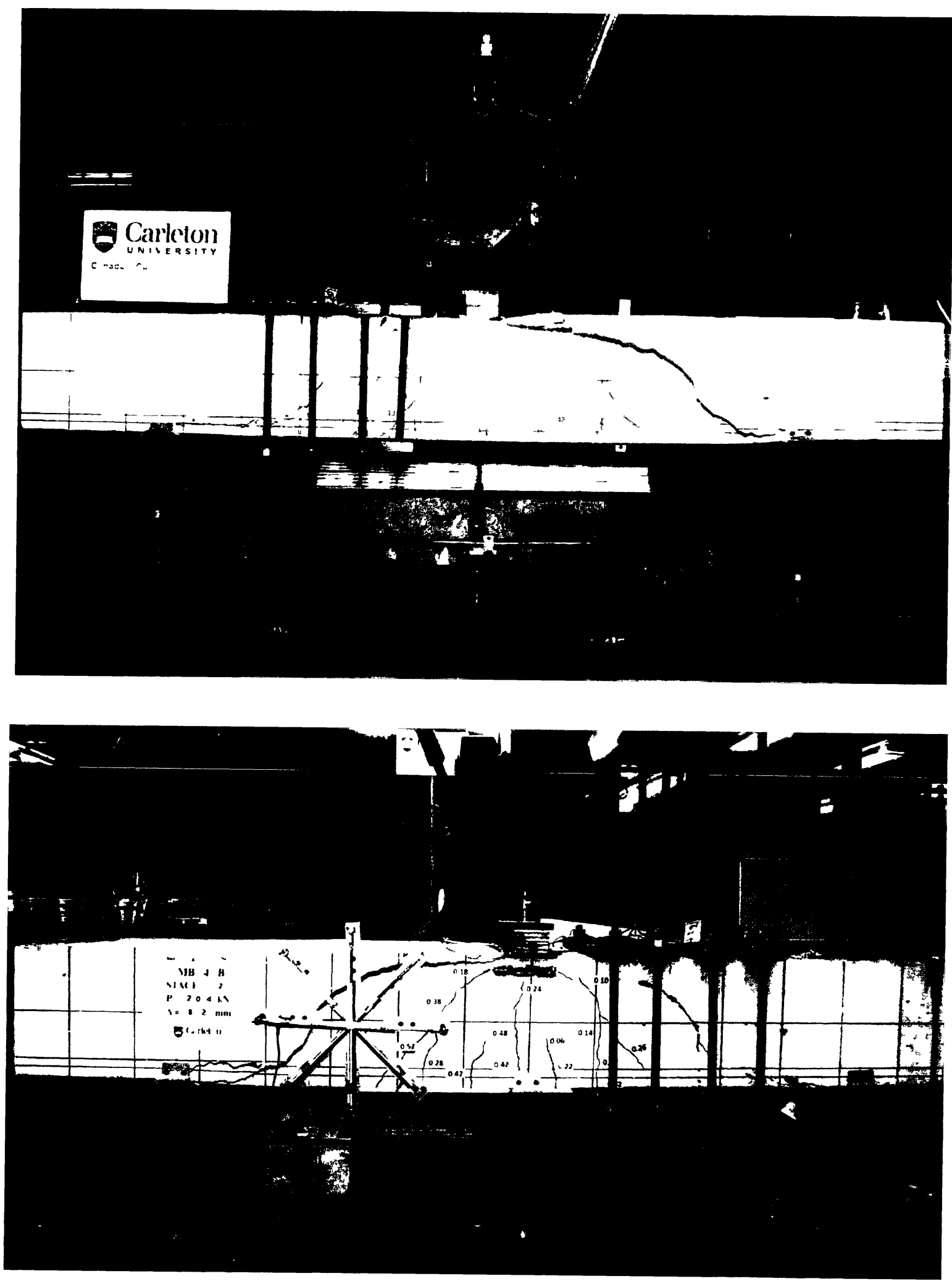

Figure 3-31: Overall View of Test Set up, Specimen MB4 (Repeated Side) 

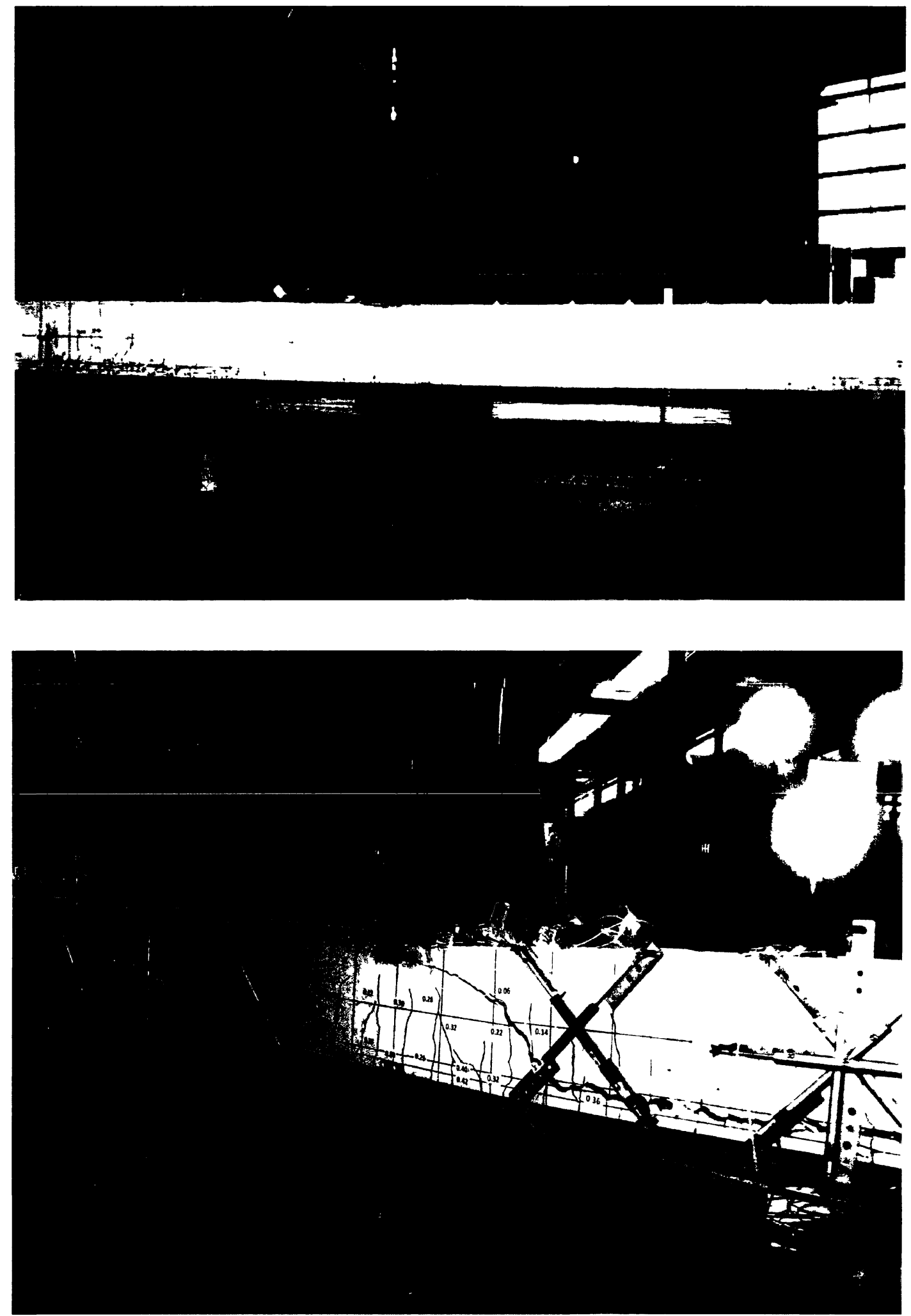

Figure 3-32: Overall View of Test Set up, Specimen MB13 

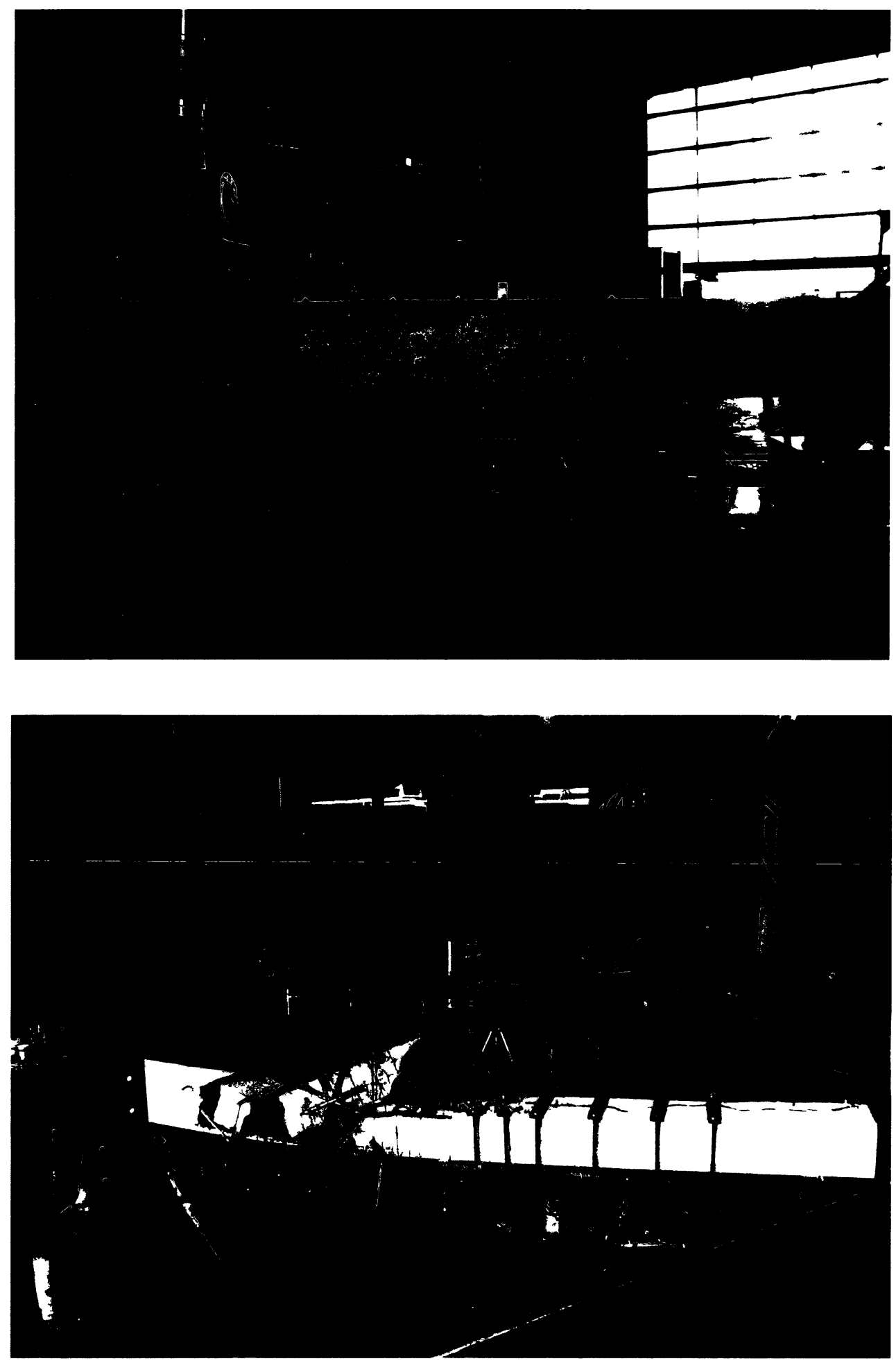

Figure 3-33: Overall View of Test Set up, Specimen MB13 (Repeated Side) 

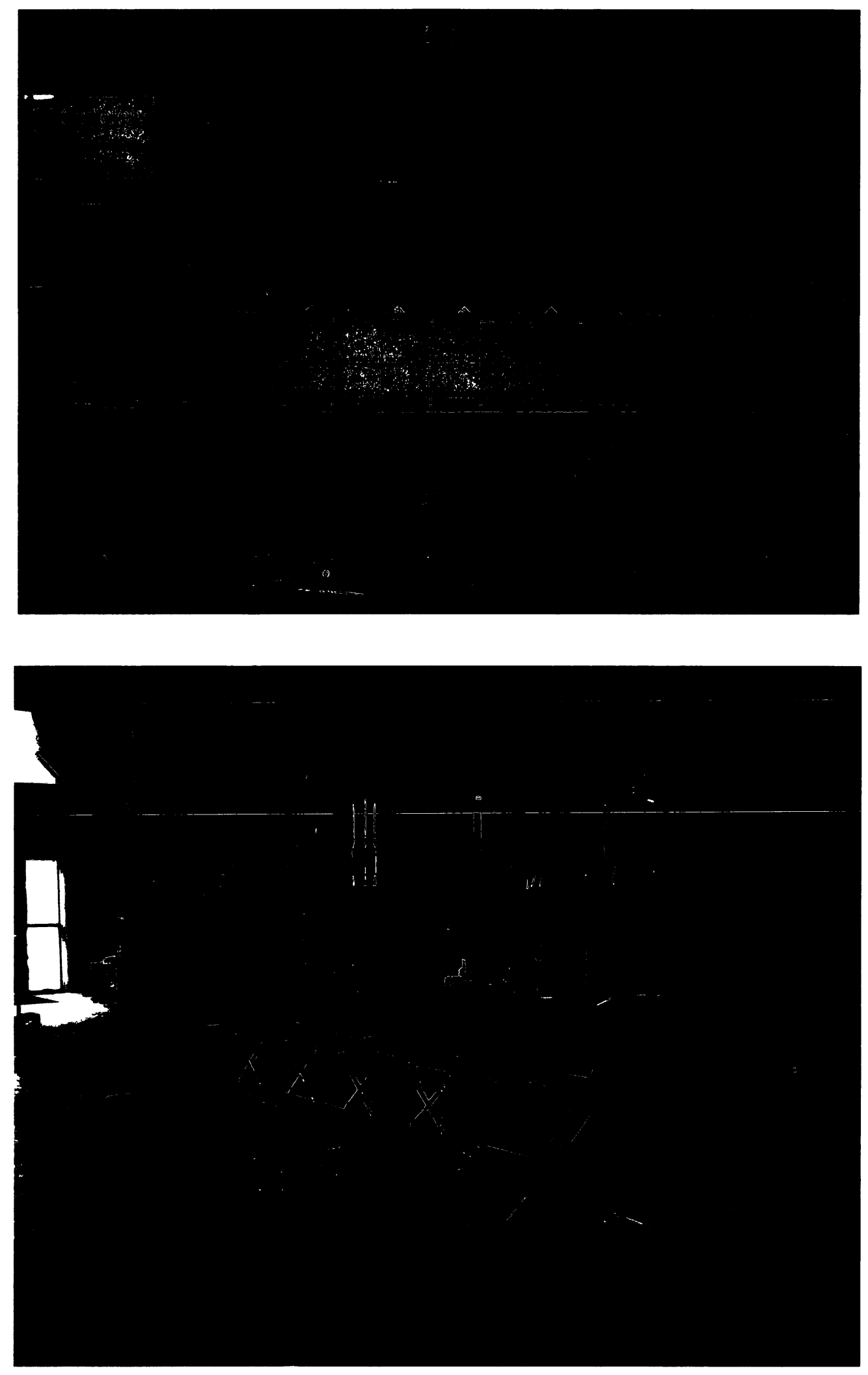

Figure 3-34: Overall View of Test Set up, Specimen MB15 


\subsection{EXPERIMENTAL RESULTS AND DISCUSSION}

\subsection{General}

This thesis focuses on fifteen reinforced concrete test specimens designed to investigate the one-way shear behavior of reinforced concrete beams and slabs constructed without stirrups. The goal is to examine the accuracy of the CSA A23.3-04 shear design method and seven other prominent shear design methods.

This section presents the experimental results portion of this research and provides a discussion of the results. For the purposes of reporting the results the specimens are grouped into four different categories based on the test variables: shear span to depth ratio (a/d) and reinforcement ratio $\rho$ (Table 4-1). Prior to discussion of the results, the typical behavior of shear failure (beam action and arch action) of the specimens will be presented. The experimental results of these four series of specimens will be presented in graphs and tables and will be discussed. The results will be then compared with seven prominent shear design methods for FRP reinforced concrete structures. The role of crack widths on the observed behavior will be also examined and discussed. 


\subsection{Typical Behavior of Shear Failure}

\subsubsection{General}

As discussed earlier (section 2.2.7) there are two fundamental mechanisms of shear failure for reinforced concrete beams: breakdown in beam action and breakdown in arch action. In beam action shear resistance is associated with plane sections remaining plane. The strut-and-tie mechanism (arch action) is associated with diagonal compression struts in the web tied by the flexural tension reinforcement. As a result, arch action depends on the inclination of the line of the strut from the load point to the support which is related to shear span to depth ratio, a/d. That is, the shear strength of beams with a/d ratios less than about 2.5 tends to be governed by strut-and-tie action, whereas in beams with $\mathrm{a} / \mathrm{d}>2.5$, shear stress tends to be governed by beam action. If the distance from the load to the support is not too great, arch action can be generally engaged following breakdown in beam action, and higher shear loads can be resisted. In practice, at the moment that beam action breaks down and switches to strut-and-tie action to control shear strength of a member, at about $2 / 3$ of the failure load daylight may become visible through the shear cracks in the member.

The typical failure mechanisms observed in the test specimens will be described with the aid of Figures 4-1 and 4-2. The photos in Figure 4-1 show the crack diagrams and crack widths of specimen MB1 which failed due to break down in beam action. The photos in Figure 4-2 show the same for specimen MB10 which failed in a strut-and-tie mode. The pattern of crack forming and propagation were almost the same for all the specimens which failed in beam action (series 2, 3 and 4) and were almost the same for the all three specimens in the $1^{\text {st }}$ series which failed in strut-and-tie action. In all specimens flexure-shear cracks developed fully in 
both shear spans prior to failure and all failed in shear prior to reaching their flexural capacity, and hence the failures were all brittle. Also, in some specimens the shear failure occurred with a big bang, accompanied by concrete pieces being violently jettisoned from the beam.

\subsubsection{Flexural Cracking}

By increasing the load, the first flexural cracks happened at the bottom (the tension side) of the mid-span and it happened roughly at the same predicted load, $\mathrm{P}_{\mathrm{cr}}$, by the following equations:

$$
\begin{aligned}
& f_{r}=\frac{M_{c r} y}{I} \\
& M_{c r}=\frac{P_{c r} L}{4} \\
& I_{g}=\frac{1}{12} b_{w} h^{3}
\end{aligned}
$$

In the above, $f_{r}$ is the modulus of rupture of concrete and is equal to $0.6 \sqrt{f^{\prime}}$, y is the distance from the neutral axis of the section to the extreme tension fiber of the section which was taken as $140 \mathrm{~mm}$ based on the geometry of the all specimens. $\mathrm{I}_{\mathrm{g}}$ is the gross moment inertia of the section. $b_{w}$ and $h$ are the specimen width and height respectively. The initial cracking load $\left(\mathrm{P}_{\mathrm{cr}}\right)$ then can be simply calculated by the following equation: 


$$
\mathrm{P}_{\mathrm{cr}}=\frac{4 \times(400) \times(280)^{3} \times 0.6 \times \sqrt{\mathrm{f}_{\mathrm{c}}^{\prime}}}{12 \times 140 \times \mathrm{L}}
$$

The cracking loads calculated using Eq. (4-4) generally corresponded with the observed cracking loads. During loading, this acted as useful confirmation of the reading from the actuator load cell. The flexural cracks (vertical cracks) started to form on both sides of the specimens from the bottom of specimen and propagate upwards as the load increased (Figures 4-1 and 4-2). The flexure-shear cracks then started to form and were inclined at a steep angle.

\subsubsection{Failure Mechanisms}

The process of shear failure due to breakdown in beam action is shown in Figure 4-1. At the last load stage before failure, a dominant flexural-shear crack had clearly formed and the inclined cracks became very wide and propagated toward the location of the load. The resulting bending of the concrete tooth then caused a relatively flat inclined crack to propagate across the root of the tooth. See the diagram in Figure 4-1, which shows an idealization of the complex flow of stresses within the beam.

Because the moment is higher on one side of the concrete tooth (the side closer to the point load), the concrete tooth rotated counter-clockwise and is pulled toward the higher moment side. This results in bending of the concrete tooth inducing flexural stresses at the root of the tooth. This rotation and the flexural stresses at the root of the tooth are counter-acted by aggregate interlocking shear stresses acting on the cracks. As the cracks get wider, the aggregate interlocking shear stresses decrease and cause the bending stresses at the root of 
the concrete tooth to increase. By increasing the load, the failure will happen as an inclined crack caused by the tensile bending stress at the root of the tooth.

The peak load in the specimens was reached along with rapid increase in the mid-span deflection. This increase in deflection, however, was caused primarily by increasing shear strains rather than by increasing flexural crack widths. The proof of this fact is there was generally little to no difference in crack width at the mid-span cracks for the last two load stages before the failure, while considerable increase in diagonal crack widths were consistently observed. As the final failure happened, the dowel action of the reinforcements caused the formation of longitudinal cracks along the length of the reinforcements toward the support (Figure 4-1).

For the $1^{\text {st }}$ series of specimens that failed by strut-and-tie action, however, by increasing the load the concrete tooth did not form but the diagonal strut formed in both sides of the beam along with increasing crack widths (Figure 4-2). As the load increased the crack widths grew wider and, as mentioned earlier, at about $2 / 3$ of the failure load daylight became visible through the shear cracks in the member. The failure then happened with crushing the concrete in compression zone.

Toward a better understanding of these two mechanisms of shear failure, consider the flexurally cracked beam without shear reinforcement shown in Figure 4-3, with shear being resisted by beam action. The depth of the compression zone, which is a function of member depth, is called kd and the flexural lever arm is jd (or $\left.d_{v}\right)$. As shown in the figure, the tensile force in the longitudinal reinforcement will remain about constant over a region of about $\mathrm{d}$ from the point load at each side because of spreading compression stresses under the loading 
plate over the beam. At the bottom of the beam the spacing of the vertical cracks will be controlled by the bond strength of reinforcement, however at mid-depth of the beam, crack spacing will be controlled by the distance required for tensile stresses in the concrete to spread out from the reinforcement or from the stiff uncracked compression zone. Consider the free body diagram of a concrete tooth which is a portion of the beam between two adjacent flexural cracks as a vertical cantilever fixed at the beam's neutral axis (Moe et. al. (1962), Kani et. al. (1964)). If the two vertical flexural cracks of a concrete tooth are narrow enough to transmit the shear stresses by aggregate interlock, then the concrete tooth will have a pure shear stress on any horizontal plane across the tooth equal to $\mathrm{V} / \mathrm{bjd}$ (Collins et. al. (2007)). If this tensile stress equals the cracking strength of the concrete, $\mathrm{f}_{\mathrm{cr}}$, then it can cause a diagonal crack at about an angle of $45^{\circ}$. In a case that the cracks are so wide that the shear stresses can be no longer transmitted across these two cracks of a concrete tooth, the horizontal shear stress of $\mathrm{V} / \mathrm{bd}_{\mathrm{v}}$ must reduce to zero at the crack locations. In order to change the tension force in the longitudinal reinforcement ( $\Delta \mathrm{T}$ portion in beam action), bending moments will develop in the concrete tooth to cause vertical stresses. In this case the concrete resists a tensile stress of $6 \mathrm{~V} / \mathrm{bjd}$. After beam action breaks down, the strut-and-tie mechanism can carry higher loads by diagonal compression struts in the web if the beam has a short shear span with a/d less than about 2.5. It can be seen in Figure 4-1 that the final failure crack initiated at the tip of a flexural-shear crack, and sloped towards the load point in a member similar to that illustrated in Figure 4-3. When beam action broke down in the specimens, the failure cracks typically resembled those in Figure 4-1 and 4-3. It appears then, that beam action failures were due to rupturing of concrete teeth. 


\subsection{Experimental Results}

A summary of specimen properties and test results obtained from the fifteen specimens is outlined in Table 4-1. Specimens are arranged in four groups based on the test variables: shear span to depth ratio $(\mathrm{a} / \mathrm{d})$, and reinforcement ratio $\rho$. However as mentioned earlier, all specimens are named by the test date, for example, MB1 refers to the first specimen tested. After failure of one side of each specimen, the broken side was clamped by pairs of steel bandages if the unbroken side was still intact, and then the specimen loaded to reach the failure at the other side. The second failure side of the specimens is referred to as the repeated side. All specimens exhibited shear failure on the repeated side as well.

The concrete compression strength $\left(\mathrm{f}_{\mathrm{c}} \mathrm{c}\right)$ for each specimen was calculated by an interpolation between the results of the series of nine cylinder tests (two cylinders crushed per test) as summarized in Table 3-4. The listed failure load $\left(\mathrm{P}_{\text {exp }}\right)$ for each part is the maximum external machine force that the specimen could resist before failure. The listed failure shear force $\left(\mathrm{V}_{\text {exp }}\right)$ is calculated at a distance $\mathrm{d}$ from the center of the loading and simply equals the maximum machine force divide by two for MB1-MB14 $\left(\mathrm{V}_{\exp }=\mathrm{P}_{\exp } / 2\right)$ and is equal to $2 / 3$ of the maximum machine force for MB15 based on the geometry and statics of the specimens. However, the shear force does not include the beam self-weight. The failure shear stresses $\left(\mathrm{V}_{\text {exp }}\right)$ listed in the table are calculated by dividing the shear force by specimen width and effective depth $\left(b_{w} d\right)$. The failure shear stresses were normalized by the concrete compression strength $\left(v_{\exp } / \sqrt{f^{\prime}}\right)$ and these values are listed. The ultimate mid-span deflection $\left(\Delta_{\mathrm{ult}}\right)$ and all strains were reported at the peak load condition. The mid-span displacements listed in Table 4-1 account for the displacements measured at the supports, and hence represent the true displacement. The shear strain $(\gamma)$ was measured with two diagonal 
LVDTs located at $\pm 45^{\circ}$ from the horizontal at the middle of the shear spans. For each part of the specimen, the side face LVDT readings at the failure side were converted to shear strains based on the following equation:

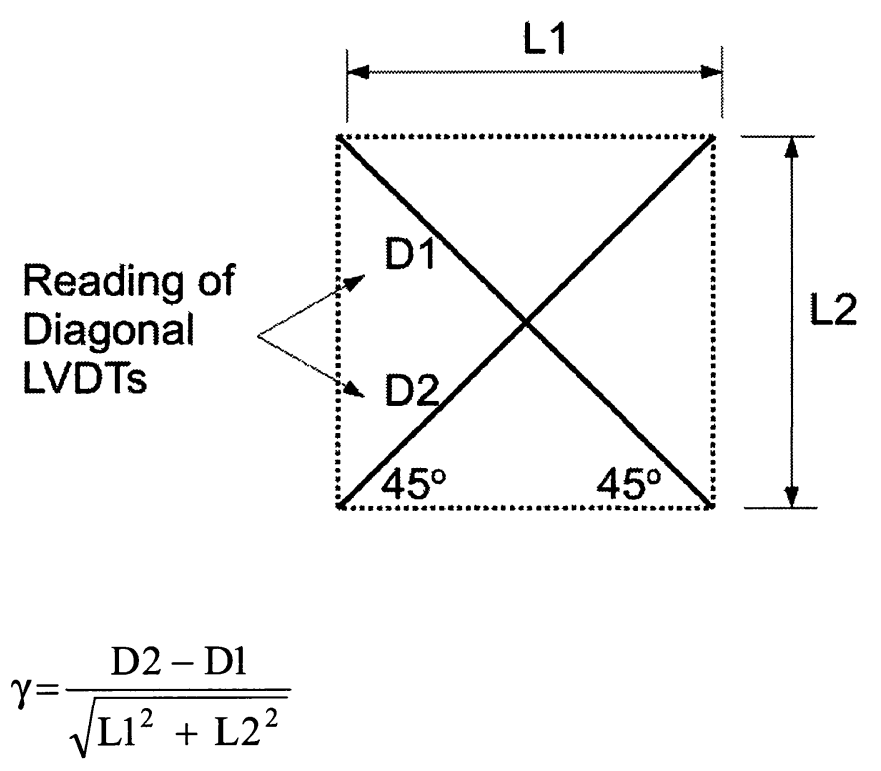

The $\varepsilon_{\mathrm{s}, \max }$ column shows the longitudinal reinforcement strain at mid-span at peak load measured with strain gauges installed on the FRP reinforcement. The max crack widths $\left(\mathrm{w}_{\max }\right)$, which were measured by using a hand-held graduated magnifying scope, are the maximum crack width measured anywhere on the beam at the last load stage before failure.

For the repeated side, each specimen was loaded up to the failure load of the first side then a load stage was taken. However, for some of the specimens the repeated side failed at the same load, therefore there was no load stage for the repeated side of those beams. The empty spaces on the crack width columns for the repeated side are due to this. No readings of midspan deflection are reported for the repeated side due to the changes in stiffness of the specimens due to the use of steel bandages. Also, following the initial failure, most of the 
strain gauges became damaged and did not work so no strain gauge records are summarized in the table for the repeated side. Specimens MB14 and MB15 were not repeated as both sides were extensively damaged during the initial failure.

\subsubsection{The 1st-series}

This section presents the test results of the $1^{\text {st }}$ group of specimens as summarized in Table 4-1. Specimens MB8, MB9 and MB10 were categorized in the first series with a constant a/d ratio equal to 2 and reinforcement ratio of $0.57,1.14$ and $2.28 \%$ respectively. The $\mathrm{M} / \rho \mathrm{Vd}$ ratio decreases by increasing the reinforcement ratio $(\rho)$ in this series. The purpose of this series was to observe the effect of having a constant value of $a / d$ but increasing reinforcement ratio, in specimens where strut-and-tie action dominates.

The load rate of the jack for this series was $0.02 \mathrm{~mm} / \mathrm{sec}$ for the first test and $0.05 \mathrm{~mm} / \mathrm{sec}$ for the repeated test of the specimens. This rate refers to the speed of the movement of the piston head on top of the specimens at the location of the load. The first load stage was taken after observing the first cracks. A few load stages then were taken before the final failure happened. For the repeated test, the first load stage was taken roughly at the same failure load of the first part. While MB8 had one load stage before failure for the repeated part, for MB9 there was no load stage because the repeated part of this specimen broke at the same failure load of the first part. For the repeated part of MB10, however, no failure was recorded due to reaching the maximum capacity of the machine which was $465 \mathrm{kN}$ so that the repeated part of this beam did not fail up to this load. 
Figure 4-4 shows the load-displacement graphs recorded for the first test of these specimens. The load-displacement pattern is similar for all the beams. That is, by increasing the load, displacement was increased about linearly up to reaching the first crack at mid-span. The load-displacement at this region is roughly linear because concrete is in the linear-elastic region prior to cracking. The drops in the load-displacement graphs are due to the $10 \%$ reduction in the load at each load stage for safety. Also, significant drops in load are associated with formations of major cracks in the specimens. It is interesting to note the differences in post-cracking stiffnesses between the three beams. That is, the stiffness considerably increases with increases in $\rho$. Most importantly, note the increases in shear strength associated with higher reinforcement ratios.

Figure 4-5 shows the applied load versus the shear strain $(\gamma)$ (calculated by Equation 4-5) for the first failure side of this series. As can be seen, similar to the load-displacement graphs, the load-shear strain graph is roughly linear up to the first cracks with a $10 \%$ reduction in load for each load stage. In this case, the formation of a major shear crack and breakdown in beam action is identified. It is interesting to note the considerable increase in shear strain associated with breakdown in beam action and engagement of arch action. Note also the increases in load resisted by the beams following breakdown in beam action. These increases are not possible in slender beams.

Figure 4-6 shows the applied load versus mid-span FRP strains recorded from the strain gauges for specimens of this series. As can be seen, the applied load-mid-span rebar strain graphs show the same pattern and have the liner increase up to the first cracks. By increasing the load, strain increased up until the failure occurred. Lower strains are associated with higher reinforcement ratios. 


\subsubsection{The 2nd-series}

In this series, MB7 and MB14 were grouped. Both beams had the same reinforcement ratio of $4.05 \%$ which is somewhat higher than all other specimens in this thesis. To obtain this high reinforcement ratio, 8 bars $\# 8$ with nominal diameter of $25 \mathrm{~mm}$ were used. As can be seen in Table 4-1, a/d ratios of these two beams were 3 and 8 respectively which lead to $\mathrm{M} / \rho \mathrm{Vd}$ ratio of 74 and 197 . The purpose of this series was to observe the effect of increasing a/d ratio with a constant value of reinforcement ratio on the failure shear stress of FRPreinforced concrete beams without shear reinforcement. It can be observed from the table that the failure shear stress of MB14 (0.97 MPa) is much smaller than MB7 (1.35 MPa). That is, having a constant value of reinforcement ratio but increasing $\mathrm{a} / \mathrm{d}$, causing higher value of $\mathrm{M} / \mathrm{\rho Vd}$, results in a smaller of failure shear stress due to increase in strain caused by higher moments. This effect cannot be captured by some of the shear design methods discussed in Chapter 2.

The load rate for the first failure part of these two specimens was $0.02 \mathrm{~mm} / \mathrm{sec}$. Specimen MB7 was loaded in a rate of $0.05 \mathrm{~mm} / \mathrm{sec}$ to obtain the shear failure for the repeated side. However, no load stage was recorded for this beam because the repeated side of this beam failed at the same failure load of the first side. For the first failure side of specimen MB14, due to the significant work involved with testing the beam, such as reading the crack widths and demec gauges and recording all results and photos, failure did not occur on the first loading day. On the first loading day, four load stages were taken up to an applied load of 95 $\mathrm{kN}$ (roughly $60 \%$ of the predicted final load) then the specimen was completely unloaded. In the morning of the following day, the specimen was reloaded to $95 \mathrm{kN}$ and then another load 
stage was taken at this load. The external clamps were unable to clamp the failed side adequately, so the repeat side could not be loaded to failure.

Figure 4-7 shows the load-displacement for the first failure side of these two specimens. The loops seen in the load-displacement of MB14 between loads $0-95 \mathrm{kN}$ is because of unloading of the specimen on the first loading day and reloading the second day. It can be seen that specimen MB14 had a mid-span deflection of $37.7 \mathrm{~mm}$, considerably greater than specimen MB-7 with $3.4 \mathrm{~mm}$ deflection. Figure 4-8 shows the applied load versus shear strain $(\gamma)$ of the failure side of the specimens. Load-shear strain graphs follow the same pattern as the other beams of this thesis, whereby there is a liner relation up to the first cracks, a drop in stiffness following cracking and increases up to failure with a drop in load at each load stage. Note the higher shear stiffness of the beam with $a / d=3$ compared to the beam with $a / d=8$. As both beams have identical reinforcement ratios, it is likely that the reduced shear stiffness is caused by wider cracks caused by the higher strains from increased moments. Figure 4-9 shows the applied load versus mid-span FRP strains recorded from the strain gauges for these two specimens. Higher strains are associated with the higher moments in MB14 $(a / d=8)$.

\subsubsection{The 3rd-Series}

The third series was arranged to make a group of 5 specimens (MB3, MB1, MB4, MB5 and MB6) with a constant a/d ratio of 3 and reinforcement ratio between 0.57-2.28 as outlined in Table 4-1. The purpose of this series was to observe the effect of an increase in reinforcement ratio on failure shear stress when the $\mathrm{M} / \rho \mathrm{Vd}$ ratio is not constant. As can be seen from the table, increasing the reinforcement ratio but having a constant value of a/d 
resulted in failure shear stresses increasing from $0.56 \mathrm{MPa}$ in specimen $\mathrm{MB} 3$ to $1.15 \mathrm{MPa}$ in specimen MB6. This appears due to decreases in strain in the longitudinal reinforcement, which is a function of $\mathrm{M} / \mathrm{\rho Vd}$.

The load rate for this series was $0.02 \mathrm{~mm} / \mathrm{sec}$ for the first part and $0.05 \mathrm{~mm} / \mathrm{sec}$ for the repeated part of the specimens. For the repeated side, while specimen MB3 had two load stages before failure and specimens MB1, MB4 and MB6 had 1 load stage before failure, specimen MB5 failed at the same failure load of the first part without taking any load stages. Figures 4-10, 4-11 and 4-12 show the P- $\Delta, \mathrm{P}-\gamma$ and P- $\varepsilon$ graphs of this series. All graphs follow the same pattern of having a linear relation up to the first cracks, with drops in load at load stages. It can be seen in Figure 4-10 that by decreasing the reinforcement ratio, the midspan deflection was increased, while the post-cracking stiffness decreased. The effects of $\rho$ on the shear stiffness (Figure 4-11) are less clear. However, there does appear to be a general trend of increased shear stiffness with increased $\rho$.

\subsubsection{The 4th-series}

This series was designed to be compared to the $3^{\text {rd }}$ series, and as such is the main focus of the thesis. Five specimens were grouped in this series (MB15, MB2, MB11, MB12 and MB13). Specimens were arranged in this group to obtain a constant value of $\mathrm{M} / \rho \mathrm{Vd}$ equal to 351 . That is, increases in the reinforcement ratio $(\rho=0.57 \%-2.28 \%)$ are associated with increases in the $\mathrm{a} / \mathrm{d}$ ratio $(\mathrm{a} / \mathrm{d}=2-8)$. Specimen MB15, which had the same properties of specimen MB8 with $a / d=2$ and $\rho=0.57 \%$, was designed to have a double curvature, so as to potentially avoid strut-and-tie behavior following breakdown in beam action (Figure 4-13). 
Interesting, MB15 failed at a shear force $(125 \mathrm{kN})$ considerably higher than MB8 $(84 \mathrm{kN})$. It is not entirely clear why this is. A potential reason might be that the beam followed strut-andtie behavior. Hence, this beam failed at a higher shear force.

Note that, with the exception of MB15, the specimens in this series failed at a roughly constant shear stress $(0.78 \mathrm{MPa}, 0.89 \mathrm{MPa}, 0.89 \mathrm{MPa}$ and $0.82 \mathrm{MPa}$ respectively for the beams with 3, 4, 6 and 8 bars). This is in contrast to the behavior exhibited in series 3 , where the failure shear stress increased as the reinforcement ratio increased.

If the failure shear stress of MB8 ( $0.84 \mathrm{MPa})$ is compared to the failure shear stress of MB2, MB11, MB12 and MB13, the roughly constant value of the failure shear stress as a function of $\mathrm{M} / \mathrm{\rho Vd}$ is evident.

It can be plainly concluded, then, that when formulating shear design equations to account for the effects of the longitudinal reinforcement, it is not the amount of reinforcement that affects shear strength, per se, but rather the strain in the reinforcement.

The load rate of the first failure for specimen MB2, MB11 and MB13 was $0.02 \mathrm{~mm} / \mathrm{sec}, 0.03$ $\mathrm{mm} / \mathrm{sec}$ for MB12 and $0.01 \mathrm{~mm} / \mathrm{sec}$ for MB15. For the repeated part, the load rate was 0.05 $\mathrm{mm} / \mathrm{sec}$ for MB2, MB11 and MB13 and it was $0.1 \mathrm{~mm} / \mathrm{sec}$ for MB12.

In specimen MB2 which had the same material and sectional properties as MB1, at two load stages the specimen was load cycled with the purpose of studying the effect of cycling load on the crack width by comparing with the results of the similar specimen (MB1). That is, after taking four load stages at $\mathrm{P}=55,75,95$ and $120 \mathrm{kN}$, the load was cycled 20 times between $\mathrm{P}=120 \mathrm{kN}$ and $64 \mathrm{kN}$. At the end of cycling, a load stage was then taken at a load of $120 \mathrm{kN}$. The next load stage then was taken at a load of $140 \mathrm{kN}$. The load was again cycled 
20 times between $\mathrm{P}=140 \mathrm{kN}$ and $64 \mathrm{kN}$ and at the end of cycling a load stage was taken at a load of $140 \mathrm{kN}$. However, there was no cycling load for the repeated part of this specimen and the beam failed after taking one load stage for this part. For the first failure part of specimen MB13, failure occurred on the $2^{\text {nd }}$ day of testing due to the large amount of work that must be done at each load stage. On the first day, 4 load stages were taken up to a load of $90 \mathrm{kN}$ (roughly $60 \%$ of the final predicted load) and then it was completely unloaded. On the second day ( 3 days after the first day) the first load stage was taken at $90 \mathrm{kN}$.

For the repeated part of specimen MB11 a load stage was taken at the same failure load as the first part $(178 \mathrm{kN})$, however, before finishing reading demec gauges and measuring crack widths, the specimen failed. This sudden failure occurred because the load was not decreased by $10 \%$ at the load stage. For specimen MB13 no load stage was taken for the repeated part of this beam since failure happened at roughly the same failure load as the first part. Failure was accompanied by a big bang and concrete delaminating. For the repeated part of specimen MB12, loading was done in two phases. During the first phase the beam lengthened a considerable amount, such that the rollers fell off at the end of the beam. Therefore, the loading was halted at a load of $154 \mathrm{kN}$. After the support was re-assembled, loading was started for a second time and failure happened without any load stage at the same failure load of the first part (Table 4-1).

Figure 4-14 shows the applied load versus mid-span displacement for this series and figures 4-15, 4-16 and 4-17 show the applied load versus mid-span displacement, rebar strain and shear strain for MB2 of this series with cycling load. Figures 4-18 and 4-19 show the applied load versus shear strain $(\gamma)$ and rebar strain for this series. All graphs follow the same pattern of linear behavior up to the first cracks with reduction in post-cracking stiffness. In Figure 4- 
18 , it can be seen that the post-cracking shear stiffnesses of each beam are roughly similar. This was not the case for series 3 . It is likely that the similarity in crack widths is the cause of the similarity of stiffnesses.

The cycles of loads for specimen MB2 resulted in considerable increases in shear strain during the second series of cycles. This increase appears to have been due to increases in diagonal crack widths. This increase in diagonal crack width can be seen in Figure 4-20. It can be seen that during the first cycles of load $(120 \mathrm{kN}-64 \mathrm{kN})$, there is no appreciable change in the maximum flexural and diagonal crack widths. However, after the second series of load cycles $(140 \mathrm{kN}-64 \mathrm{kN})$, which were close to the failure load $(155 \mathrm{kN})$, there is a considerable increase in the maximum diagonal crack width $(0.14 \mathrm{~mm}$ to $0.40 \mathrm{~mm})$ but only a small increase in the maximum flexural crack width $(0.60 \mathrm{~mm}$ to $0.68 \mathrm{~mm})$. A potential reason is the nature of the opening and closing of shear and flexural cracks. That is, by increasing load on a beam the flexural cracks grow wider, however, unloading the beam will result in closing of the flexural cracks. For diagonal cracks, however, a component of the crack width is associated sliding of the aggregates diagonally. With unloading the beam, these aggregates are not able to slide and come back to their initial position, hence, the diagonal cracks cannot fully close after each load cycle and will show a considerable increase. It appears from Figure 4-20 that cycles of high load can have a considerable effect on diagonal crack width. 


\subsection{Code Comparison}

This section will present a comparison between the experimental failure shear stresses of the fifteen specimens and those predicted by seven prominent shear design methods for FRP reinforced concrete structures. These methods were discussed in section 2.3.

Tables 4-2, 4-3, 4-4, 4-5, 4-6, 4-7 and 4-8 show a summary of the predicted results calculated from each of these methods based on the specimens' properties. It is notable to say that, for the $1^{\text {st }}$ series with $\mathrm{a} / \mathrm{d}=2$, to predict the results from the CSA method, the shear strength was taken as the larger of the beam action strength or the strut-and-tie action strength. While the sectional analysis of the $2004 \mathrm{CSA}$ method gave a shear stress of $0.73,0.91$ and $1.13 \mathrm{MPa}$ for specimens MB8, MB9 and MB10 respectively, analysis from the strut-and-tie method (Eq. 2-10 section 2.2.7) gave a higher shear stress of $0.96,1.24$ and $1.57 \mathrm{MPa}$ respectively. That is, the shear failure of the specimens of this series is predicted to be governed by strutand-tie action and gives a higher shear stress value. Appendix A gives an example of strutand-tie calculations by CSA method which has a trial-and-error process and which was performed using a spreadsheet.

All results from these codes are outlined in Table 4-9 and comparisons are made between all the shear design methods. In this table, the experimental results value for shear stress ( $\left.v_{\exp }\right)$ is an average of the failure shear stresses of both sides of the specimen. The ratio of experimental to predicted shear stress $\left(v_{\text {exp }} / v_{\text {pred }}\right)$ for each specimen is shown for each code. An average (mean) value of all $v_{\text {exp }} / v_{\text {pred }}$ values for each code is shown. The standard deviation of the predicted results for each code is also shown. The Coefficient of Variation $(\mathrm{COV})$ (calculated as $\mathrm{COV}=$ standard deviation / mean value) is a normalized measure of the dispersion of the data and is also shown. 
A percentile is the value of a variable below which a certain percent of observations fall. For a normal distribution, the $1^{\text {st }}$ percentile can be calculated as 2.33 standard deviations from the mean. The first percentile value is very useful when analyzing experimental results, as it has been traditionally used as a measure of the required material strength reduction factor (MacGregor and Bartlett (2000)). It is worth noting that, for specimen MB15, the $v_{\text {exp }} / v_{\text {pred }}$ was extremely high for all methods. As a result, to obtain a better comparison between these methods, the results of this specimen were not considered in the calculation of the mean value, standard deviation, $\mathrm{COV}$ and $1^{\text {st }}$ percentile in this table.

As can be seen from Tables 4-2 and 4-9 that the modified CSA equations for shear strength (Hoult's Equation) produce conservative, but accurate, estimates of shear strength. The average ratio of experimental to predicted shear stress, $v_{\text {exp }} / v_{\text {pred }}$ was 1.14 with a coefficient of variation $(\mathrm{COV})$ of $9.9 \%$ for the fourteen specimens. The $1^{\text {st }}$ percentile of the results predicted from this method was 0.88 . That is, it can be expected that $99 \%$ of the experimental results should be stronger than 0.88 times the strength calculated by this method. As 0.88 exceeds the ACI reduction factor for shear of 0.75 , it can be concluded that the CSA code provides safe results for the shear strength of FRP-reinforced members. In comparison, the unmodified version of the CSA A23.3 gives a relatively higher value of $v_{\exp } / v_{\text {pred }}(1.33 / 1.14=$ $11.7 \%)$, standard deviation $(0.19 / 0.11=16.8 \%)$ and $\operatorname{COV}(14.2 / 9.9=14.4 \%)$ compared to the modified version of CSA code. These results indicate that the $2^{\text {nd }}$ order approximation (the modified expression for $\beta$ ) gives more accurate predictions of the shear strength for FRPreinforced members compared to the $1^{\text {st }}$ order approximation (the unmodified version of the CSA code for steel-reinforced members). 
The results from Table 4-2 indicate that the CSA A23.3 method predict that the shear stress of members without shear reinforcement is a function of strain in the longitudinal reinforcement which is a function of $\mathrm{M} / \mathrm{\rho Vd}$. That is, the shear stress of a concrete member without shear reinforcements is not a function of reinforcement ratio $\rho$ or a/d ratio solely, rather is a function of $\mathrm{M} / \mathrm{\rho Vd}$. It can be seen the shear stresses increased by decreasing the $\mathrm{M} / \mathrm{\rho d}$ value, however, for the $4^{\text {th }}$ series this method keeps the shear stresses constant while members have a constant value of $\mathrm{M} / \mathrm{\rho Vd}$.

As might be expected, the simplified shear design method from the 1994 CSA A23.3 code (Equations 2-16 and 2-17) do not accurately or safely predict the shear strengths of these members. This is because the method is intended for steel-reinforced members.

As can be seen from Tables 4-3 and 4-9, the ACI 440 method (Frosch (2003)) predicts extremely conservative shear strength for all the series and gave the highest mean $v_{\exp } / v_{\text {pred }}$ ratio of 1.86 among these methods with a coefficient of variation of $28.8 \%$. It can be seen from the $2^{\text {nd }}$ series which have the same reinforcement ratio, this method predicts nearly the same shear strength $(0.88$ and $0.90 \mathrm{MPa})$ for both specimens of this series with a/d of 3 and 8 because this method does not account for $\mathrm{M} / \mathrm{V}$ ratio as an index for strain effect. This method could not also predict a constant value of shear stress for the $4^{\text {th }}$ series which has a constant value of $\mathrm{M} / \mathrm{\rho Vd}$, and also by comparing the $3^{\text {rd }}$ and $4^{\text {th }}$ series it can be seen that the Frosch method predicts the same shear stress for the specimens with the same value of reinforcement ratio although these specimens have difference $\mathrm{a} / \mathrm{d}$ ratio.

For the CSA Committee S806 (2002), while it would appear that this code could predict the experimental behavior of the $4^{\text {th }}$ series, in fact it does not. This is because the lower limit of 
Equation 2-19 applies for all of the specimens. As such, a designer using this code could not accurately predict the effect of increasing a/d. For this series, this code gives a relatively high mean value (1.52) with a COV of $19.6 \%$. It thus offers extremely conservative predictions.

As El-Sayed's shear strength equations gave a mean $v_{\exp } / v_{\text {pred }}$ value of 1.42 with a high COV of 28.3 , and relatively low value of $1^{\text {st }}$ percentile of 0.48 , (which is considerably smaller than the strength reduction factor for shear) it appears that this method could not be safe to use. The shear strength equation of this method does not account for size effect and effect of $\mathrm{M} / \mathrm{V}$. That is, it can be seen in Table 4-5 that for the $2^{\text {nd }}$ series it predicts a nearly constant shear stress for both specimens (1.05 and $1.02 \mathrm{MPa})$ with a/d of 3 and 8 . It also can be seen that, for specimen MB13 with $\mathrm{a} / \mathrm{d}=8$ and specimen MB6 with $\mathrm{a} / \mathrm{d}=3$, it predicted a constant shear stress. In addition, the El-Sayed shear strength equation could not predict a constant shear stress for specimens in the $4^{\text {th }}$ series which have the constant value of $M / \rho V d$. As such, the $v_{\text {exp }} / v_{\text {pred }}$ values drop as $\rho$ increases in the $4^{\text {th }}$ series, whereas the $v_{\text {exp }} / v_{\text {pred }}$ values are roughly constant for the $3^{\text {rd }}$ series.

Since the ISIS method does not account for the effect of $\rho, M / V$ and size effect for members with $d<300$, it gives a constant shear strength value for all the specimens (Table 4-6) with the highest standard deviation of 0.63 which resulted in the lowest $1^{\text {st }}$ percentile value. Clearly this method cannot ensure adequate safety against shear failure of FRP-reinforced members without shear reinforcements.

The JSCE (1997) method gave a mean value of 1.43 with a relatively high COV and standard deviation which resulted in a low value of $1^{\text {st }}$ percentile, indicating unsafe shear predictions. This method does not account for the $\mathrm{M} / \mathrm{V}$ effect which resulted in a constant shear stress 
prediction for both specimens of the $2^{\text {nd }}$ series (Table 4-7) which have a relatively high difference in $\mathrm{a} / \mathrm{d}$. This also happened for those similar specimens in the $3^{\text {rd }}$ and $4^{\text {th }}$ series which have different a/d ratio.

The Razaqpur and Isgor predictions had a mean $v_{\text {exp }} / v_{\text {pred }}$ value of 1.10 with a relatively high COV of 22.2. It appears that this method is not able to ensure adequate safety against shear failure since this method gave a $1^{\text {st }}$ percentile for the specimens of 0.53 which is smaller than the material strength reduction factor for shear. It also can be seen from Table 4-8 that this method cannot predict a constant failure stress for the $4^{\text {th }}$ series which has a constant $M / \rho V d$ value. Also note that it is not effective at capturing the behavior of the beams with a/d=2 (series 1).

It can be seen that, compared to the other methods, the 2004 CSA A23.3 method with the modified expression for $\beta$ had a $v_{\text {exp }} / v_{\text {pred }}$ ratio of 1.14 and the lowest COV of the methods. It can be concluded that CSA A23.3 method with the modified expression for $\beta$ is able to generate safe and accurate predictions of the shear strength of FRP-reinforced concrete beams and one-way slabs. This demonstrates the advantages of basing shear design methods on accurate and rational theories of shear.

Figures 4-21, 4-22, 4-23 and 4-24 show a comparison of the shear strength from the Hoult et. al. and Frosch predictions with the experimental results. Figures 4-21 and 4-22 provide the normalized shear stress versus the shear span to depth ratio, a/d. As can be seen in Figure 421 Hoult's predictions provide a conservative but rather accurate shear strength for the both specimens with either $\rho=4.05 \%$ and $\rho=2.28 \%$. That is, by increasing the $\mathrm{a} / \mathrm{d}$ ratio in these specimens the shear strength will decrease due to the increase in the strain in the longitudinal 
reinforcement. In comparison, the Frosch predictions show a poor estimation of shear strength with respect to the a/d ratio (Figure 4-22). It can be seen that the Frosch equations predict a constant shear strength for $\mathrm{a} / \mathrm{d}=3$ and 8 , and hence do not match the experimental results.

Figures 4-23 and 4-24 show the normalized failure shear stress versus reinforcement ratio for series 3 and 4. As can be seen in Figure 4-23 the Hoult modification to the 2004 CSA code predicts appropriate shear strengths for series 3 , and these match the behavior of the experimental results. That is, by increasing the reinforcement ratio but having a constant $\mathrm{a} / \mathrm{d}$

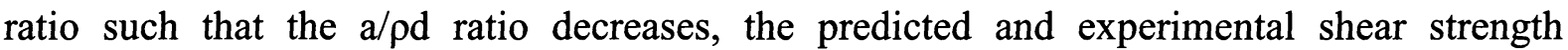
increase. In comparison, Figure 4-24 shows extremely conservative shear strength predictions from the Frosch equations.

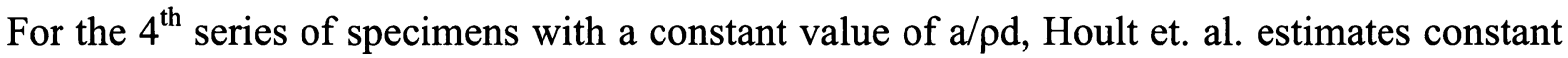
shear strengths for this series, which is appropriate compared to the experimental results. In this series if the results from specimen $\operatorname{MB} 15(\rho=0.57, a / d=2)$ are replaced with the results of specimen MB8 $(\rho=0.57, a / d=2)$ which failed in strut-and tie action, it can be seen that the experimental results follows a rather constant shear strength for the specimens of this series. However, the Frosch equations provide a very poor estimate of the shear strength for the $4^{\text {th }}$ series compared to the observed experimental behavior (Figure 4-24). From these two figures, it seems evident that it is not the percentage of longitudinal reinforcement $(\rho)$ which governs the shear strength, but rather the strain in this reinforcement which is a function both $\rho$ and $\mathrm{a} / \mathrm{d}$, and Hoult's equations can accurately estimate this shear strength. 


\subsection{Examination of the Role of Crack Widths on Observed Behavior}

As mentioned earlier, failure shear stresses of members without shear reinforcements are related to the strain in the longitudinal reinforcement, and a measure of this is $\mathrm{M} / \mathrm{\rho Vd}$. That is, the failure shear stress of these members will decrease when strain in the longitudinal reinforcement increases. Higher reinforcement stresses will result in wider cracks. As the cracks grow wide, the aggregate interlock resistance decreases and these wide cracks will not be able to transmit the shear stresses required to maintain beam action, at which point failure occurs. Any action that increases the crack widths will result in decreased shear strength of the member. In this section the effect of observed crack widths on the experimentally observed shear strengths of these members will be analyzed.

Figures $4-25,4-26,4-27$ and 4-28 show the maximum crack widths versus experimental shear stress $\left(\mathrm{V} / \mathrm{b}_{\mathrm{w}} \mathrm{d}\right)$ for each group of specimens. These crack widths are the widest single cracks width measured everywhere on the beam. For the $1^{\text {st }}$ series, three specimens were grouped with the constant $\mathrm{a} / \mathrm{d}$ of 2 . It can be seen that by decreasing the reinforcement ratio from 2.28 to $0.57 \%$, the maximum crack width tended to increase. That is, with a constant $\mathrm{a} / \mathrm{d}$ ratio but decreasing the reinforcement ratio, the parameter $\mathrm{M} / \mathrm{\rho Vd}$ will increase. Therefore, by decreasing the reinforcement ratio in this series, the strain in the longitudinal reinforcement will increase. This increase results in wider crack widths. As cracks get wider, the shear strength will decrease and specimen will fail at a smaller shear stress. However, it can be seen from this series that after beam action broke down, there was a sudden increase in the crack widths at the moment that beam action switched to the strut-and-tie action. This action allows the specimen to carry higher shear stresses before failure with higher crack width. That is, at the moment that specimens had relatively wide crack widths which are not 
able to transmit the shear stresses by beam action, shear forces will transmit to the support by strut-and-tie action through a diagonal compression strut. The sudden increases in crack width displayed in Figure 4-25 correspond to the sudden increases in shear strain displayed in Figure 4-5. Narrower cracks in Figure 4-25 are associated with a higher beam shear capacity before engaging strut-and-tie action.

In the second series, the relationship between maximum crack width and shear stress is remarkable (Figure 4-26). In this series two specimens were grouped with $8 \# 8$ bars to make $\rho=4.05$. It can be seen that for the same amount of shear stress, the specimen with $a / d=8$ has much wider cracks than the specimen with $\mathrm{a} / \mathrm{d}=3$. For instance, when both specimens had the same shear stress of $0.5 \mathrm{MPa}$, the cracks in the specimen with $\mathrm{a} / \mathrm{d}=8$ were almost 5 times wider $(0.25 \mathrm{~mm})$ than those in the specimen with $\mathrm{a} / \mathrm{d}=3(0.05 \mathrm{~mm})$. It also can be seen from this series that the crack widths tend to increase when the a/d ratio increases which is a result of increasing the strain in the longitudinal reinforcement. It is quite clear that cracks were wider in the beam with $\mathrm{a} / \mathrm{d}=8$, and this provides a convincing explanation for its lower shear strength.

For the third series (Figure 4-27) the parameter $\mathrm{M} / \mathrm{\rho Vd}$ in the specimens decreases at a constant value of a/d by increasing the reinforcement ratio. The pattern of crack widths from the $2^{\text {nd }}$ series also can be seen in the $3^{\text {rd }}$ series. That is, lower crack widths are generally associated with higher $\rho$. Increasing $\mathrm{M} / \rho \mathrm{Vd}$ (by decreasing $\rho$ at a constant value of $\mathrm{a} / \mathrm{d}$ ), resulting in higher strains in the longitudinal reinforcement, resulted in wider cracks. We can thus see that wider cracks are associated both with reduced reinforcement ratios (Figure 427) and increased a/d values (Figure 4-26). The wider cracks associated with lower 
reinforcement ratios in series 3 offer a compelling explanation for the reduced shear strengths as $\rho$ decreased.

For the $4^{\text {th }}$ series with a constant $\mathrm{M} / \mathrm{\rho Vd}$ ratio (Figure 4-28), specimens tended to have the same crack widths at low shear stresses due to the constant $\mathrm{M} / \mathrm{\rho Vd}$ value, the exception being MB15. However, as shear stress increased, higher crack widths were observed in the specimen with the highest $a / d$ and reinforcement ratio $(a / d=8, \rho=2.28 \%)$ than the specimen with the lowest $a / d$ and reinforcement ratio $(a / d=3, \rho=0.86 \%)$. That is, while both specimens with 3 and 8 bars ( $\rho=0.86 \%$ and $2.28 \%$ ) are expected to have the same strain due to the constant value of $\mathrm{M} / \mathrm{\rho Vd}$ and the same crack widths, the specimen with 8 bars shows wider cracks than the specimen with 3 bars. Furthermore, the specimen widths $a / d=4$ and $\rho=1.14 \%$ exhibited roughly similar crack widths to those in the specimens with $\mathrm{a} / \mathrm{d}=8$ and $\rho=2.28 \%$.

In Figure 4-29, the maximum crack widths for various companion beams in series 3 and 4 are plotted. These are for the beams with $\rho=1.71 \%$ and $2.28 \%$. The patterns of the crack widths in this figure match those exhibited in Figures 4-27 and 4-28. Namely, wider cracks are exhibited in the beams with higher a/d ratios and lower reinforcement ratios. Bearing in mind the importance of crack widths on shear strength, it can be seen that a/d affects shear strength, as does $\rho$.

Figure 4-30 shows a comparison between three groups of specimens. In each group, two specimens were grouped with the same value of reinforcement ratio $(0.57 \%, 1.14 \%$ or $2.28 \%$ ), however, one of the specimens of each group had $a / d=2$ while the other had $a / d=3$. In comparing the crack widths plotted in Figure 4-30, it can be seen that, prior to beam action breaking down, considerably wider cracks were observed in the beams with $a / d=3$ than the 
companion beams where $a / d=2$. For beams with $\rho=2.28 \%$, for example, at a shear stress of $1 \mathrm{MPa}$, the widest crack was $0.15 \mathrm{~mm}$ where $\mathrm{a} / \mathrm{d}=2$, whereas it was $0.4 \mathrm{~mm}$ where $\mathrm{a} / \mathrm{d}=3$, a 2.7 times increase. The effect of $\rho$ and a/d on crack widths is thus clearly exhibited in Figure 430.

Figures 4-31, 4-32, 4-33 and 4-34 show maximum crack width versus predicted mid-span FRP strain calculated based on a linear-elastic analysis of the section (Appendix B). In Figure 4-32, it can be seen that the crack widths are roughly constant as a function of reinforcement strains, though this ceases to be the case when beam action breaks down in Figure 4-31. Note, however, that the loads at which beam action break down increase with increasing strain.

The maximum crack widths as a function of longitudinal FRP strain for series 3 and 4 are shown in Figures 4-33 and 4-34. It had been expected that the patterns of crack widths in these figures would resemble that in Figure 4-32: namely, similar crack widths as a function of strain. This was not the case. Instead, with the exception of the beams with $\rho=0.57 \%$ wider cracks were observed in the specimens with higher reinforcement as a function of the longitudinal strain. This was the case in the both series 3 and 4 . 
Table 4-1: Experimental Observations

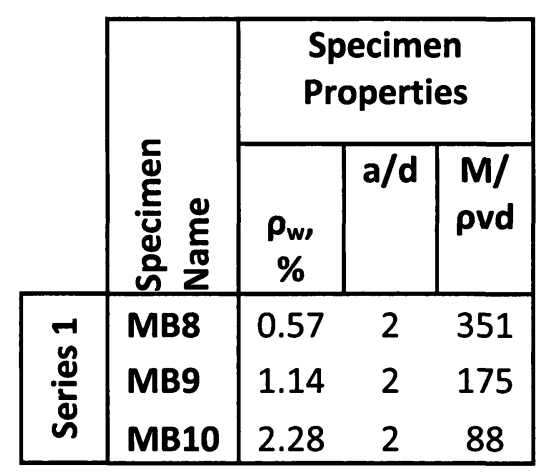

\begin{tabular}{|c|c|c|c|c|c|c|c|c|}
\hline \multicolumn{9}{|c|}{ Experimental Observations } \\
\hline $\begin{array}{l}f^{\prime} c \text {, } \\
\mathrm{MPa}\end{array}$ & $\begin{array}{c}P_{\text {exp }} \\
\text { kN }\end{array}$ & $\begin{array}{c}V_{\text {exp }} \\
k N\end{array}$ & $\begin{array}{l}V_{\text {EXP, }} \\
\text { MPa }\end{array}$ & $\begin{array}{l}v_{\text {EXP }} / \\
v^{\prime}{ }^{\prime} \mathrm{c} \\
\mathrm{MPa}\end{array}$ & $\begin{array}{c}\Delta_{x} \text { ult } \\
10^{-3}\end{array}$ & $\begin{array}{c}\gamma_{x} \text { ult } \\
10^{-3}\end{array}$ & $\begin{array}{c}\varepsilon_{\mathrm{s}, \max } \\
\mu \varepsilon\end{array}$ & $\begin{array}{c}\mathbf{w}_{\text {maxo }} \\
\mathrm{mm}^{\prime}\end{array}$ \\
\hline 51.6 & 168 & 84 & 0.84 & 0.12 & 5.8 & 9.0 & 6247 & 1.56 \\
\hline 51.0 & 239 & 120 & 1.20 & 0.17 & 5.1 & 6.1 & 3808 & 1.50 \\
\hline 50.9 & 403 & 201 & 2.01 & 0.28 & 4.4 & 4.1 & 2639 & 1.40 \\
\hline
\end{tabular}

\begin{tabular}{|c|c|c|c|c|c|c|}
\hline \multicolumn{7}{|c|}{ Experimental Observations (Repeated Side) } \\
\hline $\begin{array}{l}f^{\prime} c, \\
\mathrm{MPa}\end{array}$ & $\begin{array}{c}P_{\text {exp }} \\
\text { KN }\end{array}$ & $\begin{array}{c}V_{\text {exp }} \\
\text { kN }\end{array}$ & $\begin{array}{l}v_{\text {EXP, }} \\
\mathrm{MPa}\end{array}$ & $\begin{array}{l}v_{\text {EXP }} / \\
\text { vf'c, } \\
\text { MPa }\end{array}$ & $\begin{array}{c}\gamma_{x} \text { ult } \\
10^{-3} \\
\end{array}$ & $\begin{array}{c}\mathbf{w} \\
\max \\
\mathbf{m m}\end{array}$ \\
\hline 51.6 & 183 & 92 & 0.92 & 0.13 & 21.0 & 7.80 \\
\hline 51.0 & 239 & 120 & 1.20 & 0.17 & 6.1 & 1.50 \\
\hline 50.8 & 465 & 233 & 2.33 & 0.33 & 3.9 & 2.40 \\
\hline
\end{tabular}

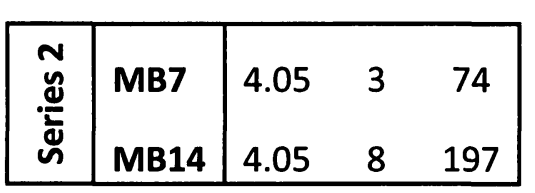

\begin{tabular}{|lcccccccc|}
\hline 51.5 & 270 & 135 & 1.35 & 0.19 & 3.4 & 1.3 & 2036 & 0.20 \\
47.8 & 195 & 97 & 0.97 & 0.14 & 37.7 & 3.2 & 10337 & 0.40 \\
\hline
\end{tabular}

\begin{tabular}{|ccccccc|}
51.5 & 269 & 134 & 1.34 & 0.19 & 0.5 & - \\
- & - & - & - & - & - & - \\
\hline
\end{tabular}

\begin{tabular}{|c|c|c|c|c|}
\hline \multirow{5}{*}{ 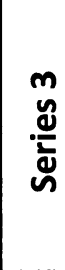 } & MB3 & 0.57 & 3 & 526 \\
\hline & MB1 & 0.86 & 3 & 351 \\
\hline & MB4 & 1.14 & 3 & 263 \\
\hline & MB5 & 1.71 & 3 & 175 \\
\hline & MB6 & 2.28 & 3 & 132 \\
\hline
\end{tabular}

\begin{tabular}{|ccccccccc|}
\hline 51.4 & 112 & 56 & 0.56 & 0.08 & 7.3 & 2.9 & 6212 & 1.20 \\
49.4 & 148 & 74 & 0.74 & 0.11 & 6.3 & 1.4 & 5233 & 0.60 \\
51.4 & 171 & 85 & 0.85 & 0.12 & 5.8 & 1.8 & 4755 & 0.60 \\
51.4 & 215 & 108 & 1.08 & 0.15 & 5.2 & 2.0 & 4024 & 0.32 \\
51.5 & 230 & 115 & 1.15 & 0.16 & 4.6 & 2.8 & 3666 & 0.42 \\
\hline
\end{tabular}

\begin{tabular}{|ccccccc|}
\hline 51.4 & 174 & 87 & 0.87 & 0.12 & 3.5 & 3.06 \\
49.6 & 159 & 80 & 0.80 & 0.11 & 1.0 & 0.62 \\
51.4 & 204 & 102 & 1.02 & 0.14 & 2.7 & 0.66 \\
51.4 & 207 & 104 & 1.04 & 0.14 & 0.9 & - \\
51.5 & 232 & 116 & 1.16 & 0.16 & 0.3 & 0.62 \\
\hline
\end{tabular}

\begin{tabular}{|c|c|c|c|c|}
\hline \multirow{5}{*}{ 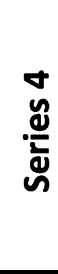 } & MB15 & 0.57 & 2 & 351 \\
\hline & MB2 & 0.86 & 3 & 351 \\
\hline & MB11 & 1.14 & 4 & 351 \\
\hline & MB12 & 1.71 & 6 & 351 \\
\hline & MB13 & 2.28 & 8 & 351 \\
\hline
\end{tabular}

\begin{tabular}{|ccccccccc|}
\hline 46.9 & $375^{(1)}$ & 125 & 1.25 & 0.18 & 8.7 & 7.9 & 8035 & 1.70 \\
50.4 & 155 & 78 & 0.78 & 0.11 & 7.3 & 4.0 & 6058 & 0.68 \\
50.6 & 178 & 89 & 0.89 & 0.13 & 15.3 & 2.5 & 6724 & 0.86 \\
49.7 & 178 & 89 & 0.89 & 0.13 & 31.7 & 5.5 & 6975 & 0.54 \\
48.2 & 165 & 82 & 0.82 & 0.12 & 47.3 & 0.7 & 6806 & 0.88 \\
\hline
\end{tabular}

\begin{tabular}{|ccccccc|}
\hline- & - & - & - & - & - & - \\
51.1 & 169 & 84 & 0.84 & 0.12 & 1.4 & 0.78 \\
51.0 & 175 & 87 & 0.87 & 0.12 & 1.4 & - \\
50.0 & 170 & 85 & 0.85 & 0.12 & 5.2 & - \\
47.7 & 163 & 81 & 0.81 & 0.12 & 2.3 & - \\
\hline
\end{tabular}

\footnotetext{
Note: ${ }^{(1)} \quad$ Maximum Machine Load
} 
Table 4-2: CSA A23.3 Predicted Results

\begin{tabular}{|l|c|c|c|c|}
\cline { 2 - 5 } \multicolumn{1}{c|}{} & \multicolumn{4}{c|}{ Specimen Properties } \\
\hline $\begin{array}{l}\text { Specimen } \\
\text { Name }\end{array}$ & $\begin{array}{c}\rho_{\text {w, }} \\
\%\end{array}$ & a/d & $\begin{array}{c}\text { M/ } \\
\text { pvd }\end{array}$ & $\begin{array}{c}\mathbf{f}^{\prime} c \text { c, } \\
\text { MPa }\end{array}$ \\
\hline MB8 & 0.57 & 2 & 351 & 52 \\
MB9 & 1.14 & 2 & 175 & 51 \\
MB10 & 2.28 & 2 & 88 & 51 \\
\hline
\end{tabular}

\begin{tabular}{|c|c|}
\hline \multicolumn{2}{|c|}{\begin{tabular}{c|c|} 
1994 CSA \\
A23.3
\end{tabular}} \\
\hline $\mathbf{V} \mathbf{V}$ & $\mathbf{V}$ \\
$\mathbf{k N}$ & $\mathbf{M P a}$ \\
\hline 119 & 1.19 \\
119 & 1.19 \\
119 & 1.19 \\
\hline
\end{tabular}

\begin{tabular}{|c|c|c|}
\hline \multicolumn{3}{|c|}{ CSA A23.3 (2004) } \\
General Method \\
\hline $\boldsymbol{\beta}$ & $\begin{array}{c}\mathbf{V} \\
\mathbf{k N}\end{array}$ & $\begin{array}{c}\mathbf{V} \\
\mathbf{M P a}\end{array}$ \\
\hline 0.090 & 58 & 0.58 \\
0.121 & 78 & 0.78 \\
0.159 & 102 & 1.02 \\
\hline
\end{tabular}

\begin{tabular}{|c|c|c|}
\hline \multicolumn{3}{|c|}{$\begin{array}{c}\text { CSA-A23.3 (2004) } \\
\text { (Hoult Eq.) }\end{array}$} \\
\hline $\boldsymbol{\beta}$ & $\begin{array}{c}\mathbf{V}, \\
\mathbf{k N}\end{array}$ & $\begin{array}{c}\mathbf{V} \\
\mathbf{M P a}\end{array}$ \\
\hline 0.112 & 73 & 0.73 \\
0.142 & 91 & 0.91 \\
0.177 & 114 & 1.14 \\
\hline
\end{tabular}

\begin{tabular}{|l|cccc|}
\hline MB7 & 4.05 & 3 & 74 & 52 \\
MB14 & 4.05 & 8 & 197 & 48 \\
\hline
\end{tabular}

\begin{tabular}{|ll|}
\hline 119 & 1.19 \\
115 & 1.15 \\
\hline
\end{tabular}

\begin{tabular}{|ccc|}
\hline 0.173 & 112 & 1.12 \\
0.119 & 74 & 0.74 \\
\hline
\end{tabular}

\begin{tabular}{|ccc|}
\hline 0.190 & 123 & 1.23 \\
0.141 & 88 & 0.88 \\
\hline
\end{tabular}

\begin{tabular}{|l|llll|}
\hline MB3 & 0.57 & 3 & 526 & 51 \\
MB1 & 0.86 & 3 & 351 & 49 \\
MB4 & 1.14 & 3 & 263 & 51 \\
MB5 & 1.71 & 3 & 175 & 51 \\
MB6 & 2.28 & 3 & 132 & 52 \\
\hline
\end{tabular}

\begin{tabular}{|ll|}
\hline 119 & 1.19 \\
117 & 1.17 \\
119 & 1.19 \\
119 & 1.19 \\
119 & 1.19 \\
\hline
\end{tabular}

\begin{tabular}{|lll|}
\hline 0.075 & 48 & 0.48 \\
0.090 & 57 & 0.57 \\
0.101 & 65 & 0.65 \\
0.120 & 77 & 0.77 \\
0.135 & 87 & 0.87 \\
\hline
\end{tabular}

\begin{tabular}{|ccc|}
\hline 0.097 & 62 & 0.62 \\
0.112 & 71 & 0.71 \\
0.123 & 80 & 0.80 \\
0.141 & 91 & 0.91 \\
0.155 & 100 & 1.00 \\
\hline
\end{tabular}

\begin{tabular}{|l|llll|}
\hline MB15 & 0.57 & 2 & 351 & 47 \\
MB2 & 0.86 & 3 & 351 & 50 \\
MB11 & 1.14 & 4 & 351 & 51 \\
MB12 & 1.71 & 6 & 351 & 50 \\
MB13 & 2.28 & 8 & 351 & 48 \\
\hline
\end{tabular}

\begin{tabular}{|ll|}
\hline 114 & 1.14 \\
118 & 1.18 \\
118 & 1.18 \\
117 & 1.17 \\
115 & 1.15 \\
\hline
\end{tabular}

\begin{tabular}{|lll|}
\hline 0.092 & 57 & 0.57 \\
0.090 & 57 & 0.57 \\
0.089 & 57 & 0.57 \\
0.089 & 57 & 0.57 \\
0.090 & 56 & 0.56 \\
\hline
\end{tabular}

\begin{tabular}{|lll|}
\hline 0.114 & 70 & 0.70 \\
0.112 & 72 & 0.72 \\
0.112 & 71 & 0.71 \\
0.112 & 71 & 0.71 \\
0.112 & 70 & 0.70 \\
\hline
\end{tabular}

\begin{tabular}{|l|c|c|c|c|}
\cline { 2 - 5 } \multicolumn{1}{c|}{} & \multicolumn{4}{c|}{ Specimen Properties } \\
\hline $\begin{array}{l}\text { Specimen } \\
\text { Name }\end{array}$ & $\begin{array}{c}\boldsymbol{\rho}_{\text {w, }} \\
\text { \% }\end{array}$ & $\begin{array}{c}\text { a/ } \\
\text { d }\end{array}$ & $\begin{array}{c}\text { M/ } \\
\text { pvd }\end{array}$ & $\begin{array}{c}\text { f'c, } \\
\text { MPa }\end{array}$ \\
\hline MB8 & 0.57 & 2 & 351 & 52 \\
MB9 & 1.14 & 2 & 175 & 51 \\
MB10 & 2.28 & 2 & 88 & 51 \\
\hline
\end{tabular}

\begin{tabular}{|c|c|}
\hline \multicolumn{2}{|c|}{$\begin{array}{c}\text { CSA-A23.3 } \\
\text { and-Tie Method }\end{array}$} \\
\hline $\begin{array}{c}\mathbf{V} \\
\text { (kN) }\end{array}$ & $\begin{array}{c}\text { V } \\
\text { (MPa) }\end{array}$ \\
\hline 96 & 0.96 \\
124 & 1.24 \\
157 & 1.57 \\
\hline
\end{tabular}


Table 4-3: ACI Method (Frosch (2003)) Predicted Results

\begin{tabular}{|l|c|c|c|c|c|c|}
\cline { 2 - 7 } \multicolumn{1}{c|}{} & \multicolumn{6}{c|}{ Specimen Properties } \\
\hline $\begin{array}{c}\text { Specimen } \\
\text { Name }\end{array}$ & $\begin{array}{c}\boldsymbol{\rho}_{\mathbf{w}} \\
\%\end{array}$ & $\begin{array}{c}\text { Ef } \\
\mathbf{G p a}\end{array}$ & $\begin{array}{c}\mathbf{a} \\
(\mathbf{m m})\end{array}$ & $\mathbf{a} / \mathbf{d}$ & $\mathbf{M} / \mathbf{p v d}$ & $\begin{array}{c}\mathbf{f}^{\prime} \mathbf{c}, \\
\mathbf{M P a}\end{array}$ \\
\hline MB8 & 0.57 & 47.6 & 500 & 2 & 351 & 51.6 \\
MB9 & 1.14 & 47.6 & 500 & 2 & 175 & 51.0 \\
MB10 & 2.28 & 47.6 & 500 & 2 & 88 & 50.9 \\
\hline
\end{tabular}

\begin{tabular}{|c|c|c|c|}
\hline \multicolumn{4}{|c|}{ ACI Method (Frosch (2003)) } \\
\hline $\begin{array}{c}\mathbf{n}= \\
\mathbf{E f} / \mathrm{Ec}\end{array}$ & $\mathbf{K}$ & $\begin{array}{c}\mathbf{V}_{\text {ACl, }} \\
\mathbf{k N}\end{array}$ & $\begin{array}{c}\mathbf{V}_{\text {ACl, }} \\
\mathbf{M P a}\end{array}$ \\
\hline 1.473 & 0.12 & 36 & 0.36 \\
1.481 & 0.17 & 50 & 0.50 \\
1.483 & 0.23 & 68 & 0.68 \\
\hline
\end{tabular}

\begin{tabular}{|l|cccccc|}
\hline MB7 & 4.05 & 51.9 & 750 & 3 & 74 & 51.5 \\
MB14 & 4.05 & 51.9 & 2000 & 8 & 197 & 47.8 \\
\hline
\end{tabular}

\begin{tabular}{|cccc|}
\hline 1.607 & 0.3 & 90 & 0.90 \\
1.668 & 0.31 & 88 & 0.88 \\
\hline
\end{tabular}

\begin{tabular}{|c|c|c|c|c|c|c|c|c|c|c|}
\hline MB3 & 0.57 & 47.6 & 750 & 3 & 526 & 51.4 & 1.475 & 0.12 & 36 & 0.36 \\
\hline MB1 & 0.86 & 47.6 & 750 & 3 & 351 & 49.4 & 1.505 & 0.15 & 43 & 0.43 \\
\hline MB4 & 1.14 & 47.6 & 750 & 3 & 263 & 51.4 & 1.475 & 0.17 & 50 & 0.50 \\
\hline MB5 & 1.71 & 47.6 & 750 & 3 & 175 & 51.4 & 1.475 & 0.2 & 60 & 0.60 \\
\hline MB6 & 2.28 & 47.6 & 750 & 3 & 132 & 51.5 & 1.474 & 0.23 & 68 & 0.68 \\
\hline MB15 & 0.57 & 47.6 & 500 & 2 & 351 & 46.9 & 1.545 & 0.12 & 35 & 0.35 \\
\hline MB2 & 0.86 & 47.6 & 750 & 3 & 351 & 50.4 & 1.49 & 0.15 & 44 & 0.44 \\
\hline MB11 & 1.14 & 47.6 & 1000 & 4 & 351 & 50.6 & 1.487 & 0.17 & 50 & 0.50 \\
\hline MB12 & 1.71 & 47.6 & 1500 & 6 & 351 & 49.7 & 1.5 & 0.2 & 59 & 0.59 \\
\hline MB13 & 2.28 & 47.6 & 2000 & 8 & 351 & 48.2 & 1.524 & 0.23 & 67 & 0.67 \\
\hline
\end{tabular}


Table 4-4: CSA Committee S806 (2002) Predicted Results

\begin{tabular}{|l|c|c|c|c|c|c|}
\cline { 2 - 7 } \multicolumn{1}{c|}{} & \multicolumn{7}{c|}{ Specimen Properties } \\
\hline $\begin{array}{c}\text { Specimen } \\
\text { Name }\end{array}$ & $\begin{array}{c}\boldsymbol{\rho}_{\text {w }} \\
\text { \% }\end{array}$ & $\begin{array}{c}\text { Ef } \\
\text { Gpa }\end{array}$ & a (mm) & a/d & M/ pvd & $\begin{array}{c}\text { f'c, } \\
\text { MPa }\end{array}$ \\
\hline MB8 & 0.57 & 47.6 & 500 & 2 & 351 & 51.6 \\
MB9 & 1.14 & 47.6 & 500 & 2 & 175 & 51.0 \\
MB10 & 2.28 & 47.6 & 500 & 2 & 88 & 50.9 \\
\hline
\end{tabular}

\begin{tabular}{|c|c|c|c|}
\hline \multicolumn{4}{|c|}{ CSA Committee S806 (2002) } \\
\hline $\mathbf{V}_{\mathbf{f}} \mathbf{d} / \mathbf{M}_{\mathbf{f}}$ & $\mathbf{\Phi c}$ & $\begin{array}{c}\mathbf{V}_{\mathbf{s 8 0 6}} \\
\mathbf{k N}\end{array}$ & $\begin{array}{c}\mathbf{V}_{\text {s806, }} \\
\mathbf{M P a}\end{array}$ \\
\hline 0.50 & 0.83 & 60 & 0.60 \\
0.50 & 0.83 & 70 & 0.70 \\
0.50 & 0.83 & 88 & 0.88 \\
\hline
\end{tabular}

\begin{tabular}{|l|cccccc|}
\hline MB7 & 4.05 & 51.9 & 750 & 3 & 74 & 51.5 \\
MB14 & 4.05 & 51.9 & 2000 & 8 & 197 & 47.8 \\
\hline
\end{tabular}

\begin{tabular}{|llll|}
\hline 0.33 & 0.83 & 96 & 0.96 \\
0.13 & 0.83 & 68 & 0.68 \\
\hline
\end{tabular}

\begin{tabular}{|l|llllll|}
\hline MB3 & 0.57 & 47.6 & 750 & 3 & 526 & 51.4 \\
MB1 & 0.86 & 47.6 & 750 & 3 & 351 & 49.4 \\
MB4 & 1.14 & 47.6 & 750 & 3 & 263 & 51.4 \\
MB5 & 1.71 & 47.6 & 750 & 3 & 175 & 51.4 \\
MB6 & 2.28 & 47.6 & 750 & 3 & 132 & 51.5 \\
\hline
\end{tabular}

\begin{tabular}{|llll|}
\hline 0.33 & 0.83 & 60 & 0.60 \\
0.33 & 0.83 & 58 & 0.58 \\
0.33 & 0.83 & 61 & 0.61 \\
0.33 & 0.83 & 70 & 0.70 \\
0.33 & 0.83 & 77 & 0.77 \\
\hline
\end{tabular}

\begin{tabular}{|l|cccccc|}
\hline MB15 & 0.57 & 47.6 & 500 & 2 & 351 & 46.9 \\
MB2 & 0.86 & 47.6 & 750 & 3 & 351 & 50.4 \\
MB11 & 1.14 & 47.6 & 1000 & 4 & 351 & 50.6 \\
MB12 & 1.71 & 47.6 & 1500 & 6 & 351 & 49.7 \\
MB13 & 2.28 & 47.6 & 2000 & 8 & 351 & 48.2 \\
\hline
\end{tabular}

\begin{tabular}{|llll|}
\hline 0.50 & 0.83 & 57 & 0.57 \\
0.33 & 0.83 & 59 & 0.59 \\
0.25 & 0.83 & 59 & 0.59 \\
0.17 & 0.83 & 59 & 0.59 \\
0.13 & 0.83 & 58 & 0.58 \\
\hline
\end{tabular}


Table 4-5: El-Sayed et. al. (2006) Predicted Results

\begin{tabular}{|l|c|c|c|c|c|c|}
\cline { 2 - 7 } \multicolumn{1}{c|}{} & \multicolumn{7}{c|}{ Specimen Properties } \\
\hline $\begin{array}{c}\text { Specimen } \\
\text { Name }\end{array}$ & $\begin{array}{c}\boldsymbol{\rho}_{\mathbf{w}} \\
\%\end{array}$ & $\begin{array}{c}\mathbf{E}_{\mathbf{f}} \\
\mathbf{G p a}\end{array}$ & $\mathbf{a}(\mathbf{m m})$ & $\mathbf{a} / \mathbf{d}$ & $\mathbf{M} / \mathbf{\rho v d}$ & $\begin{array}{c}\mathbf{f}_{c}^{\prime}, \\
\mathbf{M P a}\end{array}$ \\
\hline MB8 & 0.57 & 47.6 & 500 & 2 & 351 & 51.6 \\
MB9 & 1.14 & 47.6 & 500 & 2 & 175 & 51.0 \\
MB10 & 2.28 & 47.6 & 500 & 2 & 88 & 50.9 \\
\hline
\end{tabular}

\begin{tabular}{|c|c|c|c|}
\hline \multicolumn{4}{|c|}{ El-Sayed et. al. (2006) } \\
\hline $\begin{array}{c}\text { f'c } \\
\text { psi }\end{array}$ & $\boldsymbol{\beta}_{\mathbf{1}}$ & $\begin{array}{c}\mathbf{V}_{\text {EL-SAYED, }} \\
\text { kN }\end{array}$ & $\begin{array}{c}\mathbf{V}_{\text {EL }} \\
\text { MPa }\end{array}$ \\
\hline 7484 & 0.68 & 53 & 0.53 \\
7397 & 0.68 & 66 & 0.66 \\
7382 & 0.68 & 84 & 0.84 \\
\hline
\end{tabular}

\begin{tabular}{|lcccccc|}
\hline MB7 & 4.05 & 51.9 & 750 & 3 & 74 & 51.5 \\
MB14 & 4.05 & 51.9 & 2000 & 8 & 197 & 47.8 \\
\hline
\end{tabular}

\begin{tabular}{|llll|}
\hline 7469 & 0.68 & 105 & 1.05 \\
6933 & 0.70 & 102 & 1.02 \\
\hline
\end{tabular}

\begin{tabular}{|c|c|c|c|c|c|c|c|c|c|c|}
\hline MB3 & 0.57 & 47.6 & 750 & 3 & 526 & 51.4 & 7455 & 0.68 & 53 & 0.53 \\
\hline MB1 & 0.86 & 47.6 & 750 & 3 & 351 & 49.4 & 7165 & 0.69 & 60 & 0.60 \\
\hline MB4 & 1.14 & 47.6 & 750 & 3 & 263 & 51.4 & 7455 & 0.68 & 67 & 0.67 \\
\hline MB5 & 1.71 & 47.6 & 750 & 3 & 175 & 51.4 & 7455 & 0.68 & 76 & 0.76 \\
\hline MB6 & 2.28 & 47.6 & 750 & 3 & 132 & 51.5 & 7469 & 0.68 & 84 & 0.84 \\
\hline MB15 & 0.57 & 47.6 & 500 & 2 & 351 & 46.9 & 6802 & 0.71 & 51 & 0.51 \\
\hline MB2 & 0.86 & 47.6 & 750 & 3 & 351 & 50.4 & 7310 & 0.68 & 60 & 0.60 \\
\hline MB11 & 1.14 & 47.6 & 1000 & 4 & 351 & 50.6 & 7339 & 0.68 & 66 & 0.66 \\
\hline MB12 & 1.71 & 47.6 & 1500 & 6 & 351 & 49.7 & 7208 & 0.69 & 75 & 0.75 \\
\hline MB13 & 2.28 & 47.6 & 2000 & 8 & 351 & 48.2 & 6991 & 0.70 & 82 & 0.82 \\
\hline
\end{tabular}


Table 4-6: ISIS-M03-01 Predicted Results

\begin{tabular}{|l|c|c|c|c|c|}
\cline { 2 - 6 } \multicolumn{1}{c|}{} & \multicolumn{5}{c|}{ Specimen Properties } \\
\hline $\begin{array}{c}\text { Specimen } \\
\text { Name }\end{array}$ & $\begin{array}{c}\boldsymbol{\rho}_{\mathrm{w}} \\
\text { \% }\end{array}$ & $\mathrm{E}_{\mathrm{f}}$ Gpa & a/d & M/ pvd & $\begin{array}{c}\mathbf{f}^{\prime} \mathrm{c}, \\
\mathrm{MPa}\end{array}$ \\
\hline MB8 & 0.57 & 47.6 & 2 & 351 & 51.6 \\
MB9 & 1.14 & 47.6 & 2 & 175 & 51.0 \\
MB10 & 2.28 & 47.6 & 2 & 88 & 50.9 \\
\hline
\end{tabular}

\begin{tabular}{|c|c|c|}
\hline \multicolumn{3}{|c|}{ ISIS-M03-01 } \\
\hline $\boldsymbol{\Phi c}$ & $\begin{array}{c}\mathbf{V}_{\text {ISIS, }} \\
\mathbf{~ k N}\end{array}$ & $\begin{array}{c}\mathbf{V}_{\text {ISIS, }} \\
\mathbf{M P a}\end{array}$ \\
\hline 0.83 & 58 & 0.58 \\
0.83 & 58 & 0.58 \\
0.83 & 58 & 0.58 \\
\hline
\end{tabular}

\begin{tabular}{|l|ccccc|}
\hline MB7 & 4.05 & 51.9 & 3 & 74 & 51.5 \\
MB14 & 4.05 & 51.9 & 8 & 197 & 47.8 \\
\hline
\end{tabular}

\begin{tabular}{|lll|}
\hline 0.83 & 61 & 0.61 \\
0.83 & 58 & 0.58 \\
\hline
\end{tabular}

\begin{tabular}{|l|lllll|}
\hline MB3 & 0.57 & 47.6 & 3 & 526 & 51.4 \\
MB1 & 0.86 & 47.6 & 3 & 351 & 49.4 \\
MB4 & 1.14 & 47.6 & 3 & 263 & 51.4 \\
MB5 & 1.71 & 47.6 & 3 & 175 & 51.4 \\
MB6 & 2.28 & 47.6 & 3 & 132 & 51.5 \\
\hline
\end{tabular}

\begin{tabular}{|lll|}
\hline 0.83 & 58 & 0.58 \\
0.83 & 57 & 0.57 \\
0.83 & 58 & 0.58 \\
0.83 & 58 & 0.58 \\
0.83 & 58 & 0.58 \\
\hline
\end{tabular}

\begin{tabular}{|l|lllll|}
\hline MB15 & 0.57 & 47.6 & 2 & 351 & 46.9 \\
MB2 & 0.86 & 47.6 & 3 & 351 & 50.4 \\
MB11 & 1.14 & 47.6 & 4 & 351 & 50.6 \\
MB12 & 1.71 & 47.6 & 6 & 351 & 49.7 \\
MB13 & 2.28 & 47.6 & 8 & 351 & 48.2 \\
\hline
\end{tabular}

\begin{tabular}{|lll|}
\hline 0.83 & 55 & 0.55 \\
0.83 & 57 & 0.57 \\
0.83 & 58 & 0.58 \\
0.83 & 57 & 0.57 \\
0.83 & 56 & 0.56 \\
\hline
\end{tabular}


Table 4-7: JSCE (1997) Predicted Results

\begin{tabular}{|l|c|c|c|c|}
\cline { 2 - 5 } \multicolumn{1}{c|}{} & \multicolumn{4}{c|}{ Specimen Properties } \\
\hline $\begin{array}{c}\text { Specimen } \\
\text { Name }\end{array}$ & $\begin{array}{c}\boldsymbol{\rho}_{\mathrm{w}} \\
\%\end{array}$ & $\begin{array}{c}\text { Ef } \\
\text { Gpa }\end{array}$ & a/d & M/ pvd \\
\hline MB8 & 0.6 & 47.6 & 2 & 351 \\
MB9 & 1.1 & 47.6 & 2 & 175 \\
MB10 & 2.3 & 47.6 & 2 & 88 \\
\hline
\end{tabular}

\begin{tabular}{|c|c|c|c|c|c|c|c|}
\hline \multicolumn{10}{|c|}{ JSCE (1997) } \\
\hline $\boldsymbol{\beta}_{\mathbf{d}}$ & $\boldsymbol{\beta}_{\mathrm{p}}$ & $\boldsymbol{\beta}_{\mathbf{n}}$ & $\mathbf{f}_{\mathbf{m c d}}=\mathbf{f}^{\prime} \mathbf{c}$ & $\mathbf{f}_{\text {vcd }}$ & $\boldsymbol{\gamma}_{\mathbf{b}}$ & $\begin{array}{c}\mathbf{V}_{\text {ISCE, }} \\
\mathbf{k N}\end{array}$ & $\begin{array}{c}\mathbf{v}_{\text {JSCE, }} \\
\mathbf{M P a}\end{array}$ \\
\hline 1.41 & 0.51 & 1 & 51.6 & 0.72 & 1 & 52 & 0.52 \\
1.41 & 0.65 & 1 & 51 & 0.72 & 1 & 66 & 0.66 \\
1.41 & 0.82 & 1 & 50.9 & 0.72 & 1 & 83 & 0.83 \\
\hline
\end{tabular}

\begin{tabular}{|l|cccc|}
\hline MB7 & 4.1 & 51.9 & 3 & 74 \\
MB14 & 4.1 & 51.9 & 8 & 197 \\
\hline
\end{tabular}

\begin{tabular}{|llllllll|}
\hline 1.41 & 1.02 & 1 & 51.5 & 0.72 & 1 & 104 & 1.04 \\
1.41 & 1.02 & 1 & 47.8 & 0.72 & 1 & 104 & 1.04 \\
\hline
\end{tabular}

\begin{tabular}{|l|llll|}
\hline MB3 & 0.6 & 47.6 & 3 & 526 \\
MB1 & 0.9 & 47.6 & 3 & 351 \\
MB4 & 1.1 & 47.6 & 3 & 263 \\
MB5 & 1.7 & 47.6 & 3 & 175 \\
MB6 & 2.3 & 47.6 & 3 & 132 \\
\hline
\end{tabular}

\begin{tabular}{|llllllll|}
\hline 1.41 & 0.51 & 1 & 51.4 & 0.72 & 1 & 52 & 0.52 \\
1.41 & 0.59 & 1 & 49.4 & 0.72 & 1 & 60 & 0.60 \\
1.41 & 0.65 & 1 & 51.4 & 0.72 & 1 & 66 & 0.66 \\
1.41 & 0.74 & 1 & 51.4 & 0.72 & 1 & 75 & 0.75 \\
1.41 & 0.82 & 1 & 51.5 & 0.72 & 1 & 83 & 0.83 \\
\hline
\end{tabular}

\begin{tabular}{|l|llll|}
\hline MB15 & 0.6 & 47.6 & 2 & 351 \\
MB2 & 0.9 & 47.6 & 3 & 351 \\
MB11 & 1.1 & 47.6 & 4 & 351 \\
MB12 & 1.7 & 47.6 & 6 & 351 \\
MB13 & 2.3 & 47.6 & 8 & 351 \\
\hline
\end{tabular}

\begin{tabular}{|llllllll|}
\hline 1.41 & 0.51 & 1 & 46.9 & 0.72 & 1 & 52 & 0.52 \\
1.41 & 0.59 & 1 & 50.4 & 0.72 & 1 & 60 & 0.60 \\
1.41 & 0.65 & 1 & 50.6 & 0.72 & 1 & 66 & 0.66 \\
1.41 & 0.74 & 1 & 49.7 & 0.72 & 1 & 75 & 0.75 \\
1.41 & 0.82 & 1 & 48.2 & 0.72 & 1 & 83 & 0.83 \\
\hline
\end{tabular}


Table 4-8: Razaqpur and Isgor (2006) Predicted Results

\begin{tabular}{|c|c|c|c|c|}
\hline & \multicolumn{4}{|c|}{ Specimen Properties } \\
\hline $\begin{array}{c}\text { Specimen } \\
\text { Name }\end{array}$ & $\begin{array}{l}\rho_{w,} \\
\%\end{array}$ & $a / d$ & $\begin{array}{l}\text { M/ } \\
\text { pvd }\end{array}$ & $\begin{array}{l}\mathrm{f}^{\prime} \mathrm{c} \\
\mathrm{MPa}\end{array}$ \\
\hline MB8 & 0.57 & 2 & 351 & 52 \\
\hline MB9 & 1.14 & 2 & 175 & 51 \\
\hline MB10 & 2.28 & 2 & 88 & 51 \\
\hline
\end{tabular}

\begin{tabular}{|c|c|c|c|c|c|c|c|c|}
\hline \multicolumn{10}{|c|}{ Razaquur and Isgor (2006) } \\
\hline $\begin{array}{c}\mathbf{V}_{\mathbf{f}} \mathbf{d} / \\
\mathbf{M}_{\mathbf{f}}\end{array}$ & $\mathbf{\Phi}_{\mathbf{c}}$ & $\mathbf{K}_{\mathbf{m}}$ & $\mathbf{K}_{\mathbf{s}}$ & $\begin{array}{c}\mathbf{M}_{\mathbf{f}} / \\
\mathbf{V}_{\mathbf{f}} \mathbf{d}\end{array}$ & $\mathbf{K}_{\mathbf{a}}$ & $\mathbf{K}_{\mathbf{r}}$ & $\begin{array}{c}\mathbf{V}_{\text {Raz.. }} \\
\mathbf{k N}\end{array}$ & $\begin{array}{c}\mathbf{V}_{\mathbf{R a z} .} \\
\mathbf{M P a}\end{array}$ \\
\hline 0.50 & 0.83 & 0.63 & 1 & 2 & 1.25 & 6.5 & 123 & 1.23 \\
0.50 & 0.83 & 0.63 & 1 & 2 & 1.25 & 8.2 & 143 & 1.43 \\
0.50 & 0.83 & 0.63 & 1 & 2 & 1.25 & 10.3 & 143 & 1.43 \\
\hline
\end{tabular}

\begin{tabular}{|l|cccc|}
\hline MB7 & 4.05 & 3 & 74 & 52 \\
MB14 & 4.05 & 8 & 197 & 48 \\
\hline
\end{tabular}

\begin{tabular}{|ccccccccc|}
\hline 0.33 & 0.83 & 0.48 & 1 & 3 & 1 & 12.8 & 138 & 1.38 \\
0.13 & 0.83 & 0.25 & 1 & 8 & 1 & 12.8 & 69 & 0.69 \\
\hline
\end{tabular}

\begin{tabular}{|l|llll|}
\hline MB3 & 0.57 & 3 & 526 & 51 \\
MB1 & 0.86 & 3 & 351 & 49 \\
MB4 & 1.14 & 3 & 263 & 51 \\
MB5 & 1.71 & 3 & 175 & 51 \\
MB6 & 2.28 & 3 & 132 & 52 \\
\hline
\end{tabular}

\begin{tabular}{|ccccccccc|}
\hline 0.33 & 0.83 & 0.48 & 1 & 3 & 1 & 6.5 & 75 & 0.75 \\
0.33 & 0.83 & 0.48 & 1 & 3 & 1 & 7.4 & 83 & 0.83 \\
0.33 & 0.83 & 0.48 & 1 & 3 & 1 & 8.2 & 92 & 0.92 \\
0.33 & 0.83 & 0.48 & 1 & 3 & 1 & 9.3 & 103 & 1.03 \\
0.33 & 0.83 & 0.48 & 1 & 3 & 1 & 10.3 & 113 & 1.13 \\
\hline
\end{tabular}

\begin{tabular}{|l|llll|}
\hline MB15 & 0.57 & 2 & 351 & 47 \\
MB2 & 0.86 & 3 & 351 & 50 \\
MB11 & 1.14 & 4 & 351 & 51 \\
MB12 & 1.71 & 6 & 351 & 50 \\
MB13 & 2.28 & 8 & 351 & 48 \\
\hline
\end{tabular}

\begin{tabular}{|ccccccccc|}
\hline 0.50 & 0.83 & 0.63 & 1 & 2 & 1.25 & 6.5 & 117 & 1.17 \\
0.33 & 0.83 & 0.48 & 1 & 3 & 1 & 7.4 & 84 & 0.84 \\
0.25 & 0.83 & 0.40 & 1 & 4 & 1 & 8.2 & 75 & 0.75 \\
0.17 & 0.83 & 0.30 & 1 & 6 & 1 & 9.3 & 64 & 0.64 \\
0.13 & 0.83 & 0.25 & 1 & 8 & 1 & 10.3 & 57 & 0.57 \\
\hline
\end{tabular}


Table 4-9: Comparison of Shear Design Methods for FRP Reinforced Concrete Slabs

\begin{tabular}{|c|c|c|c|c|}
\hline \multirow{2}{*}{ 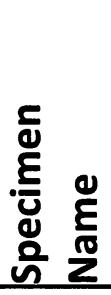 } & \multicolumn{4}{|c|}{ Specimen Properties } \\
\hline & $\begin{array}{c}\rho_{w,} \\
\%\end{array}$ & $a / d$ & $\begin{array}{l}M / \\
\text { pvd }\end{array}$ & $\begin{array}{l}v_{\text {EXP, }} \\
\text { Mpa }\end{array}$ \\
\hline MB8 & 0.57 & 2 & 351 & 0.88 \\
\hline MB9 & 1.14 & 2 & 175 & 1.20 \\
\hline MB10 & 2.28 & 2 & 88 & 2.17 \\
\hline
\end{tabular}

\begin{tabular}{|c|c|c|c|c|c|c|c|c|}
\hline $\begin{array}{c}\text { CSA-A23.3-04 } \\
\text { (Hoult Eq.) }\end{array}$ & $\begin{array}{c}\text { CSA A23.3 } \\
\text { (2004) }\end{array}$ & $\begin{array}{c}1994 \text { CSA } \\
\text { A23.3 }\end{array}$ & $\begin{array}{l}\text { ACI Method } \\
\text { Frosch } \\
(2003)\end{array}$ & $\begin{array}{c}\text { CSA S806 } \\
(2002)\end{array}$ & $\begin{array}{c}\text { El-Sayed } \\
(2006)\end{array}$ & $\begin{array}{l}\text { ISIS-M03- } \\
01\end{array}$ & $\begin{array}{c}\text { JSCE } \\
\text { (1997) }\end{array}$ & $\begin{array}{c}\text { Razaqpur } \\
\text { and Isgor } \\
(2006)\end{array}$ \\
\hline$v_{\text {EXP }} / v_{\text {CSA }}$ & $v_{\text {EXP }} / v_{\text {CSA }}$ & $\begin{array}{l}v_{\text {EXP/ }} \\
v_{\text {CSA }}\end{array}$ & $\mathbf{v}_{\text {EXP/ }} \mathbf{v}_{\mathrm{ACl}}$ & $\begin{array}{l}v_{\text {EXP/ }} \\
v_{S 806}\end{array}$ & $v_{E X P /} v_{E I}$ & $v_{\text {EXP/ }} v_{\text {ISIS }}$ & $\begin{array}{l}\mathbf{v}_{\text {EXP/ }} \\
\mathbf{v}_{\text {JSCE }}\end{array}$ & $v_{\text {EXP } /} v_{\text {RP }}$ \\
\hline $0.91^{(1)}$ & $0.91^{(1)}$ & $0.91^{(1)}$ & 2.42 & 1.46 & 1.66 & 1.51 & 1.68 & 0.72 \\
\hline $0.97^{(1)}$ & $0.97^{(1)}$ & $0.97^{(1)}$ & 2.40 & 1.72 & 1.80 & 2.07 & 1.82 & 0.84 \\
\hline $1.38^{(1)}$ & $1.38^{(1)}$ & $1.38^{(1)}$ & 3.20 & 2.47 & 2.60 & 3.76 & 2.61 & 1.52 \\
\hline
\end{tabular}

\begin{tabular}{|l|llcc|}
\hline MB7 & 4.05 & 3 & 74 & 1.35 \\
MB14 & 4.05 & 8 & 197 & 0.97 \\
\hline
\end{tabular}

\begin{tabular}{|l|l|l|l|l|l|l|l|l|}
\hline 1.10 & 1.20 & 1.13 & 1.49 & 1.40 & 1.29 & 2.22 & 1.30 & 0.97 \\
1.11 & 1.31 & 0.85 & 1.10 & 1.44 & 0.95 & 1.67 & 0.94 & 1.40 \\
\hline
\end{tabular}

\begin{tabular}{|l|llll|}
\hline MB3 & 0.57 & 3 & 526 & 0.71 \\
MB1 & 0.86 & 3 & 351 & 0.77 \\
MB4 & 1.14 & 3 & 263 & 0.94 \\
MB5 & 1.71 & 3 & 175 & 1.06 \\
MB6 & 2.28 & 3 & 132 & 1.15 \\
\hline
\end{tabular}

\begin{tabular}{|l|l|l|l|l|l|l|l|l|}
\hline 1.14 & 1.48 & 0.60 & 1.97 & 1.19 & 1.35 & 1.23 & 1.36 & 0.95 \\
1.08 & 1.35 & 0.66 & 1.76 & 1.32 & 1.28 & 1.35 & 1.28 & 0.93 \\
1.18 & 1.44 & 0.79 & 1.88 & 1.54 & 1.41 & 1.62 & 1.42 & 1.02 \\
1.16 & 1.36 & 0.89 & 1.76 & 1.51 & 1.38 & 1.82 & 1.40 & 1.02 \\
1.15 & 1.33 & 0.97 & 1.69 & 1.50 & 1.37 & 1.99 & 1.39 & 1.02 \\
\hline
\end{tabular}

\begin{tabular}{l|llll|} 
MB15 & 0.57 & 2 & 351 & 1.25 \\
MB2 & 0.86 & 3 & 351 & 0.81 \\
MB11 & 1.14 & 4 & 351 & 0.88 \\
MB12 & 1.71 & 6 & 351 & 0.87 \\
MB13 & 2.28 & 8 & 351 & 0.82 \\
\hline
\end{tabular}

Average (Mean):

Standard deviation:

COV (\%):

$1^{\text {st }}$ Percentile:

\begin{tabular}{|l|l|l|l|l|l|l|l|l|}
\hline 1.77 & 2.20 & 1.10 & 3.52 & 2.19 & 2.43 & 2.25 & 2.38 & 1.06 \\
1.13 & 1.41 & 0.69 & 1.85 & 1.37 & 1.35 & 1.41 & 1.35 & 0.97 \\
1.23 & 1.54 & 0.75 & 1.77 & 1.49 & 1.33 & 1.53 & 1.34 & 1.17 \\
1.23 & 1.53 & 0.74 & 1.46 & 1.47 & 1.15 & 1.52 & 1.15 & 1.36 \\
1.17 & 1.46 & 0.71 & 1.22 & 1.41 & 1.00 & 1.46 & 0.99 & 1.44 \\
\hline 1.14 & 1.33 & 0.86 & 1.86 & 1.52 & 1.42 & 1.80 & 1.43 & 1.10 \\
0.11 & 0.19 & 0.21 & 0.54 & 0.30 & 0.40 & 0.63 & 0.41 & 0.24 \\
9.9 & 14.2 & 24.2 & 28.8 & 19.6 & 28.3 & 35.2 & 28.7 & 22.2 \\
0.88 & 0.89 & 0.38 & 0.61 & 0.83 & 0.48 & 0.32 & 0.48 & 0.53 \\
\hline
\end{tabular}

Note:

(1) Strut-and-Tie Prediction 

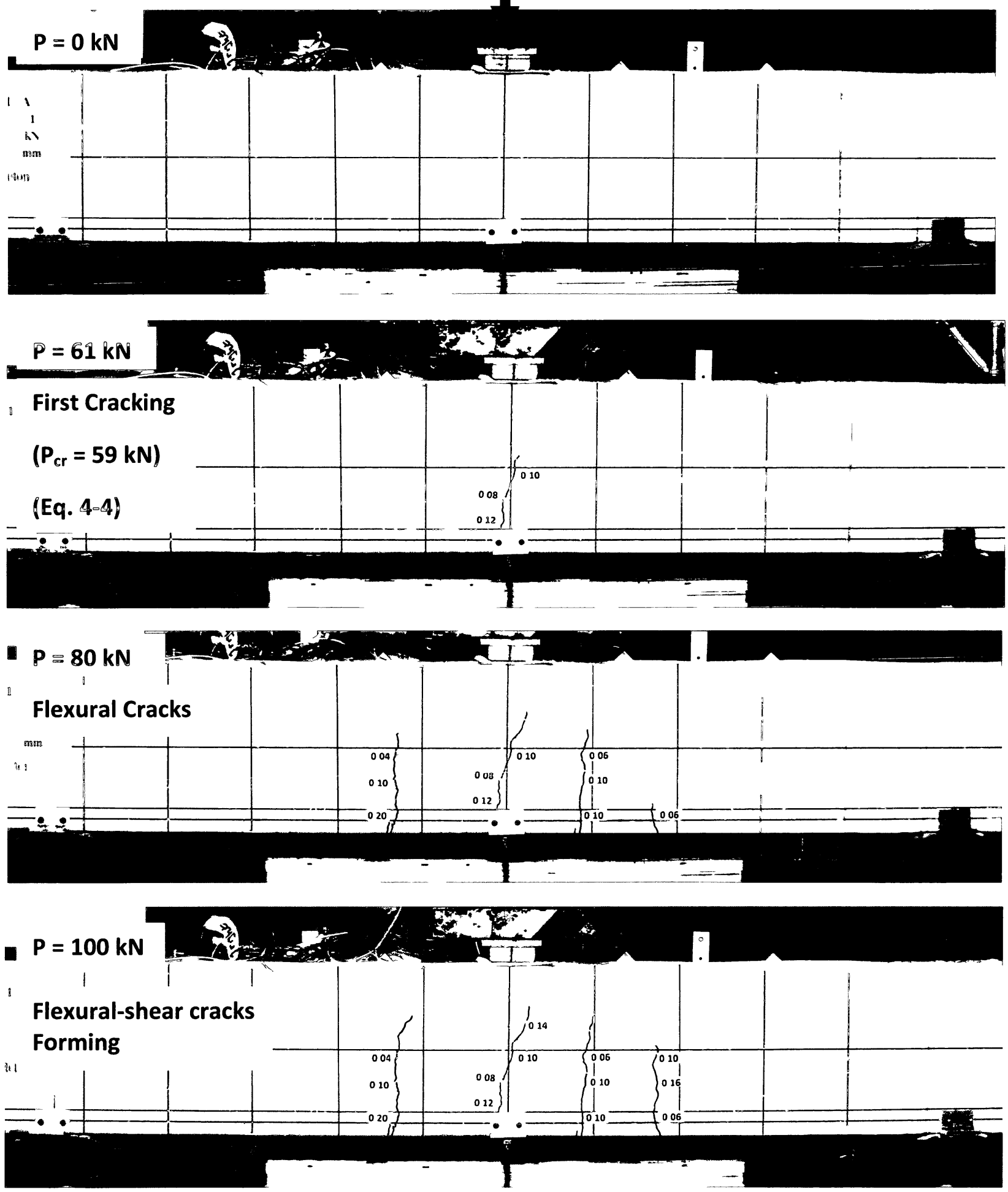

Figure 4-1: Typical Failure Mechanism of Beam Action (Specimen MB1) 

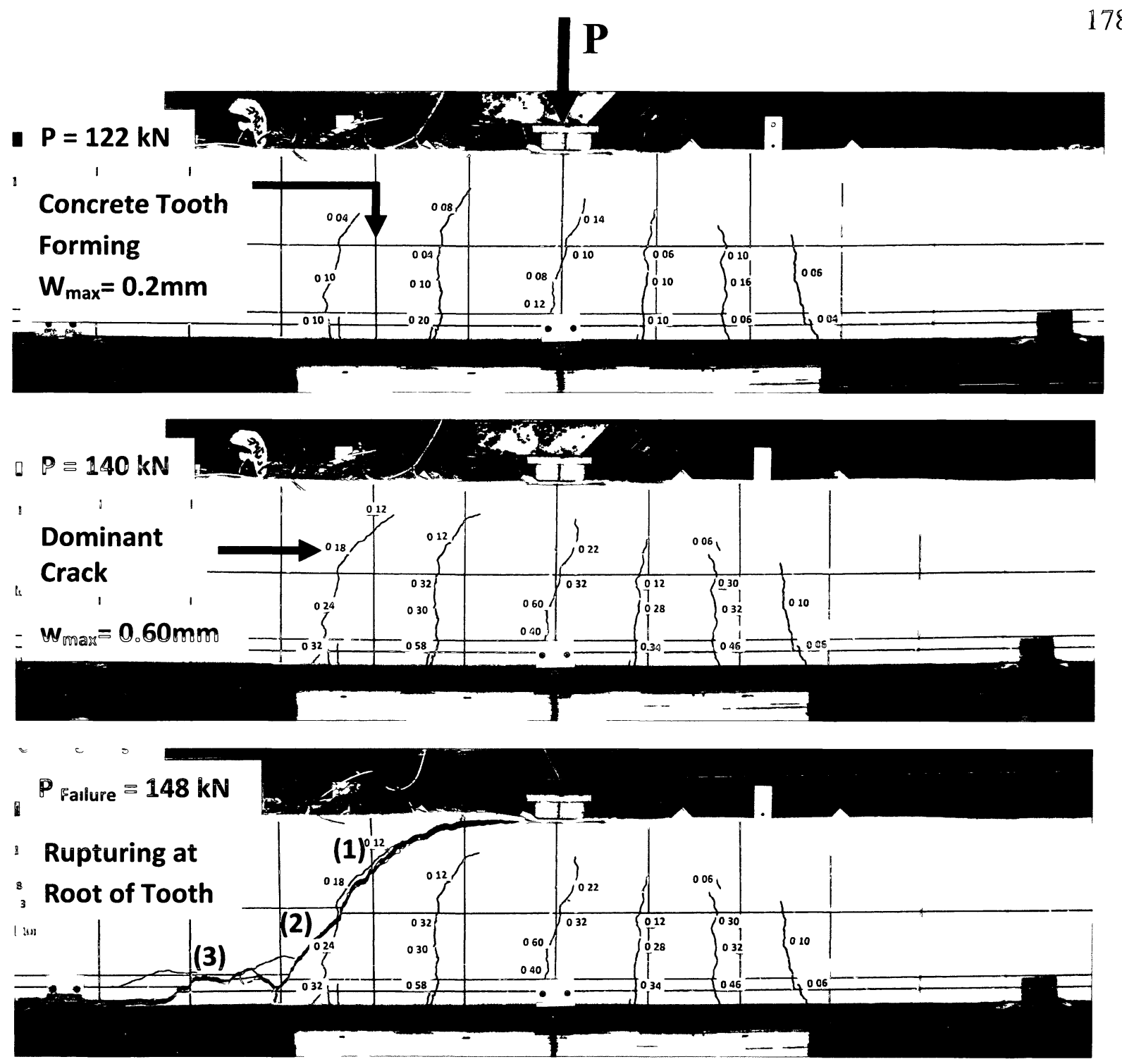

(1) Inclined cracks propagation toward the location of the point load

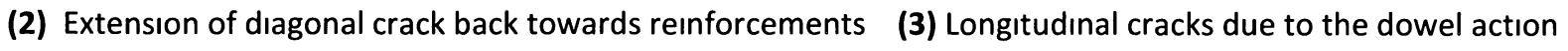

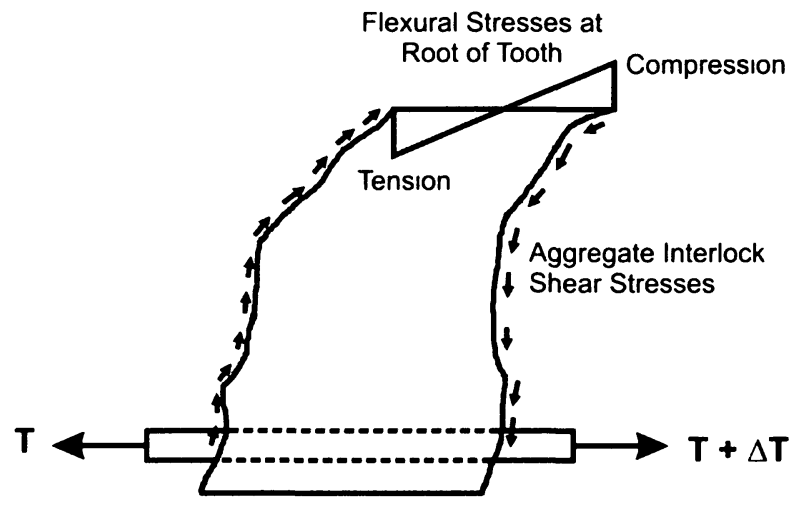

Figure 4-1: (Continued) 

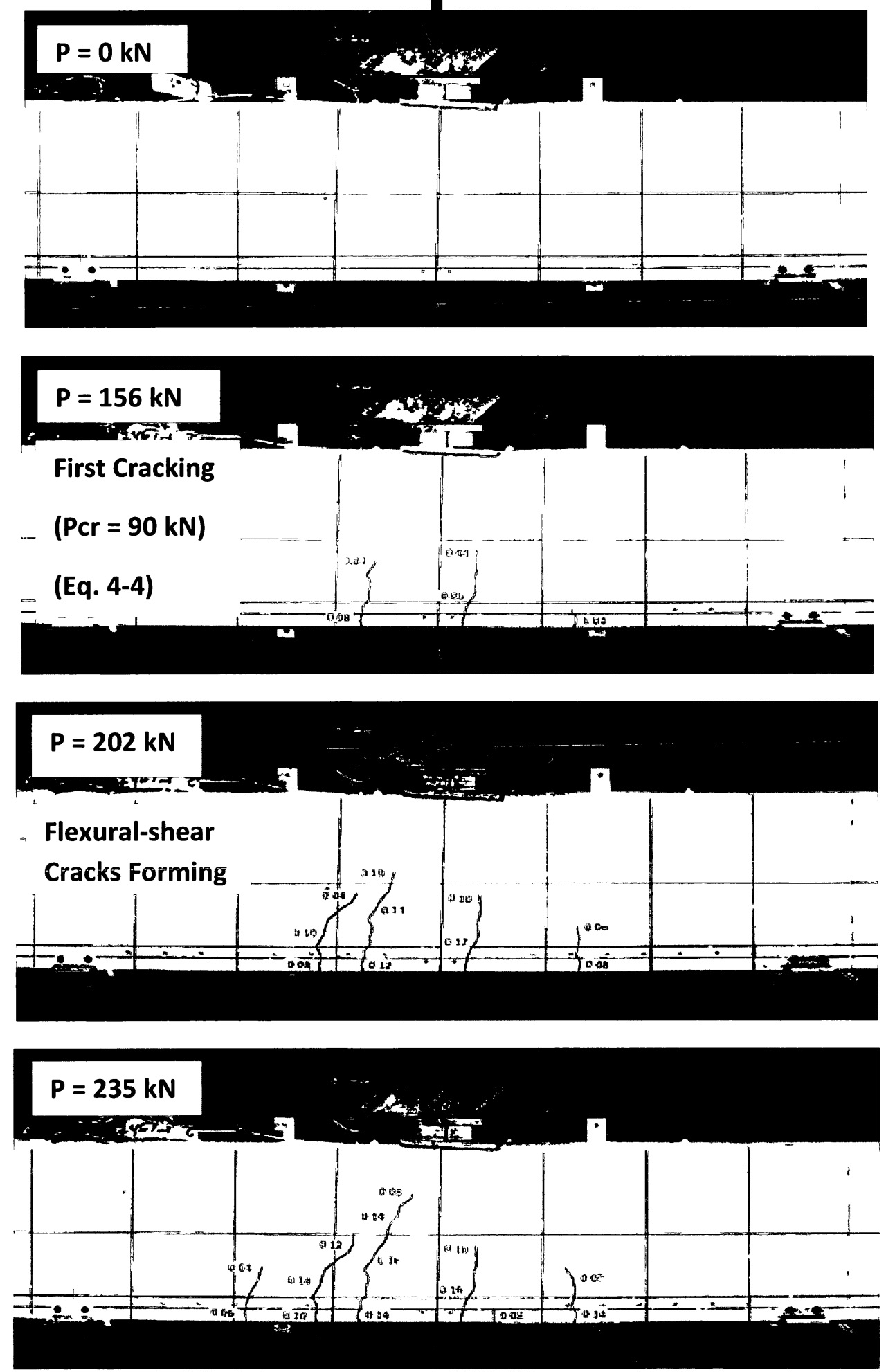

Figure 4-2: Typical Failure Mechanism of Arch Action (Specimen MB10) 

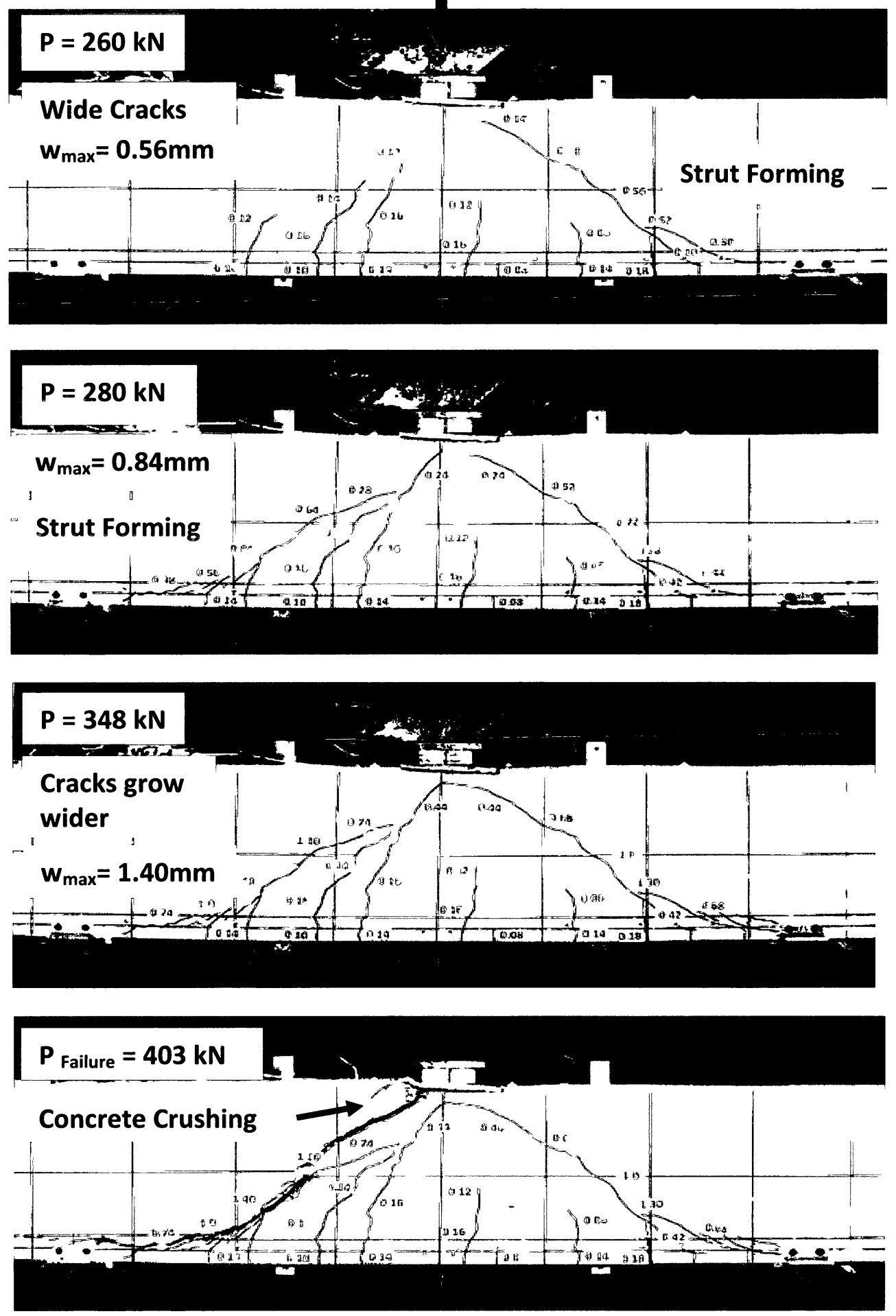

Figure 4-2: (Continued) 

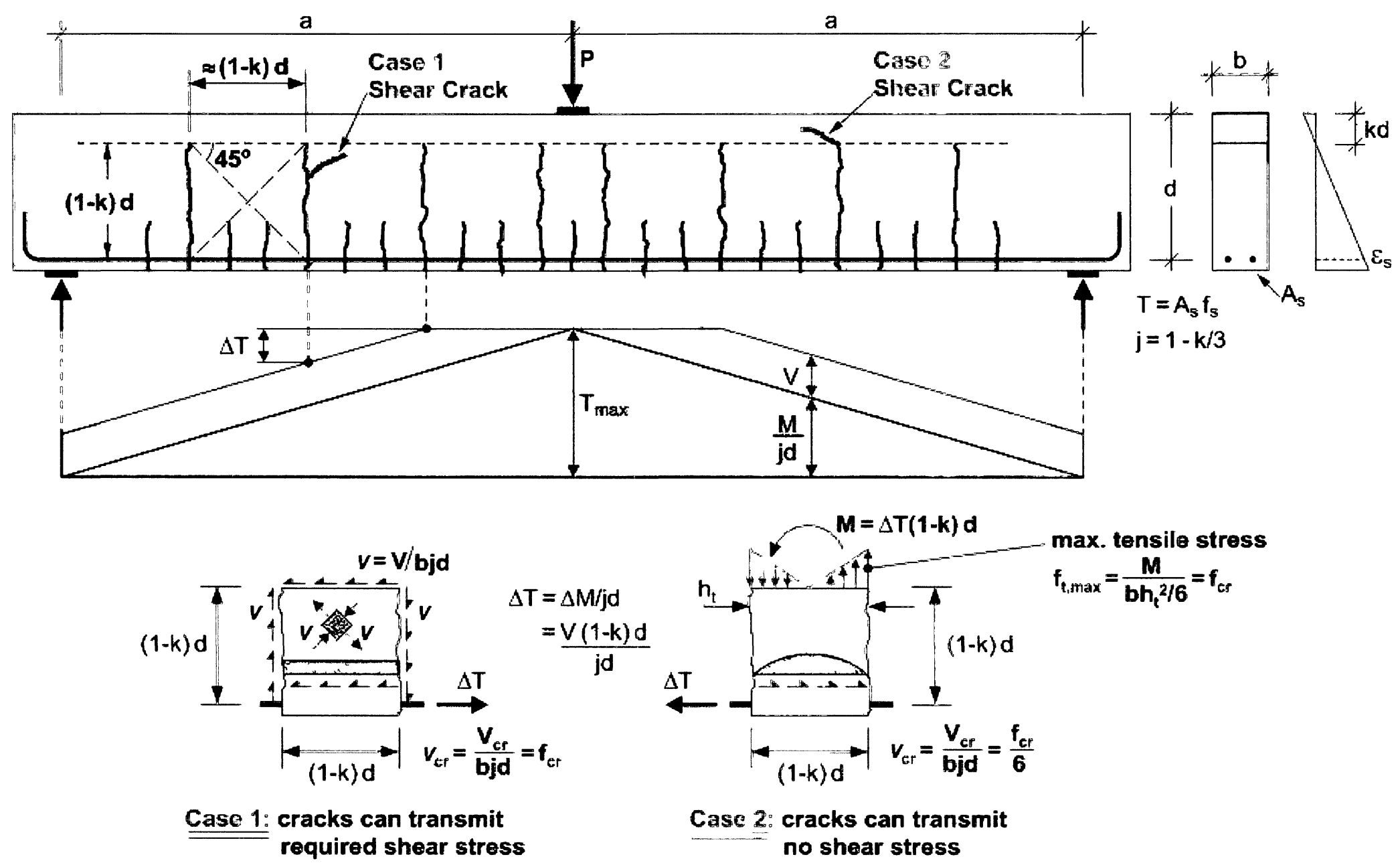

Figure 4-3: Development of the Cracks in Beam Action

(Adopted from Collins et. al. (2007)) 


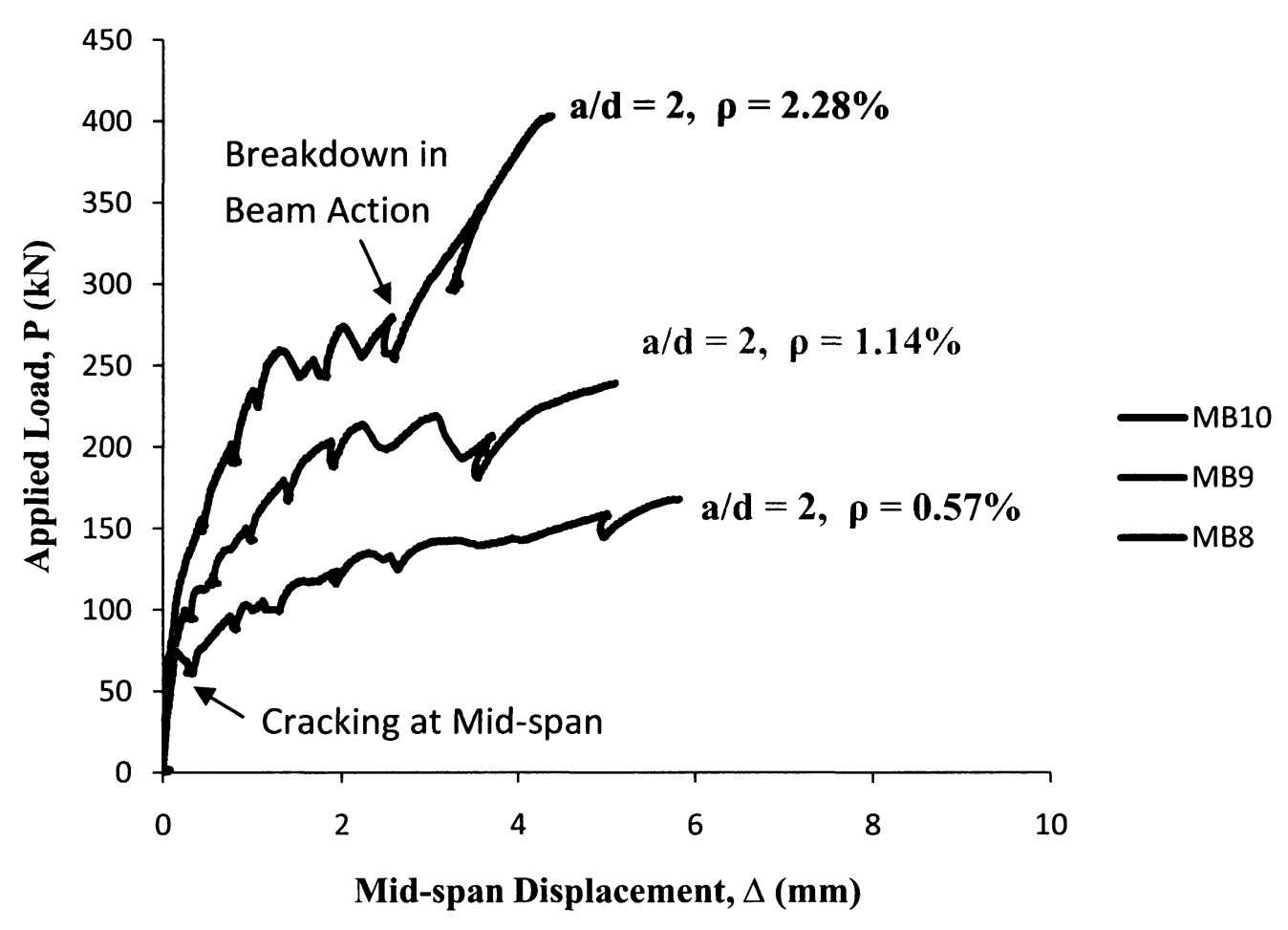

Figure 4-4: Applied Load vs Displacement, $1^{\text {st }}$ Series

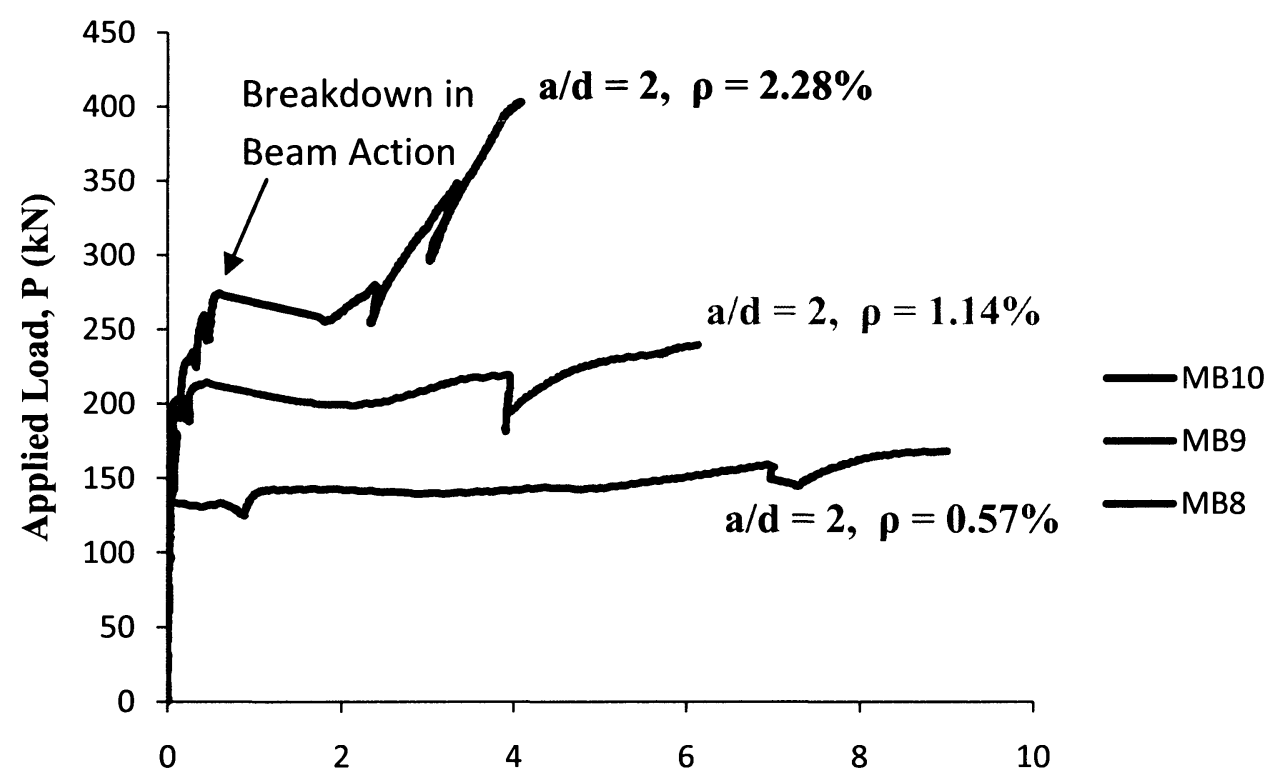

Shear Strain, $\gamma(\mathrm{mm} / \mathrm{m})$

Figure 4-5: Applied Load vs Shear Strain, $1^{\text {st }}$ Series 


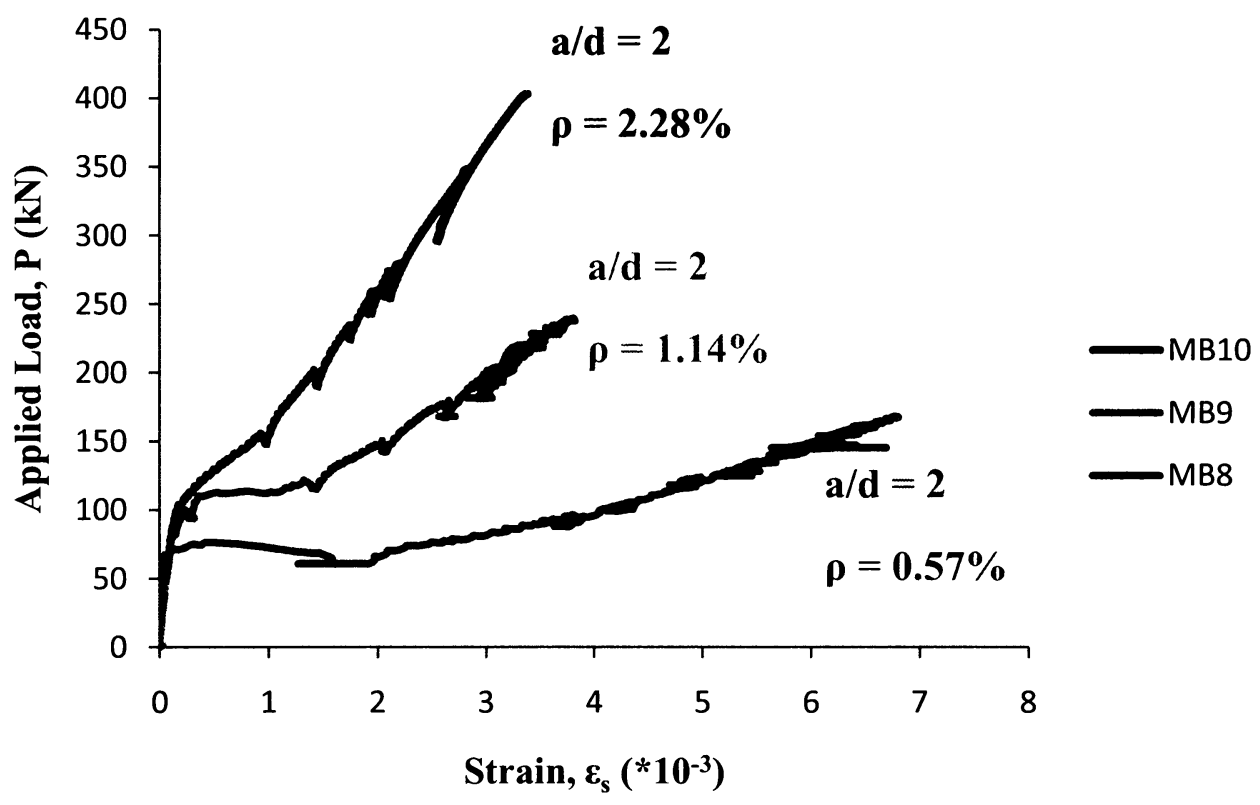

Figure 4-6: Applied Load vs Mid-Span FRP Strain, $1^{\text {st }}$ Series

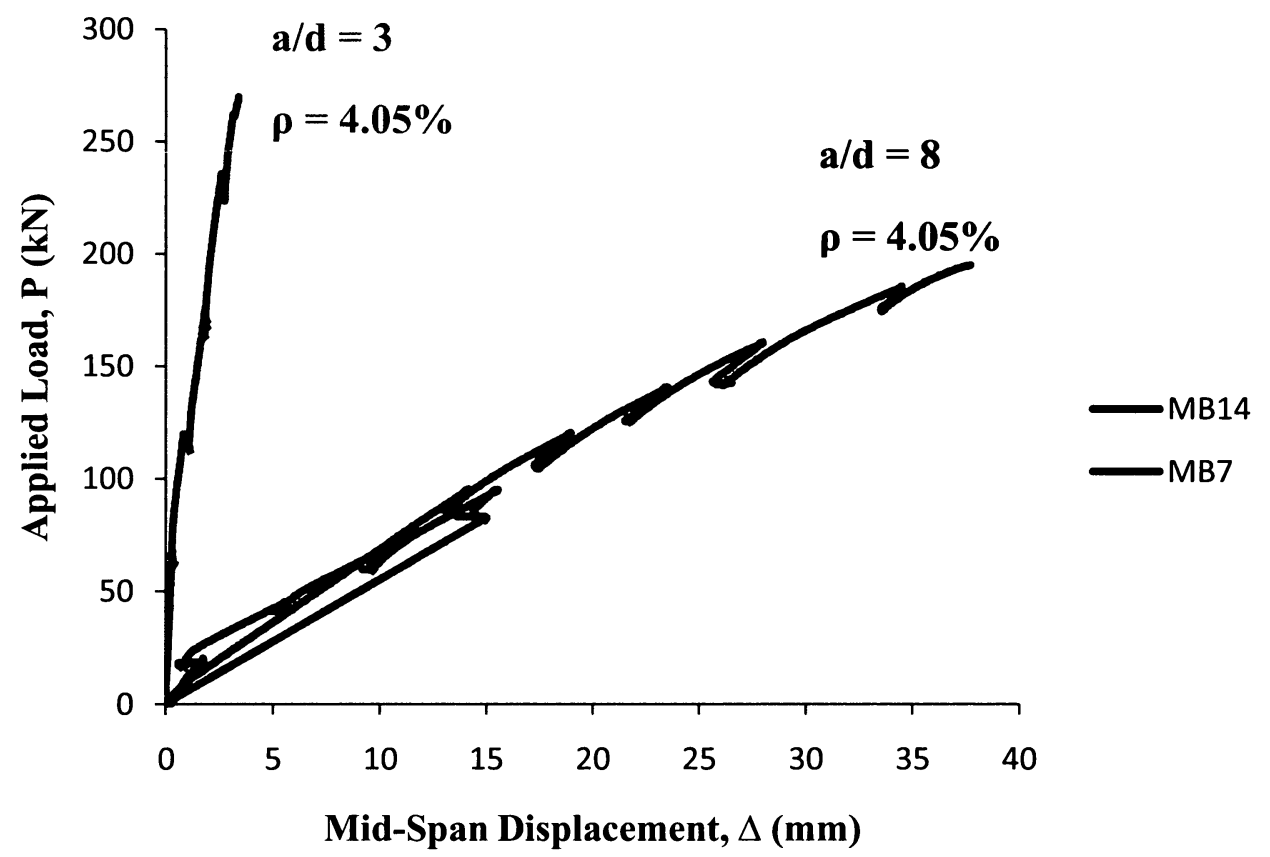

Figure 4-7: Applied Load vs Displacement, $2^{\text {nd }}$ Series 


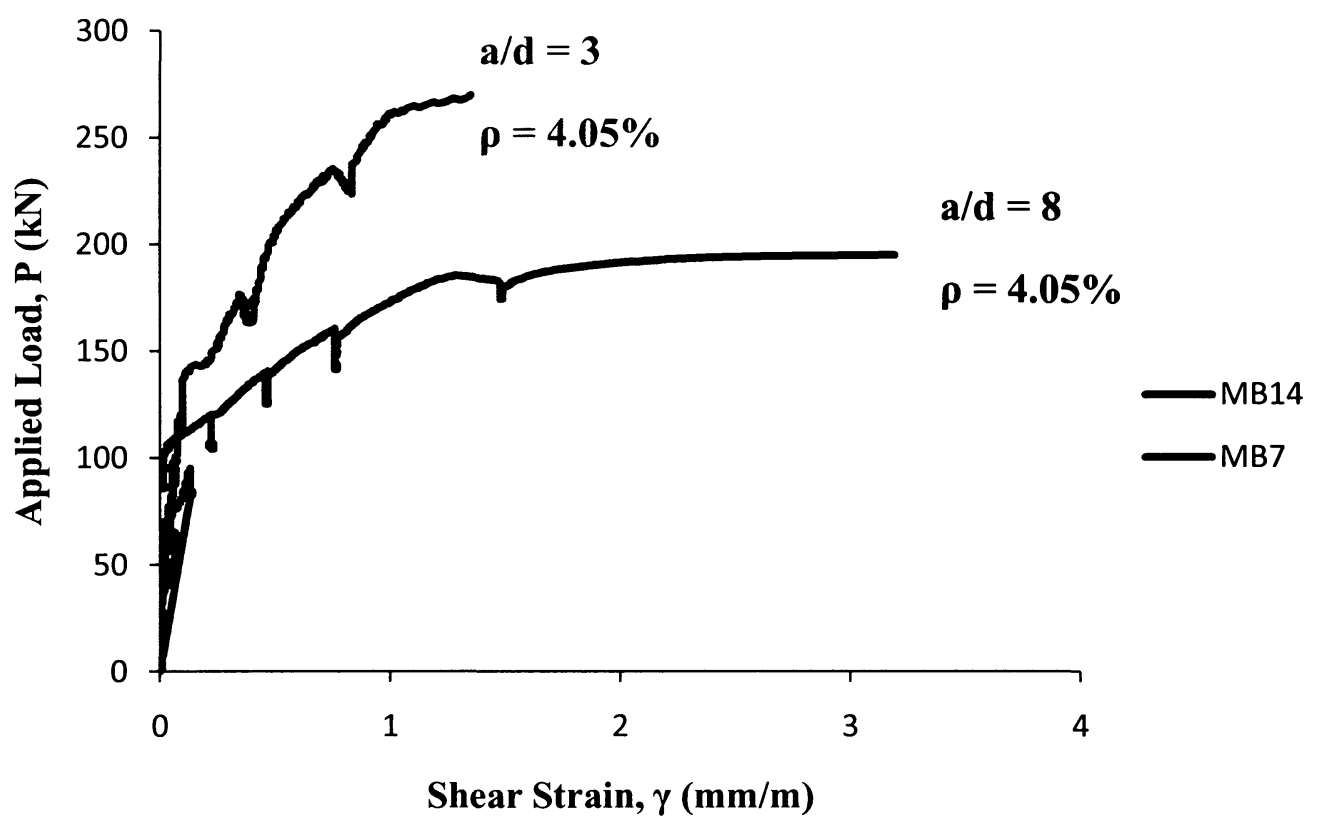

Figure 4-8: Applied Load vs Shear Strain, $2^{\text {nd }}$ Series

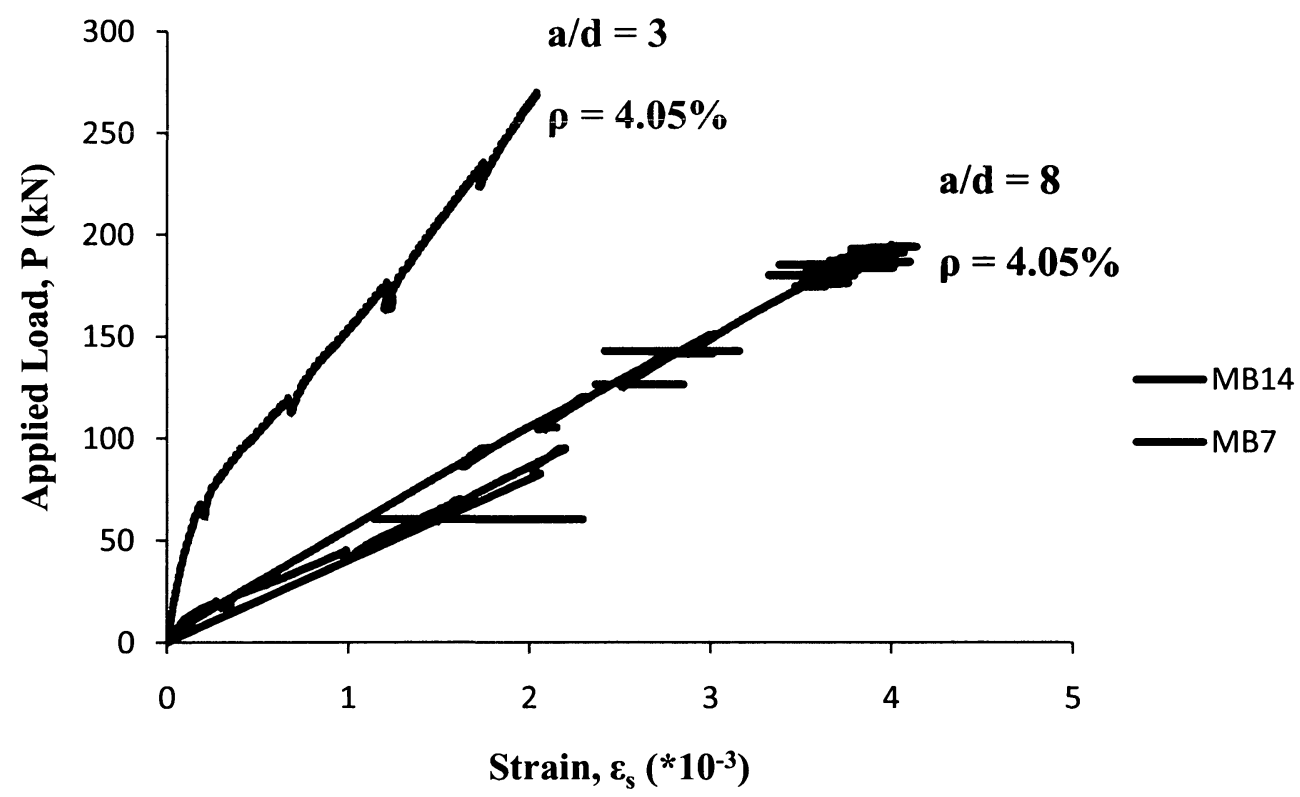

Figure 4-9: Applied Load vs FRP Strain, $2^{\text {nd }}$ Series 


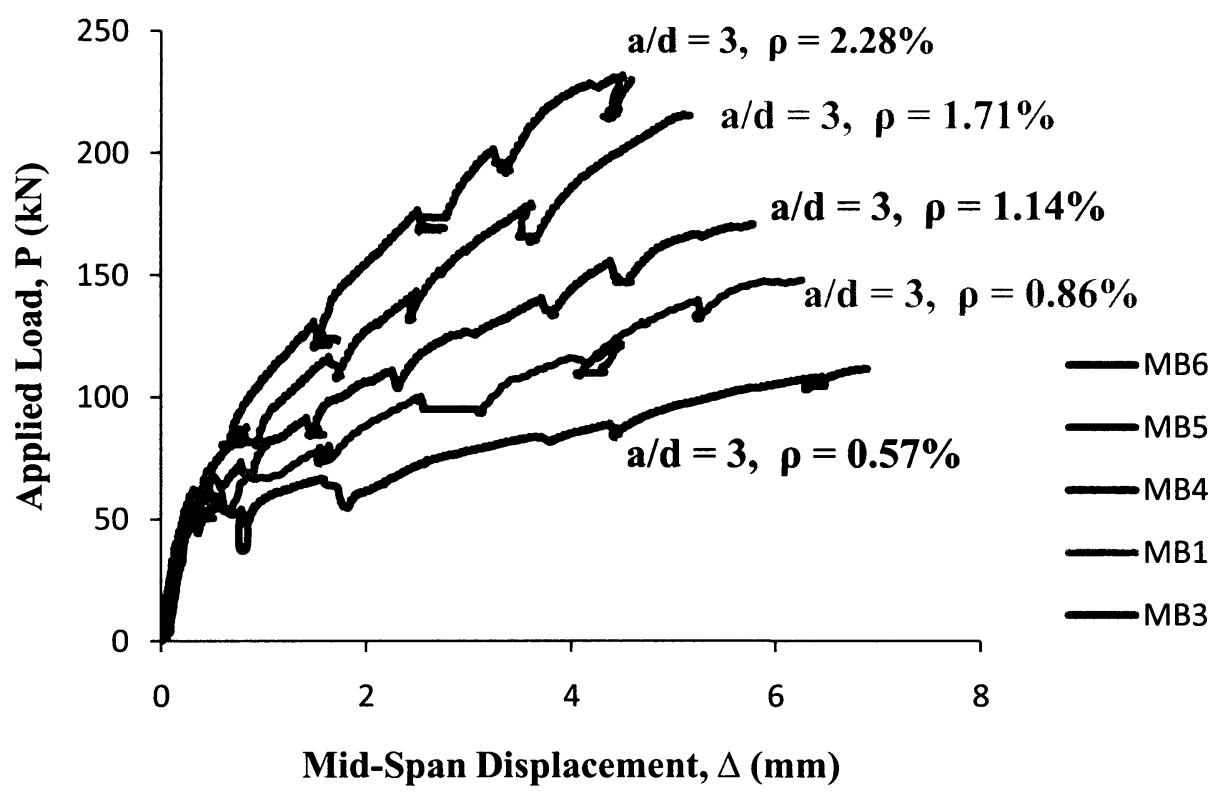

Figure 4-10: Applied Load vs Displacement, $3^{\text {rd }}$ Series

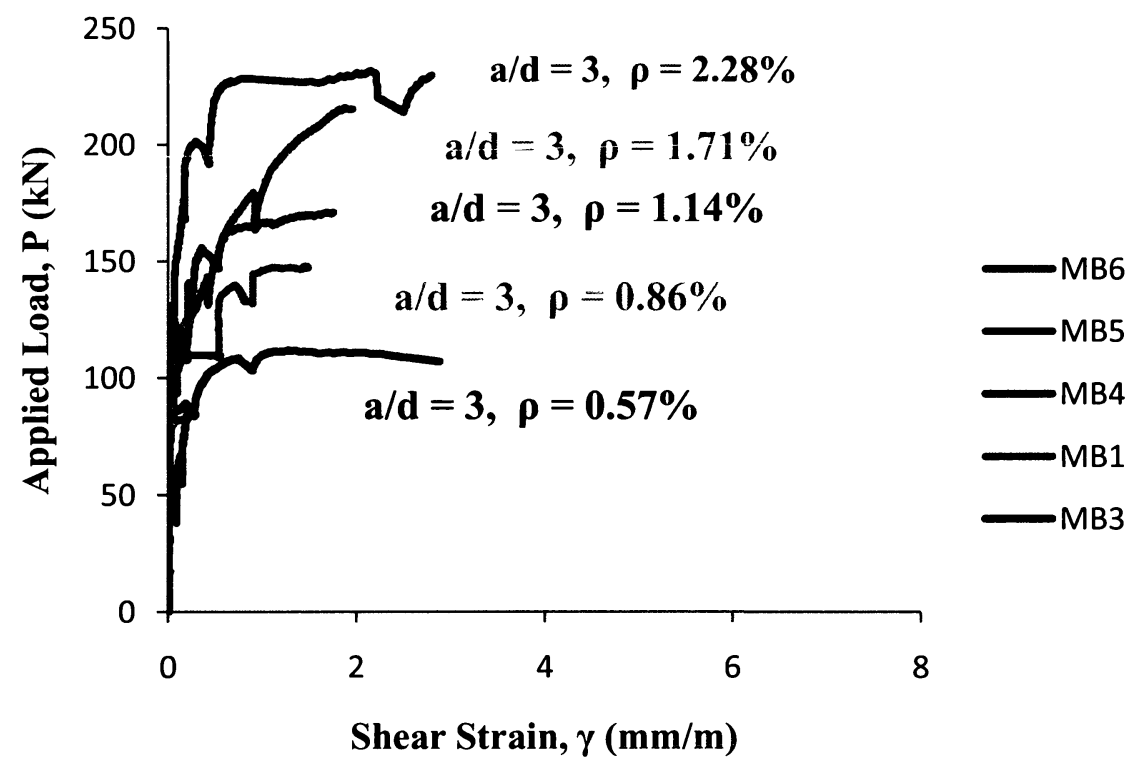

Figure 4-11: Applied Load vs Shear Strain, $3^{\text {rd }}$ Series 


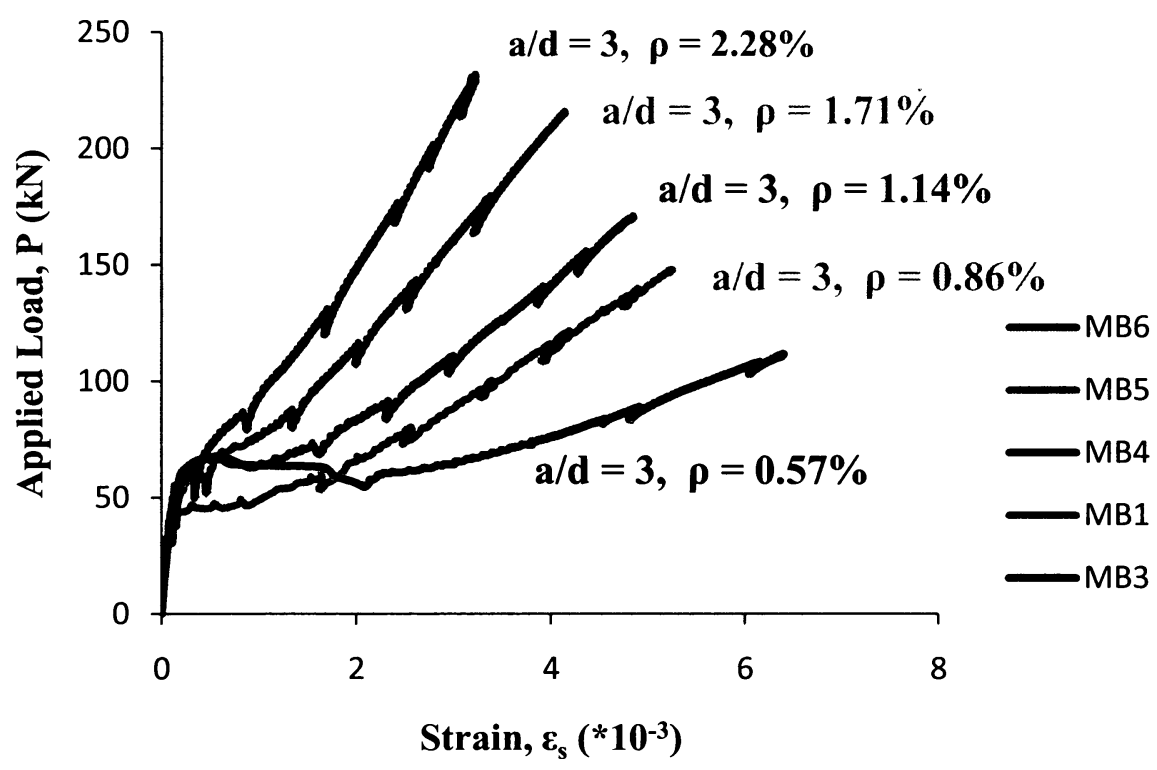

Figure 4-12: Applied Load vs Mid-Span FRP Strain, $3^{\text {rd }}$ Series 

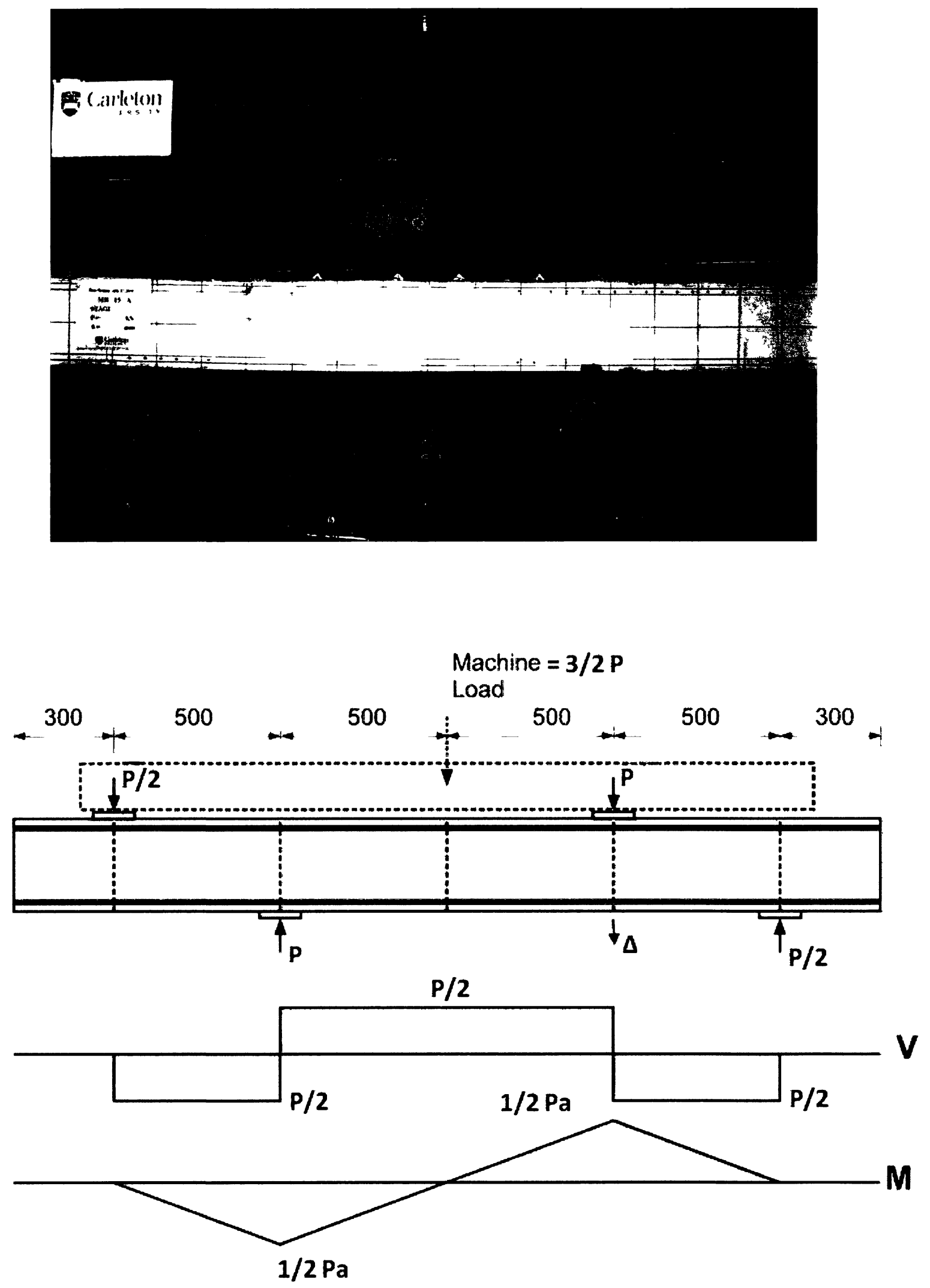

Figure 4-13: General View of Specimen MB15 with Shear and Moment Diagram 


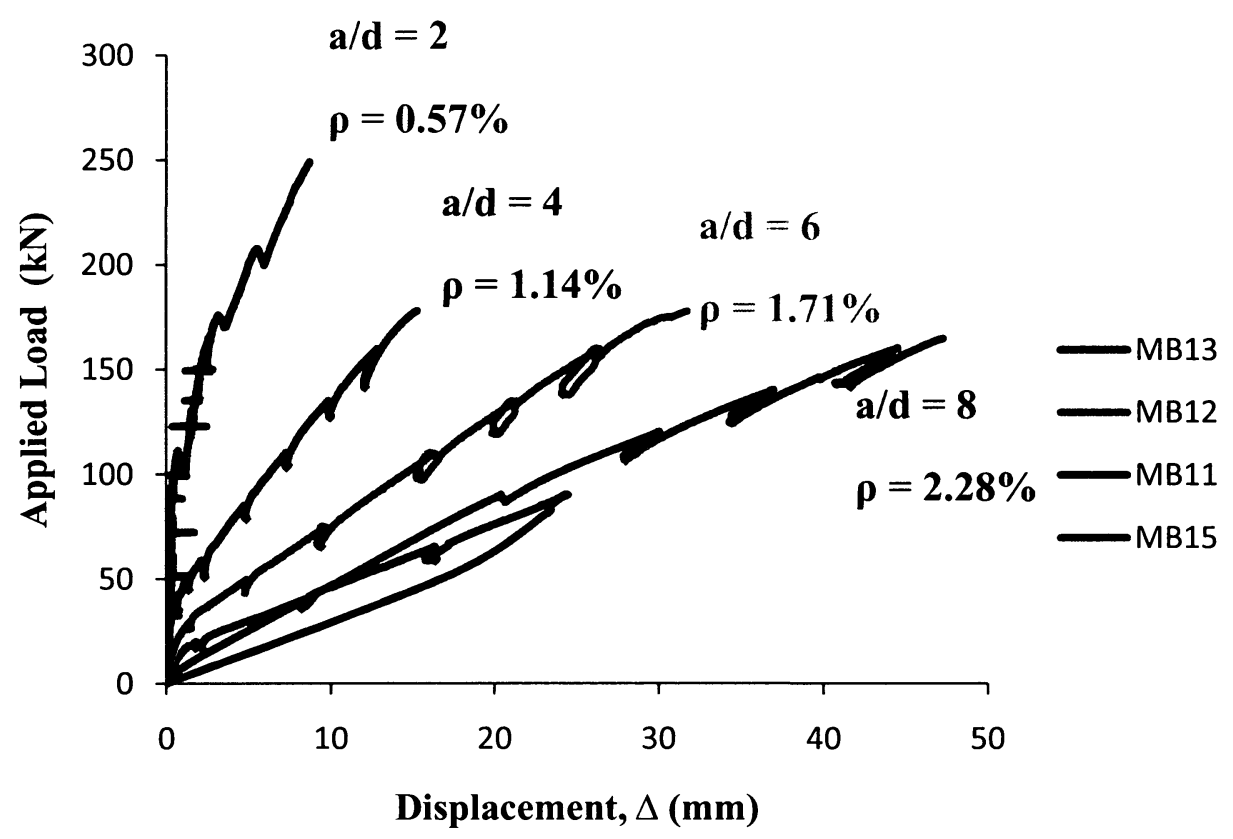

\begin{abstract}
MB11, MB12, MB13: $\quad$ Applied Load = Machine Load
MB15:

Applied Load = 2/3 Machine Load (Figure 4-13)
\end{abstract}

Figure 4-14: Applied Load vs Displacement, $4^{\text {th }}$ Series

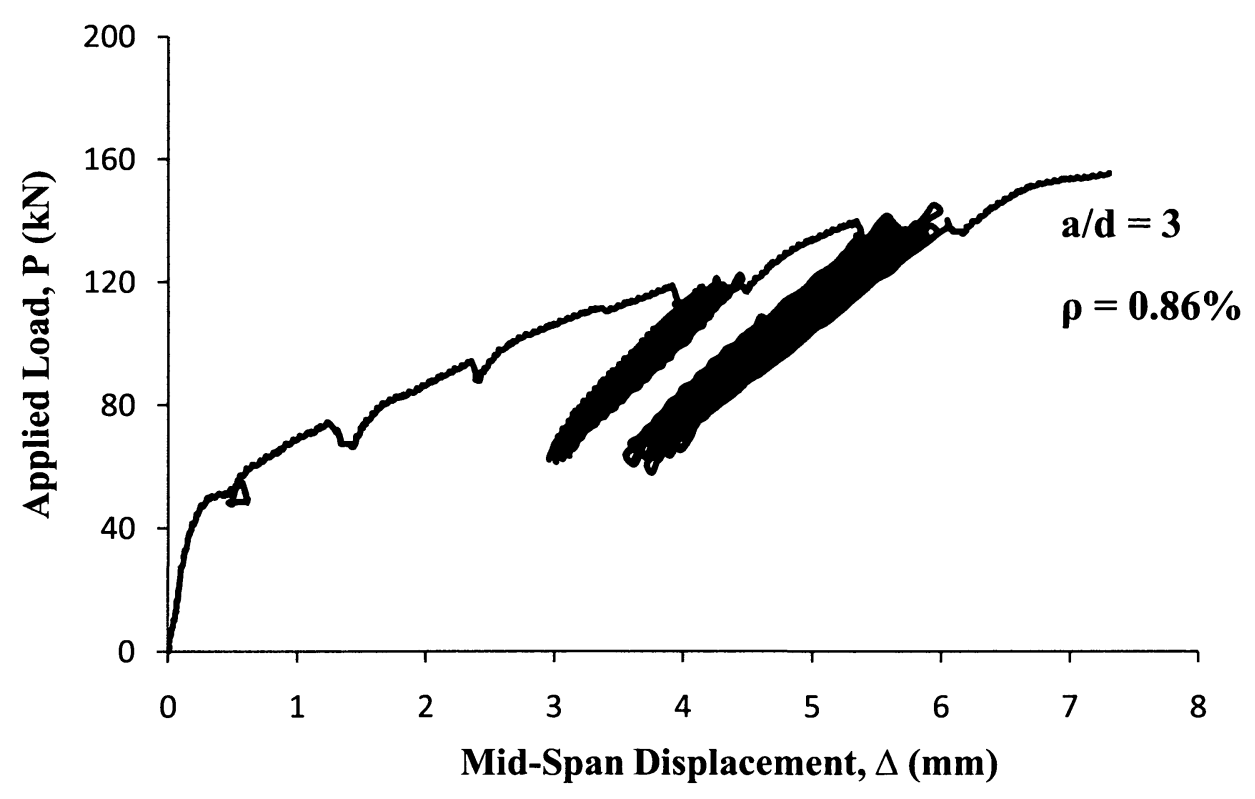

Figure 4-15: Applied Load vs Displacement, MB2 (Cycle Loading) 


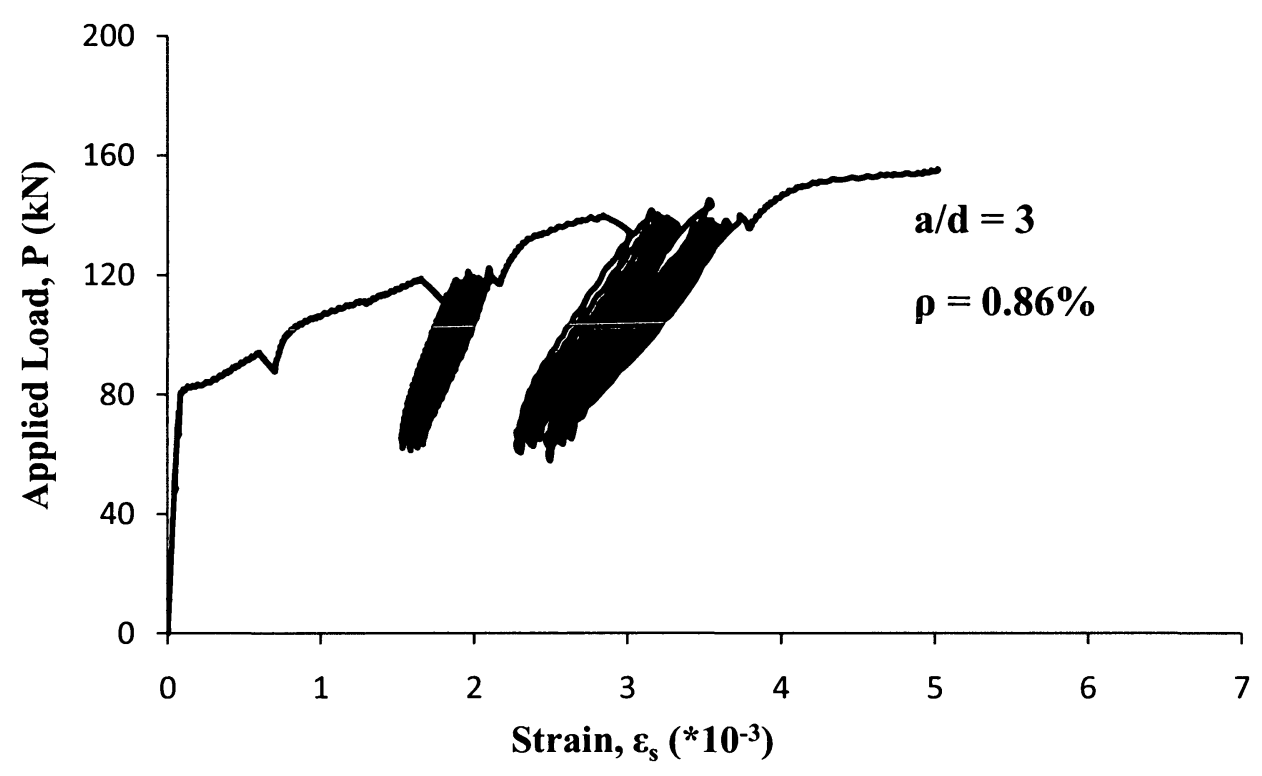

Figure 4-16: Applied Load vs FRP Strain, MB2 (Cycle Loading)

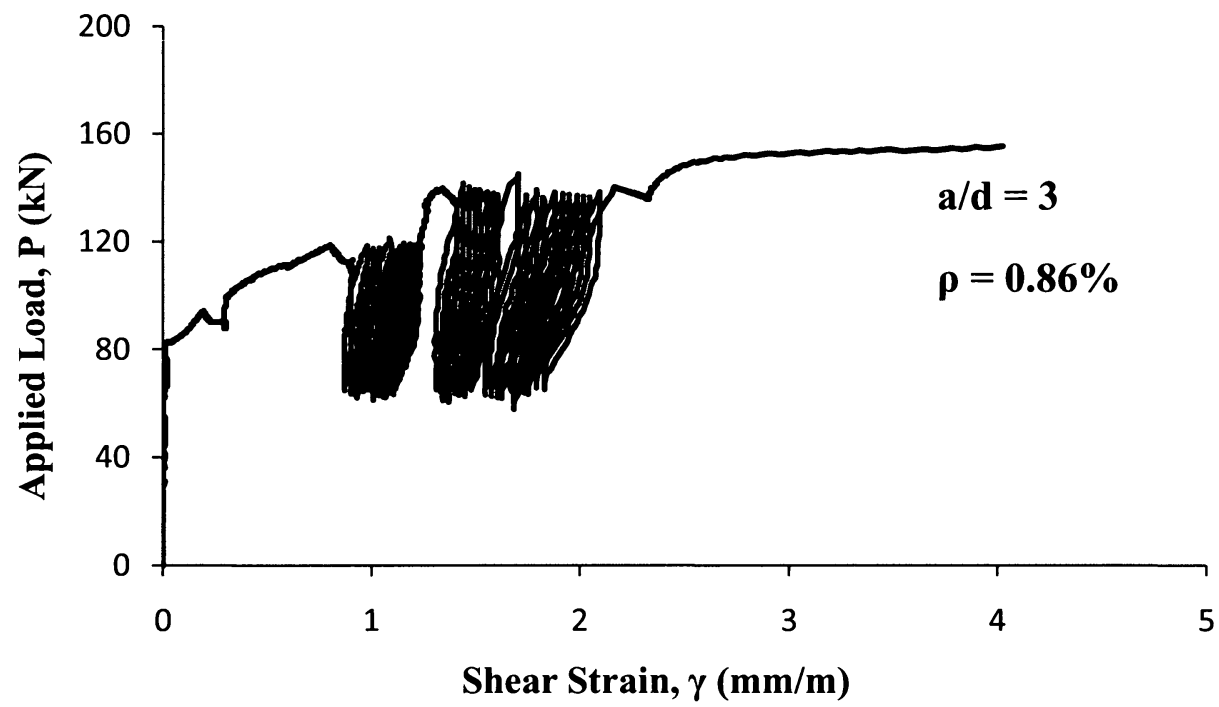

Figure 4-17: Applied Load vs Shear Strain, MB2 (Cycle Loading) 


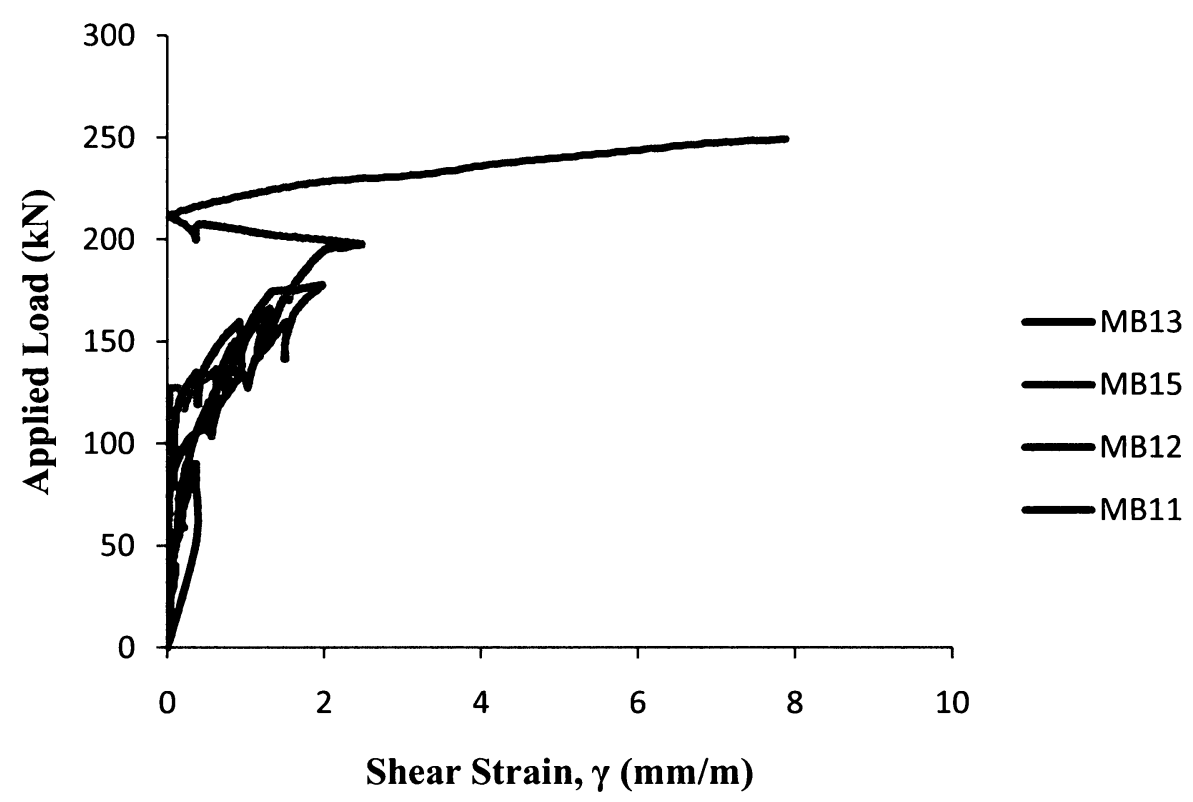

$\begin{array}{ll}\text { MB11, MB12, MB13: } & \text { Applied Load }=\text { Machine Load } \\ \text { MB15: } & \text { Applied Load }=2 / 3 \text { Machine Load (Figure 4-13) }\end{array}$

Figure 4-18: Applied Load vs Shear Strain, $4^{\text {th }}$ Series

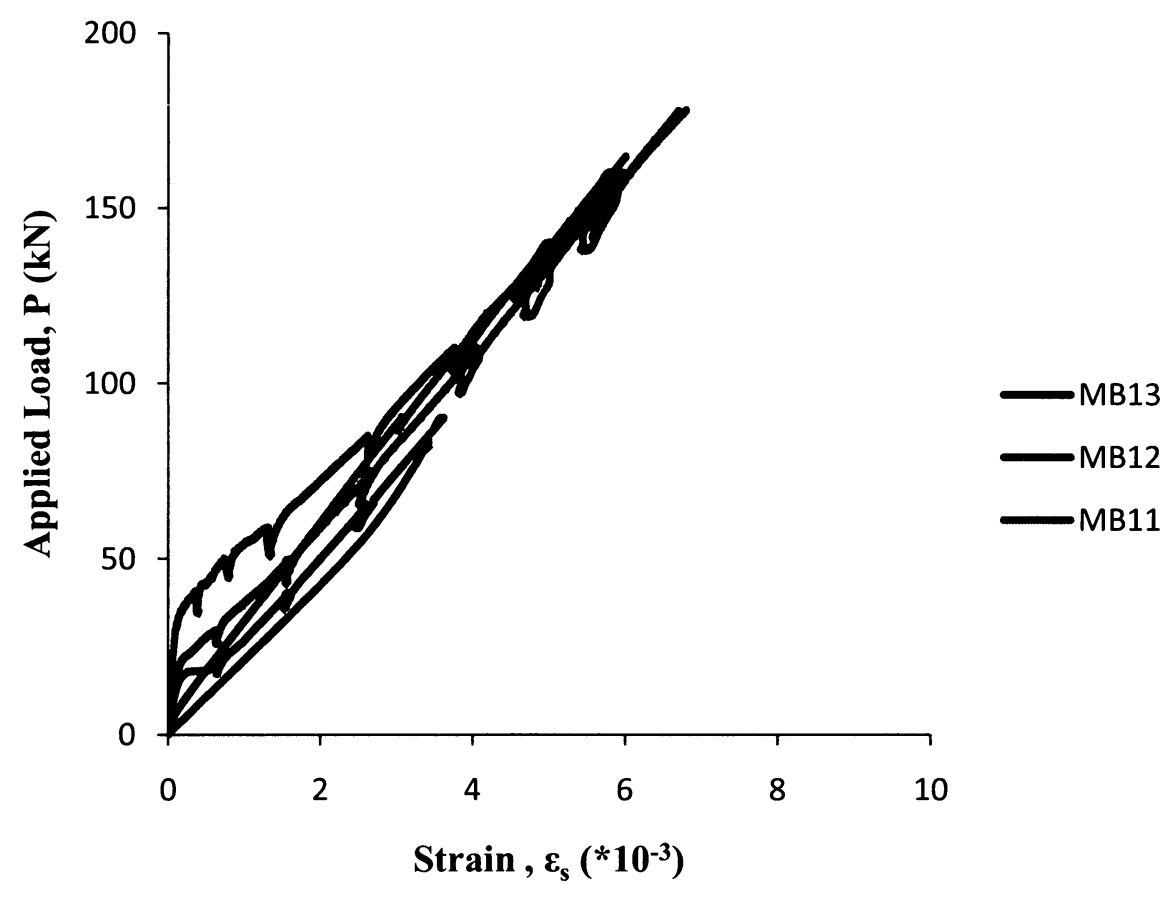

Figure 4-19: Applied Load vs FRP Strain, $4^{\text {th }}$ Series 

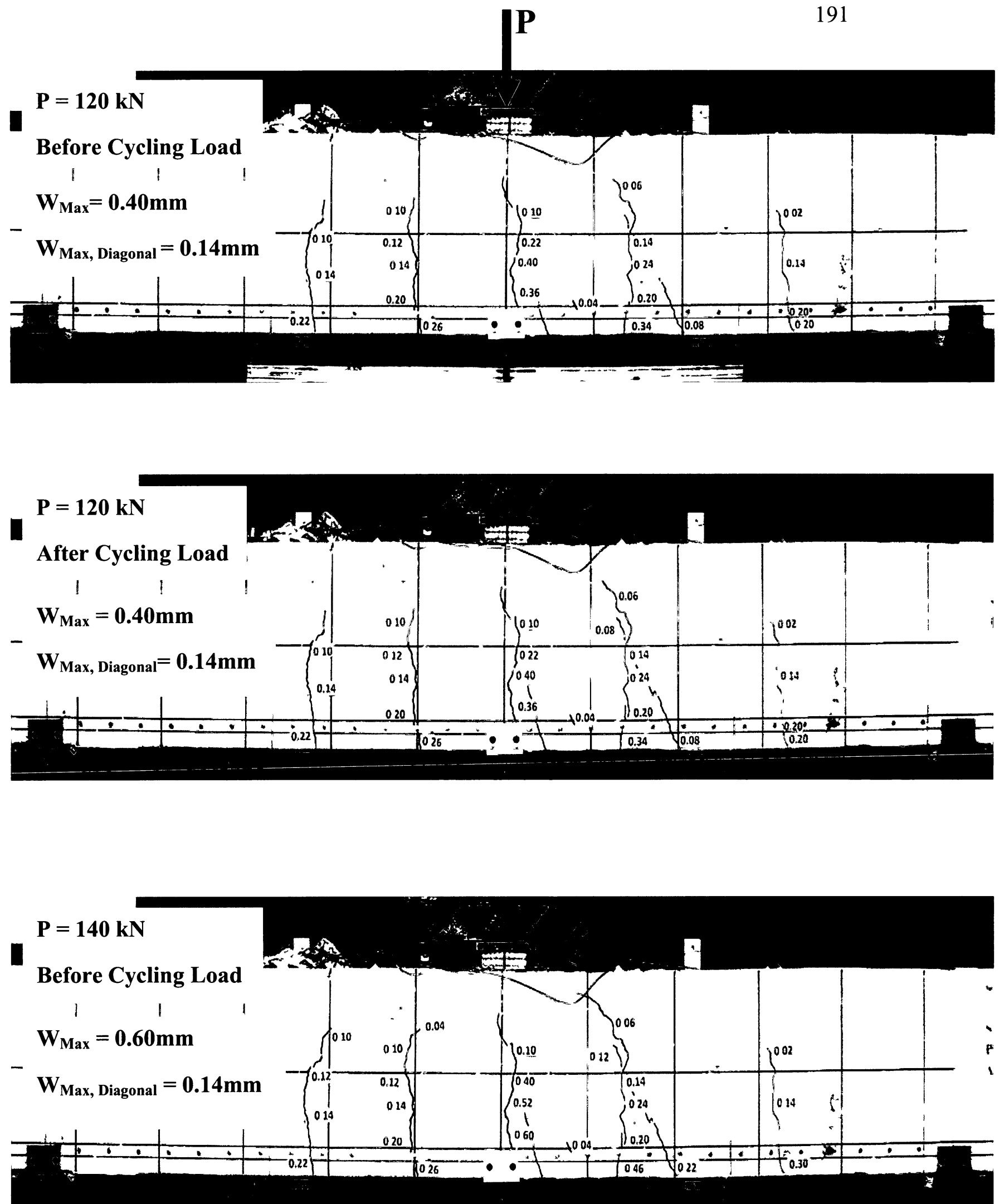

Figure 4-20: Effect of Cycle Loading on Crack width, Specimen MB2 

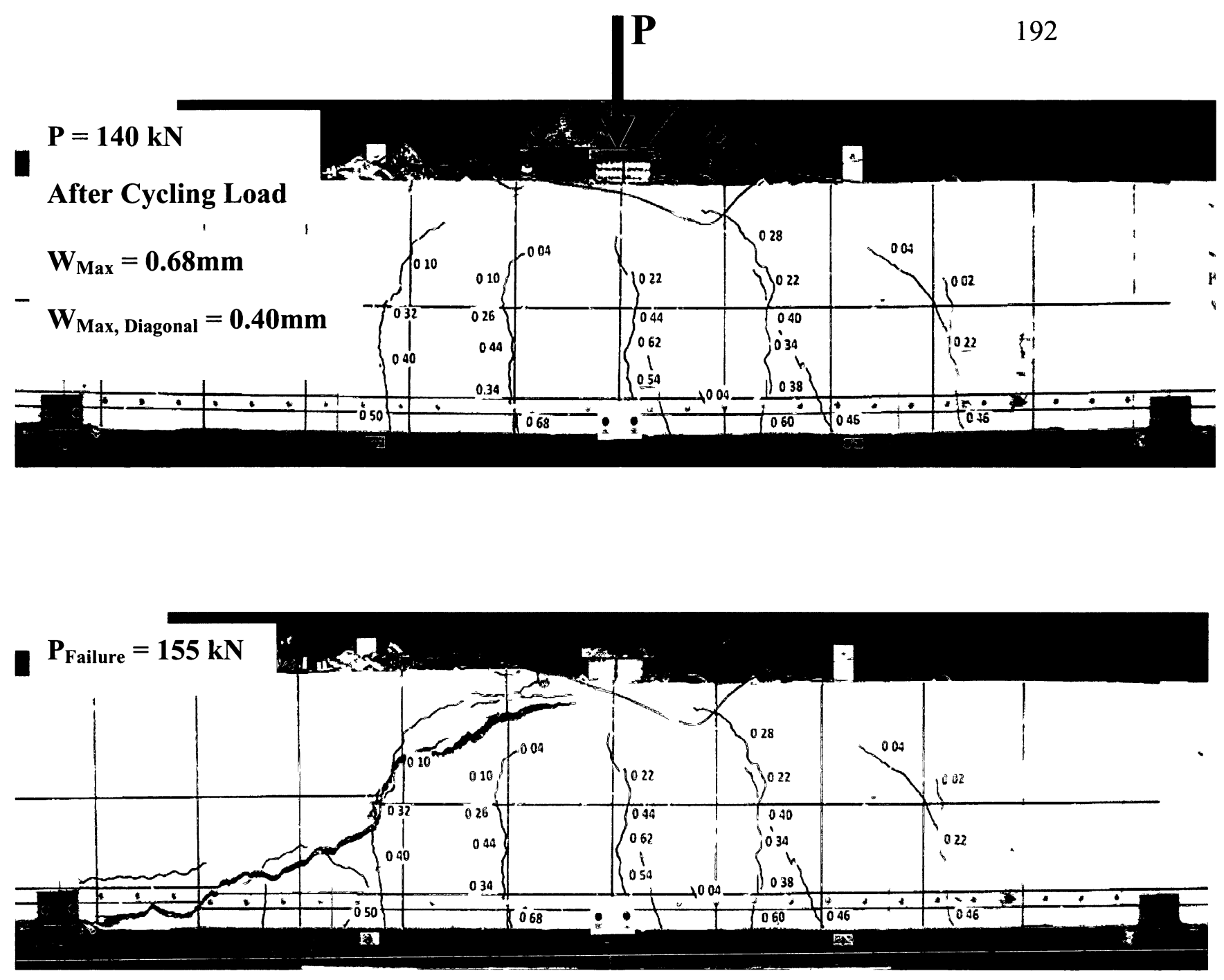

Figure 4-20: (Continued) 


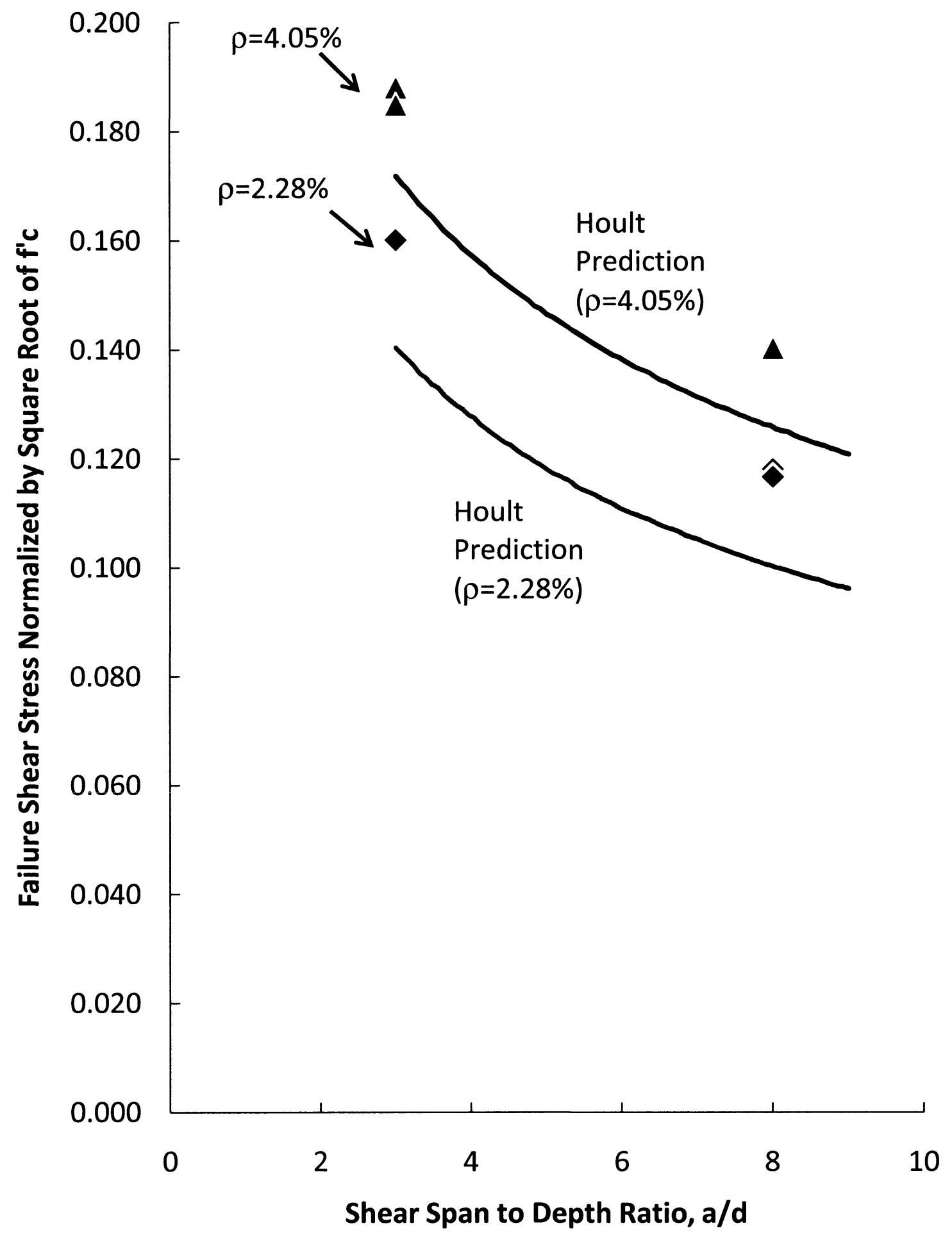

Figure 4-21: Comparison of Experimental Results with Hoult Prediction

$$
(\rho=2.28 \text { and } 4.05 \%)
$$




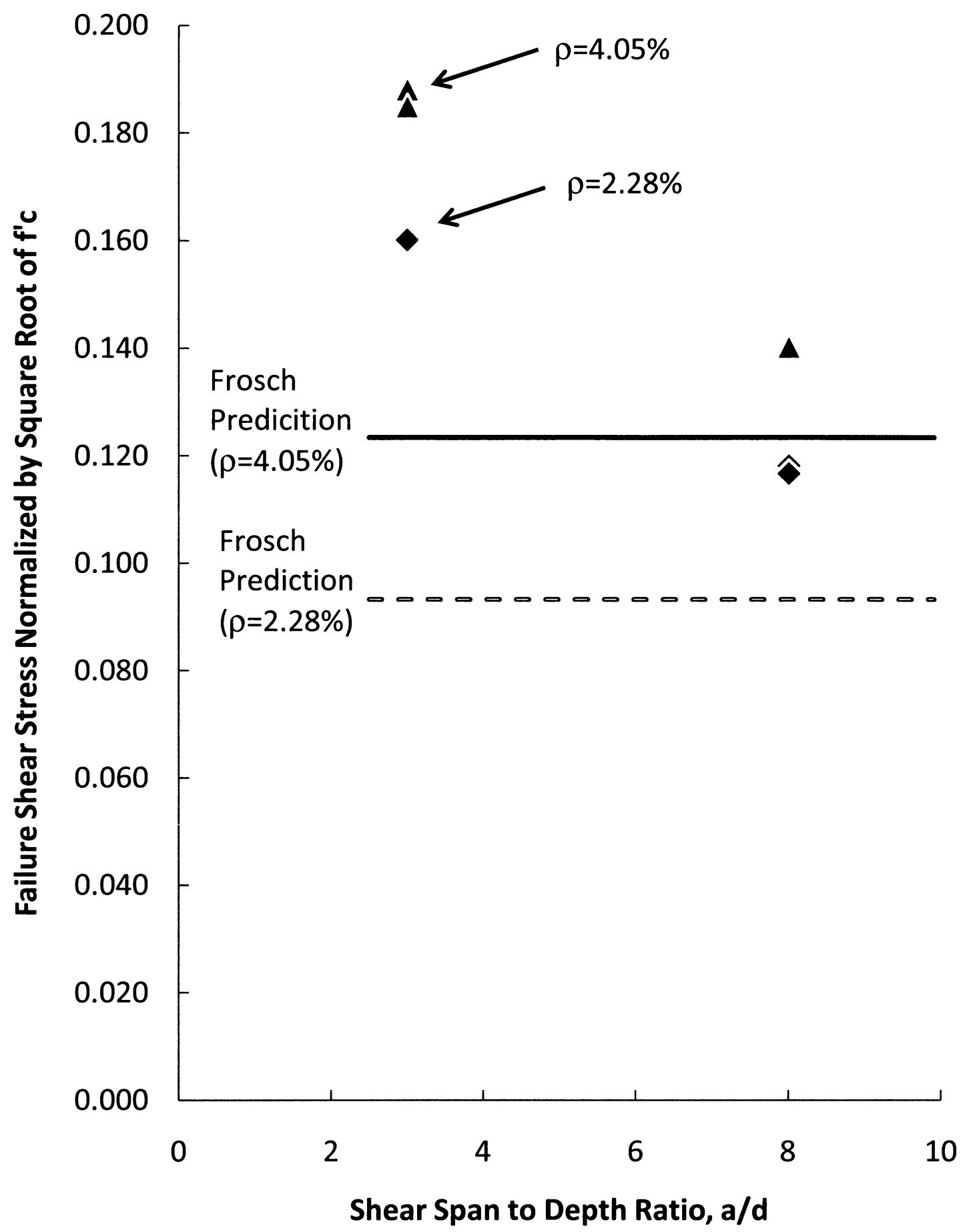

Figure 4-22: Comparison of Experimental Results with Frosch Prediction

$$
(\rho=2.28-4.05 \%)
$$




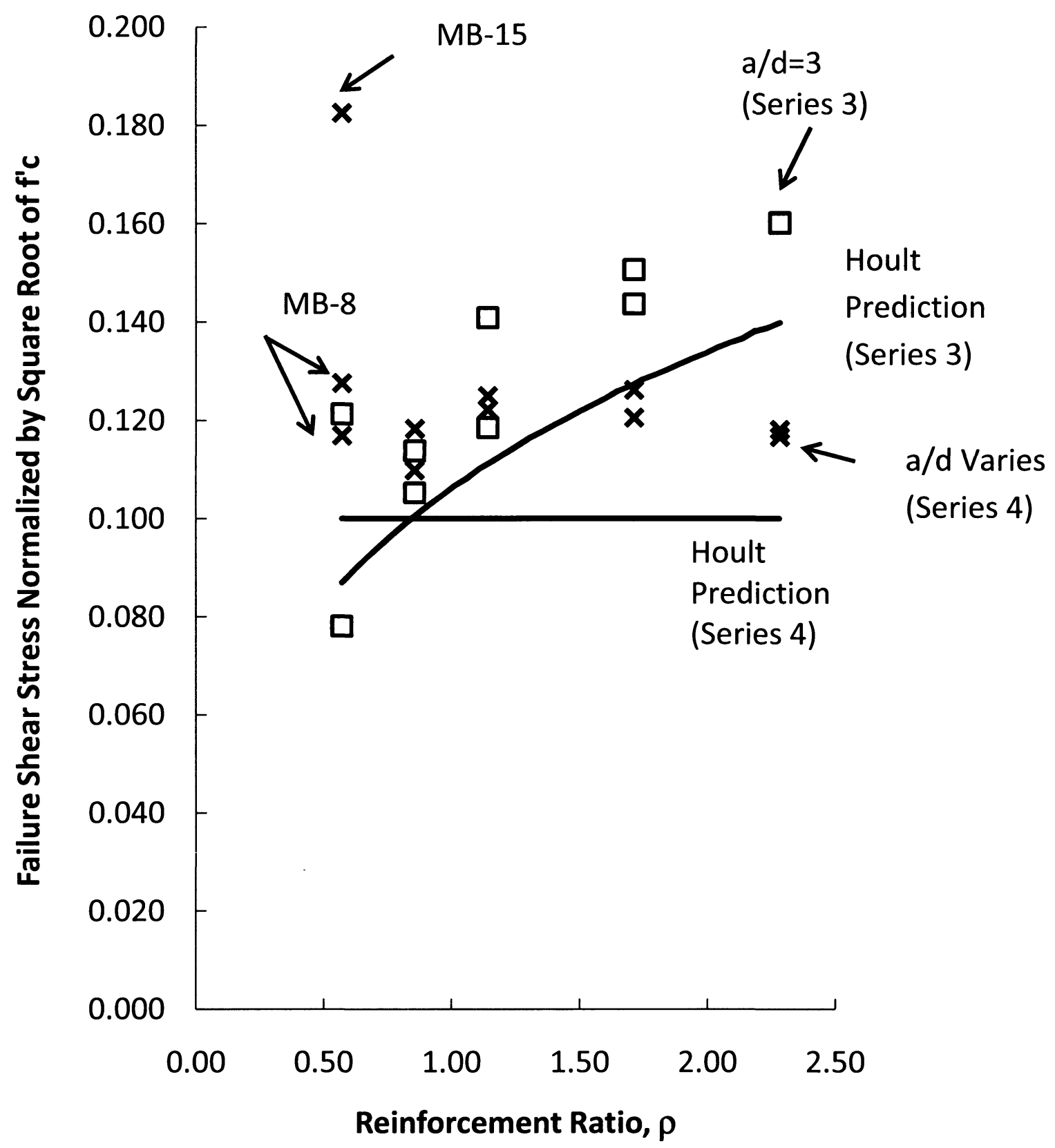

Figure 4-23: Comparison of Experimental Results with Hoult Prediction (Series 3 and 4) 


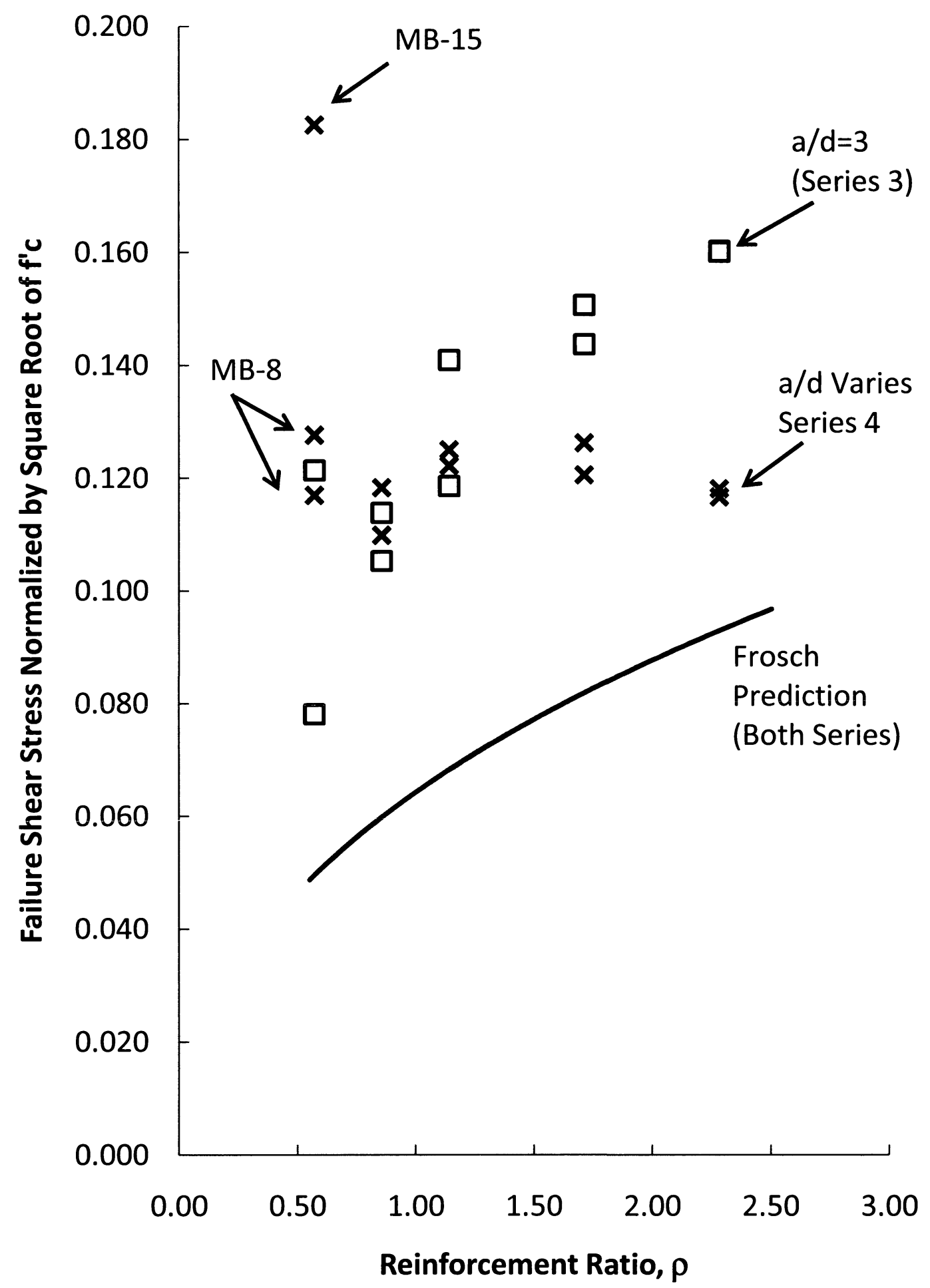

Figure 4-24: Comparison of Experimental Results with Frosch Prediction (Series 3 and 4) 
Max Crack Width (mm)
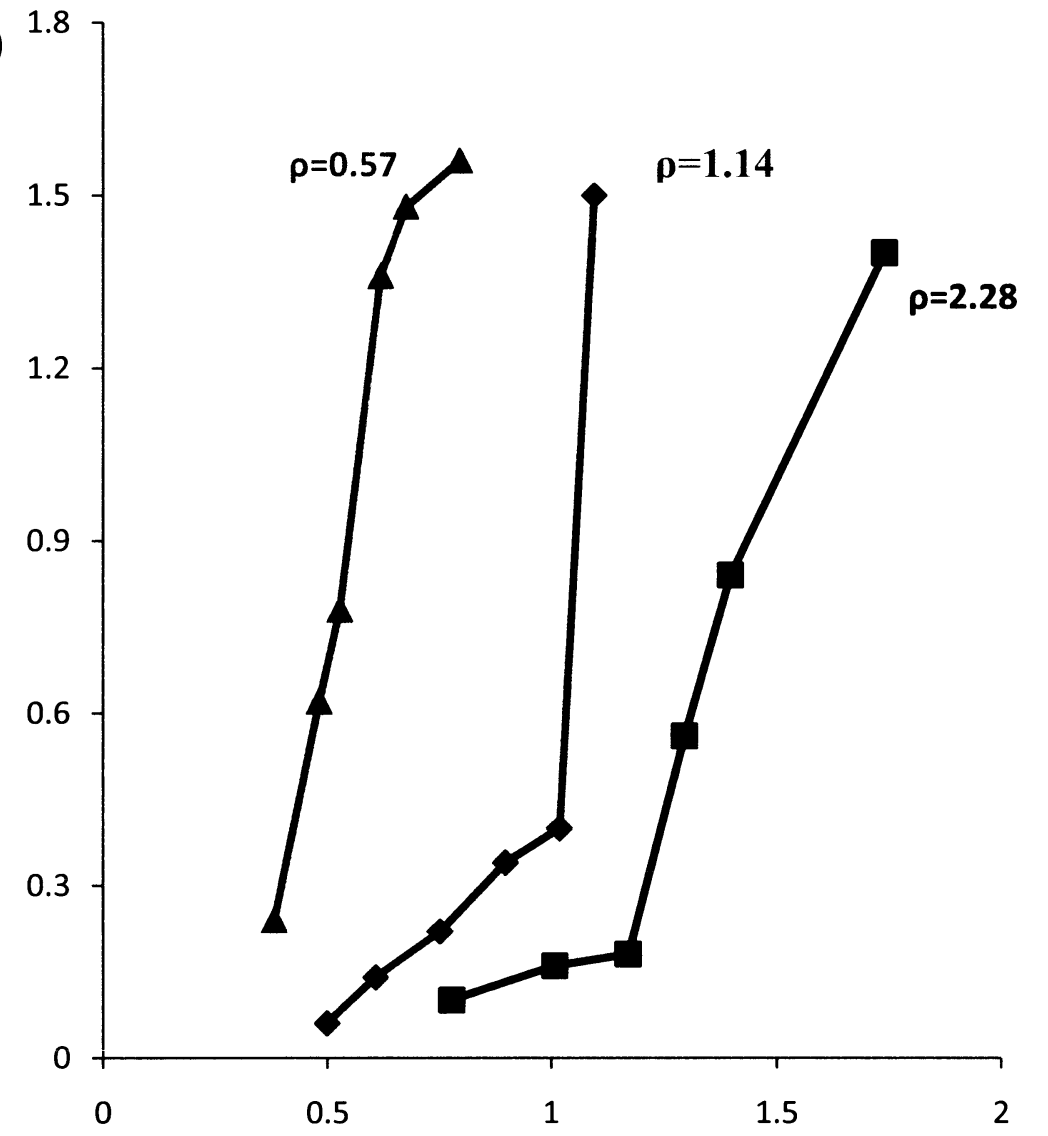

Experimental Shear Stress, $\left(\mathrm{V} / \mathrm{b}_{\mathrm{w}} \mathrm{d}\right)$ (MPa) $\rho=0.57-2.28$

$\mathbf{a} / \mathbf{d}=\mathbf{2}$ 


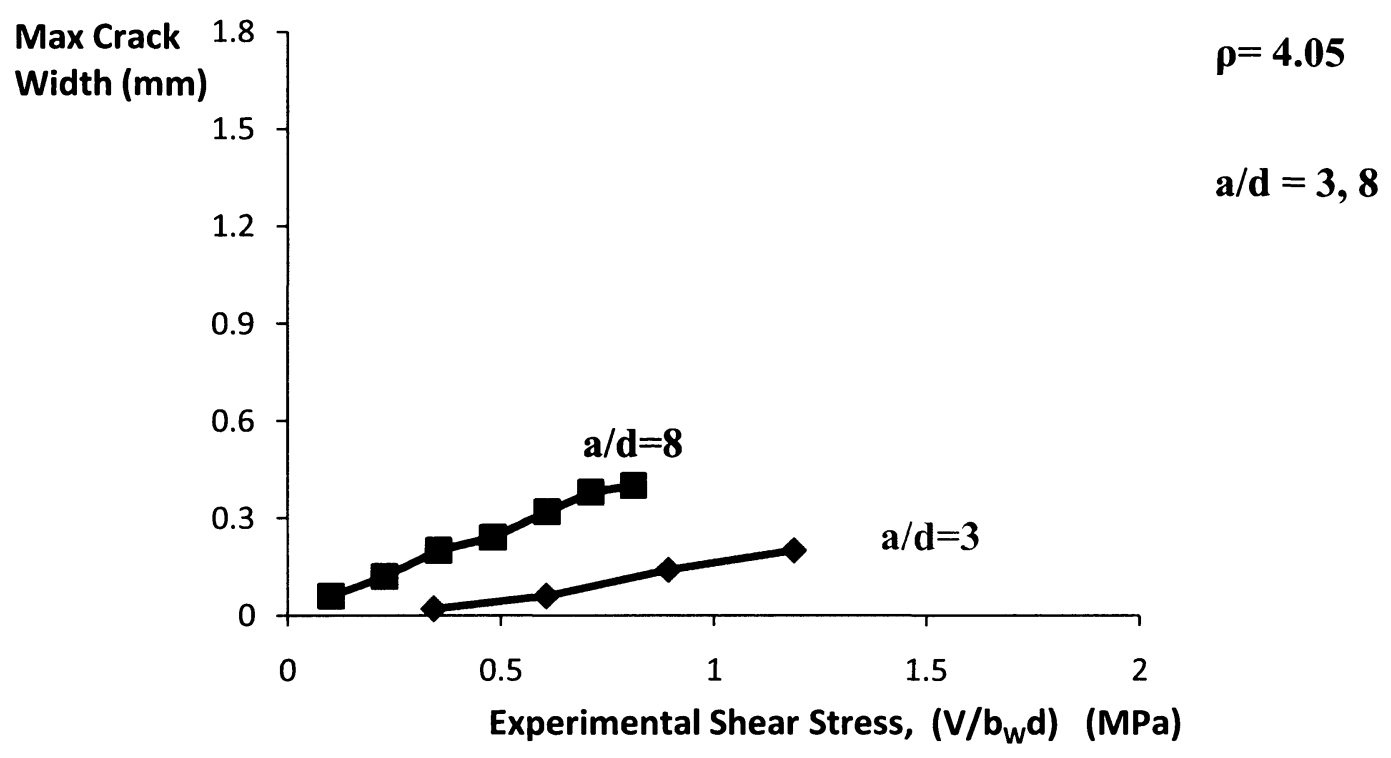

Figure 4-26: Maximum Crack Width vs Experimental Shear Stress, $2^{\text {nd }}$ Series

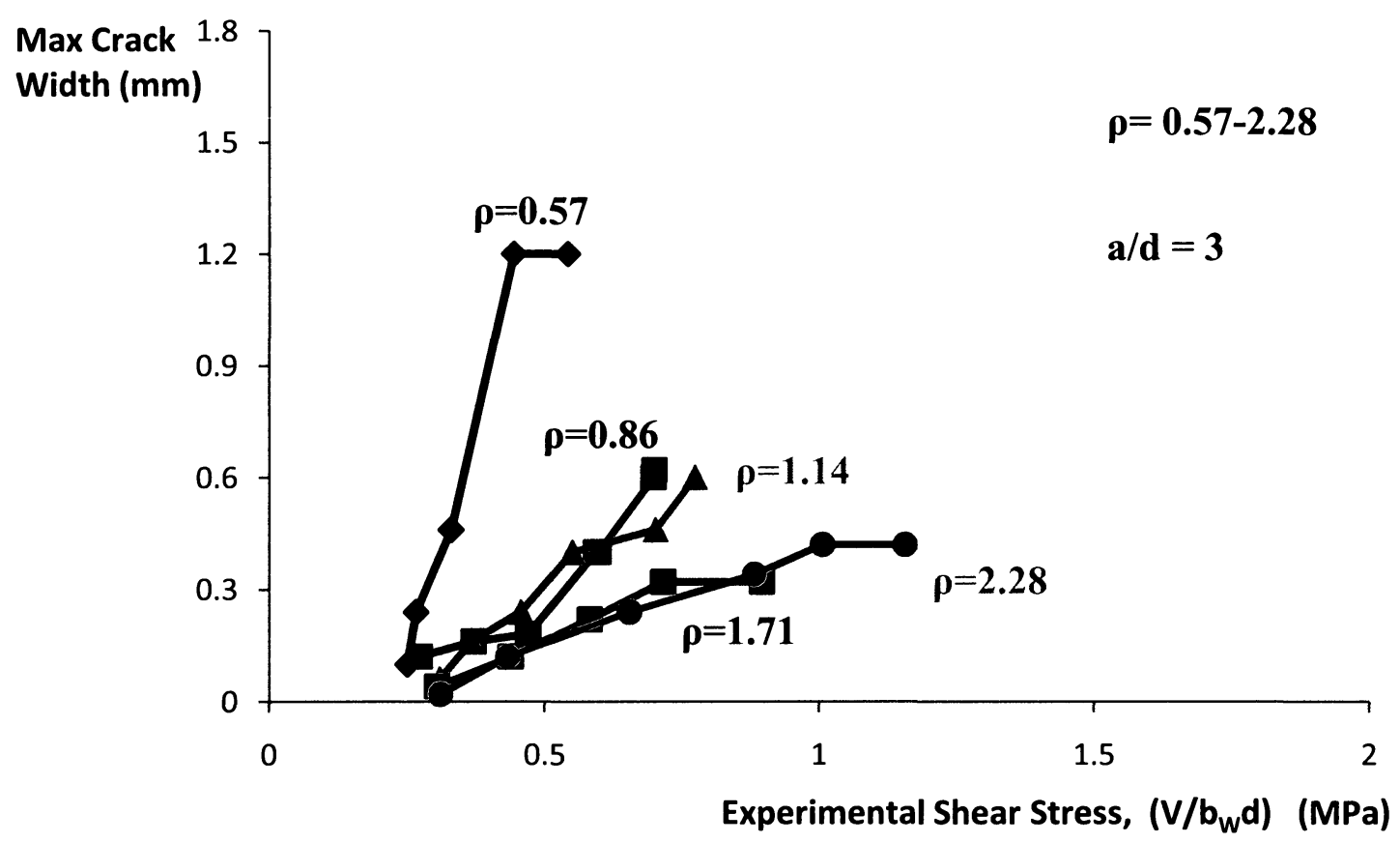

Figure 4-27: Maximum Crack Width vs Experimental Shear Stress, $3^{\text {rd }}$ Series 


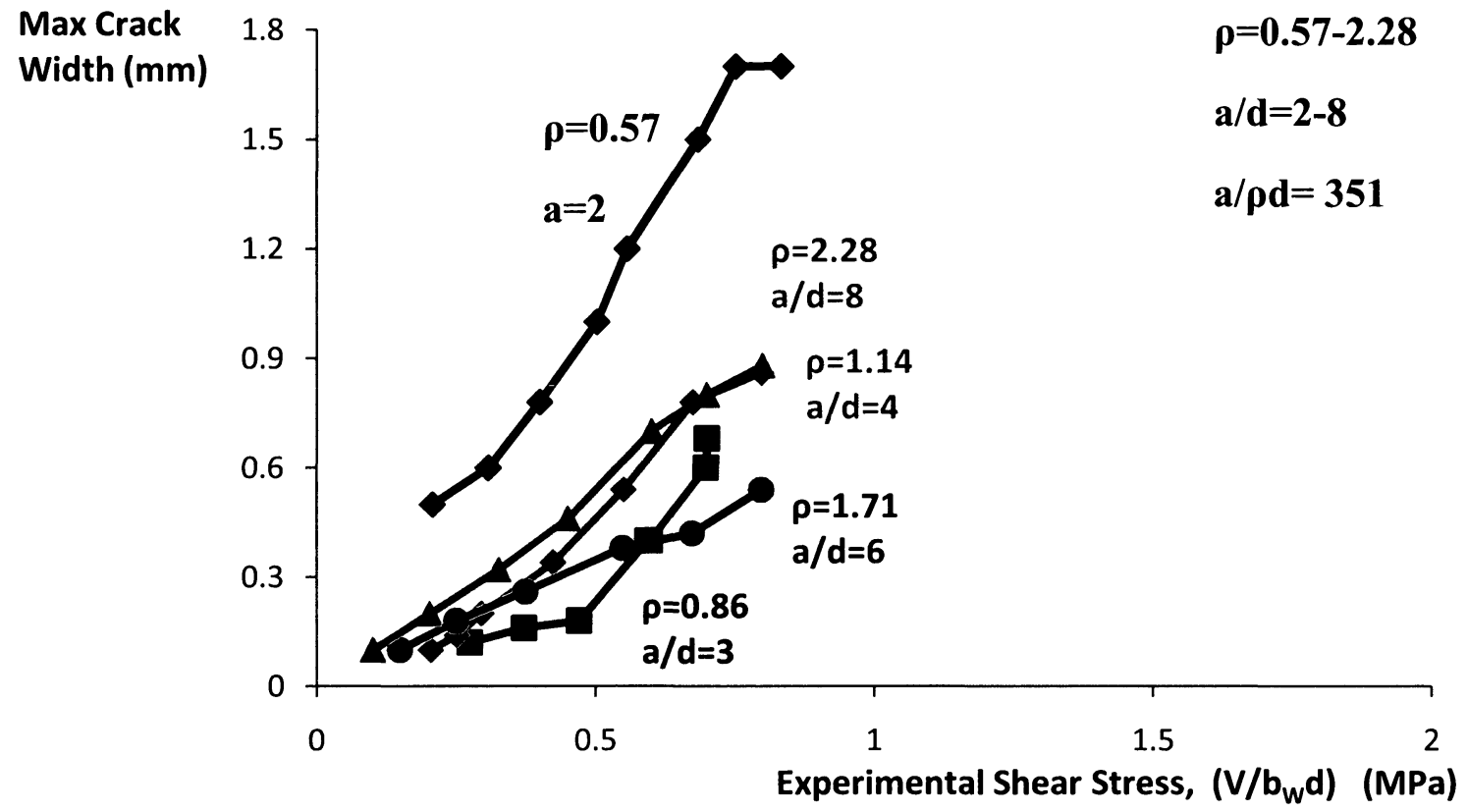

Figure 4-28: Maximum Crack Width vs Experimental Shear Stress, $4^{\text {th }}$ Series

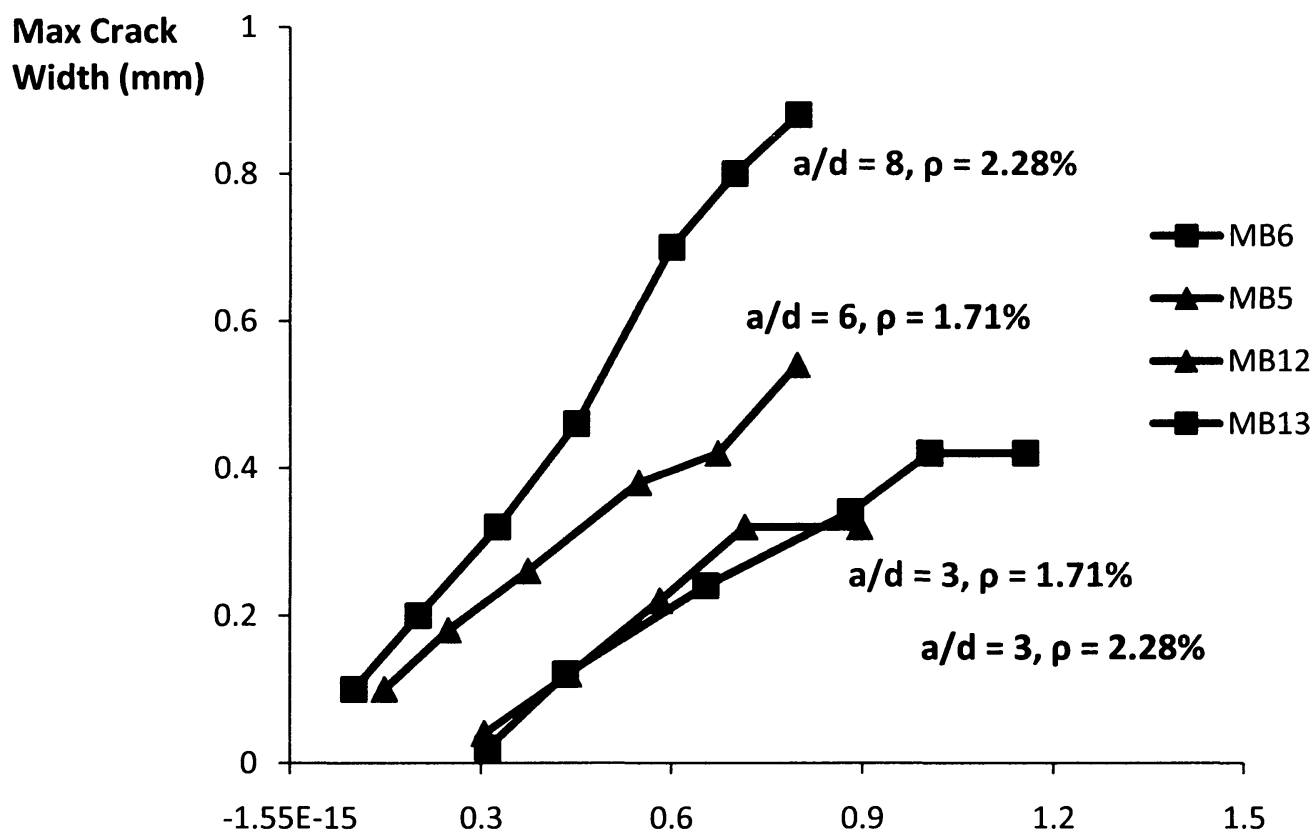

Experimental Shear Stress, $\left(\mathrm{V} / \mathrm{b}_{\mathrm{w}} \mathrm{d}\right)$ (MPa)

Figure 4-29: Comparison of Maximum Crack Widths

(Between Various Series 3 and Series 4 Specimens) 


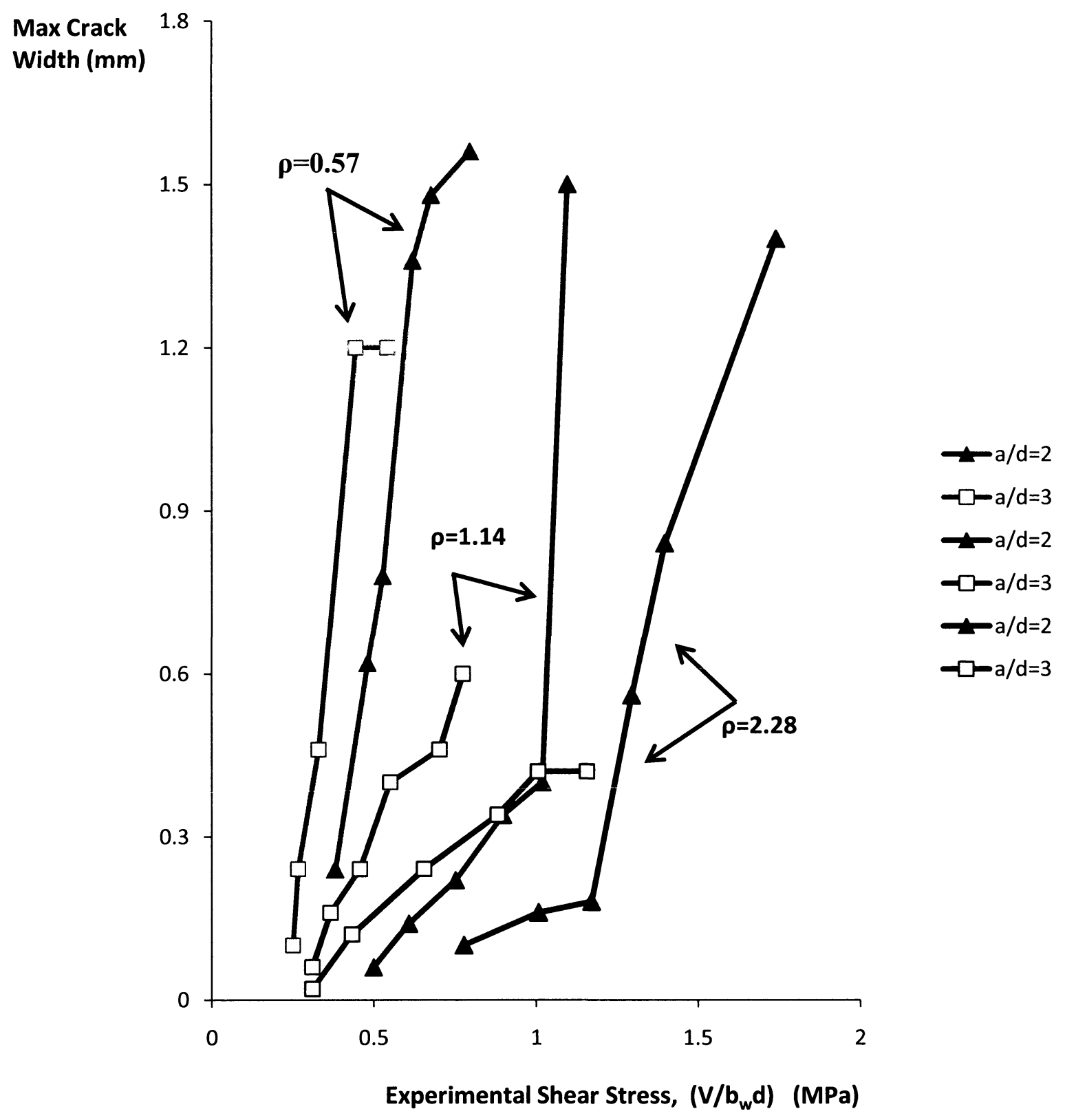

Figure 4-30: Maximum Crack Width vs Experimental Shear Stress (Comparison) 


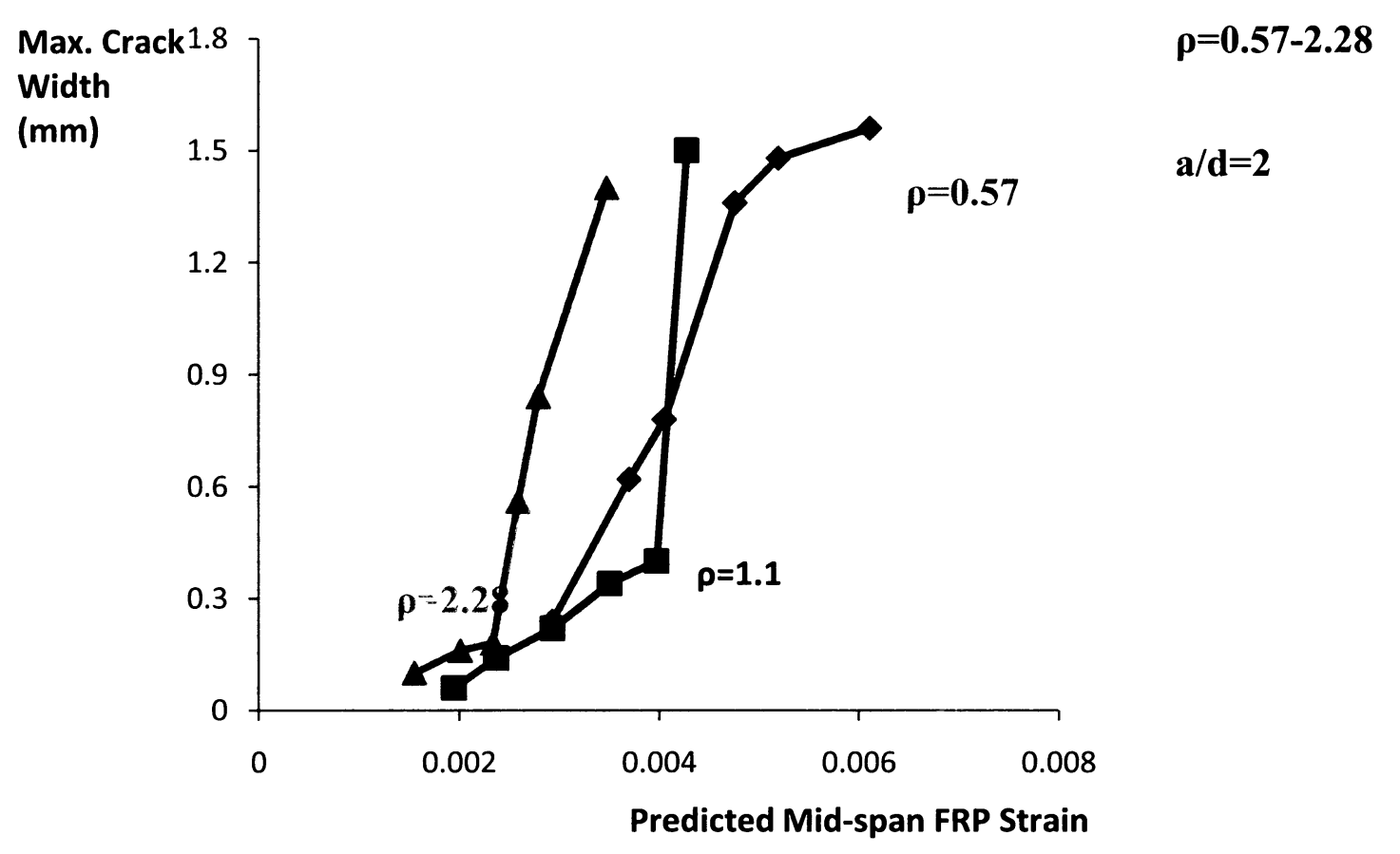

Figure 4-31: Maximum Crack Width vs Predicted Mid-Span FRP Strain, $1^{\text {st }}$ Series

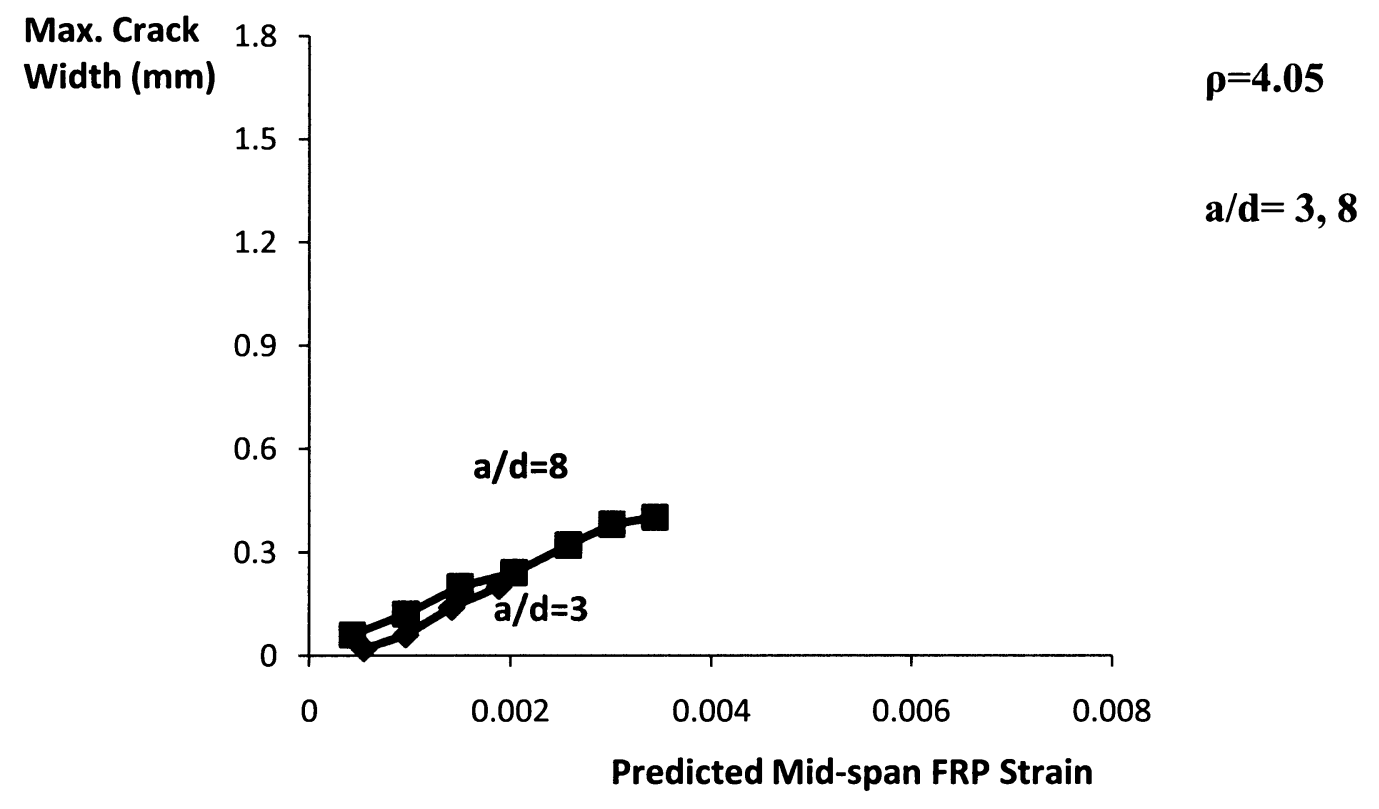

Figure 4-32: Maximum Crack Width vs Predicted Mid-Span FRP Strain, $2^{\text {nd }}$ Series 


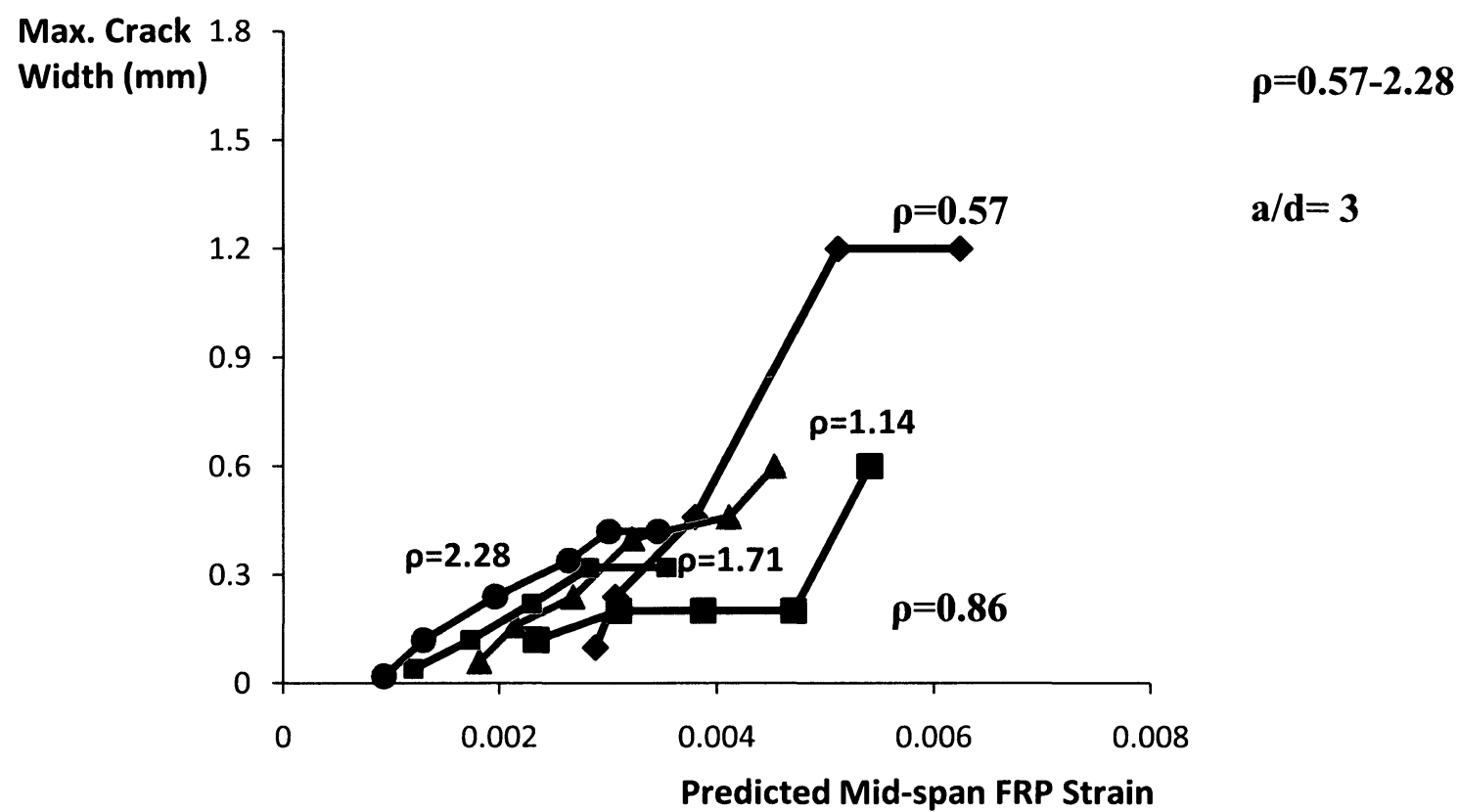

Figure 4-33: Maximum Crack Width vs Predicted Mid-Span FRP Strain, $3^{\text {rd }}$ Series

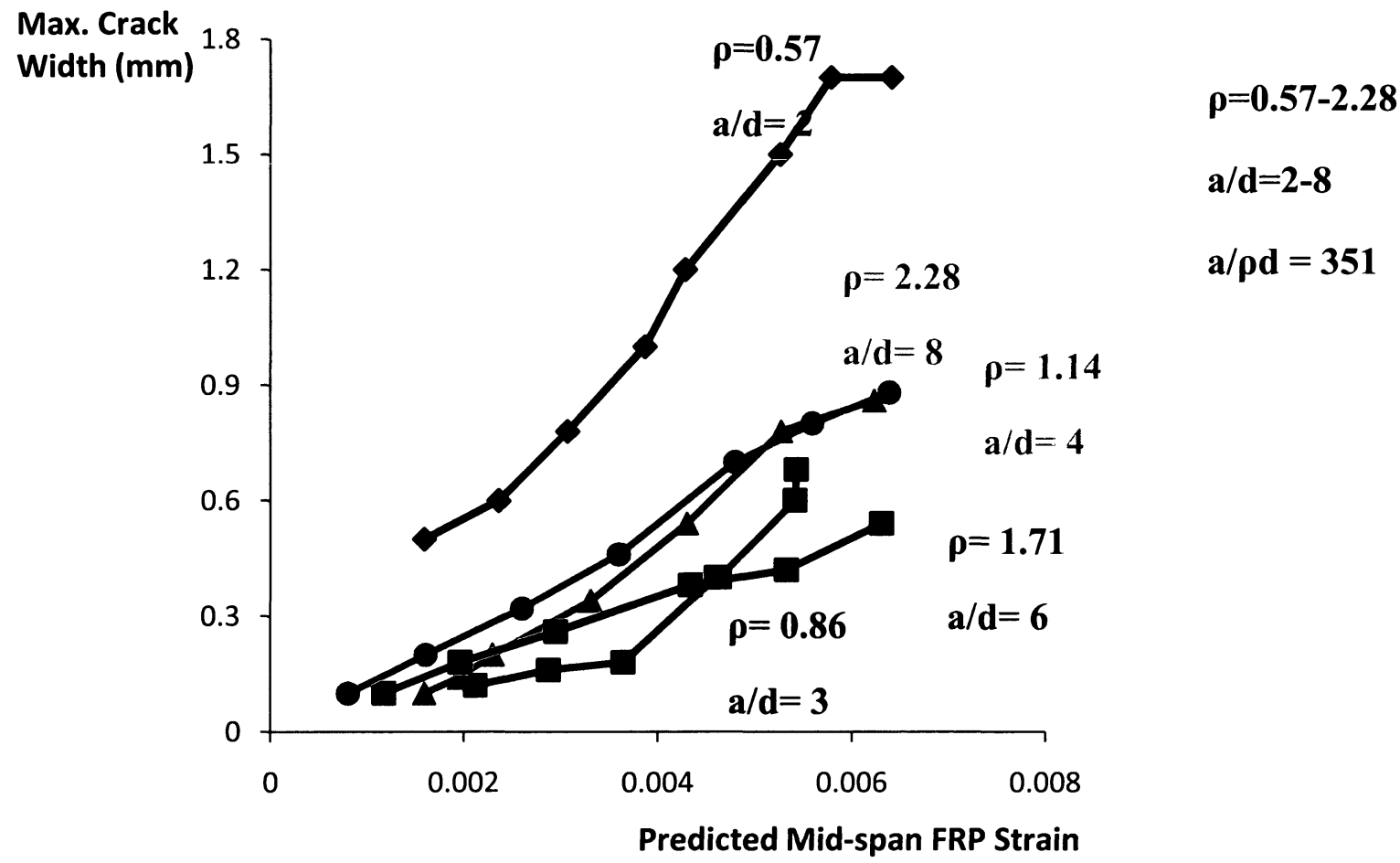

Figure 4-34: Maximum Crack Width vs Predicted Mid-Span FRP Strain, $4^{\text {th }}$ Series 


\subsection{CONCLUDING REMARKS}

This thesis has presented the results of fifteen FRP-reinforced concrete test specimens designed to investigate the one-way shear behavior of reinforced concrete beams and slabs constructed without stirrups. The emphasis has been on the effect of $\mathrm{M} / \mathrm{\rho Vd}$ ratio on the shear strength of members without stirrups as a measure of strain in the longitudinal reinforcement, and the accuracy of the CSA A23.3-04 shear design method and seven other prominent shear design methods. The experimental study consisted of load testing fifteen shear critical, FRP reinforced concrete members without stirrups which were grouped into four different categories based on the test variables: shear span to depth ratio $(\mathrm{a} / \mathrm{d})$ and reinforcement ratio $\rho$. All specimens were shear-critical, simply supported and subjected to point loads.

Review of the experimental database of FRP-reinforced concrete beams indicated that there are no series of tests in which $\rho$ and a/d are varied in such a way that the $M / \rho V d$ ratio is kept constant, and there is also a lack of experimental data for beams with high a/d ratios. To address these cases, this experimental study consisted of beams with high $\mathrm{a} / \mathrm{d}$ ratios $(\mathrm{a} / \mathrm{d}=8)$ and also consisted of a series of beams with a constant value of $\mathrm{M} / \mathrm{\rho Vd}$ $\left(4^{\text {th }}\right.$ series $)$.

It was shown that FRP reinforced concrete exhibits behavior in shear that is similar to steel-reinforced concrete members. The $\mathrm{M} / \mathrm{\rho Vd}$ ratio can be used as a measure of the reinforcement strain in FRP-reinforced concrete, and hence is a factor governing shear strength. This is because shear failure in concrete members without shear reinforcement 
occurs in the concrete, not in the reinforcement. The CSA shear design provisions, which are based on a rational theory of the behavior of reinforced concrete in shear, and are not based on the empirical curves fit to test results, was accurately able to account for the use of FRP reinforcements with their low modulus of elasticity and offered the most accurate prediction of shear strength for these specimens compared to the other prominent method. Further, the modified CSA-A.23.3 (Hoult's Equation) can more accurately model the effects of FRP reinforcements.

It can be summarized from this study that the longitudinal reinforcement ratio, $\rho$, does not govern shear strength solely, but rather it is the strain in this reinforcement which is related to $\mathrm{M} / \mathrm{\rho Vd}$ that governs shear strength. This means that, simply, shear strength of a given section can be expected to stay constant if the amount of the longitudinal reinforcement doubles when the moment doubles. Among those prominent shear design methods, only the CSA and modified CSA shear design methods can truly predict this fact. It can be concluded that design methods formulated in terms of the $\mathrm{M} / \mathrm{V}$ ratio and $\rho$ are better able to predict shear strengths of practical FRP-reinforced concrete members.

The tests performed in this thesis have also shown that by slightly changing the a/d ratio from 3 to 2 , the governing mode of shear failure changed from beam action to strut-andtie action. It was shown that the shear strength in members having a constant value of a/d but increasing reinforcement ratio, in specimens where strut-and-tie action dominates, increased due to the decrease in strain in the longitudinal reinforcement. This fact also was reflected in the data from the $3^{\text {rd }}$ series of specimens where beam action dominated. The failure shear stress in this case increased by increasing the amount of reinforcement ratio at a constant $\mathrm{a} / \mathrm{d}$ ratio. 
It was found in the data from the $2^{\text {nd }}$ series that there is a considerable decrease in shear strength of members as the a/d ratio increases. The failure shear stress of MB14 with $\mathrm{a} / \mathrm{d}=8$ and $\rho=4.05 \%$ was $0.97 \mathrm{MPa}$ which is $28 \%$ smaller than MB7 $(1.35 \mathrm{MPa})$ which had the same reinforcement ratio but considerable smaller a/d ratio of 3 . That is, having a constant value of reinforcement ratio but increasing a/d, causing a higher value of $\mathrm{M} / \rho \mathrm{Vd}$, results in a smaller value of failure shear stress due to increase in strain in the longitudinal reinforcement caused by higher moments. Figures $2-20$ and 2-21 show that the 2004 CSA method can truly provide a conservative but rather accurate shear strength for the both specimens with either $\rho=4.05 \%$ and $\rho=2.28 \%$. However, the Frosch predictions show a poor estimation with respect to the $\mathrm{a} / \mathrm{d}$ ratio and estimates a conservative and inappropriate constant shear strength for both specimens with $\mathrm{a} / \mathrm{d}=3$ and 8. While the El-sayed, ISIS and JSCE equations predict a similar shear failure for these two specimens, the CSA S806 method predict a failure shear stress of $0.96 \mathrm{MPa}$ and 0.68 MPa for MB7 and MB14 respectively, and the Razaqpur equations predict a failure shear stress of $1.38 \mathrm{MPa}$ and $0.69 \mathrm{MPa}$ for MB7 and MB 14 respectively. It can be concluded that the 2004 CSA shear provisions offer a reasonably consistent level of accuracy and safety across all data regardless of the reinforcement ratio or span-to-depth ratio.

The results from $3^{\text {rd }}$ series of tests indicated that increasing the reinforcement ratio at a constant a/d ratio will cause the shear strength to increase. The shear design methods described in this thesis all predict this behavior but, the CSA A23.3 and Hoult methods account for the increases most accurately. For the $4^{\text {th }}$ series specimens with a constant value of $\mathrm{M} / \mathrm{\rho Vd}$, unlike the experimental results and CSA prediction, Frosch's predictions provides a very poor estimate of the shear strength for this series with an 
increase in shear strength for those specimen which have the constant $\mathrm{M} / \mathrm{\rho Vd}$ ratio. None of the other methods could accurately predict the failure shear strengths for this series.

Comparison between the prominent shear design methods for the test data of this study showed that the CSA A23.3 method with the modified expression for $\beta$ (Hoult's Equation) is able to generate safe and accurate predictions of the shear strength of FRPreinforced concrete beams and one-way slabs. This is due to the theoretical derivation of this method from the MCFT. It can simply be concluded that the shear provisions of the CSA code (Hoult's Equations) can be adopted as a safe and accurate shear design method for FRP-reinforced beams and slabs without stirrups. 


\section{REFERENCES}

ACI-ASCE Committee 326 (1962). "Shear and Diagonal Tension, Journal of the American Concrete Institude”, Proceedings, Volume 59, No.1,2 and 3, January: pp.1-30, February: pp.277-334, March: pp.352 - 396.

ACI Committee 440. (1996). State of the Art Report on Fiber Reinforced Plastic Reinforcement for Concrete Structures, ACI 440R-96, American Concrete Institute, Detroit, Michigan, 68pp.

ACI Committee 318 (2008). Building Code Requirements for Structural Concrete and Commentary, Detroit, MI, 465pp

CSA Committee A23.3. (1994) Design of Concrete Structures, CSA A23.3-94, Canadian Standards Association, Toronto, Ontario, Canada 220 pp.

CSA Committee S806. (2002). Design and Construction of building Components with Fiber Reinforced Polymers, CSA-S806-02, Canadian Standards Association, Toronto, Ontario, Canada, 177 pp.

CSA Committee A23.3 (2004), Design of Concrete Structures, CSA A23.3-04, Canadian Standards Association, Toronto, Ontario, Canada, 214 pp.

ISIS-M03-01. (2001). "Reinforcing Concrete Structures with Fiber Reinforced Polymers." The Canadian Network of Centres of Excellence on Intelligent Sensing for Innovative Structures, ISIS Canada, University of Manitoba, Winnipeg, Canada, 81pp.

Japan Society for Civil Engineers (JSCE). (1997). "Recommendations for Design and Construction of Concrete Structures Using Continuous Fibre Reinforced Materials", Research Committee on Continuous Fibre Reinforced Materials, A. Machida, Ed. Tokyo, Japan, 325pp 
Joint ACI-ASCE Committee 445 (1998). "Recent Approaches to Shear Design of Structural Concrete. Journal of Structural Engineering”, ASCE, Volume 124, No.12, pp. $1375-1417$.

MacGregor, J.G. and Bartlett, M. (2000). Reinforced Concrete, Mechanics and Design, $1^{\text {st }}$ Canadian Edition, Prentice-Hall Canada, Scarborough, Ontario, 10425pp.

Bazant Z.P. and Yu Q. (2005). "Designing Against Size Effect on Shear Strength of Reinforced Concrete Beams without Stirrups", Journal of Structural Engineering, ASCE. Volume 131, No. 12, pp.1877 - 1897.

Bentz, E.C., Vecchio, F.J., Collins, M.P. (2006). "Simplified Modified Compression Field Theory for Calculating Shear Strength of Reinforced Concrete Elements", ACI Structural Journal, Volume 103, No.4, pp. 614 - 624.

Bentz, E.C. and Collins, M.P. (2006). "Development of the 2004 Canadian Standards Association (CSA) A23.3 Shear Provisions for Reinforced Concrete", Canadian Journal of Civil Engineering, Volume 33, No.5, pp.521 - 534.

Bilow, D.N., Kamara, M.E. (2008). "Fire and Concrete Structures", Proceedings of the 2008 Structures Congress. April 24-26, 2008, Vancouver, BC, Canada; Sponsored by the Structural Engineering Institute (SEI) of the American Society of Civil Engineers (ASCE) pp:1 - 10 .

Bresler, B., and Pister, K. S. (1958). "Strength of Concrete Under Combined Stresses," ACI Journal, Proceedings Vol.55, No.9, pp. 321 - 345.

Collins, M.P., Bentz, E., Sherwood E.G. and XIE, L. (2007) "An Adequate Theory for the Shear Strength of Reinforced Concrete Structures", Morley Symposium on Concrete Plasticity and its Application, University of Cambridge, July 23, pp.75 - 94.

Collins, M.P., Bentz, E.C. and Sherwood, E.G. (2008). "Where is Shear Reinforcement Required? A Review of Research Results and Design Procedures," ACI Structural Journal, Vol.105, No.6, Sep - Dec, pp. 589 - 599. 
El-Sayed, A.K., El-Salakawy, E., and Benmokrane, B. (2005). "Shear Strength of OneWay Concrete Slabs Reinforced with Fiber-Reinforced Polymer Composite Bars", Journal of Composits for Construction, Vol.9, No.2, pp.147 - 157.

El-Sayed, A.K., El-Salakawy, E. and Benmokrane, B. (2006). "Shear Strength of FRPReinforced Concrete Beams without Transverse Reinforcement." ACI Structural Journal, Vol.103, No.2, pp.235-243.

El-Sayed, A.K., El-Salakawy, E.F., and Benmokrane, B. (2006). "Shear Capacity of High-Strength Concrete Beams Reinforced With FRP Bars," ACI Structural Journal, Vol.103, No.3, pp.383-389.

Faza, S.S., GangaRao, H.V.S., (1992). "Bending and Bond Behaviour of Concrete Beams Reinforced with Fiber Reinforced Plastic Rebars". WVDOH-RP-83 Phase I Report, West Virginia University, Morgantown, pp $128-173$.

Fenwick, R.C. and Paulay, T. (1964). "Discussion of Kani (1964)", Journal of the American. Concrete Institute, Proceedings, No.61, No.12, pp.1590 - 1595.

Fenwick, R. C., and Pauley, T. (1964). discussion of "The Riddle of Shear Failure and its Solution," by G. N. J. Kani, ACI Journal, Proceedings Vol.61, No.12, pp. 1590 - 1595.

Fenwick, R. C., and Paulay, T. (1968). "Mechanisms of Shear Resistance of Concrete Beams," Journal of the Structural Division, ASCE, Vol.94, No.ST10, pp. 2235 - 2350.

Hanson, J. A., (1958) "Shear Strength of Lightweight Reinforced Concrete Beams," ACI Journal, Proceedings Vol.55, No.9, pp. $387-403$.

Hoult N.A., Sherwood E.G., Bentz E.C. and Collins M.P. (2008). "Does the Use of FRP Reinforcement Change the One-Way Shear Behaviour of Reinforced Concrete Slabs?", ASCE Journal of Composites for Construction, Volume 12, No.2, pp.125 - 133.

Kani M.W., Huggins, M.W., and Wittkopp R.R. (1979). "Kani on Shear Reinforced Concrete", University of Toronto, Canada 225pp. 
Katz, A., Berman, N. and Bank, L.C. (1999). "Effect of High Temperature on the Bond Strength of FRP Rebars". ASCE Journal of Composites for Construction, Volume 3, No.2, pp.73-81.

Lubell, A., Sherwood E.G., Bentz E.C. and Collins M.P. (2004). "Safe Shear Design of Large, Wide Beams", Concrete International, Volume 26, No.1, pp.66 - 78.

MacGregor, J. G. (1964). discussion of "The Riddle of Shear Failure and its Solution," by G. N. J. Kai, ACI Journal, Proceedings Vol.61, No.12, pp. 1598 - 1604.

Moe, J. (1962). discussion of "Shear and Diagonal Tension," by Joint ACI - ASCI Committee 326, ACI Journal, Proceedings Vol.59, No.9, pp. 1334 - 1339.

Moody, K. G., Viest, I. M., Elstner, R.C. and Hognestad, E., "Shear Strength of Reinforced Concrete Beams, Part 1-Tests of Simple Beams," ACI Journal, Proceedings Vol.51, No.12, Dec. 1954, pp. $317-332$.

Moretto, O. (1955). discussion of "Ultimate Strength of Simply-Supported Prestressed Concrete Beams without Web Reinforcement," by E. M. Zwoyer and C. P. Siess, ACI Journal, Proceedings Vol. 52, No.12, Part 2, pp. 200/2 - 200/5.

Razaqpur, A.G., Isgor, B.O., Greenaway, S. and Selley, A. (2004). "Concrete contribution to the shear resistance of fiber reinforced polymer reinforced concrete members", Journal of Composites for Construction, Vol.8, No.5, pp.452 - 460.

Razaqpur, A.G. and Isgor, B.O., (2006). "Proposed Shear Design Method for FRPReinforced Concrete Members without Stirrups", ACI Structural Journal, Vol.103, No.1, pp.93- 102.

Rostasy, F. (1992). "Fiber Composite Elements and Techniques as Non-Metallic Reinforcement of Concrete", Brite Project 4142/BREU-CT 91 0515, Evaluation of Potentials and Production Techniques of FRP, Technical Report Task 1.

Saafi, M. (2002). "Effect of Fire on FRP Reinforced Concrete Members", Journal of Composite Structures, Volume 58, No.1, pp. 11 - 20. 
Sen, R., Mariscal, D. and Shahawy, M. (1993). "Investigation of S-2 Glass/Epoxy Strands in Concrete", Fiber-Reinforced-Plastic Reinforcement for Concrete StructuresInternational Symposium. ACI SP-183, Vancouver, British Columbia, Canada, pp. 15 33.

Sherwood E.G., Bentz E.C. and Collins M.P. (2007). "Effect of Aggregate Size on BeamShear Strength of Thick Slabs", Structural Journal American Concrete Institute. Volume 104, No.2, pp. $180-190$.

Sherwood, E.G., Bentz, E., Collins, M.P. (2008) "Prediction of the Shear Strength of FRP Reinforced Slabs using the CSA A23.3 Design Code", Proceedings of the CSCE Annual Conference, Structural Specialty Conference, Quebec City, Canada, June 10-13, pp. 2505 -2514 .

Shioya T. (1989). "Shear Properties of Large Reinforced Concrete Member", Special Report of the Institute of Technology, Shimizu Corporation, Issue 25, 198pp (in Japanese).

Taylor H.P.J (1970). "Investigation of Forces Carried Across Cracks in Reinforced Concrete Beams by Interlock of Aggregates", TRA 42.447, Cement and Concrete Association, London, 22pp.

Tureyen, A.K. and Frosch, R.J. (2003). "Safe Concrete Shear Strength: Another Perspective”, ACI Structural Journal, Volume 100, No.5, pp.609- 615.

Vecchio, F.J., Collins, M.P. (1986). "The Modified Compression-Field Theory for Reinforced Concrete Elements Subjected to Shear", Journal of the American Concrete Institute, Volume 83, No.2, pp.219-231.

Walther, R. (1962). "Calculation of the Shear Strength of Reinforced and Prestressed Concrete Beams by the Shear Failure Theory," Beton-und Stahlbetonbau, Translation 110, Cement and Concrete Association, Vol.57, No.11, pp. $261-271$. 
Zwoyer, E.M. and Siess, C.P. (1954) "Ultimate Strength of Simply-Supported Prestressed Concrete Beams without Web Reinforcement," Journal of the American Concrete Institute, Vol. 29, No. 2, Proceedings Vol. 51, pp. $181-200$. 
APPENDIX A: Sample Calculation of Strut-and-Tie Model by CSA Method 
This appendix presents the strut-and-tie procedure based on the CSA method that used in Chapter 4 to predict shear strength of the $1^{\text {st }}$ series of the specimens which have a reinforcement ratio of $0.57,1.14$ or 2.28 , and a/d ratio of 2 . Figure A-1 shows a sample strut-and-tie model of a beam. In this figure the parameters which are used in this calculation were shown. The following steps must be followed in order to find the applied load P:

1) Select a value for the flexural compression depth " $a_{\text {flex }}$ " as the first guess.

2) Select the flexural compression depth as the compression depth of the strut " $a_{\text {select }}$ "

3) Determine the angle of principal compression: $\theta_{s}=a \tan \left(\frac{d-0.5 a_{\text {select }}}{a_{\text {shear }}}\right)$

4) Determine ratio of diagonal strut force (D) to total applied load (P): $\frac{D}{P}=\frac{1}{2 \sin \left(\theta_{s}\right)}$

5) Determine ratio of tension tie force $(T)$ to total applied load $(P): \frac{T}{P}=\frac{D \cos \left(\theta_{S}\right)}{P}$

6) Calculate width of strut based on the geometry: $\mathrm{w}_{\mathrm{s}}=\mathrm{l}_{\mathrm{b}} \sin \left(\theta_{\mathrm{s}}\right)+\mathrm{w}_{\mathrm{l}} \cos \left(\theta_{\mathrm{s}}\right)$, which $\mathrm{w}_{1}$ equals to $\mathrm{w}_{1}=2(\mathrm{~h}-\mathrm{d})$.

7) Estimate value of applied load $(P)$ at failure: $P_{\text {guess }}$

8) Calculate compressive stress in strut $\left(f_{2}\right): f_{2}=\frac{P_{\text {guess }} \times\left(\frac{D}{P}\right)}{w_{s} \times b_{w}}$

9) Calculate strain in tension chord $\left(\varepsilon_{\mathrm{s}}\right): \varepsilon_{\mathrm{s}}=\frac{\mathrm{P}_{\text {guess }} \times\left(\frac{T}{\mathrm{P}}\right)}{\mathrm{A}_{\mathrm{s}} \times \mathrm{E}_{\mathrm{S}}}$

10) Calculate principal tensile strain $\left(\varepsilon_{1}\right): \varepsilon_{1}=\varepsilon_{s}+\left(\varepsilon_{s}+0.002\right) \times \cot ^{2}\left(\theta_{s}\right)$ 
11) Determine maximum allowable strut stress $\left(f_{2, \max }\right): f_{2, \max }=\frac{f^{\prime}{ }_{c}}{\left(0.8+170 \varepsilon_{1}\right)} \leq 0.85 f^{\prime}$. Where $\mathrm{f}_{\mathrm{c}}$ must be less than $80 \mathrm{MPa}$.

12) Calculate ratio of $\left(\frac{f_{2}}{f_{2, \max }}\right)$. If this ratio reaches 1 , convergence is obtained.

13) Calculate new estimate of applied load $\left(P_{\text {new }}\right): \quad P_{\text {new }}=\frac{P_{\text {guess }}}{\left(1+f_{2} / f_{2, \max }\right) / 2}$

14) An iteration process is performed back to step 7 , so that applied load (P) converged which will be the maximum force that can be resisted by the strut.

15) Calculate stress in flexural compression chord $\left(f_{\text {flex }}\right)$ by taking the compression force equals to the tension force. This value should be equal to $0.85 \hat{f}_{c}$ if fully convergence obtain: $f_{\text {flex }}=\frac{P \times(T / P)}{a_{\text {select }} b_{w}}$

16) Calculate new estimate of $a_{\text {select: }} a_{\text {select, new }}=a_{\text {select }}\left(\frac{1+\left(f_{\text {flex }} /\left(0.85 f^{\prime}{ }_{c}\right)\right)}{2}\right)$

17) Iterate with this new value until obtaining convergence on both the inner loop (steps 7-14) and the outer loop (steps 3-17)

These calculations performed with a spreadsheet using goal-and-sick method. In one row of the spreadsheet, multiple analyses were performed simultaneously. Then, calculations from step 14 back to step 7 were copied in the new columns afterwards, so that, the inner routine can be automatically converged. And by copying the results from step 17 back to step 2, the outer routine also can be automatically converged. The numerical calculations were performed for the three specimens of this series with the characteristics are presented from the spreadsheet (Table A-1). 
Table A-1: Numerical Calculations of Strut-And-Tie Model for the $1^{\text {st }}$ Series

Strut-and-Tie Analysis:

\begin{tabular}{|c|c|c|c|c|c|c|c|c|c|c|c|c|c|c|c|}
\hline \begin{tabular}{|l} 
Specimen \\
Name
\end{tabular} & $\begin{array}{c}\text { b } \\
\mathbf{m m}\end{array}$ & $\begin{array}{c}\mathrm{D} \\
\mathrm{Mm}\end{array}$ & $\begin{array}{c}d_{v} \\
m m\end{array}$ & $\begin{array}{c}\mathbf{h} \\
\mathbf{m m}\end{array}$ & $\begin{array}{c}\text { a } \\
\text { (shear) } \\
\mathrm{mm}\end{array}$ & $\begin{array}{c}\mathrm{a}_{\mathrm{g}} \\
\mathrm{mm}\end{array}$ & $\begin{array}{c}A_{s} \\
\left(\mathrm{~mm}^{2}\right)\end{array}$ & $\begin{array}{c}\text { Es } \\
(\mathrm{MPa})\end{array}$ & $\begin{array}{l}\rho \\
\%\end{array}$ & $a / d$ & $\begin{array}{c}\mathbf{f}_{\mathrm{c}}^{\prime} \\
\mathrm{MPa}\end{array}$ & $\begin{array}{c}\mathrm{I}_{\mathrm{b}} \\
(\mathrm{mm})\end{array}$ & $\begin{array}{l}2(\mathrm{~h}-\mathrm{d}) \\
(\mathrm{mm})\end{array}$ & $\begin{array}{c}0.85 f^{\prime} \\
\mathrm{MPa}\end{array}$ & $\begin{array}{c}V=P / 2 \\
k N\end{array}$ \\
\hline
\end{tabular}

\begin{tabular}{|c|c|c|c|c|c|c|c|c|c|c|c|c|c|c|c|}
\hline MB8 & 400 & 250 & 225 & 280 & 500 & 9.5 & 570 & 47600 & 0.0057 & 2 & 51.6 & 75 & 60 & 43.9 & 95.6 \\
\hline MB9 & 400 & 250 & 225 & 280 & 500 & 9.5 & 1140 & 47600 & 0.0114 & 2 & 51.0 & 75 & 60 & 43.3 & 124.2 \\
\hline MB10 & 400 & 250 & 225 & 280 & 500 & 9.5 & 2280 & 47600 & 0.0228 & 2 & 50.8 & 75 & 60 & 43.2 & 156.8 \\
\hline
\end{tabular}


Table A-1 Continued

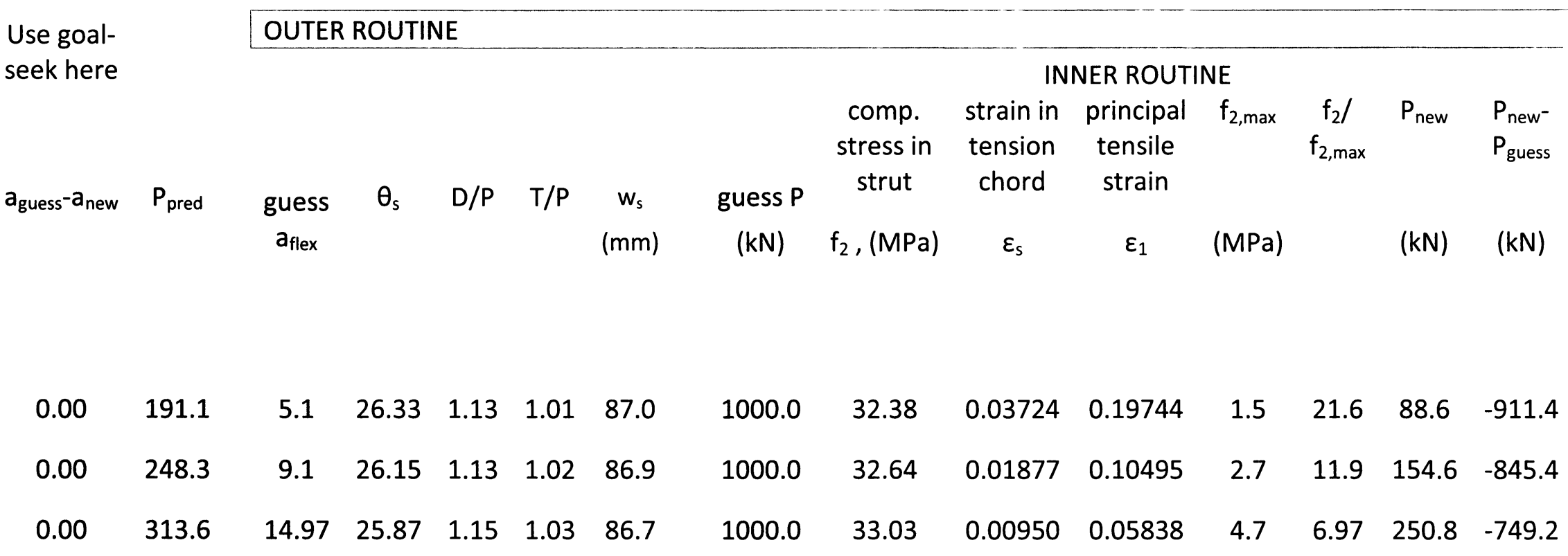


Table A-1 Cont.

\begin{tabular}{|c|c|c|c|c|c|c|c|}
\hline \multicolumn{8}{|c|}{$\begin{array}{c}\text { OUTER } \\
\text { ROUTINE }\end{array}$} \\
\hline \multicolumn{8}{|c|}{ INNER ROUTINE } \\
\hline$P_{\text {new }}$ & $\begin{array}{l}\text { Compression } \\
\text { stress in strut }\end{array}$ & $\begin{array}{l}\text { strain in } \\
\text { tension } \\
\text { chord }\end{array}$ & $\begin{array}{c}\text { principal } \\
\text { tensile } \\
\text { strain }\end{array}$ & $f_{2, \max }$ & $\begin{array}{c}f_{2} / \\
f_{2, \max }\end{array}$ & $P_{\text {new }}$ & $P_{\text {new }}-P_{\text {guess }}$ \\
\hline$(\mathrm{kN})$ & $\mathrm{f}_{2},(\mathrm{MPa})$ & $\varepsilon_{\mathrm{s}}$ & $\varepsilon_{1}$ & (MPa) & & $(k N)$ & $(k N)$ \\
\hline 88.6 & 2.87 & 0.00330 & 0.02494 & 10.2 & 0.2803 & 138.5 & 49.823 \\
\hline 154.6 & 5.05 & 0.00290 & 0.02324 & 10.7 & 0.4704 & 210.3 & 55.699 \\
\hline 250.8 & 8.29 & 0.00238 & 0.02101 & 11.6 & 0.7131 & 292.9 & 42.007 \\
\hline
\end{tabular}


Table A-1 Cont.

\begin{tabular}{|c|c|c|c|c|c|c|c|}
\hline \multicolumn{8}{|c|}{ OUTER ROUTINE } \\
\hline \multicolumn{8}{|c|}{ INNER ROUTINE } \\
\hline$P_{\text {new }}$ & $\begin{array}{l}\text { Compression } \\
\text { stress in strut }\end{array}$ & $\begin{array}{l}\text { strain in } \\
\text { tension } \\
\text { chord }\end{array}$ & $\begin{array}{c}\text { principal } \\
\text { tensile } \\
\text { strain }\end{array}$ & $f_{2, \max }$ & $\begin{array}{c}f_{2} / \\
f_{2, \max }\end{array}$ & $P_{\text {new }}$ & $P_{\text {new }}-P_{\text {guess }}$ \\
\hline$(k N)$ & $\mathrm{f}_{2},(\mathrm{MPa})$ & $\varepsilon_{\mathrm{s}}$ & $\varepsilon_{1}$ & (MPa) & & $(\mathrm{kN})$ & $(\mathrm{kN})$ \\
\hline 138.5 & 4.48 & 0.00516 & 0.03437 & 7.8 & 0.5772 & 175.6 & 37.118 \\
\hline 210.3 & 6.86 & 0.00395 & 0.02863 & 9.0 & 0.7630 & 238.6 & 28.272 \\
\hline 292.9 & 9.67 & 0.00278 & 0.02311 & 10.7 & 0.9004 & 308.2 & 15.355 \\
\hline
\end{tabular}


Table A-1 Cont.

\begin{tabular}{|c|c|c|c|c|c|c|c|}
\hline \multicolumn{8}{|c|}{ OUTER ROUTINE } \\
\hline \multicolumn{8}{|c|}{ INNER ROUTINE } \\
\hline$P_{\text {new }}$ & $\begin{array}{l}\text { Compression } \\
\text { stress in strut }\end{array}$ & $\begin{array}{l}\text { strain in } \\
\text { tension } \\
\text { chord }\end{array}$ & $\begin{array}{c}\text { principal } \\
\text { tensile } \\
\text { strain }\end{array}$ & $f_{2, \max }$ & $\begin{array}{c}f_{2} / \\
f_{2, \max }\end{array}$ & $P_{\text {new }}$ & $P_{\text {new }}-P_{\text {guess }}$ \\
\hline$(k N)$ & $\mathrm{f}_{2},(\mathrm{MPa})$ & $\varepsilon_{\mathrm{s}}$ & $\varepsilon_{1}$ & (MPa) & & $(k N)$ & $(k N)$ \\
\hline 175.6 & 5.68 & 0.00654 & 0.04140 & 6.6 & 0.8635 & 188.4 & 12.860 \\
\hline 238.6 & 7.79 & 0.00448 & 0.03136 & 8.3 & 0.9365 & 246.4 & 7.819 \\
\hline 308.2 & 10.18 & 0.00293 & 0.02387 & 10.5 & 0.9737 & 312.3 & 4.113 \\
\hline
\end{tabular}


Table A-1 Cont.

\begin{tabular}{|c|c|c|c|c|c|c|c|}
\hline \multicolumn{8}{|c|}{ OUTER ROUTINE } \\
\hline \multicolumn{8}{|c|}{ INNER ROUTINE } \\
\hline$P_{\text {new }}$ & $\begin{array}{l}\text { Compression } \\
\text { stress in strut }\end{array}$ & $\begin{array}{c}\text { strain in } \\
\text { tension } \\
\text { chord }\end{array}$ & $\begin{array}{c}\text { principal } \\
\text { tensile } \\
\text { strain }\end{array}$ & $f_{2, \max }$ & $\begin{array}{c}f_{2} / \\
f_{2, \max }\end{array}$ & $P_{\text {new }}$ & $\begin{array}{l}P_{\text {new }} \\
P_{\text {guess }}\end{array}$ \\
\hline$(k N)$ & $\mathrm{f}_{2},(\mathrm{MPa})$ & $\varepsilon_{\mathrm{s}}$ & $\varepsilon_{1}$ & (MPa) & & $(k N)$ & $(k N)$ \\
\hline 188.4 & 6.10 & 0.00702 & 0.04383 & 6.3 & 0.9757 & 190.8 & 2.319 \\
\hline 246.4 & 8.04 & 0.00463 & 0.03212 & 8.1 & 0.9875 & 248.0 & 1.550 \\
\hline 312.3 & 10.32 & 0.00297 & 0.02408 & 10.4 & 0.9937 & 313.3 & 0.981 \\
\hline
\end{tabular}


Table A-1 Cont.

\begin{tabular}{|c|c|c|c|c|c|c|c|}
\hline \multicolumn{8}{|c|}{ OUTER ROUTINE } \\
\hline \multicolumn{8}{|c|}{ INNER ROUTINE } \\
\hline$P_{\text {new }}$ & $\begin{array}{l}\text { Compression } \\
\text { stress in strut }\end{array}$ & $\begin{array}{c}\text { strain in } \\
\text { tension } \\
\text { chord }\end{array}$ & $\begin{array}{c}\text { principal } \\
\text { tensile } \\
\text { strain }\end{array}$ & $f_{2, \max }$ & $\begin{array}{c}f_{2} / \\
f_{2, \max }\end{array}$ & $P_{\text {new }}$ & $\begin{array}{l}P_{\text {new }} \\
P_{\text {guess }}\end{array}$ \\
\hline$(\mathrm{kN})$ & $\mathrm{f}_{2},(\mathrm{MPa})$ & $\varepsilon_{\mathrm{s}}$ & $\varepsilon_{1}$ & (MPa) & & $(k N)$ & $(k N)$ \\
\hline
\end{tabular}

$\begin{array}{llllllll}190.8 & 6.18 & 0.00710 & 0.04427 & 6.2 & 0.9966 & 191.1 & 0.322 \\ 248.0 & 8.09 & 0.00465 & 0.03227 & 8.1 & 0.9978 & 248.2 & 0.279 \\ 313.3 & 10.35 & 0.00298 & 0.02413 & 10.4 & 0.9986 & 313.5 & 0.227\end{array}$


Table A-1 Cont.

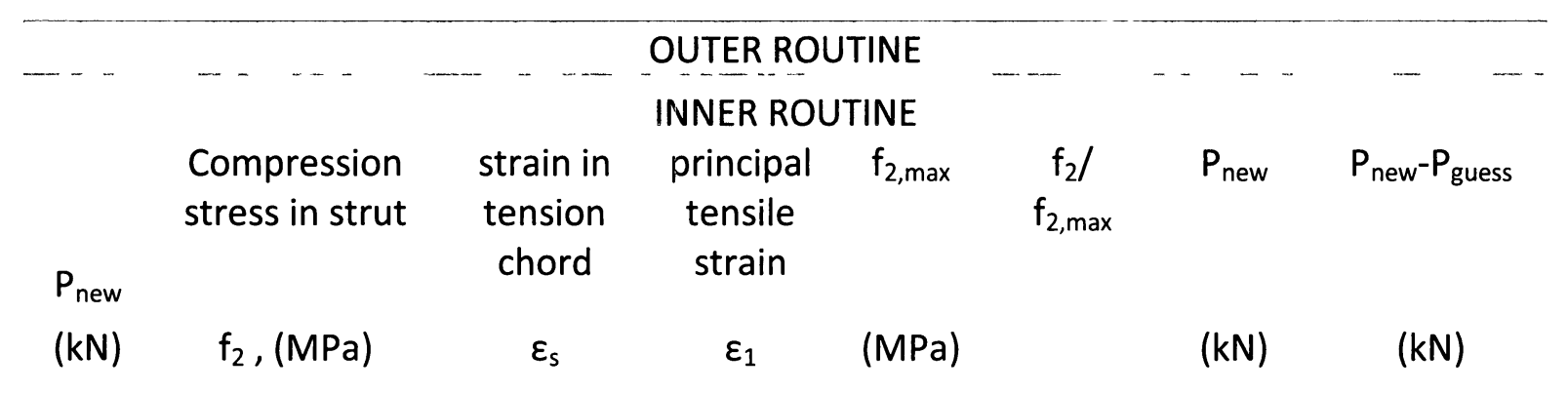

$\begin{array}{llllllll}191.1 & 6.19 & 0.00712 & 0.04433 & 6.2 & 0.9996 & 191.1 & 0.043 \\ 248.2 & 8.10 & 0.00466 & 0.03229 & 8.1 & 0.9996 & 248.3 & 0.049 \\ 313.5 & 10.36 & 0.00298 & 0.02414 & 10.4 & 0.9997 & 313.6 & 0.052\end{array}$


Table A-1 Cont.

\begin{tabular}{|c|c|c|c|c|c|c|c|}
\hline \multicolumn{8}{|c|}{ OUTER ROUTINE } \\
\hline \multicolumn{8}{|c|}{ INNER ROUTINE } \\
\hline$P_{\text {new }}$ & $\begin{array}{l}\text { Compression } \\
\text { stress in strut }\end{array}$ & $\begin{array}{l}\text { strain in } \\
\text { tension } \\
\text { chord }\end{array}$ & $\begin{array}{c}\text { principal } \\
\text { tensile } \\
\text { strain }\end{array}$ & $f_{2, \max }$ & $\begin{array}{c}f_{2} / \\
f_{2, \max }\end{array}$ & $P_{\text {new }}$ & $\begin{array}{l}P_{\text {new }} \\
P_{\text {guess }}\end{array}$ \\
\hline$(k N)$ & $\mathrm{f}_{2},(\mathrm{MPa})$ & $\varepsilon_{\mathrm{s}}$ & $\varepsilon_{1}$ & (MPa) & & $(k N)$ & $(\mathrm{kN})$ \\
\hline 191.1 & 6.19 & 0.00712 & 0.04434 & 6.2 & 0.9999 & 191.1 & 0.006 \\
\hline 248.3 & 8.10 & 0.00466 & 0.03230 & 8.1 & 0.9999 & 248.3 & 0.009 \\
\hline 313.6 & 10.36 & 0.00298 & 0.02414 & 10.4 & 0.9999 & 313.6 & 0.012 \\
\hline
\end{tabular}


Table A-1 Cont.

\begin{tabular}{|c|c|c|c|c|c|c|c|}
\hline \multicolumn{8}{|c|}{ OUTER ROUTINE } \\
\hline \multicolumn{8}{|c|}{ INNER ROUTINE } \\
\hline$P_{\text {new }}$ & $\begin{array}{l}\text { Compression } \\
\text { tress in strut }\end{array}$ & $\begin{array}{l}\text { strain in } \\
\text { tension } \\
\text { chord }\end{array}$ & $\begin{array}{c}\text { principal } \\
\text { tensile } \\
\text { strain }\end{array}$ & $f_{2, \max }$ & $\begin{array}{c}f_{2} / \\
f_{2, \max }\end{array}$ & $P_{\text {new }}$ & $\begin{array}{l}P_{\text {new }} \\
P_{\text {guess }}\end{array}$ \\
\hline$(\mathrm{kN})$ & $\mathrm{f}_{2},(\mathrm{MPa})$ & $\varepsilon_{\mathrm{s}}$ & $\varepsilon_{1}$ & (MPa) & & $(k N)$ & $(k N)$ \\
\hline 191.1 & 6.19 & 0.00712 & 0.04434 & 6.2 & 1.0000 & 191.1 & 0.001 \\
\hline 248.3 & 8.10 & 0.00466 & 0.03230 & 8.1 & 1.0000 & 248.3 & 0.002 \\
\hline 313.6 & 10.36 & 0.00298 & 0.02414 & 10.4 & 1.0000 & 313.6 & 0.003 \\
\hline
\end{tabular}


Table A-1 Cont.

\begin{tabular}{|c|c|c|c|c|c|c|c|}
\hline & \multicolumn{7}{|c|}{ OUTER ROUTINE } \\
\hline & \multicolumn{7}{|c|}{ INNER ROUTINE } \\
\hline$P_{\text {new }}$ & $\begin{array}{l}\text { Compression } \\
\text { stress in strut }\end{array}$ & $\begin{array}{l}\text { strain in } \\
\text { tension } \\
\text { chord }\end{array}$ & $\begin{array}{c}\text { principal } \\
\text { tensile } \\
\text { strain }\end{array}$ & $f_{2, \max }$ & $\begin{array}{c}f_{2} / \\
f_{2, \max }\end{array}$ & $P_{\text {new }}$ & $\begin{array}{l}P_{\text {new }} \\
P_{\text {guess }}\end{array}$ \\
\hline$(k N)$ & $f_{2},(M P a)$ & $\varepsilon_{\mathrm{s}}$ & $\varepsilon_{1}$ & (MPa) & & $(\mathrm{kN})$ & $(\mathrm{kN})$ \\
\hline 191.1 & 6.19 & 0.00712 & 0.04434 & 6.2 & 1.0000 & 191.1 & 0.000 \\
\hline 248.3 & 8.10 & 0.00466 & 0.03230 & 8.1 & 1.0000 & 248.3 & 0.000 \\
\hline 313.6 & 10.36 & 0.00298 & 0.02414 & 10.4 & 1.0000 & 313.6 & 0.001 \\
\hline
\end{tabular}


Table A-1 (Concluded)

\begin{tabular}{|c|c|c|c|c|c|c|c|c|c|}
\hline \multirow{2}{*}{$\ldots$} & \multirow{2}{*}{$\cdots$} & \multicolumn{3}{|c|}{ OUTER ROUTINE } & \multirow{2}{*}{\multicolumn{2}{|c|}{$\cdots$}} & \multirow{2}{*}{$\ldots$} & \multirow{2}{*}{$f_{\text {flex }}$} & \multirow[b]{3}{*}{$a_{\text {new }}$} \\
\hline & & \multicolumn{3}{|c|}{ INNER ROUTINE } & & & & & \\
\hline$P_{\text {new }}$ & $\begin{array}{l}\text { Compression } \\
\text { stress in strut }\end{array}$ & $\begin{array}{l}\text { strain in } \\
\text { tension } \\
\text { chord }\end{array}$ & $\begin{array}{c}\text { principal } \\
\text { tensile } \\
\text { strain }\end{array}$ & $f_{2, \max }$ & $\begin{array}{c}f_{2} / \\
f_{2, \max }\end{array}$ & $P_{\text {new }}$ & $\begin{array}{l}P_{\text {new }} \\
P_{\text {guess }}\end{array}$ & (MPa) & \\
\hline$(\mathrm{kN})$ & $\mathrm{f}_{2},(\mathrm{MPa})$ & $\varepsilon_{\mathrm{s}}$ & $\varepsilon_{1}$ & $(\mathrm{MPa})$ & & $(k N)$ & $(\mathrm{kN})$ & & \\
\hline 191.1 & 6.19 & 0.00712 & 0.04434 & 6.2 & 1.0000 & 191.1 & 0.000 & 43.86 & 5.10 \\
\hline 248.3 & 8.10 & 0.00466 & 0.03230 & 8.1 & 1.0000 & 248.3 & 0.000 & 43.33 & 9.09 \\
\hline 313.6 & 10.36 & 0.00298 & 0.02414 & 10.4 & 1.0000 & 313.6 & 0.000 & 43.18 & 14.97 \\
\hline
\end{tabular}




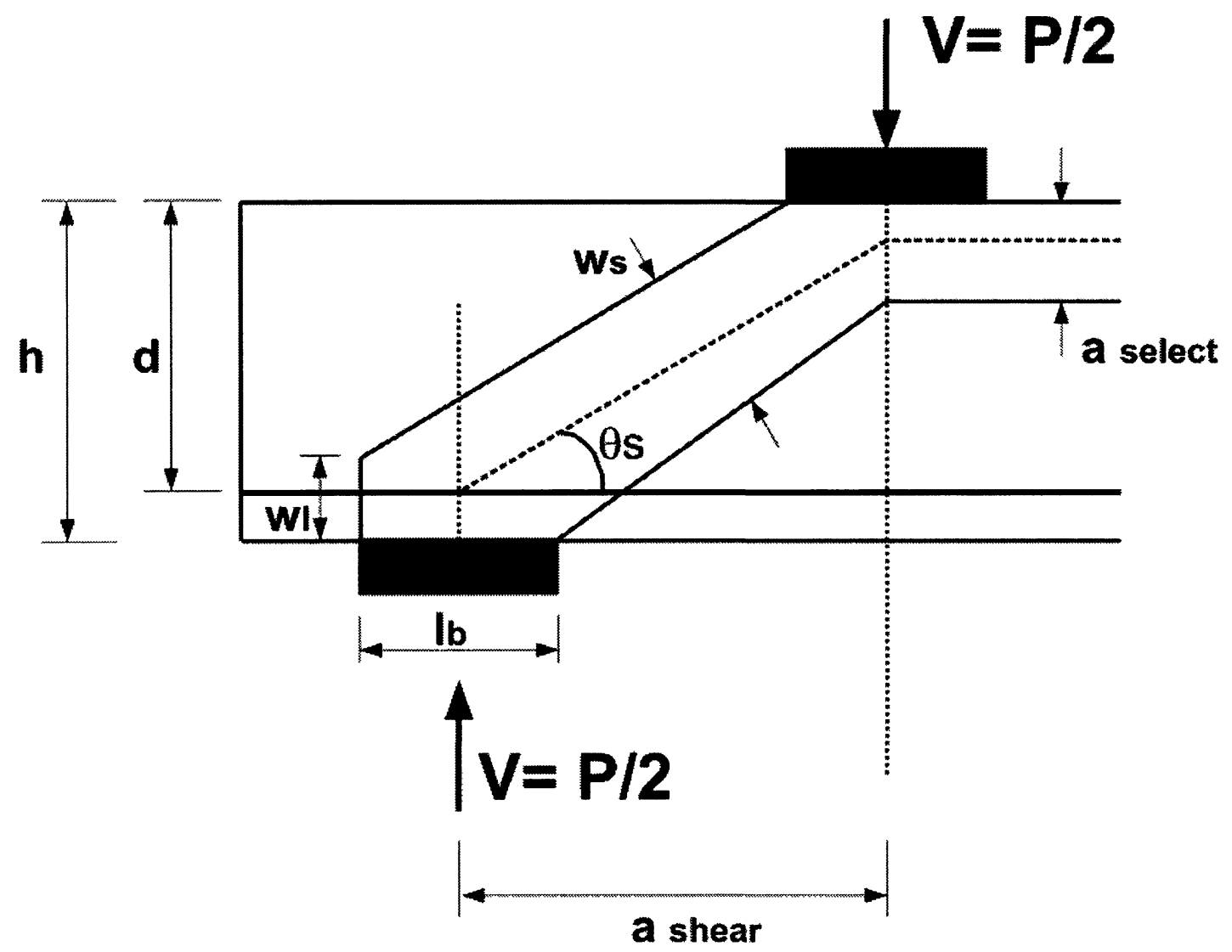

Figure A-1: Sample Strut-And-Tie Model of a Beam 
APPENDIX B: Sample Calculation of FRP mid-span Strain by

CSA Method for Specimen MB3 
This appendix presents a sample calculation of mid-span FRP strain, $\varepsilon_{\mathrm{FRP}}$, by CSA method which used in Chapter 4. $\varepsilon_{\mathrm{FRP}}$ can be calculated at each load stage, however, this sample calculation was performed for specimen MB3 to find the maximum mid-span FRP. The following steps must be followed in order to find the mid-span FRP strain, $\varepsilon_{\mathrm{FRP}}$ :

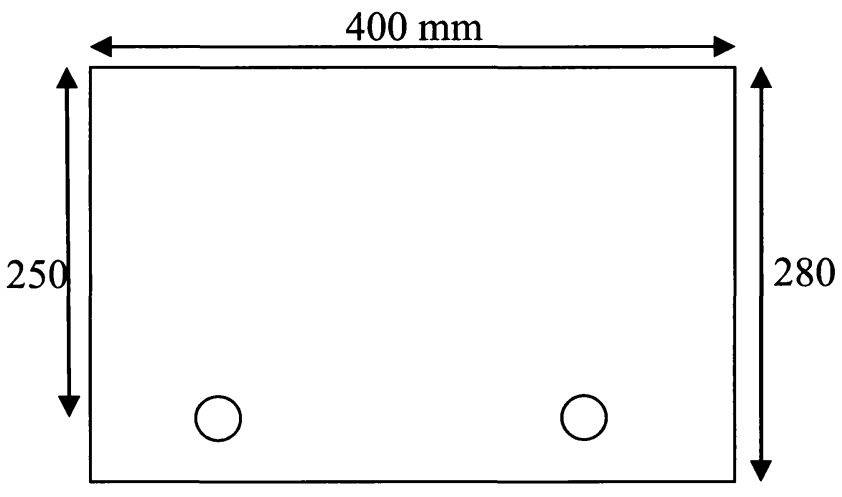

$$
\begin{array}{r}
f_{c}^{\prime}=51.36 \mathrm{Mpa} \\
A_{F R P}=2 * 285.02=570.04 \mathrm{~mm}^{2} \\
E_{c}=4500 * \sqrt{f_{c S}^{\prime}}=32250 \mathrm{Mpa} \\
n=\frac{E_{F R P}}{E_{c}}=\frac{47.6 * 1000}{32250}=1.48 \\
\rho=\frac{A_{F R P}}{b * d}=\frac{570.04}{400 * 250.5}=0.00569
\end{array}
$$

$k=-n \rho+\sqrt{(n \rho)^{2}+2 n \rho}=0.12147$

$k d=0.12 * 250.5=30.427 \mathrm{~mm}$

$J=1-\frac{k}{3}=0.96 \quad I_{c r}=\frac{b *(k * d)^{3}}{3}+n * A_{F R P} *(d-k d)^{2}$

$I_{c r}=\frac{400 *(30.427)^{2}}{3}+1.48 * 570.04 *(250.5-30.427)^{2}=44615482 \mathrm{~mm}^{4}$

$$
P_{\text {Failure }}=111.77 \mathrm{KN} \quad M=\frac{P l}{4}=\frac{111.77 * 1.5}{4}=41.91 \mathrm{KN} . \mathrm{m}
$$




$$
\begin{aligned}
& F_{C, T o p}=\frac{2 M}{J k b d^{2}}=\frac{2 * 41.91 * 10^{6}}{0.96 * 0.12 * 400 *(250.5)^{2}}=28.66 \mathrm{MPa} \\
& F_{F R P}=\frac{M}{A_{F R P} * J d}=\frac{41.91 * 10^{6}}{570.04 * 0.96 * 250.5}=305.91 \mathrm{MPa} \\
& \varepsilon_{F R P}=\frac{F_{F R P}}{E_{F R P}}=\frac{306.12}{47.6 * 1000}=0.00643
\end{aligned}
$$

